\title{
The sense of dietary fat : food intake and body weight regulation
}

Citation for published version (APA):

Kamphuis, M. M. J. W. (2003). The sense of dietary fat : food intake and body weight regulation. [Doctoral Thesis, Maastricht University]. Datawyse / Universitaire Pers Maastricht.

https://doi.org/10.26481/dis.20030704mk

Document status and date:

Published: 01/01/2003

DOI:

10.26481/dis.20030704mk

Document Version:

Publisher's PDF, also known as Version of record

\section{Please check the document version of this publication:}

- A submitted manuscript is the version of the article upon submission and before peer-review. There can be important differences between the submitted version and the official published version of record.

People interested in the research are advised to contact the author for the final version of the publication, or visit the DOI to the publisher's website.

- The final author version and the galley proof are versions of the publication after peer review.

- The final published version features the final layout of the paper including the volume, issue and page numbers.

Link to publication

\footnotetext{
General rights rights.

- You may freely distribute the URL identifying the publication in the public portal. please follow below link for the End User Agreement:

www.umlib.nl/taverne-license

Take down policy

If you believe that this document breaches copyright please contact us at:

repository@maastrichtuniversity.nl

providing details and we will investigate your claim.
}

Copyright and moral rights for the publications made accessible in the public portal are retained by the authors and/or other copyright owners and it is a condition of accessing publications that users recognise and abide by the legal requirements associated with these

- Users may download and print one copy of any publication from the public portal for the purpose of private study or research.

- You may not further distribute the material or use it for any profit-making activity or commercial gain

If the publication is distributed under the terms of Article $25 \mathrm{fa}$ of the Dutch Copyright Act, indicated by the "Taverne" license above, 


\section{THE SENSE OF DIETARY FAT}

food intake and body weight regulation 


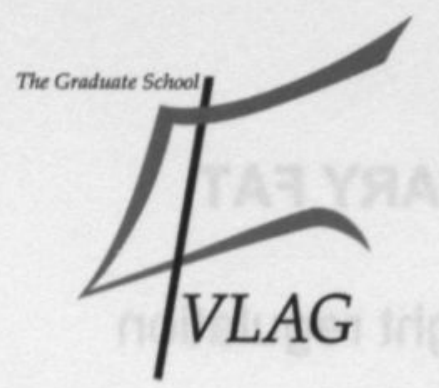

The studies presented in this thesis were performed at the Nutrition and Toxicology Research Institute Maastricht (NUTRIM), which participates in the Graduate School VLAG (Food technology, Agrobiotechnology, Nutrition and Health Sciences), accredited by the Royal Netherlands Academy of Arts and Sciences

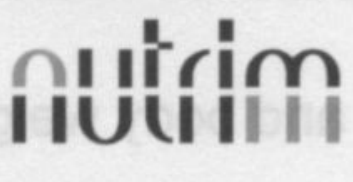

The research described in this thesis was supported by grants from Novartis Consumer Health Ltd. and Unilever Health Institute.

Printing of this thesis was financially supported by Unilever Health Institute, Nederlandse Associatie voor de Studie van Obesitas, Numico Research, Dr. Ir. van de Laar Foundation, which is gratefully acknowledged by the author.

Marleen MJW Kamphuis, Maastricht 2003

Cover design: MMJW Kamphuis / A Schenk

Cover: $\quad$ Face Fragment by A Love

Lay-out: MMJW Kamphuis

Printed by: Datawyse, Universitaire Pers Maastricht 


\section{THE SENSE OF DIETARY FAT}

\section{food intake and body weight regulation}

\section{PROEFSCHRIFT}

ter verkrijging van de graad van doctor

aan de Universiteit Maastricht,

op gezag van de Rector Magnificus,

Prof. Dr. AC Nieuwenhuijzen Kruseman,

volgens het besluit van het College van Decanen,

in het openbaar te verdedigen op

vrijdag 4 juli 2003 om 14.00 uur

door

\section{Marleen Maria Johanna Willemien Kamphuis}

geboren op 6 juli 1976 te Losser 


\section{Promotor}

Prof. Dr. Ir. WHM Saris

\section{Co-promotor}

Dr. MS Westerterp-Plantenga

\section{Beoordelingscommissie}

Prof. dr. ir. PA van den Brandt (voorzitter)

Dr. ir. C de Graaf (Wageningen Universiteit)

Prof. dr. ir. RP Mensink

Prof dr. PB Soeters

Prof. dr. A Tremblay (Université Laval, Quebec, Canada) 
Aan mijn ouders 



\section{CONTENTS}

1 General introduction

2 PROP sensitivity affects macronutrient selection

3 Fat-specific satiety in humans for fat high in linoleic acid versus fat high in oleic acid

4 The role of linoleic acid taste perception in the etiology of obesity

5 The effect of addition of linoleic acid on food intake regulation in linoleic acid tasters and linoleic acid non-tasters

6 The effect of conjugated linoleic acid supplementation after weight loss on appetite and food intake in overweight subjects

7 The effect of conjugated linoleic acid supplementation after weight loss on body weight regain, body composition, and resting metabolic rate in overweight subjects

8 Diacylglycerols affect substrate oxidation and appetite in humans

Summary

Samenvatting

Dankwoord 

General introduction 
besity is defined as an excessive accumulation of body fat resulting in an increased body mass. In adults, body mass is corrected for height by using the body mass index, which is calculated as body mass (kilograms) divided by height (meters) squared $\left(\mathrm{BMl}=\mathrm{kg} / \mathrm{m}^{2}\right)$. The World Health Organisation ${ }^{1}$ has made classifications of the body mass index in order to define normal weight, overweight and obesity (table 1). Moreover, the health risks associated with each BMI category has been described. Obesity is related with an increased risk for type 2 diabetes, cardiovascular diseases ${ }^{2,3}$, hypertension as well as an increase in metabolic risk factors, e.g. hyperlipidaemia and an increased LDL/HDL ratio ${ }^{4.5}$, leading to very high health care costs ${ }^{6}$. In adults ${ }^{7}$ as well as in children ${ }^{8}$, the incidence and prevalence of obesity is increasing reaching alarming levels. This is not only the case in developed countries, but also in developing countries?

Table 1: adult BMI classifications of the World Health Organisation ${ }^{1}$

\begin{tabular}{|c|c|c|}
\hline BMI $\left(\mathrm{kg} / \mathrm{m}^{2}\right)$ & classification & associated health risks \\
\hline$<18.5$ & underweight & $\begin{array}{l}\text { low (but increased risk for other clinical } \\
\text { problems) }\end{array}$ \\
\hline $18.5-<25.0$ & normal range & average \\
\hline$\geq 25.0$ & overweight & mildly increased \\
\hline$\geq 30.0$ & obese & increased \\
\hline $30.0-<35.0$ & class I & moderately increased \\
\hline $35.0-<40.0$ & class II & severely increased \\
\hline$\geq 40.0$ & class III & very severely increased \\
\hline
\end{tabular}

Diet-induced obesity is a result of a long-term imbalance between energy expenditure and energy intake by which the surplus of energy is stored as triacylglycerol in the adipose tissue. Only a long-term balance between energy expenditure and energy intake will maintain a stable body weight. In other words, factors that affect energy expenditure and/or energy intake may affect body weight. For instance, dietary fat has been related to energy intake ${ }^{10}$, but also to energy expenditure and could therefore be related to obesity.

\section{THE ROLE OF DIETARY FAT IN ENERGY INTAKE}

As an implication of excessive energy intake, dietary fat is often associated with the development of obesity ${ }^{11,12}$. Several studies have shown that fat intake or fat preference are related to the fat mass of subjects ${ }^{13-16}$. However, the relation between fat intake and fat mass was shown to be only a result of the relation between fat intake and energy intake ${ }^{17}$. But how does dietary fat cause high energy intake and therefore contribute to weight gain and the development of obesity?

\section{Energy content of macronutrients}

First of all, high-fat foods are high-energy foods. Per gram dietary fat contains more energy $(37 \mathrm{~kJ} / \mathrm{g}$ ) than carbohydrates and proteins (both $17 \mathrm{~kJ} / \mathrm{g}$ ). Because of its high energy content, dietary fat could affect energy intake ${ }^{18.19}$, especially since subjects regulate their food intake on the short term through consumption by weight of food and not by energy content ${ }^{20-24}$. Therefore high-fat foods might easily lead to a high energy intakes ${ }^{20.25}$ by means of passive overconsumption.

\section{Taste perception}

Humans can perceive foods following the basic tastes, i.e. sweet, sour, salt, bitter as well as umami, the taste of mono-sodium glutamate ${ }^{26}$. Taste receptor cells are located within taste buds, which are found in papillae. Three different kinds of papillae exist: fungiform, foliate and vallate, respectively found at the anterior, lateral and posterior sides of the tongue. Human fungiform papillae consist of 3 to 5 taste buds, whereas the foliate and 
vallate papillae can consist of several hundred taste buds ${ }^{27}$. Even though it is often thought that a specific area on the tongue corresponds to only one specific taste, this appears not to be the case. Since morphological differences between the different areas are present, some areas might be more sensitive than others to a certain taste ${ }^{28}$. Many taste receptor cells are sensitive to multiple taste stimuli, and not just for one specific taste $^{27.28}$. However, a specific taste receptor cell might be more sensitive for one taste stimulus than for other stimuli.

Accumulating evidence suggests that dietary fat can be 'tasted' by rats. Furthermore, this fat perception seems to be related to fat intake regulation ${ }^{29-32}$. Gilbertson and co-workers showed that in vitro a small concentration $(10 \mu \mathrm{M})$ of free linoleic acid dose-dependently inhibits the $\mathrm{K}^{+}$current of delayed rectifying potassium channels (DRKC) in taste receptor cells of rat tongue epithelium ${ }^{29-31}$, which indicates an increase in activity of those cells by linoleic acid. In contrast, the same concentration of free oleic acid did not have an increased activity compared to saline ${ }^{29.30}$. Furthermore, in a taste aversion test, the ability to perceive this low concentration of linoleic acid by rats was confirmed ${ }^{33}$. Interestingly, differences in the ability of linoleic acid to inhibit DRKC in tongue epithelium of taste receptor cells between dietary fat-preferring and dietary fat-avoiding rat strains have been shown ${ }^{31}$, in that an increased linoleic acid sensitivity in fat-avoiding rats compared to fat-preferring rats was observed. In addition, when placed on a high-fat diet, the dietary fat-preferring rat strain became rapidly obese, while the dietary fat-avoiding strain reduced their fat intake and remained lean ${ }^{34}$. The hypothesis stresses that in rats, dietary fat intake is reduced by linoleic acid taste sensitivity which may play a role in the prevention, and thus the etiology of obesity. Until now, no study has investigated whether this linoleic acid taste sensitivity is also present in humans. This question might be of importance regarding the hypothesis that linoleic acid sensitivity might be related to fat intake, which may consequently affect energy intake and therefore body weight regulation.

In humans, dietary fat perception has been linked to the sensitivity for the bitter taste of 6- $n$-propylthiouracyl (PROP). The sensitivity to PROP is a heritable trait, which follows recessive Mendelian pattern of inheritance ${ }^{35.36}$. Approximately $70 \%$ of a Caucasian population is sensitive for a low concentration of PROP (tasters), whereas the remaining $30 \%$ is not able to taste it (non-tasters). In more recent studies, the PROP tasters are further divided into supertasters and medium tasters by rating the bitterness of PROP against the saltiness of $\mathrm{NaCl}^{37}$. The ability to taste PROP has been associated with dietary fat taste sensitivity ${ }^{38-42}$. PROP tasters, were able to discriminate between low and high fat food products, whereas PROP non-tasters were unable. However, this effect, i.e. relation between PROP taster status and fat perception has not been confirmed ${ }^{43}$.

\section{Selection of food}

Many factors affect the selection of food and therefore might play a role in energy intake regulation. First of all, sensory properties of the food affect the hedonic value of food and might thus be important in food selection. Dietary fat is palatable and therefore high fat diets might be more tasty than low fat diets and might consequently promote consumption $^{18}$. A relationship between preference for dietary fat and obesity is shown in that hedonic ratings for fats increases with increasing body mass ${ }^{44}$, and obese people have a stronger preference for high fat and sweet foods than lean subjects ${ }^{45}$.

Genetics factors might also be important in food selection. For example, some studies have investigated the effect of PROP taster status on macronutrient selection, but results are contradictory. In one study, dietary fat intake was lower in PROP tasters ${ }^{46}$, whereas in another study PROP tasters derived a greater percentage of their energy from dietary fat compared to non-tasters ${ }^{47}$. 


\section{Satiety in food intake regulation}

In order to study the effect of dietary fat on energy intake, understanding of mechanisms involved in food intake regulation as well as in appetite control, is necessary. Several components are involved in short-term food intake regulation, i.e. meal initiation, meal size and characteristics, meal termination, intermeal interval and meal frequency (figure 1). These components are dependent on feelings of hunger, appetite, satiation, satiety and sensory specific satiety ${ }^{48}$.

Hunger is defined as the feeling to eat because of a physiological need for energy or macronutrients, whereas appetite refers to the desire to eat at a certain point of time, which is often, but not always related to feelings of hunger. Appetite might be a consequence of a physiological hunger, but also other factors like availability of a palatable food, might affect appetite. Therefore, both hunger and appetite are involved in meal initiation, and play a role in meal size and meal composition. Both satiation and satiety refers to inhibition of hunger and appetite. Satiation is the suppression of hunger and appetite within a meal, while satiety refers to the inhibition of hunger and appetite after food consumption. Thus satiation is involved in meal termination, whereas satiety affects the intermeal interval and therefore meal frequency ${ }^{48}$. Different processes are involved in satiety and satiation, represented by the satiety cascade (figure 2). The satiety cascade shows the processes through which food affects the biological system and, therefore feelings and behavior. The four mediating processes involved in the satiety cascade are sensory, cognitive, post-ingestive and post-absorptive in nature ${ }^{49,50}$. The perception of sensory properties of a certain food, e.g. taste, olfaction (smell), temperature, texture (mouth feeling) and appearance are factors involved in the sensory process related to the satiety cascade and affect satiation. Factors involved in the cognitive process are attitudes to a certain food, e.g. the idea that a certain food is (un)healthy might affect the intake of that food. Post-ingestive processes, i.e. effects after consumption of a food, but not due to absorptive effects of that food, imply gastric distension and emptying as well as the release of hormones when food is processed. Post-absorptive processes, which are involved in the late phase of the satiety cascade include effects of the digested and absorbed food components like blood glucose concentrations and hepatic fat oxidation ${ }^{49,50}$. The satiety cascade, as a behavioral pattern takes place parallel with peripheral physiological and metabolic mechanisms, and mechanisms at brain level represented as a psychobiological system (figure 3 ). Appetite control is a synchronous activity of the mechanisms at the three levels and is dependent on the kind of food that is consumed ${ }^{49}$.

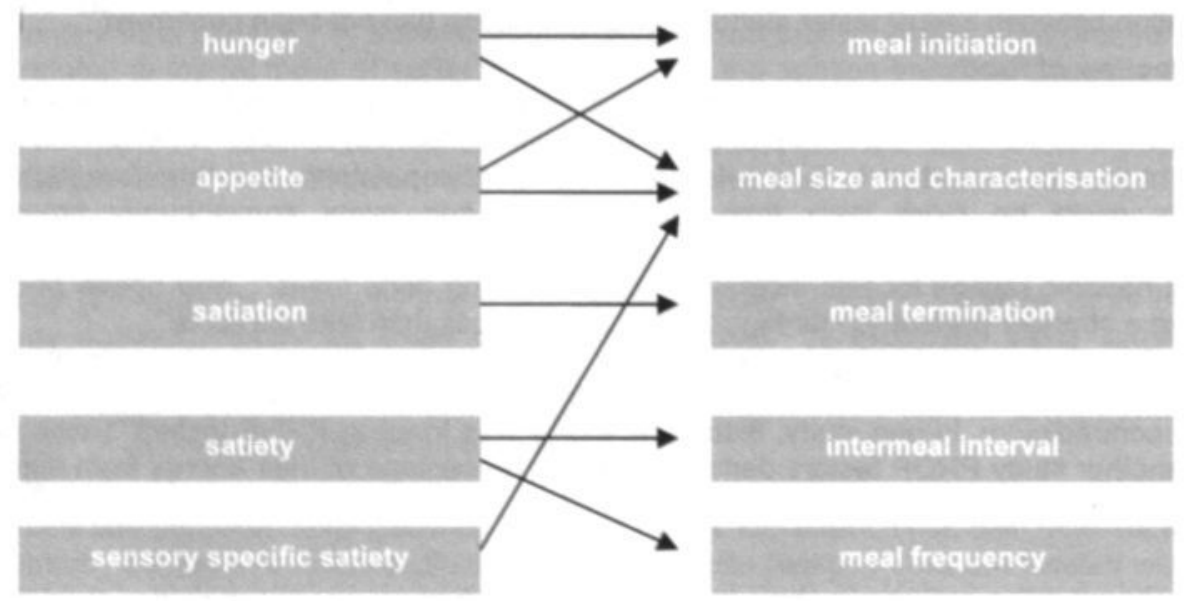

Figure 1: factors involved in short-term food intake regulation; adapted from ${ }^{48}$ 


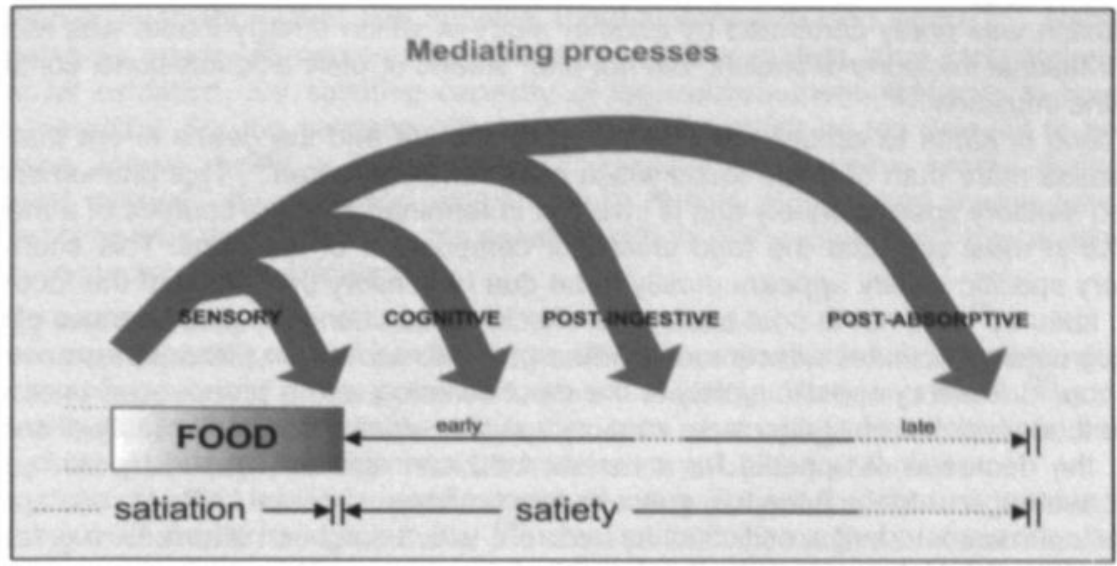

Figure 2: the satiety cascade ${ }^{40}$

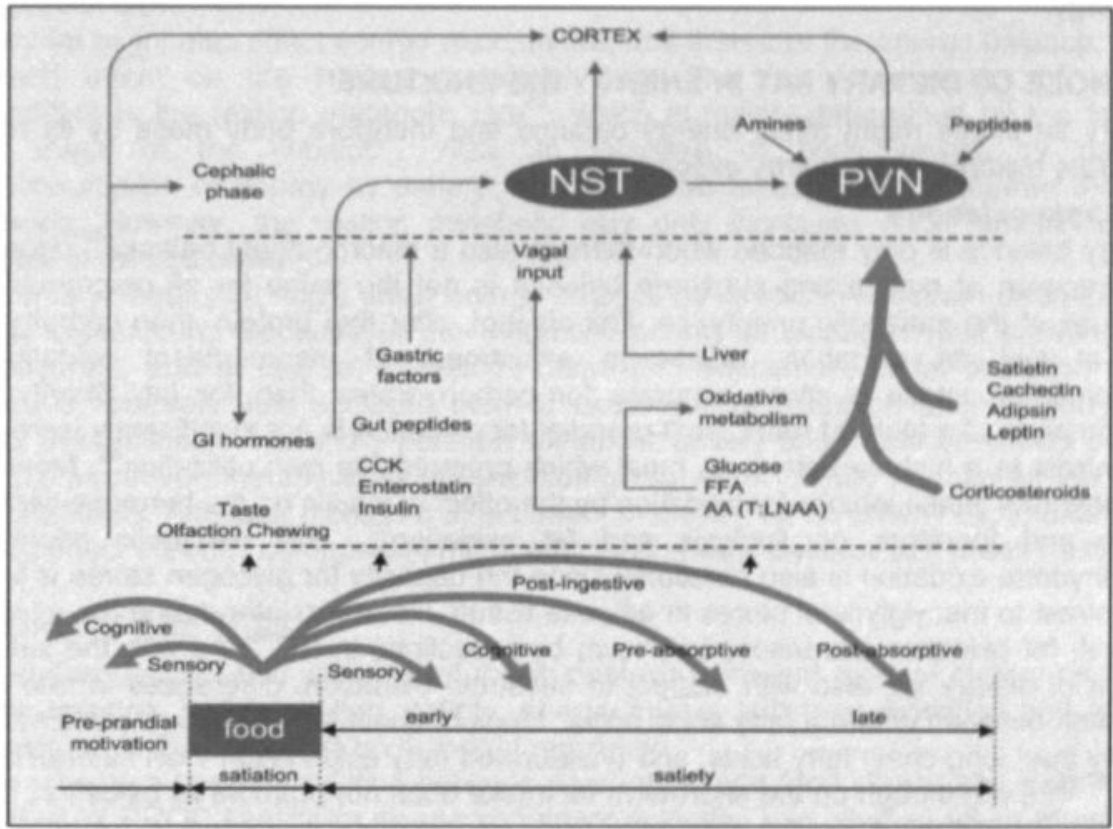

Figure 3: the satiety cascade related to three levels of operation of the psychobiological system, i.e. the behavioral pattern, peripheral physiology and metabolism, and brain activity $^{48} \mathrm{PVN}=$ paraventricular nucleus, NST=nucleus of the tractus solitarius. $C C K=$ cholecystokinin, $A A=a m i n o$ acids, $T=$ tryptophan, $L N A A=$ large neutral amino acids

Even though dietary fat intake leads to potent satiety signals, e.g. CCK and enterostatin release as well as a slow clearing from the gut, which are peripheral biomarkers of satiety, in general, dietary fat seems to have a smaller effect on short-term satiation and satiety than foods high in carbohydrates, whereas protein is the most satiating macronutrient ${ }^{20,51-53}$. However, it has been shown that dietary fat prolongs the intermeal interval compared to carbohydrate ${ }^{54}$, which might be caused by the relation between hepatic fat oxidation and satiety ${ }^{55}$. Differences in satiating capacity might be present when discriminating between different types of fat. Only a few studies investigated the effects of saturation of fats on satiety. One study concluded that mono-unsaturated fatty acids were less satiating than saturated or poly-unsaturated fatty acids ${ }^{56,57}$. This 
conclusion was partly confirmed by another study in which energy intake was reduced after intestinal infusions of linoleic, but not after stearic or oleic acid infusions, compared to saline infusions ${ }^{58.59}$.

As a food is eaten to satiety, the pleasantness of taste and the desire to eat that food decreases more than of those foods which have not been eaten ${ }^{60}$. This phenomenon is named sensory specific satiety and is involved in termination of the courses of a meal as well as in meal size and the food choice or composition of the meal. This short-term sensory specific satiety appears mostly to be due to sensory properties of the food (e.g. taste, texture $)^{61}$ and not to post-absorptive effects, since change in pleasantness of taste is the greatest 2 minutes after a meal, with a gradual recovery in pleasantness over the next hour ${ }^{60}$. Sensory specific satiety is the most common with a pronounced taste while staple foods lack the ability to cause sensory specific satiety. Next to similarity of sensory input, the decrease of appetite for a certain food can also be caused by similarity of macronutrient content. Because macronutrients have different effects on appetite regulation, macronutrient specific satiety occurs ${ }^{60}$, which has been shown for e.g. fat ${ }^{62}$.

In summary, the high energy density of dietary fat, together with its hedonics and the low ability of high-fat foods to induce short-term satiety may lead to passive overconsumption of energy.

\section{THE ROLE OF DIETARY FAT IN ENERGY EXPENDITURE}

Dietary fat intake might affect energy balance and therefore body mass by its role in substrate oxidation and energy expenditure.

\section{Substrate oxidation}

Energy balance is only reached when there is also a macronutrient balance ${ }^{63}$. However the precision of maintaining substrate balance is not the same for all macronutrients. Because of the metabolic priority, i.e. first alcohol, after that protein, than carbohydrate and at last fat oxidation, short-term adjustment of macronutrient oxidation to macronutrient intake is more accurate for carbohydrates than for fat. Shortly after consumption of a high-fat meal, post-prandial fat oxidation is not significantly increased, in contrast to a high-carbohydrate meal which promotes its own utilization ${ }^{64}$. Moreover, carbohydrate intake inhibits fat oxidation by the effect of insulin on the hormone-sensitive lipase and therefore on lipolysis and fat oxidation ${ }^{65}$. This metabolic priority for carbohydrate oxidation is also functional since the capacity for glycogen stores is limited in contrast to triacylglycerol stores in adipose tissue. However, later during the intermeal interval, fat oxidation increases, as shown by reductions in $\mathrm{RQ}^{66}$. As with the satiating effects of dietary fat, also with respect to substrate oxidation, differences in rate of fat oxidation between different fatty acids occur. Medium-chain fatty acids are oxidized more rapidly than long-chain fatty acids, and unsaturated fatty acids faster than saturated fatty acids $^{67,68}$. Even though on the short-term fat intake does not promote its oxidation, under normal circumstances on the long term (7d), fat oxidation is related to fat intake ${ }^{69.70}$, although this relationship is weaker compared to the carbohydrate oxidation after longterm high carbohydrate intake ${ }^{71,72}$. This long-term adaptation of the respiratory quotient to the food quotient might be related to nutrient stores, i.e. lowered glycogen stores $^{69,73,74}$, which stimulates a more rapid switch from carbohydrate oxidation to fat oxidation.

Also differences in efficiency of nutrient utilization between the different macronutrients are present. The efficiency of nutrient utilization is higher for dietary fat $(97-98 \%)$ than for carbohydrate $(92-94 \%)$ or protein $(70-75 \%)$. So, whereas intake of protein and to a smaller extent carbohydrate induces a greater cost of energy for the body, dietary fat shows the highest efficiency in nutrient utilization and therefore energy preservation ${ }^{75}$.

The substrate oxidation can also be linked to energy balance via its effect on energy intake. It has been suggested that the level of (hepatic) fuel oxidation gives a feed back signal that links the oxidative fuel metabolism to food intake regulation ${ }^{55}$. Indeed, it has been shown that when fat is post-absorptively oxidized in the liver, this hepatic fat 
oxidation is inversely related with appetite and therefore with food intake ${ }^{76,77}$. Parallel to the metabolic priority of macronutrient oxidation, i.e. first protein, than carbohydrate and at last fat oxidation, the satiating capacity of the macronutrients appears to have the same hierarchy. So, the satiating effects of dietary fat might be too delayed to prevent excessive intake during a high-fat meal ${ }^{75}$. However, it sustains satiety during the intermeal interval ${ }^{54}$ by increased oxygen intake due to diet-induced thermogenesis ${ }^{78}$. This explains why the hierarchy in the satiating effects of the macronutrients parallels the priority in macronutrient oxidation.

\section{Energy expenditure}

Daily energy expenditure can be divided in several components, i.e. sleeping metabolic rate, the energy cost of arousal, the diet-induced thermogenesis, and the energy cost of physical activity. Basal metabolic rate is the sum of sleeping metabolic rate and the energy cost of arousal. Resting metabolic rate refers to basal metabolic rate.

Dietary fat may affect energy expenditure by affecting diet-induced thermogenesis. It has been shown that after a high-fat diet, the diet-induced thermogenesis was significantly lowered compared to a high-carbohydrate, high-protein diet. This caused a tendency for a lower $24 \mathrm{~h}$ energy expenditure with the high-fat diet compared to the high-carbohydrate, high-protein diet ${ }^{79}$.

Dietary fat might also affect energy expenditure, and therefore the energy balance, by its (indirect) effect on the resting metabolic rate. The main component of energy expenditure is the resting metabolic rate ${ }^{80}$, which is mainly determined by the fat-free body mass of the subject ${ }^{81}$. With an increase of body weight by passive overconsumption of energy by dietary fat, next to fat mass, also the fat-free mass is increased. However, the resting metabolic rate only increases as a function of the increase in fat-free mass.

In summary, dietary fat might affect energy balance by its role in substrate oxidation and energy expenditure. Because of the metabolic priority of oxidation (first protein, than carbohydrate, and at last fat oxidation), short-term adjustment of fat oxidation to fat intakes is relatively less accurate than of carbohydrate oxidation after carbohydrate intake. This oxidation hierarchy parallels metabolic satiety and therefore affects energy balance. Moreover, the efficiency of utilization is higher for dietary fat than for the other macronutrients. Although there is a direct effect of dietary fat on energy expenditure, the indirect effect via body composition might affect the energy balance to a greater extent.

\section{OUTLINE OF THE THESIS}

The studies described in the present thesis deal with different roles of dietary fat in the energy balance, i.e. perception, satiety, energy intake, substrate oxidation and energy expenditure, in the context of body weight regulation.

To investigate a possible relation between perception, and food choice and food intake, the effect of PROP sensitivity on macronutrient selection was studied when measuring actual intakes (chapter 2). To extend this to the effect of fats consisting of different types of fatty acids (high in linoleic acid, high in oleic acid and high in $\gamma$-linolenic acid) on food intake regulation, possible fat-specific satiety was assessed. In addition, it was determined whether subjects were able to discriminate between the different oils and whether this taste sensitivity was related to the possible satiating effects of the oils (chapter 3). Furthermore, it was investigated whether humans were able to perceive a low concentration of free linoleic acid as well as the same concentration of free oleic acid. A taste perception test was developed that allowed discrimination of $10 \mu \mathrm{M}$ linoleic acid tasters from $10 \mu \mathrm{M}$ linoleic acid non-tasters. Moreover, the effect of linoleic acid sensitivity on relevant parameters with respect to the etiology of obesity such as body mass index and macronutrient selection was investigated (chapter 4 ). The next study examined if addition of a low concentration of free linoleic acid to ice cream would affect food intake regulation differently in linoleic acid tasters and in linoleic acid non-tasters (chapter 5). The last chapters focus on body weight regulation. Several positive effects 
of conjugated linoleic acid (CLA) supplementation on body composition in rats have been published. CLA has been shown to increase fat-free mass and to decrease fat mass in rats $^{82-88}$. Only a few human intervention trials with CLA have been conducted, investigating the effects of CLA on weight loss or fat mass loss. However, the effects of CLA might be more abundant when investigating while subjects are in state of weight (re)gain. Therefore we studied the effect of CLA supplementation after weight loss on appetite and food intake (chapter 6) as well as on body weight regain, body composition, and resting metabolic rate (chapter 7) in overweight subjects. In the last study, we focused on fat oxidation by investigating the effect of diacylglycerol compared to triacylglycerol intake on fat oxidation and appetite (chapter 8). Several studies have shown that modest intake of diacylglycerol in stead of triacylglycerol has beneficial effects on lipid metabolism ${ }^{89-93}$ and body composition ${ }^{94-96}$ probably due to an enhanced (post-prandial) fat oxidation.

The thesis finishes with a general discussion on the significance of dietary fat or fatty acids in the etiology of obesity as well as dietary-fat-related possibilities for obesity prevention or treatment, including the results of the studies described (chapter 9).

\section{REFERENCES}

1 WHO. 1998. Obesity: preventing and managing the global epidemic. Geneva: WHO. WHO/NUT/NCD/98.91

2 Kannel WB. Effect of weight on cardiovascular disease. Nutrition 1997; 13: 157-158

3 Manson JE, GA Colditz, MJ Stampfer, WC Willett, B Rosner, RR Monson, FE Speizer, CH Hennekens. A prospective study of obesity and risk of coronary heart disease in women. $N$ Engl J Med 1990; 322: 882-889

4 Wing RR, CH Bunker, LH Kuller, KA Matthews. Insulin, body mass index and cardiovascular risk factors in premenopausal women. Arteriosclerosis 1989; 9: 479-484

5 Pi-Sunyer FX. Medical hazards of obesity. Ann Intern Med 1993; 119: 655-660

6 Seidell J. The impact of obesity on health status: some implications for health care costs. Int J Obes 1995; 19: S13-16

7 Flegal KM, MD Carroll, CL Ogden, CL Johnson. Prevalence and Trends in Obesity Among US Adults, 1999-2000. JAMA 2002; 288: 1723-1727

8 Ogden CL, KM Flegal, MD Carroll, CL Johnson. Prevalence and Trends in Overweight Among US Children and Adolescents, 1999-2000. JAMA 2002; 288: 1728-1732

9 Seidell JC. Obesity, insulin resistance and diabetes--a worldwide epidemic. Br J Nutr 2000; 83: S5-8

10 Astrup A, GK Grunwald, EL Melanson, WH Saris, JO Hill. The role of low-fat diets in body weight control: a meta-analysis of ad libitum dietary intervention studies. Int $\mathrm{J}$ Obes Relat Metab Disord 2000; 24: 1545-1552

11 Tucker LA, M Kano. Dietary fat and body fat: a mulivariate study of 205 adult females. Am J Clin Nutr 1992; 56: 616-622

12 Romieu I, WC Willet, MJ Stampfer, GA Colditz, L Samson, B Rosner, CH Hennekens, FE Speizer. Energy intake and other determinantes of relative weight. Am J Clin Nutr 1988; 47: 406-412

13 Dreon DM, B Frey-Hewitt, N Ellsworth, PT Williams, RB Terry, PD Wood. Dietary fat:carbohydrate ratio and obesity in middle-aged men. Am J Clin Nutr 1988; 47: 995-1000

14 Miller WC, AK Lindeman, J Wallace, M Niederpruem. Diet composition, energy intake, and exercise in relation to body fat in men and women. Am J Clin Nutr 1990; 52: 426-430

15 Tremblay A, G Plourde, JP Despres, C Bouchard. Impact of dietary fat content and fat oxidation on energy intake in humans. Am J Clin Nutr 1989; 49: 799-805

16 Mela DJ, DA Sacchetti. Sensory preferences for fats: relationships with diet and body composition. Am J Clin Nutr 1991; 53: 908-915

17 Westerterp KR, WP Verboeket-van de Venne, MS Westerterp-Plantenga, EJ Velthuis-te Wierik, C de Graaf, JA Weststrate. Dietary fat and body fat: an intervention study. Int $J$ Obes Relat Metab Disord 1996; 20: 1022-1026

18 Drewnowski A. Energy density, palatability, and satiety: implications for weight control. Nutr Rev 1998; $56: 347-353$

19 Holt SH, JC Miller, P Petocz, E Farmakalidis. A satiety index of common foods. Eur J Clin Nutr 
$1995 ; 49: 675-690$

20 Blundell JE, JR Cotton, H Delargy, S Green, A Greenough, NA King, CL Lawton. The fat paradox: fat-induced satiety signals versus high fat overconsumption. Int $J$ Obes Relat Metab Disord 1995; 19: 832-835

21 Lissner L, DA Levitsky, BJ Strupp, HJ Kalkwarf, DA Roe. Dietary fat and the regulation of energy intake in human subjects. Am J Clin Nutr 1987; 46: 886-892

22 Stubbs RJ, P Ritz, WA Coward, AM Prentice. Covert manipulation of the ratio of dietary fat to carbohydrate and energy density: effect on food intake and energy balance in free-living men eating ad libitum. Am J Clin Nutr 1995; 62: 330-337

23 Westerterp-Plantenga MS. Eating behavior in humans, characterized by cumulative food intake curves-a review. Neurosci Biobehav Rev 2000; 24: 239-248

24 Westerterp-Plantenga MS. Analysis of energy density of food in relation to energy intake regulation in human subjects. Br J Nutr 2001; 85: 351-361

25 Blundell JE, JI Macdiarmid. Passive overconsumption. Fat intake and short-term energy balance. Ann N Y Acad Sci 1997; 827: 392-407

26 Lindemann B. A taste for umami. Nat Neurosci 2000; 3: 99-100

27 Gilbertson TA, S Damak, RF Margolskee. The molecular physiology of taste transduction. Cur Opin Neurobiol 2000; 10: 519-527

28 Lindemann B. Receptors and transduction in taste. Nature 2001; 413: 219-225

29 Gilbertson TA, T Fontenot, L Liu, H Zhang. WT Monroe. Fatty acid modulation of K+ channels in taste receptor cells: gustatory cues for dietary fat. Am J Physiol 1997; 272: C1203-C1210

30 Gilbertson TA. Gustatory mechanisms for the detection of fat. Curr Opin Neurobiol 1998; 8 : 447-452

31 Gilbertson TA, L Liu, DA York, GA Bray. Dietary fat preferences are inversely correlated with peripheral gustatory fatty acid sensitivity. Ann N Y Acad Sci 1998; 855: 165-168

32 Gilbertson T, I Kim, L Liu. Sensory cues for dietary fat: implications for macronutrient preferences. In: Ailhaud GB Guy-Grand (eds). Progress in Obesity Research. John Libbey \& Company Ltd.: 1998, pp 167-171

33 Smith JC, EM Fisher, V Maleszewski, B McClain. Orosensory factors in the ingestion of corn oil/sucrose mixtures by the rat. Physiol Behav 2000; 69: 135-146

34 Schemmel R, O Mickelsen, JL Gill. Dietary obesity in rats: Body weight and body fat accretion in seven strains of rats. J Nutr 1970; 100: 1041-1048

35 Fox AL. The relationship between chemical constitution and taste. Proc Natl Acad Sci 1931; 18: $115-120$

36 Snyder LH. Inherited taste deficiency. Science 1931; 74: 151-152

37 Bartoshuk LM,VB Duffy, IJ Miller. PTC/PROP tasting: anatomy, psychophysics, and sex effects. Physiol Behav 1994; 56: 1165-1171

38 Duffy VB, LM Baroshuk, LA Lucchina, LH Snyder, A Tym. 1996. Supertasters of PROP (6-npropylthiouracil) rate the highest creaminess to high-fat milk products. In AChemS. Sarisota, Florida. 598

39 Nasser JA, CJ Chou, HR Kissileff, CN Boozer, FX Pi-Sunyer. PROP taster status and the ability to detect the presence of added conjugated linoleic acid in high fat ice cream. Obes Res 1999; 7: $87 \mathrm{~S}$

40 Tepper BJ, RJ Nurse. Fat perception is related to PROP taster status. Physiol Behav 1997; 61: 949-954

41 Tepper BJ, RJ Nurse. PROP taster status is related to fat perception and preference. Ann $\mathrm{N} \mathrm{Y}$ Acad Sci 1998; 30: 802-804

42 Tepper BJ. Does genetic taste sensitivity to PROP influence food preferences and body weight? Appetite 1999; 32: 422

43 Yackinous C, JX Guinard. Relation between PROP taster status and fat perception, touch, and olfaction. Physiol Behav 2001; 72: 427-737

44 Drewnowski A, JD Brunzell, K Sande, PH Iverius, MR Greenwood. Sweet tooth reconsidered: taste responsiveness in human obesity. Physiol Behav 1985; 35: 617-622

45 Drewnowski A. Dietary fats: perceptions and preferences. J Am Coll Nutr 1990; 9: 431-435

46 Savage J, HIM Davidson. 2000. Genetic sensitivity to PROP and its relationship with energy intake and short time satiety. Paris: Eur J Clin Nutr. S15

47 Yackinous CA, JX Guinard. Relation between PROP (6-n-propylthiouracil) taster status, taste anatomy and dietary intake measures for young men and women. Appetite 2002; 38: 201-209 
48 Melanson KJ, MS Westerterp-Plantenga, LA Campfield, WH Saris. Short-term regulation of food intake in humans. In: Westerterp-Plantenga MS, AB SteffensA Tremblay (eds). Regulation of food intake and energy expenditure. EDRA: Milano, 1999, pp 37-84

49 Blundell JE, CL Lawton, AJ Hill. Mechanisms of appetite control and their abnormalities in obese patients. Horm Res 1993; 39 (Suppl 3): 72-76

50 Hetherington MH, JE Blundell. Eating disorders. In: Westerterp-Plantenga MS, AB SteffensA Tremblay (eds). Regulation of food intake and energy expenditure. EDRA: Milano, 1999, pp 99-117

51 Lawton CL, VJ Burley, JK Wales, JE Blundell. Dietary fat and appetite control in obese subjects: weak effects on satiation and satiety. Int J Obes 1993; 17: 409-416

52 Stubbs RJ, MC van Wyk, AM Johnstone, CG Harbron. Breakfasts high in protein, fat or carbohydrate: effect on within-day appetite and energy balance. Eur J Clin Nutr 1996; 50: 409 417

53 Rolls BJ, DJ Shide. 1994. Dietary fat and the control of food intake. In Appetite and body weight regulation; suger, fat, and macronutrient substitutes. Fernstrom JD, Miller, G.D., editor. Boca Raton: CRC Press. 167-177

54 Melanson KJ, MS Westerterp-Plantenga, WHM Saris, FJ Smith, LA Campfield. Blood glucose patterns and appetite in time-blinded humans: carbohydrate versus fat. J Appl Physiol 1999; 277: R337-R345

55 Langhans W. Metabolic control of food intake. Role of the liver. In: Westerterp-Plantenga MS, AB Steffens A Tremblay (eds). Regulation of food intake and energy expenditure. EDRA: Milano, 1999, pp 185-199

56 Lawton C, H Delargy, F Smith, J Blundell. Does the degree of saturation of fatty acids affect post-ingestive satiety? Int J Obes 1997; 21: S35

57 Lawton CL, HJ Delargy, J Brockman, FC Smith, JE Blundell. The degree of saturation of fatty acids influences post-ingestive satiety. Br J Nutr 2000; 83: 473-482

58 French S, S Mutuma, J Francis, N Read, G Meijer. 1998. The effect of fatty composition on intestinal satiety in man. In Internation Congress on Obesity. Paris: Int J Obes. S82

59 French SJ. The effects of specific nutrients on the regulation of feeding behaviour in human subjects. Proc Nutr Soc 1999; 58: 533-539

60 Rolls BJ. Sensory-specific Satiety. Nutr Rev 1986; 44: 93-101

61. Guinard JX, P Brun. Sensory-specific satiety: comparison of taste and texture effects. Appetite 1998; 31: 141-157

62 Westerterp-Plantenga MS, MJW IJedema, NEG Wijckmans-Duijsens. The role of macronutrient selection in determining patterns of food intake in obese and non-obese women. Eur J Clin Nutr 1996; 50: 580-591

63 Tremblay A, C Bouchard. Dietary fats and thermogenesis. Ann N Y Acad Sci 1997; 827: 408416

64 Flatt JP. Use and storage of carbohydrate and fat. Am J Clin Nutr 1995; 61: 952S-959S

65 Jequier E. Carbohydrates as a source of energy. Am J Clin Nutr 1994; 59: S682-S685

66 Verboeket-van de Venne WP, KR Westerterp. Influence of the feeding frequency on nutrient utilization in man: consequences for energy metabolism. Eur J Clin Nutr 1991; 45: 161-169

67 DeLany JP, MM Windhauser, CM Champagne, GA Bray. Differential oxidation of individual dietary fatty acids in humans. Am J Clin Nutr 2000; 72: 905-911

68 Piers LS, KZ Walker, RM Stoney, MJ Soares, K O'Dea. The influence of the type of dietary fat on postprandial fat oxidation rates: monounsaturated (olive oil) vs saturated fat (cream). Int $J$ Obes Relat Metab Disord 2002; 26: 814-821

69 Schrauwen P, WD van Marken Lichtenbelt, WH Saris, KR Westerterp. Changes in fat oxidation in response to a high-fat diet. Am J Clin Nutr 1997; 66: 276-282

70 Kunz I, U Schorr, K Rommling. S Klaus, AM Sharma. Habitual fat intake and basal fat oxidation in obese and non-obese Caucasians. Int J Obes Relat Metab Disord 2002; 26: 150 156

71 Thomas CD, JC Peters, GW Reed, NN Abumrad, M Sun, JO Hill. Nutrient balance and energy expenditure during ad libitum feeding of high-fat and high-carbohydrate diets in humans. $A m J$ Clin Nutr 1992; 55: 934-942

72 Horton TJ, H Drougas, A Brachey, GW Reed, JC Peters, JO Hill. Fat and carbohydrate overfeeding in humans: different effcts on energy storage. Am J Clin Nutr 1995; 62: 19-29

73 Schrauwen P, WD van Marken Lichtenbelt, WH Saris, KR Westerterp. Role of glycogenlowering exercise in the change of fat oxidation in response to a high-fat diet. Am J Physiol 
1997; 273: E623-629

74 Schrauwen P, WD Lichtenbelt, WH Saris, KR Westerterp. Fat balance in obese subjects: role of glycogen stores. Am J Physiol 1998; 274: E1027-1033

75 Jequier E. Pathways to obesity. Int J Obes Relat Metab Disord 2002; 26 (Suppl 2): S12-17

76 Kahler A, M Zimmermann, W Langhans. Suppression of hepatic fatty acid oxidation and food intake in men. Nutrition 1999; 15: 819-828

77 Scharrer E, W Langhans. Control of food intake by fatty acid oxidation. Am J Physiol 1986; 250: R1003-1006

78 Westerterp-Plantenga MS, KR Westerterp, M Rubbens, CRT Verwegen, JP Richelet, B Gardette. Appetite at "high altitude" [operation everest III (Comex-'97)]: a simulated ascent of Mount Everest. J Appl Physiol 1999; 87: 391-399

79 Westerterp KR, SA Wilson, V Rolland. Diet induced thermogenesis measured over $24 \mathrm{~h}$ in a respiration chamber: effect of diet composition. Int J Obes Relat Metab Disord 1999; 23: 287 . 292

80 Westerterp KR. Energy expenditure. In: Westerterp-Plantenga MS, EWHM FredrixAB Steffens (eds). Food intake and energy expenditure. CRC Press: Boca Raton, 1994, pp 235-258

81 Ravussin E, C Bogardus. Relationship of genetics, age, and physical fitness to daily energy expenditure and fuel utilization. Am J Clin Nutr 1989; 49: 968-975

82 Park Y, KJ Albright, W Liu, JM Storkson, ME Cook, MW Pariza. Effect of conjugated linoleic acid on body composition in mice. Lipids 1997; 32: 853-858

83 Park Y, JM Storkson, KJ Albright, W Liu, MW Pariza. Evidence that the trans-10,cis-12 isomer of conjugated linoleic acid induces body composition changes in mice. Lipids 1999; 34: 235241

84 Park Y, KJ Albright, JM Storkson, W Liu, ME Cook, MW Pariza. Changes in body composition in mice during feeding and withdrawal of conjugated linoleic acid. Lipids 1999; 34: 243-248

85 West DB, JP Delany, PM Camet, FY Blohm, AA Truett, J Scimeca. Effects of conjugated linoleic acid on body fat and energy metabolism in the mouse. Am J Physiol 1998; 275: R667R672

86 West DB, FY Blohm, AA Truett, JP DeLany. Conjugated linoleic acid persistently increases total energy expenditure in AKR/J mice without increasing uncoupling protein gene expression. J Nutr 2000; 130: 2471-2477

87 DeLany JP, F Blohm, AA Truett, JA Scimeca, DB West. Conjugated linoleic acid rapidly reduces body fat content in mice without affecting energy intake. Am J Physiol 1999; 276: R1172-R1179

88 Azain MJ, DB Hausman, MB Sisk, WP Flatt, DE Jewell. Dietary conjugated linoleic acid reduces rat adipose tissue cell size rather than cell number. J Nutr 2000; 130: 1548-1554.

89 Taguchi H, H Watanabe, K Onizawa, T Nagao, N Gotoh, T Yasukawa, R Tsushima, H Shimasaki, $\mathrm{H}$ Itakura. Double-blind controlled study on the effects of dietary diacylglycerol on postprandial serum and chylomicron triacylglycerol responses in healthy humans. $J \mathrm{Am}$ Coll Nutr 2000; 19: 789-796

90 Watanabe H, K Onizawa, H Taguchi, N Fujimori, S Naito, N Gotoh, T Yasukawa, M Hattori, H Shimasaki. Effects of diacylglycerols on lipid metabolism in human. Nippon Yukagaku Kaishi 1997; 46: 309-314

91 Hara K, K Onizawa, H Honda, K Otsuji, T Ide, M Murata. Dietary diacylglycerol-dependent reduction in serum triacylglycerol concentration in rats. Ann Nutr Metab 1993; 37: 185-191

92 Murata M, T Ide, K Hara. Reciprocal responses to dietary diacylglycerol of hepatic enzymes of fatty acid synthesis and oxidation in the rat. Br J Nutr 1997; 77: 107-121.

93 Yamamoto K, H Asakawa, K Tokunaga, H Watanabe, N Matsuo, I Tokimitsu, N Yagi. Longterm ingestion of dietary diacylglycerol lowers serum triacylglycerol in type II diabetic patients with hypertriglyceridemia. J Nutr 2001; 131: 3204-3207

94 Murase T, T Mizuno, T Omachi, K Onizawa, Y Komine, H Kondo, T Hase, I Tokimitsu. Dietary diacylglycerol suppresses high fat and high sucrose diet- induced body fat accumulation in C57BL/6J mice. J Lipid Res 2001; 42: 372-378

95 Nagao T, H Watanabe, N Goto, K Onizawa, H Taguchi, N Matsuo, T Yasukawa, R Tsushima, H Shimasaki, H Itakura. Dietary diacylglycerol suppresses accumulation of body fat compared to triacylglycerol in men in a double-blind controlled trial. J Nutr 2000; 130: 792-797

96 Watanabe H, T Nagao, N Goto, Y Fukushima, K Onizawa, H Taguchi, T Ohmachi, T Yasukawa, S Naito, H Shimasaki, H Itakura. Long-term effects of dietary diacylglycerols on body fat metabolism in man. Nippon Yukagaku Kaishi 1998; 47: 369-376 



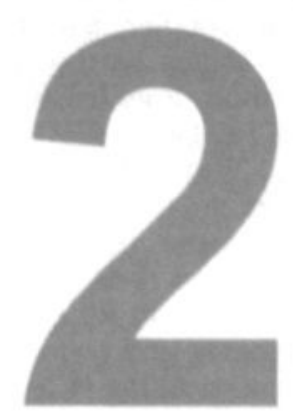

\section{PROP sensitivity affects macronutrient selection}

Marleen MJW Kamphuis

Margriet S Westerterp-Plantenga

| Physiology and Behavior, in press 


\section{ABSTRACT}

The objective was to study the effect of 6-n-propylthiouracyl (PROP) taster status on macronutrient selection. Thirteen PROP non-tasters and 23 PROP tasters were offered 3 ad libitum lunches in at random order; a high fat (HF; CHO/P/F: 30/10/60), a high carbohydrate ( $\mathrm{HCHO} ; 80 / 10 / 10)$ and a mixed lunch consisting of products of the $\mathrm{HF}$ and $\mathrm{HCHO}$ lunch. PROP tasters compared to PROP non-tasters ate relatively more fat $(47 \pm 9$ vs. $38 \pm 10$ energy $\%, p<0.05)$ and less carbohydrate $(45 \pm 9$ vs. $53 \pm 10$ energy $\%, p<0.05)$ from the MIX lunch. When dividing PROP tasters into supertasters and medium tasters, the same relation between PROP taster status and macronutrient selection was observed $(p<0.05)$. The energy density of the food consumed was higher for PROP tasters than for PROP non-tasters $(p<0.05)$. Protein, food $(g)$ and energy $(k J)$ intake, appetite and hedonic value were not different between PROP tasters and PROP nontasters. At the $\mathrm{HCHO}$ as well as $\mathrm{HF}$ lunch, no differences with respect to macronutrient selection, food and energy intake, appetite levels and hedonic value between PROP tasters and PROP non-tasters were observed. However, at the HF lunch energy density of the food consumed was higher for PROP tasters than for PROP non-tasters, but this effect was not observed during the $\mathrm{HCHO}$ lunch. Hunger and satiety scores did not differ between PROP tasters and PROP non-tasters. The hedonic value was higher for the MIX lunch compared to the $\mathrm{HCHO}$ and $\mathrm{HF}$ lunch for PROP tasters as well as for PROP non-tasters.

In conclusion, PROP tasters ingest more of the high-fat foods than of the highcarbohydrate foods from a mixed lunch compared to PROP non-tasters.

\section{ACKNOWLEDGEMENTS}

We would like to thank Manuela Lejeune and Eva Kovacs for their assistance with the macronutrient-specific food choice test.

This study was supported by Novartis Consumer Health Ltd., Nyon, Switzerland. 
S ensitivity to the bitter taste of 6-n-propylthiouracyl (PROP) is a heritable trait, which follows recessive Mendelian pattern of inheritance ${ }^{1,2}$. Approximately $70 \%$ of a Caucasian population are sensitive for a low concentration of PROP (tasters), whereas the remaining $30 \%$ are not able to taste it (non-tasters). In recent studies, the PROP tasters are further divided into supertasters and medium tasters by rating the bitterness of PROP against the saltiness of $\mathrm{NaCl}^{3}$.

The ability to taste PROP has long been associated with an enhanced sensitivity for other bitter compounds ${ }^{4-7}$, food preference ${ }^{8-10}$, and fat perception ${ }^{11}$. PROP tasters, but not PROP non-tasters, were able to discriminate differences in fat content between $40 \%$ fat and $10 \%$ fat salad dressing. Moreover, PROP tasters had no preference for either dressing, whereas the PROP non-tasters preferred the $40 \%$ fat dressing ${ }^{12,13}$. However, this effect, i.e. relation between PROP taster status and fat perception has not been confirmed $^{14}$. The effect of PROP taster status on macronutrient selection has hardly been studied and the results are contradictory. Savage and Davidson ${ }^{15}$ observed that female PROP supertasters ate relatively less fat and more carbohydrates than nontasters, whereas in a study by Yackinous and Guinard ${ }^{16}$ female PROP tasters derived a greater percentage of their energy from fat compared to PROP non-tasters. However, both studies did not measure actual intake, but used $24 \mathrm{~h}$ food intake diaries ${ }^{15}$ or food frequency questionnaires ${ }^{16}$.

Therefore, the aim of the present study was to further investigate whether PROP taster status affects macronutrient selection, i.e. actual intake rather than reported intake.

\section{MATERIAL AND METHODS}

\section{Subjects}

Thirty-six subjects (14 men and 22 women) were recruited by advertisements in local newspapers and participated in this study. Selection was based upon being healthy, no use of any medication known to affect body weight and/or appetite, being non-smoking. and at most moderate alcohol-users (max 10 glasses/week). Height was measured using a wall-mounted stadiometer (Seca, model 220, Hamburg. Germany). Body weight (in underwear) was measured on a digital balance (Seca, model 707, Hamburg, Germany; weighing accuracy of $0.1 \mathrm{~kg}$ ) in fasted state and after voiding the bladder. Body Mass Index (BMI, $\mathrm{kg} / \mathrm{m}^{2}$ ) was calculated as weight $\left(\right.$ height $\left.^{2}\right)$. The degree of dietary restraint was determined by the Three-Factor Eating Questionnaire (TFEQ, score F1s 9) ${ }^{17,18}$.

All subjects gave their written informed consent. The study was approved by the Medical Ethics Committee of Maastricht University.

\section{Test protocol}

The subjects came four times to the university, i.e. one time to determine subjects' PROP taster status and three times during lunchtime for a macronutrient specific food choice test.

\section{PROP taster status}

PROP taster status of the subjects was determined as follows. Five concentrations of $\mathrm{NaCl}(0.01-1 \mathrm{M})$ increasing in half-log steps and five concentrations of PROP $\left(3.2 \times 10^{-5}\right.$ $-3.2 \times 10^{-3} \mathrm{M}$ ) increasing in half log steps were rated using a $150 \mathrm{~mm}$ visual analogue scale (VAS). The VAS were anchored with 'not salt/bitter at all' (left) and 'extremely salt/bitter' (right). Samples were tasted and expectorated. Subjects rinsed with water in between each sample until the taste of PROP or $\mathrm{NaCl}$ had disappeared. This procedure was used to generate suprathreshold taste intensity functions for the two compounds. When these functions are superimposed, the slope of the PROP curve appears much lower than the slope for the $\mathrm{NaCl}$ curve in non-tasters. The PROP curve overlaps with the $\mathrm{NaCl}$ curve in medium tasters. Supertasters have a steeper slope for PROP than for $\mathrm{NaCl}$ functions ${ }^{3,19}$.

\section{Macronutrient-specific food choice test}

Subjects came three times, once a week, to the university for an ad libitum lunch 
experiment. Each test, subjects came at the same time. They were asked to eat a habitual breakfast that morning and to eat nothing after that until lunch at the university. In a random order, the 3 ad libitum lunches were offered one each time; a highcarbohydrate ( $\mathrm{HCHO}$ ) lunch, a high-fat (HF) lunch and a lunch consisting of products of the high fat and high carbohydrate lunch (MIX). Food products of the HF lunch were croissants with full-fat cheese or sliced meat, and sausage rolls, while rolls with low-fat cheese or jam, and currant buns were offered in the $\mathrm{HCHO}$ lunch. The macronutrient composition (CHO/P/F) of the lunches offered was $30 / 10 / 60$ for the HF lunch, $80 / 10 / 10$ for the $\mathrm{HCHO}$ lunch and in principle $60 / 10 / 30$ for the MIX lunch. Before and after each lunch, hunger and satiety scores were measured with a $100 \mathrm{~mm}$ VAS so that $\Delta$ hunger and $\Delta$ satiety scores over lunch could be calculated. In addition, the hedonic value of each lunch was obtained with a $100 \mathrm{~mm}$ VAS. The anchors used for the hunger and satiety scores as well as for hedonic value were 'not hungry/satiated/delicious at all' (left) and 'extremely hungry/satiated/delicious'. The hedonic value was measured with each food item during its consumption and the mean of those values was taken as the hedonic value. Subjects were asked before the start of the study whether they were familiar and liked the food items their were going to be offered during the lunch experiments. All subjects were familiar with the food items and liked them.

\section{Data analysis}

First, subjects were visually classified as PROP supertasters, medium tasters or nontasters by comparing the psychophysical functions of PROP and $\mathrm{NaCl}$, except for 4 doubtful cases. A 2-factor repeated measures ANOVA was used to compare PROP intensity ratings with $\mathrm{NaCl}$ intensity ratings for PROP non-tasters, medium tasters and supertasters (Statview SE Graphics ${ }^{\mathrm{TM}}$ ). The doubtful cases were assigned to one of the three groups by the criteria that the p-value for the 2-factor ANOVA should decrease for classification as PROP supertaster or non-taster or increase for the classification as a PROP medium taster. Post noc anailysis was conducted' with a paireu' t-dest (Statvievv' SE Graphics ${ }^{\mathrm{TM}}$ ), to determine possible differences between PROP and $\mathrm{NaCl}$ intensity ratings per concentration for PROP non-tasters, medium tasters and supertasters. A Bonferonni correction was applied, since 5 concentrations were tested.

Possible differences between PROP non-tasters and PROP tasters (PROP supertasters and medium tasters together) were analyzed with an unpaired $t$-test (Statview SE Graphics ${ }^{\mathrm{TM}}$ ). Possible differences between PROP supertasters, PROP medium tasters and PROP non-tasters were analyzed with factorial ANOVA (Statview SE Graphics ${ }^{\mathrm{TM}}$ ). Possible differences between lunches regarding appetite and hedonic value were analyzed using repeated measures ANOVA. Post hoc analysis was conducted with Scheffe F-test (Statview SE Graphics ${ }^{\mathrm{TM}}$ ).

Since 17 subjects conducted only the MIX lunch experiment and not the $\mathrm{HF}$ and $\mathrm{HCHO}$ lunch experiments, the results of the $\mathrm{HF}$ and $\mathrm{HCHO}$ lunch tests are presented of 19 subjects and the results of the MIX lunch of 36 subjects.

The level of significance is set at $p<0.05$. Data are presented as means \pm standard deviations (SD).

\section{RESULTS}

\section{PROP tasters}

The 2-factor repeated measures ANOVA revealed a significant Solution $\mathrm{x}$ Repeated measure for PROP supertasters $(F(50,4)=5.4, p<0.001)$ and PROP non-tasters $(F(60,4)=1.2, P<0.0001)$, but not for $P R O P$ medium tasters $(F(55,4)=5.4, p=0.93)$. Based on the classification, the PROP/ $\mathrm{NaCl}$ ratios (sum of intensity ratings of the 5 PROP concentrations divided by the sum of intensity ratings of the $5 \mathrm{NaCl}$ concentrations) were as follows: $<0.8$ for PROP non-tasters, $\geq 0.8$ and $\leq 1.2$ for medium tasters and $>1.2$ for PROP supertasters. As such, 11 men and 12 women were characterized as PROP tasters and 13 subjects as PROP non-tasters. Of the 23 PROP tasters, 4 male and 7 female PROP tasters were classified as PROP supertasters (figure 1). 


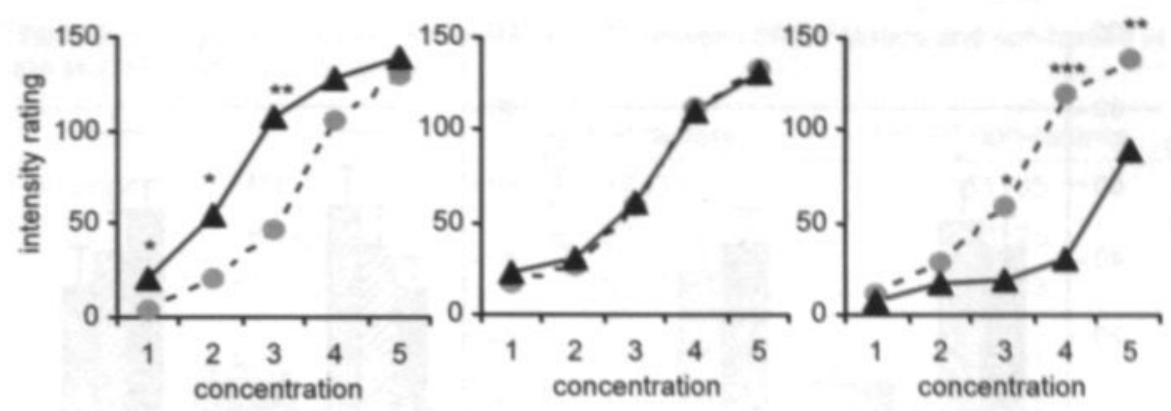

$\cdots-\cdots \mathrm{NaCl} \longrightarrow$ PROP

PROP supertasters

PROP medium tasters

PROP non-tasters

Figure 1: psychophysical functions for $\mathrm{NaCl}$ and PROP showing the relation between perceived taste intensity and stimulus concentration for PROP supertasters, medium tasters and non-tasters. 2-factor repeated measures ANOVA revealed a significant solutionxrepeated measure for PROP supertasters $(F(50,4)=5.4, p<0.001)$ and PROP nontasters $(F(60,4)=13.2, p<0.0001)$, but not for PROP medium tasters $(F(55,4)=5.4, p=0.93)$. Post hoc analysis with a paired $t$-test with Bonferroni correction was applied. " $p<0.05$. ${ }^{*} p<0.01, \cdots p<0.001$ significantly different between PROP and $\mathrm{NaCl}$

Table 1 shows the baseline characteristics of the total group as well as for the PROP tasters and PROP non-tasters. Both groups did not differ with respect to age, weight and BMI. Factor 1 of the Three-Factor Eating Questionnaire of Stunkard and Messick represents cognitive restrained eating behavior. A score $\$ 9$ means that subjects are dietary unrestraint. This means that in the present study at group level PROP tasters as well as non-tasters were unrestrained eaters.

\section{Macronutrient selection and energy intake}

At the MIX lunch experiment, PROP tasters compared to PROP non-tasters ate relatively more fat $(47 \pm 9$ vs. $38 \pm 10$ energy $\%, d f=34, t$-value $=2.6, p<0.05)$ and less carbohydrate $(45 \pm 9$ vs. $53 \pm 10$ energy $\%, d f=34, t$-value $=-2.5, p<0.05)$, while no difference in protein intake was observed (figure 2). When dividing PROP tasters into PROP supertasters and medium tasters (figure 3 ), the same relation between PROP taster status and macronutrient selection was observed for fat and carbohydrate intake ( $F$ at: $F(35,2)=3.9$, $p<0.05$ and $\mathrm{CHO}: F(35,2)=3.5, p<0.05)$, i.e. PROP supertasters ate relatively more fat and less carbohydrate than medium tasters who ate relatively more fat and less carbohydrate than non-tasters. However, PROP tasters and non-tasters did not differ with respect to food intake ( $273 \pm 87$ vs. $239 \pm 72 \mathrm{~g}$, respectively, $d f=34, t$-value $=1.2, n s$ ), energy intake $(3.8 \pm 1.1$ vs. $3.1 \pm 1.0 \mathrm{MJ}$, respectively, $d f=34, t$-value=1.9, $p<0.1)$. With respect to energy density, PROP tasters ate more energy dense foods compared to PROP non-tasters $(14.1 \pm 1.6$ vs. $13.0 \pm 1.5 \mathrm{~kJ} / \mathrm{g}$, respectively, $d f=34, t$-value $=2.0, p<0.05)$ at the MIX lunch experiment.

Table 1: baseline characteristics of the total group $(n=36)$, and of the PROP tasters $(n=22)$ and PROP non-tasters ( $n=14)$

\begin{tabular}{lccc}
\hline & total group & PROP tasters & $\begin{array}{c}\text { PROP non- } \\
\text { tasters }\end{array}$ \\
\hline age $(\mathrm{y})$ & $32 \pm 9$ & $31 \pm 10$ & $34 \pm 9$ \\
body weight $(\mathrm{kg})$ & $74 \pm 13$ & $76 \pm 13$ & $72 \pm 11$ \\
$\mathrm{BMI}^{1}\left(\mathrm{~kg} / \mathrm{m}^{2}\right)$ & $25 \pm 4$ & $25 \pm 4$ & $26 \pm 4$ \\
$\mathrm{~F}^{1}$ & $6 \pm 4$ & $6 \pm 4$ & $5 \pm 4$ \\
\hline
\end{tabular}




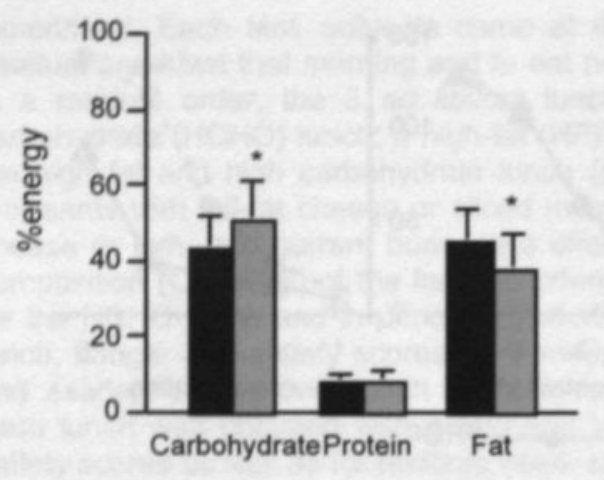

Figure 2: macronutrient selection of PROP tasters (black bars) and PROP non-tasters (grey bars) at a MIX lunch experiment consisting of high fat and high carbohydrate products. PROP tasters ate relatively less carbohydrate and more fat than PROP non-tasters (both " $p<0.05$ ).

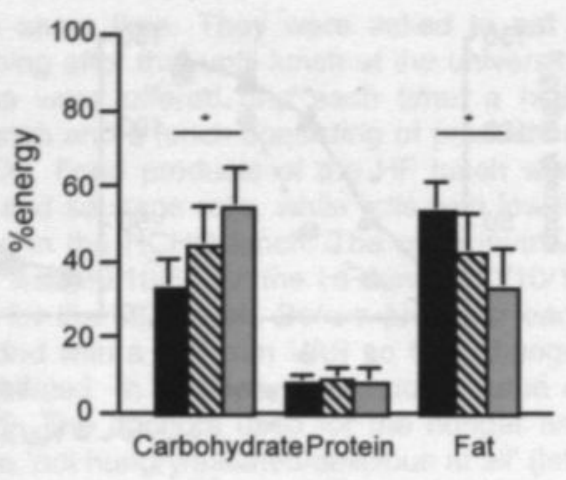

Figure 3: macronutrient selection of PROP supertasters (black bars), PROP medium tasters (striped bars) and PROP non-tasters (grey bars) at a MIX lunch experiment consisting of high fat and high carbohydrate products. A relation between PROP taster status and carbohydrate and fat intake was observed (Fat: $F(35,2)=3.0, \quad p<0.05$ and $\mathrm{CHO}$ : $\left.F(35,2)=2.8,{ }^{*} p<0.05\right)$.

At the $\mathrm{HCHO}$ as well as at the HF lunch, no differences between PROP tasters and nontasters with respect to macronutrient selection (figure 4 and 5), food intake (HF 239 \pm 121 vs. $197 \pm 26 \mathrm{~g}, \mathrm{df}=17, t$-value $=0.8, \mathrm{~ns} ; \mathrm{HCHO} 290 \pm 142 \mathrm{vs} .258 \pm 84 \mathrm{~g}, \mathrm{df}=17, t$-value $=0.5$, $\mathrm{ns}$ ) and energy intake (HF $4.0 \pm 2.0$ vs. $3.3 \pm 0.4 \mathrm{MJ}$, df=17, $t$-value $=0.8, \mathrm{~ns}$; $\mathrm{HCHO} 2.9 \pm 1.3$ vs. $2.5 \pm 0.8 \mathrm{MJ}, \mathrm{df}=17, t$-value $=0.6, \mathrm{~ns})$ was observed. At the HF lunch energy density was higher for the PROP taster than non-tasters $(16.6 \pm 0.1$ vs. $16.5 \pm 0.0 \mathrm{~kJ} / \mathrm{g}, \mathrm{df}=17, t$ value=2.2, $p<0.05$ ), while no effect of PROP taster status on energy density during the $\mathrm{HCHO}$ lunch was observed $(10.0 \pm 0.6$ vs. $9.9 \pm 0.4 \mathrm{~kJ} / \mathrm{g}$ for PROP tasters and non-tasters respectively, $d f=17, t$-value $=0.2, n s$ ).

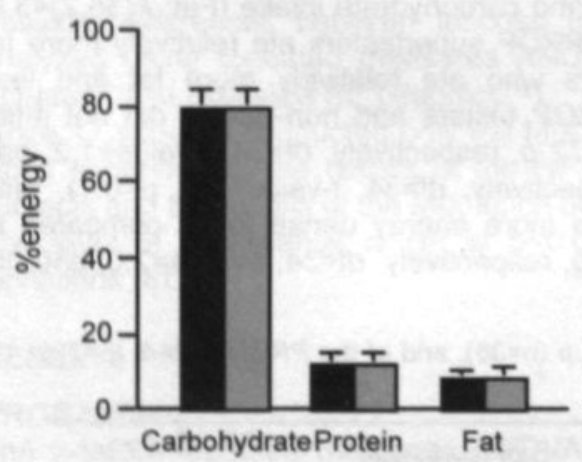

Figure 4: macronutrient selection of PROP tasters (black bars) and PROP non-tasters (grey bars) at a $\mathrm{HCHO}$ lunch experiment consisting high carbohydrate products. No difference between PROP tasters and PROP non-tasters was observed.

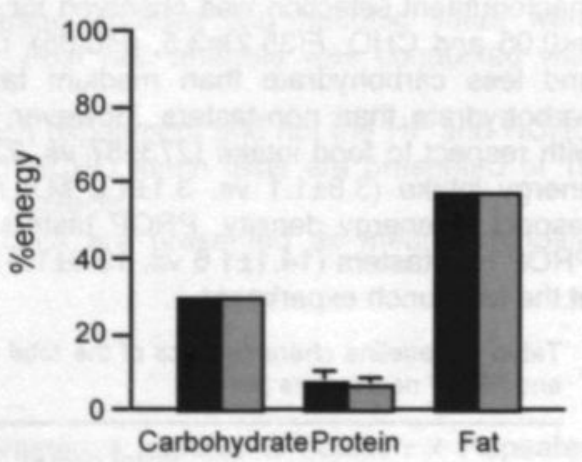

Figure 5: macronutrient selection of PROP tasters (black bars) and PROP non-tasters (grey bars) at a HF lunch experiment consisting high fat products. No difference between PROP tasters and PROP non-tasters was observed. 
Table 2: $\Delta$ hunger and $\triangle$ satiety scores (mm VAS) between PROP tasters and non-tasters at the MIX, HF and $\mathrm{HCHO}$ lunch test

\begin{tabular}{llcc}
\hline & & PROP tasters & PROP non-tasters \\
\hline \multirow{2}{*}{$\Delta$ hunger ${ }^{1}$} & MIX & $-47 \pm 31$ & $-51 \pm 35$ \\
& HCHO & $-67 \pm 19$ & $-56 \pm 25$ \\
& HF & $-60 \pm 19$ & $-62 \pm 23$ \\
\multirow{4}{*}{$\Delta$ satiety $^{1}$} & MIX & $62 \pm 18$ & $68 \pm 21$ \\
& HCHO & $68 \pm 18$ & $63 \pm 27$ \\
& HF & $65 \pm 14$ & $58 \pm 29$ \\
\hline
\end{tabular}

'Ahunger and $\Delta$ satiety are calculated as the hunger or satiety score after the lunch minus the hunger or satiety score before the lunch measured with a $100 \mathrm{~mm}$ VAS.

Table 3: hedonic value (mm VAS) of PROP tasters and non-tasters at the MIX, HF and $\mathrm{HCHO}$ lunch test

\begin{tabular}{lcc}
\hline & PROP tasters & PROP non-tasters \\
\hline MIX & $77 \pm 12^{1}$ & $77 \pm 10^{1}$ \\
HCHO & $61 \pm 12$ & $66 \pm 18$ \\
HF & $69 \pm 13$ & $70 \pm 15 S$ \\
\hline
\end{tabular}

'significantly different from $\mathrm{HCHO}$ and $\mathrm{HF}(\mathrm{p}<0.05)$

\section{Appetite}

The $\Delta$ hunger and $\Delta$ satiety levels did not differ between PROP tasters and non-tasters at the MIX, HCHO or HF lunch experiment (table 2).

\section{Hedonic value}

No effect of PROP taster status was observed for the hedonic value of the MIX, HCHO or $\mathrm{HF}$ lunch (table 3 ). However, the hedonic value was higher for the MIX lunch compared to the HCHO and HF lunch for PROP tasters as well as PROP non-tasters, with no differences between $\mathrm{HCHO}$ and $\mathrm{HF}$ lunch.

\section{DISCUSSION}

In the present study, macronutrient selection was affected by PROP taster status. When offering an ad libitum lunch consisting of macronutrient-specific high-fat and highcarbohydrate food products, a difference in macronutrient selection was observed. PROP tasters ate relatively more fat and less carbohydrate than PROP non-tasters did. Moreover, when dividing PROP tasters into PROP supertasters and PROP medium tasters, the same relation was observed. The effect of PROP taster status on macronutrient selection was not observed when offering either only high-fat products or high-carbohydrate products. This difference between the MIX lunch and the HF as well as $\mathrm{HCHO}$ lunch could be due to the characteristics of the food products. Probably, the macronutrient composition diversity within the HF lunch as well as within the $\mathrm{HCHO}$ lunch was limited. Macronutrient-specific food choice hardly have been shown in the literature mainly because of lack of macronutrient specificity in the buffet offered, and when it was present, it only occurred with macronutrient-specific food items ${ }^{20}$. Because the energy density of the food consumed at the MIX lunch of the PROP tasters was slightly higher compared to non-tasters, this affected energy intake, although this did not reach the level of significance. Since the energy density consumed at the HF was 16.6 $\mathrm{kJ} / \mathrm{g}$ and at the $\mathrm{HCHO}$ lunch $10.0 \mathrm{~kJ} / \mathrm{g}$, but 13.0 vs. $14.1 \mathrm{~kJ} / \mathrm{g}$ during the MIX lunch, it can be concluded that during the MIX lunch, PROP tasters did not eat only high-fat foods. In 
other words, PROP tasters ate preferably high-fat foods, but also some highcarbohydrate food items, whereas PROP non-tasters ate preferably high-carbohydrate foods and some high-fat food items. Subjects were familiar with the food products offered and therefore they knew whether they were eating high-fat or high carbohydratefood items. Apparently, compensation for energy density affecting energy intake took place by 'learned satiety' ${ }^{21}$.

Although a difference in macronutrient selection between PROP tasters and non-tasters was observed, at the same time, no differences with respect to energy intake, hedonics or appetite was observed. Obviously. PROP tasters ingested more fat and less carbohydrates while reaching the same level of hedonics, energy intake and appetite compared to non-tasters. During the MIX lunch, however, the food choice lead to higher hedonic values than during the $\mathrm{HCHO}$ and $\mathrm{HF}$ lunches in both groups. We suggest that the taste perception by the subject may play a role in their food choice that optimizes hedonic value.

Results of previous studies relating PROP taster status to macronutrient selection showed discrepancy in their results. Yackinous and Guinard ${ }^{16}$ found that PROP tasting women reported to derive a greater percentage of their energy from fat compared to nontasters. Moreover, PROP taster status affected the reported intake of fat-containing products for men. In contrast, in the study of Savage and Davidson ${ }^{15}$ female PROP supertasters reported to eat relatively less fat and more carbohydrates than non-tasters did. The results of the latter study are supported by the finding of a recent study with 4and 5-year-old children ${ }^{22}$ in which PROP tasters compared to non-tasters seemed to have a lower intake of fat. This effect was largely due to differences observed in the girls. However, the previous studies did not measure actual intake like in the present study, but used 24 h food intake diaries ${ }^{15}$ or food frequency questionnaires ${ }^{16,22}$. This could have lead to (selective) underreporting or under-eating ${ }^{23}$. Moreover, the methods used for classification of PROP taster status might be different between the different studies. For example in the study of Keller et al. ${ }^{22}$. PROP taster status was determined with only one concentration of PROP, while in the present study as well as in the study by Yackinous and Guinard, 5 concentrations of PROP were tested against 5 concentrations of $\mathrm{NaCl}$. Furthermore, in our as well as in the study of Yackinous and Guinard subjects were assigned to one of the three PROP groups using the psychophysical functions of both solutions without measuring threshold concentrations. Data analysis revealed that our PROP groups were discriminated maximally and no overlap of the PROP/NaCl ratios was observed between groups. The contradictory results might also been influenced by gender. In the previous studies, the association between PROP taster status and macronutrient selection was often only observed in women, whereas in the present study, men and women were analyzed together. Because of the small subgroups, a separate analysis for men and women is therefore not possible in the present study. Moreover, only savory high-fat foods were served. It is unknown whether the effects observed in the present study, would also be present when sweet high fat products were served.

Studies on the effect of PROP taster status on an increased sensitivity for other compounds, e.g. capsaicin or other bitter compounds, and its effect on food preference are reported more often ${ }^{5,8,10.11}$. Also, PROP taster status has been linked to fat perception. It has been shown that PROP taster status was related to fat sensitivity ${ }^{11,12}$. PROP medium tasters and supertasters, but not non-tasters were able to discriminate the difference in fat content between salad dressings with 10 and $40 \%$ fat. Moreover, PROP medium tasters and supertasters showed no preference for either dressing. whereas PROP non-tasters preferred the high-fat dressing. An explanation for this result might be that because PROP tasters could discriminate between the samples, $10 \%$ of fat already led to a high hedonic response whereas the PROP non-tasters needed the highfat sample for the same hedonic response. This finding, i.e. an increased sensitivity for fat of PROP tasters was confirmed in a study by Nasser et al. ${ }^{24}$. In the latter study, PROP taster status was related with the ability to detect a difference in ice creams with 
addition of conjugated linoleic acid compared to the original ice cream. Also Duffy et al. ${ }^{25}$ observed an effect of PROP taster status on creaminess ratings of high-fat milk products. In contrast, no effect of PROP taster status on sensitivity for fat was observed by Yackinous and Guinard ${ }^{14}$. If PROP taster status is indeed related to an increased fat sensitivity, this does not have to imply that this would inversely affect food or fat intake. It can be argued that subjects that are more sensitive for fat consequently like fat products better and therefore eat those more often. On the contrary, it can be hypothesized that because they are more sensitive, they need less of that type of food to get the same sensation.

Next to an increased sensitivity for fat, the effect of PROP taster status on fat preference is investigated. Bartoshuk et al. observed an inverse relationship for PROP sensitivity and the liking of high fat foods for women, but this was not observed in men ${ }^{8}$. On the other hand, Drewnowski et al. observed no effect of PROP taster status on sensory perception or preference for mixtures of milk, cream and sugar in females ${ }^{7}$. Although preference and actual intake are related, this relationship is rather weak.

In conclusion, the present study shows that when offering a mixed meal consisting of high-carbohydrate as well as high-fat products, PROP tasters ingest more of the high-fat foods compared to the high-carbohydrate foods than non-tasters do; their taste perception might play a role in their macronutrient choice so that hedonics are optimized, while energy intake and appetite were not affected.

\section{REFERENCES}

1 Fox AL. The relationship between chemical constitution and taste. Proc Natl Acad Sci 1931, 18: $115-120$

2 Snyder LH. Inherited taste deficiency. Science 1931: 74:151-152

3 Bartoshuk LM, VB Duffy, IJ Miller. PTC/PROP tasting: anatomy, psychophysics, and sex effects. Physiol Behav 1994; 56: 1165-1171

4 Drewnowski A, SA Henderson, AB Shore. Genetic sensitivity to 6-n-propylthiouracil (PROP) and hedonic responses to bitter and sweet tastes. Chem Senses 1997; 22: 27-37

5 Ly A, A Drewnowski. PROP (6-n-Propylthiouracil) tasting and sensory responses to caffeine. sucrose, neohesperidin dihydrochalcone and chocolate. Chem Senses 2001; 26: 41-47

6 Drewnowski A, SA Henderson, AB Shore, A Barratt-Fornell. Nontasters, tasters, and supertasters of 6-n-Propylthiouracil (PROP) and hedonic response to sweet. Physiol Behav 1997; 62: 649-655

7 Drewnowski A, SA Henderson, A Barratt-Fornell. Genetic sensitivity to 6-n-propylthiouracil and sensory responses to sugar and fat mixtures. Physiol Behav 1998; 63: 771-777

8 Bartoshuk LM, VB Duffy, K Fast, B Green, J Kveton, LA Lucchina, JM Prutkin, DJ Snyder, K Tie. 1999. Sensory variability, food preferences, and BMI in non-, medium and supertasters of PROP. In SSIB. Sand Key, Clearwater Beach, Florida, USA. 19

9 Drewnowski A, SA Henderson, A Barratt-Fornell. Genetic taste markers and food preferences. Drug Metab Dispos 2001; 29: 535-538

10 Kaminski LC, SA Henderson, A Drewnowski. Young women's food preferences and taste responsiveness to 6-n- propylthiouracil (PROP). Physiol Behav 2000; 68: 691-697

11 Tepper BJ, RJ Nurse. Fat perception is related to PROP taster status. Physiol Behav 1997; 61 949-954

12 Tepper BJ, RJ Nurse. PROP taster status is related to fat perception and preference. Ann $N$ Y Acad Sci 1998; 30: 802-804

13 Tepper BJ. Does genetic taste sensitivity to PROP influence food preferences and body weight? Appetite 1999; 32: 422

14 Yackinous C. JX Guinard. Relation between PROP taster status and fat perception, touch, and olfaction. Physiol Behav 2001; $72: 427-737$

15 Savage J, HIM Davidson. 2000. Genetic sensitivity to PROP and its relationship with energy intake and short time satiety. Paris: Eur J Clin Nutr. S15

16 Yackinous CA, JX Guinard. Relation between PROP (6-n-propylthiouracil) taster status, taste anatomy and dietary intake measures for young men and women. Appetite 2002; 38: 201-209

17 Stunkard A., S Messick. The three-factor eating questionnaire to measure dietary restraint, disinhibition, and hunger. J Psychosom Res 1985; 29: 71-83 
18 Westerterp-Plantenga MS, CRT Verwegen. The appetizing effect of an aperitif in overweight and normal-weight humans. Am J Clin Nutr 1999; 69: 205-212

19 Kamphuis MMJW, MS Westerterp-Plantenga, WHM Saris. Fat specific satiety in humans for fat high in linoleic acid versus fat high in oleic acid. Eur J Clin Nutr 2001; 55: 499-508

20 Westerterp-Plantenga MS, MJW IJedema, NEG Wijckmans-Duijsens. The role of macronutrient selection in determining patterns of food intake in obese and non-obese women. Eur J Clin Nutr 1996; 50: 580-591

21 Westerterp-Plantenga MS. Analysis of energy density of food in relation to energy intake regulation in human subjects. Br J Nutr 2001; 85: 351-361

22 Keller KL, L Steinmann, RJ Nurse, BJ Tepper. Genetic taste sensitivity to 6-n-propylthiouracil influences food preference and reported intake in preschool children. Appetite 2002; 38: 3-12

23 Goris AHC, MS Westerterp-Plantenga, KR Westerterp. Undereating and underrecording of habitual food intake in obese men: selective underreporting of fat intake. Am J Clin Nutr 2000; 71: $130-134$

24 Nasser JA, CJ Chou, HR Kissileff, CN Boozer, FX Pi-Sunyer. PROP taster status and the ability to detect the presence of added conjugated linoleic acid in high fat ice cream. Obes Res 1999; 7: $87 \mathrm{~S}$

25 Duffy VB, LM Baroshuk, LA Lucchina, LH Snyder, A Tym. 1996. Supertasters of PROP (6-npropylthiouracil) rate the highest creaminess to high-fat milk products. In AChemS. Sarisota, Florida. 598 



\section{Fat-specific satiety in humans for fat high in linoleic acid versus fat high in oleic acid}

\section{Marleen MJW Kamphuis}

Margriet S Westerterp-Plantenga Wim HM Saris

European Journal of Clinical Nutrition 2001; 55(6) 499-508 


\section{ABSTRACT}

Objective: to investigate the effect of 2 week use of oils high in linoleic (LA), $\gamma$-linolenic (GLA) and oleic acid (OA) on energy intake (EI), macronutrient composition, parameters of appetite and taste perception.

Design: a randomized placebo-controlled 2-week treatment, followed by a test day.

Setting: two-week treatments: daily life; Test day: laboratory restaurant.

Subjects: eight overweight men and eight overweight women (body mass index $27.4 \pm 0.4$ $\mathrm{kg} / \mathrm{m}^{2}$ )

Interventions: three two-week-treatment, in which subjects replaced their habitual fat products by three different oils, (relatively) high in LA $(66.8 \%)$, GLA $(20.2 \%)$ or OA $(79.6 \%$, placebo). The wash-out periods were 2 weeks. Before each intervention period, taste perception and sensory specific satiety was tested.

Results: even though energy intake was higher during dinner, subjects ate relatively less fat with LA $(45.0 \pm 9.4$ energy\%, $p<0.05)$ than with OA $(48.3 \pm 8.3$ energy $\%)$. Subjects did not distinguish the oils with the different fatty acids from each other. There was no relation between satiety or fat specific satiety and taste characterization without as well as with sucrose. Although no differences were seen for the AUC of the appetite profile, at mid-afternoon subjects were less satiated with LA $(46.1 \pm 6.2 \mathrm{~mm}, \mathrm{p}<0.05)$ or GLA $(45.1 \pm 5.8 \mathrm{~mm}, \mathrm{p}<0.01)$ than after treatment OA $(62.5 \pm 4.8 \mathrm{~mm}) .24 \mathrm{~h} \mathrm{El}$ on the test day was 7.6-8.0 MJ and did not differ between treatments.

Conclusions: fat-specific satiety during dinner with LA vs. OA was shown after a twoweek treatment of each oil, but no change in general satiety. Fat-specific satiety was not related to taste perception or characterization of the oils.

\section{ACKNOWLEDGEMENTS}

This study was supported by Novartis Consumer Health Ltd., Nyon, Switzerland. 
$\mathrm{t}$ is a common knowledge that the prevalence of obesity has increased in the United States ${ }^{1}$, as well as in Europe ${ }^{2}$ during the last decades. In fact, it is becoming a serious health problem. Next to cardiovascular diseases ${ }^{3.4}$, obesity is related to other diseases or risk factors for diseases like hypertension, increased LDL and decreased HDL serum cholesterol concentrations, hyperlipidaemia and non-insulin dependent diabetes mellitus ${ }^{5,6}$.

Diet-induced obesity is caused by long-term energy imbalance, in which energy intake is higher than energy expenditure. As an implication of excessive energy intake, fat intake is often associated with the development of obesity ${ }^{7.8}$. Several studies have shown that fat intake is related to the fat mass of subjects ${ }^{2-11}$, which relationship was shown to be only a result of the relation between fat intake and energy intake ${ }^{12}$. How does fat intake cause high energy intakes and therefore contribute to weight gain and the development of obesity? Firstly, the hedonics of foods might be important in food selection. Fat is palatable and therefore high-fat diets might be more tasty than low-fat diets and would promote consumption. A relationship between preference for fat and obesity is shown in that hedonic ratings for fats increases with increasing body mass ${ }^{13}$, and obese people have a stronger preference for high-fat and sweet foods than lean subjects ${ }^{14}$. High-fat foods are energy dense because of its Atwater-factor, i.e. $37 \mathrm{~kJ} / \mathrm{g}$ for fat, compared to 17 $\mathrm{kJ} / \mathrm{g}$ for carbohydrates and proteins, which could affect energy intake as well ${ }^{15,16}$. The energy density of a food or diet, i.e. total metabolizable energy consumed with the macronutrients divided by the total weight of food and water consumed, is greatly determined by its fat content ${ }^{15,17,18}$.

In addition, the poor ability of fat to induce short-term satiety might cause high energy intakes as well. High-fat foods seem to have a smaller effect on short-term satiety than foods high in carbohydrates ${ }^{10-22}$. However, in the course of a day, macronutrient specific satiety for fat has been shown ${ }^{23}$. The high energy density of fat, together with the low ability of high-fat foods to induce short-term satiety may lead to passive overconsumption of fat and/or energy ${ }^{19,24}$.

Fat intake has been mainly observed as a passive overconsumption facilitated by its hedonics, energy density, and relatively low short-term satiety effect. However, little is known about the recognition of fat by the body. Recently, a relation between perception of fatty acids and dietary preference for fat has been shown in rats. Gilbertson $\theta t$ al. ${ }^{25}$ demonstrated that free poly-unsaturated fatty acids (PUFA's) inhibit delayed rectifying $\mathrm{K}^{+}$ channels (DRK channels) in mammalian taste receptor cells, which in turn would lead to an increase in activity of the taste cells. Interestingly, the effects were only seen for cisPUFA's (arachidonic, linoleic and linolenic acid), but not for the mono-unsaturated fatty acid oleic acid. Moreover, DRK channels in tongue tissue of OM rats with a preference for high fat diets were less sensitive to the cis-PUFA's, than DRK channels of S5B rats. The latter rats prefer diets high in carbohydrates ${ }^{26}$. In addition, when placed on a high-fat diet, OM rats get rapidly obese, while the S5B rats reduce their food intake and remain lean. Thus, an inverse relation between fatty acid perception and fat preferences is seen in rats. Some evidence for a possible role of fat perception in humans has been shown by Tepper et al. ${ }^{27,28}$. They showed a relationship between PROP taster status and ability to discriminate between differences in fat concentrations in humans. PROP medium and supertasters were able to discriminate a $10 \%$ fat salad dressing from a $40 \%$ fat salad dressing.

Many studies have examined the effect of fat intake on satiety and/or food intake, compared to other macronutrients, without discriminating between different types of fat. Only a few studies investigated the effects of saturation of fats on satiety. After a lunch high in oleic acid (55 energy \% of fat), energy intake during a buffet-dinner was higher than after a lunch high in linoleic or stearic/oleic acid ${ }^{29}$. From this study they concluded that mono-unsaturated fatty acids were less satiating than saturated or poly-unsaturated fatty acids. These results were partly confirmed by a study of French et al ${ }^{30,31}$, They found that after intestinal infusions of linoleic, stearic and oleic acids, subsequent energy intake was reduced after linoleic acid infusion compared to saline. 
Another study investigating the effect of fatty acids on body weight was conducted by Phinney et al. ${ }^{32}$. They observed a reduced weight regain after weight loss by $\gamma$-linolenate. After weight loss, subjects who consumed $5 \mathrm{~g}$ of borage oil (high in $\gamma$-linolenic acid) regained less weight than subjects who used $5 \mathrm{~g}$ of olive oil (high in oleic acid) per day during a one-year-period.

The aim of the present study was to test the hypothesis whether subjects were able to discriminate between different oils that were high in linoleic, $\gamma$-linolenic or oleic (control) acid. Subsequently, we assessed whether a diet high in linoleic or $\gamma$-linolenic acid was more effective in reducing energy or specific macronutrient intakes and inducing satiety compared to a diet high in oleic acid. Finally, we tested the hypothesis that in humans taste perception and satiety effects of oils with different fatty acids, i.e. linoleic and $\gamma$ linolenic vs. oleic acid are related.

\section{METHODS}

\section{Subjects}

Forty-two subjects were recruited by advertisements in local newspapers. Twenty-six subjects (12 men and 14 women, body mass index (BMI) $25-30 \mathrm{~kg} / \mathrm{m}^{2}$, age $20-55$ years) were selected for the experiment. For selection, subjects had to be healthy and at least 3 months weight stable prior to the study. They did not use any medication known to affect body weight and/or appetite, were non-smoking, and only moderate alcohol-users. Eight overweight men and eight overweight women completed the study. 10 subjects dropped out for several reasons; 3 subjects for illness not related to the treatment and 7 subjects because of the frequency of laboratory visits. Table 1 shows the baseline characteristics of the 16 subjects. Body weight (after an overnight fast) was measured on a digital balance (SECA, model 707, Hamburg, Germany, weighing accuracy of $0.01 \mathrm{~kg}$ ) while subjects were wearing underwear. Height was measured to the nearest $0.005 \mathrm{~m}$. BMI $\left(\mathrm{kg} / \mathrm{m}^{2}\right)$ was calculated as body weight $(\mathrm{kg})$ divided by height $(\mathrm{m})$ squared. Body weight was measured at the beginning and end of each intervention period. The degree of dietary restraint was determined by the Three-Factor Eating Questionnaire (TFEQ) ${ }^{33}$ and by the Herman/Polivy restraint questionnaire $(\mathrm{HP})^{34}$.

Table 1: baseline characteristics of the subjects $(n=16)$

\begin{tabular}{lccc}
\hline & all subjects $(\mathrm{n}=16)$ & men $(\mathrm{n}=8)$ & women $(\mathrm{n}=8)$ \\
\hline age $(\mathrm{y})$ & $41.6 \pm 8.6$ & $41.9 \pm 6.9$ & $41.4 \pm 10.5$ \\
$\mathrm{BMI}{ }^{1}\left(\mathrm{~kg} / \mathrm{m}^{2}\right)$ & $27.4 \pm 1.5$ & $27.8 \pm 1.6$ & $26.9 \pm 1.5$ \\
$\mathrm{HP}^{2}$ & $14.8 \pm 3.2$ & $14.0 \pm 1.9$ & $15.5 \pm 4.1$ \\
$\mathrm{~F}^{3}$ & $5.8 \pm 3.6$ & $4.5 \pm 3.3$ & $7.0 \pm 3.5$ \\
$\mathrm{~F}^{3}$ & $6.1 \pm 2.8$ & $6.0 \pm 3.6$ & $6.1 \pm 4.8$ \\
$\mathrm{F3}^{3}$ & $5.6 \pm 3.6$ & $5.5 \pm 5.6$ & $5.8 \pm 5.2$ \\
PROP-taster $^{3}$ & 9 & 3 & $6^{5}$ \\
\hline
\end{tabular}

${ }^{1} \mathrm{BMI}=$ Body mass index ${ }^{2} \mathrm{HP}=$ Herman-Polivy restraint ${ }^{3} \mathrm{~F} 1$ (cognitive restraint), $\mathrm{F} 2$ (inhibition) and F3 (hunger) from Three-Factor Eating Questionnaire (TFEQ) "number of PROP-tasters which are supertasters and medium-tasters together ${ }^{5} n=7$

PROP taster status of the subjects was identified as follows. Since PROP taster status does not influence intensity judgments for $\mathrm{NaCl}, \mathrm{NaCl}$ serves as a standard against of which the PROP function can be compared. Five concentrations of $\mathrm{NaCl}(0.01-1 \mathrm{M})$ increasing in half-log steps and five concentrations of PROP $\left(3.2 \times 10^{-5}-3.2 \times 10^{-3} \mathrm{M}\right)$ increasing in half log steps were rated using a $150 \mathrm{~mm}$ visual analogue scale (VAS). Samples were tasted and expectorated. Subjects rinsed with water in between each sample. This procedure was used to generate suprathreshold taste intensity functions for 
the two compounds. When these functions are superimposed, the slope of the PROP curve appears much lower than the slope for the $\mathrm{NaCl}$ curve in non-tasters (NT). The PROP curve overlaps with the $\mathrm{NaCl}$ curve in medium tasters (MT). Supertasters (ST) have a steeper slope for PROP than for $\mathrm{NaCl}$ functions ${ }^{35}$.

Because of missing data for one woman, data of PROP-taster status is presented of 15 subjects.

All subjects gave their written consent. The study was approved by the Medical Ethics Committee of Maastricht University.

\section{Experimental design}

The design of the study was a single blind, randomized placebo-controlled trial, which consisted of three two-week-treatments alternated by a two-week wash-out period, to ensure that women were always in the same phase of their menstrual cycle. In the week before the start of each intervention period taste perception, taste characterization and sensory specific satiety of the oils was tested. At day 15 of each intervention period, the subjects came to the department for assessment of their $24 \mathrm{~h}$ food intake and appetite profile. Moreover, a blood sample was taken after an overnight fast.

The oil high in linoleic acid (LA) was 'Becel dieet olie' (Van den Berg. Unilever, Vlaardingen The Netherlands) and contained $66.8 \%$ LA. 'Borage oil' (Eurochem, Feinchemie $\mathrm{GmbH}$, Munchen, Germany) was used as the oil containing a relatively high percentage of $\gamma$-linoleic acid (GLA, 20.2\%). The placebo oil was 'Hozol oil' (Contined B.V., Bennekom, The Netherlands) which is high in oleic acid (OA, 79.6\%). Oleic acid is the control fatty acid, since Gilbertson et al. ${ }^{25.26}$ showed that oleic acid did not give any taste perception reaction.

Total fatty acid composition of the oils was determined by analyses on a gas chromatogrhaph. Lipids were extracted according to the method of Folch. The oils were saponified and the fatty acids (FA) transmethylated to the corresponding methylesters (FAME) by reaction with acetyl choleride ${ }^{36}$. The FAMEs were separated and quantified by using a HP 5890 II gas chromatograph, fitted with a 50 m CP sil88 capillary column with $0.25 \mathrm{~mm}$ ID and $0.12 \mu \mathrm{m}$ film thickness (Chrompack $\otimes$, Middelburg. The Netherlands). A standard fame mixture was used to identify the FAME's by means of the retention times.

Taste perception and taste characterization of LA and of GLA rich oils were determined in comparison to the placebo oil, which was high in OA. Also $24 \mathrm{~h}$ food intake and the appetite profile were assessed with LA and GLA in comparison to OA. The methods are described below. The hedonic value was assessed during a pre-protocol phase, and did not differ between the oils (LA: $74.3 \pm 23.2$, GLA $68.9 \pm 36.5$ and OA $73.6 \pm 30.7 \mathrm{~mm} / 100$ mm VAS).

\section{Taste perception protocol}

All taste perception tests were executed by the same experimenter, who took care that it was exactly the same procedure every time. The ability to discriminate between the different oils was tested using the triangle test. Subjects were offered three samples of oil: two alike, and one different. The question asked was 'which sample is odd'? This test is effective to determine if overall differences exist. Moreover, it can select subjects for ability to discriminate differences ${ }^{37}$. During such a test, the following procedure was used. Subjects rinsed their mouth with water, followed by chewing on a piece of white bread and rinsing their mouth again. The water and bread had to be expectorated. This procedure was followed after each sample. After they had rinsed their mouth, subjects tasted the oil sample. The sample also had to be expectorated. After a row of three samples, the subjects had to fill in a questionnaire with the question: 'which oil is odd to the other two?'. After filling in the questionnaire, there was a resting period of 30 seconds before starting with the next session. Each time, 2 series of 6 trials were conducted; before the LA intervention, LA was tested against GLA ( 6 trials) and OA (6 trials). Before the GLA intervention, GLA was tested against $L A$ and $O A$ and before the OA intervention, OA was tested against LA and GLA. 
The taste perception test was conducted without as well as with sucrose ( $9 \mathrm{~g} / \mathrm{L})$. Sucrose served as a stimulator of the taste cell.

\section{Taste characterization protocol}

In order to characterize the taste of the oils, the following test was executed, in a standardized form (CSO, Wageningen, The Netherlands). Subjects tasted and expectorated the oils. Before and after tasting each oil subjects rinsed their mouth with water followed by chewing on a piece of white bread and rinsing their mouth again. Subjects were asked: 'How neutral is the oil?'. The subjects rated their characterization on a $100 \mathrm{~mm}$ VAS. The VAS was anchored from 'not neutral at all' on the left to 'extremely neutral' on the right.

\section{4h food intake and appetite profile protocol}

During the two-week intervention periods, subjects replaced their habitual fat products with one of the three different oils (LA, GLA or OA) each 2-week period. The order of use was at random. Subjects had to use $20 \mathrm{ml}$ test oil for preparing their lunch and $25 \mathrm{ml}$ for dinner during the intervention period. Furthermore, they were not allowed to use other fats (butter, margarine, low-fat margarine, oil etc.) and they had to minimize the ingestion of products high in fat (cookies, cake, snacks etc). During the wash-out period, subjects consumed a self-selected diet. At day 1 of each intervention period, subjects were provided with the test oil. The oil had to be used for preparation of lunch and dinner, daily for a period of two weeks. At day 15 of each intervention period, subjects came to our department for assessment of their $24 \mathrm{~h}$ food intake and appetite profile. All subjects came in a fasted state (from 10.00 p.m. the evening before) and body weight was measured. After that, breakfast was consumed at home and it was the same for each test day. For lunch and dinner, subjects came to the department, where an ad libitum lunch/dinner was served. The lunch consisted of a pasta-salad (energy density: 3.37 $\mathrm{kJ} / \mathrm{g}, 23.7,5.3$ and $71.0 \%$ energy from protein, fat and carbohydrate, respectively) served with $20 \mathrm{ml}$ test oil. For dinner, first 100 grams of pasta and 100 grams of bolognese-sauce (energy density: $3.10 \mathrm{~kJ} / \mathrm{g}, 26.7,47.5$ and $25.8 \%$ energy from protein, fat and carbohydrate, respectively) mixed with $15 \mathrm{ml}$ test oil was offered. Furthermore a salad with $10 \mathrm{ml}$ of oil was offered. This amount of food had to be eaten completely. After that, subjects could take more pasta and bolognese sauce ad libitum and in proportions chosen by themselves. Also, more salad was offered ad libitum. Subjects were allowed to eat a low-fat dessert ad libitum, which was either a low-fat fruit yogurt or a low-fat vanilla yogurt. Once subjects had chosen for one kind of dessert, the same was offered on each test day. Snacks were offered ad libitum during the test day. The subjects were allowed to consume drinks and fruit during the test day. The experimenter recorded the amount of food eaten in the laboratory restaurant on this day. Subjects recorded the other foods consumed in a controlled food intake diary.

During the test day, the parameters of the appetite profile were measured with a number of questions using an anchored $100 \mathrm{~mm}$ VAS. The questions were the following: How hungry are you?; How full are you?; How satiated are you?; How thirsty are you?; (those questions were anchored with: not at all - very) and: How much do you desire to eat (anchored: not much - very much). This took place at 10 fixed points in time: before and after breakfast, at mid-morning, before and after lunch, at mid-afternoon, before and after dinner, at mid-evening and before going to sleep ${ }^{38}$.

At day 4 and 15 of the intervention period, a Dutch translation of the Three-Factor Eating Questionnaire (TFEQ) ${ }^{38}$ was used to determine if there were changes in dietary restraint of the subjects during the intervention periods. Possible changes in dietary restraint were compared between the intervention periods. A mood questionnaire was filled in as well at day 15 of each intervention period. Parameters of mood were measured with a number of questions using an anchored $100 \mathrm{~mm}$ anchored VAS. The questions were the following: How relaxed are you?, How down are you?, How pleasant do you feel?, How angry are you?. How scared do you feel?, and How sad are you?. The VAS was anchored with: not at all - very much. 


\section{Sensory specific satiety}

As a food is eaten to satiety, the pleasantness of taste of that food and the desire to eat it decrease more than of those foods which have not been eaten ${ }^{39}$.

We hypothesized that if LA has a more pronounced taste effect than OA, sensory specific satiety with LA would be stronger than with OA. We expressed sensory specific satiety as a larger decrease of pleasantness of taste after consumption of the test oil, in comparison with the change in pleasantness of taste of the oils that were not eaten. To determine sensory specific satiety the different oils $(10 \mathrm{~g})$ were offered with a cucumber salad $(75 \mathrm{~g})$. Before the test salad we determined the pleasantness of taste of each oil with small cups with cucumber $(5 \mathrm{~g})$ and oil $(2 \mathrm{~g})$. Each cup contained a different oil. The order of offer was ad random. After the three small samples, the test salad was offered ad libitum. After the test salad, the three small cups with cucumber $(5 \mathrm{~g})$ and oil $(2 \mathrm{~g})$ were offered again. The order was the same as before the test salad.

While the subjects were consuming the small samples, they filled in a $100 \mathrm{~mm}$ anchored VAS, with the question: 'How pleasant is the taste now in your mouth?'. This procedure was executed with one type of oil before the intervention period in which that oil was consumed.

\section{Blood parameters}

At day 15 of each intervention period, a fasting blood sample of $10 \mathrm{ml}$ was obtained and mixed with EDTA to prevent clotting. Plasma was obtained by centrifugation $\left(4^{\circ} \mathrm{C}, 3000\right.$ $\mathrm{rpm}, 10 \mathrm{~min}$ ) and stored at $-80^{\circ} \mathrm{C}$ until analysis of glucose by a hexokinase method (Roche Diagnostics, Hoffman-La Roche, Basel, Switzerland), triglycerides (GPO-trinder 337. Sigma), glycerol by a glycerolkinase-lipase method (Boehringer, Mannheim, Germany), $\beta$-hydroxy butyrate by the method of Moore et al. ${ }^{40}$ using a semi-automated centrifugal spectrophometer (Cobas Fara, Roche Diagnostics), and insulin with ELISA (Mercodia 10-1113-01).

\section{Compliance}

Fatty acid composition of plasma phospholipids was used to measure compliance. Lipids were extracted according to the method of Bligh and Dyer ${ }^{41}$. Aminopropyl bonded silica columns $(500 \mathrm{mg} / 2.8 \mathrm{ml})$ were used to separate phospholipids from the total lipid extract $^{42}$. The phospholipids were saponified and the fatty acids (FA) transmethylated to the corresponding methylesters (FAME) by reaction with $10 \%$ BF3 in methanol at $100^{\circ} \mathrm{C}$ for one hour ${ }^{43}$. The FAMEs were separated and quantified by using a HP 5890 ॥ gas chromatograph, fitted with a $50 \mathrm{~m}$ CP sil88 capillary column with $0.25 \mathrm{~mm}$ ID and 0.12 $\mu \mathrm{m}$ film thickness (Chrompack $\otimes$, Middelburg. The Netherlands). A standard fame mixture was used to identify the FAME's by means of the retention times.

\section{Statistical analysis}

Data are presented as means \pm standard deviations (SD). Data of plasma fatty acid composition of phospholipids are expressed as \%wt/wt of total fatty acids.

The required number of correct answers in order to show significant differences in taste perception at the triangle test is 5 out of $6(83.3 \%)$. This consist of $33.3 \%$ of giving the right answer by chance, plus at least $50 \%$ right of the remaining discrimination possibility ${ }^{37}$.

Possible differences in taste characterization between treatments were analyzed with a repeated-measures analysis of variance (ANOVA). Post hoc analysis was done with the Scheffe F-test (Statview SE GraphicsTM). Difference in taste characterization of the oils without and with sucrose was tested with a paired $t$-test (Statview SE GraphicsTM).

Since the number of supertasters $(n=3)$ was small in our study, we combined the group of medium-tasters and supertasters to one group, called 'tasters' $(n=9)$. Possible differences in output parameters between tasters and non-tasters and between men and women were analyzed with unpaired $t$-test. 
Possible differences in food intake, macronutrient composition, appetite profile, sensory specific satiety and blood profile between treatments were analyzed with a repeatedmeasures analysis of variance (ANOVA). Post hoc analysis was done with the Scheffe F-test (Statview SE GraphicsTM).

The area under the curve of the appetite profile was calculated for $24 \mathrm{~h}$ interpolating the part that takes place at night.

Linear regression was used to analyze a possible relation between satiety and taste perception or satiety and taste characterization.

The level of significance was set at $p<0.05$.

\section{RESULTS}

Since no differences in gender were seen for taste characterization, appetite profile, energy intake, body weight change or sensory specific satiety, data for men and women are taken together. Only for taste perception, the results differed so these data are presented for men and women separately. No differences for PROP-taster status were seen for taste perception, taste characterization, appetite profile, energy intake, body weight change or sensory specific satiety, so all data for PROP-tasters and non-tasters are taken together.

\section{Compliance}

Table 2 shows the fatty acid composition of plasma phospholipids. After two-week consumption of LA, the percentage of linoleic acid in plasma phospholipids was significantly higher than after a two-week consumption of GLA or OA. Moreover, the percentage of $\gamma$-linolenic acid in phospholipids were raised after GLA consumption compared to LA or OA and the percentage of oleic acid in phospholipids were higher after OA consumption compared to LA or GLA.

Table 2: concentration of fatty acids in plasma phospholipids ( $\%$ wt/wt of total fatty acids) of subjects $(n=7)$ after two-week consumption of oils high in linoleic acid (LA), $\gamma$-linolenic acid (GLA) or oleic acid (OA)

\begin{tabular}{|c|c|c|c|}
\hline & LA & GLA & OA \\
\hline$\%$ linoleic acid & $23.4 \pm 2.5$ & $19.3 \pm 2.3^{1}$ & $20.1 \pm 1.0^{1}$ \\
\hline$\% \gamma$-linolenic acid & $0.1 \pm 0.0^{2}$ & $0.3 \pm 0.1$ & $0.04 \pm 0.0^{2}$ \\
\hline$\%$ oleic acid & $9.0 \pm 1.1^{3}$ & $9.0 \pm 2.3^{3}$ & $10.8 \pm 1.1$ \\
\hline \multirow{2}{*}{\multicolumn{4}{|c|}{$\begin{array}{l}\text { 'significantly different from LA }(p<0.005){ }^{2} \text { significantly different from GLA }(p<0.001) \\
\text { significantly different from OA }(p<0.05) \\
\text { Table 3: number of correct answers during the taste perception test of men }(n=8) \text { and } \\
\text { women }(n=8)\end{array}$}} \\
\hline & & & \\
\hline Without sucrose & LA vs. OA & GLA vs. OA & LA vs. GLA \\
\hline men & $2.4 \pm 0.8$ & $3.1 \pm 1.1$ & $2.4 \pm 1.0$ \\
\hline women & $3.1 \pm 1.2$ & $2.8 \pm 1.5$ & $3.8 \pm 1.2^{\prime}$ \\
\hline with sucrose & LA vs. OA & GLA vs. OA & LA vs. GLA \\
\hline men & $2.4 \pm 0.5$ & $3.4 \pm 1.7$ & $3.2 \pm 1.6$ \\
\hline women & $3.9 \pm 1.2^{1}$ & $3.1 \pm 1.0$ & $4.8 \pm 1.2$ \\
\hline
\end{tabular}

Since each combination was tested twice, the data given is the mean of two series of 6 trials. The oils, linoleic acid (LA), $\gamma$-linolenic acid (GLA) and oleic acid (OA) were tested without and with sucrose. In order to correctly identify the odd sample, subjects had to give 5 out of 6 correct answers 'significantly different between men and women $(p<0.05)$ 
Table 4: area under the curve for parameters of appetite (measured 10 times during 24 hours) at the test day after a two-week consumption of oils high in linoleic acid (LA), $\gamma$ linolenic acid (GLA) and oleic acid (OA)

\begin{tabular}{lccc}
\hline & LA & GLA & OA \\
\hline hunger & $785 \pm 307$ & $763 \pm 301$ & $798 \pm 298$ \\
fullness & $891 \pm 355$ & $917 \pm 411$ & $944 \pm 410$ \\
satiety & $932 \pm 342$ & $944 \pm 404$ & $1091 \pm 280$ \\
thirst & $807 \pm 343$ & $976 \pm 199$ & $945 \pm 257$ \\
desire to eat & $821 \pm 320$ & $736 \pm 292$ & $860 \pm 263$ \\
\hline
\end{tabular}

\section{Taste perception}

Subjects did not distinguish the different oils from each other when the oils were presented without sucrose, nor with sucrose. On average, in $50 \%$ of the cases, the oils were detected correctly.

Women could distinguish GLA without sucrose from OA without sucrose better than men (table 3). Moreover, women could distinguish LA with sucrose from OA with sucrose better than men. However, the women did not reach the discrimination level of $83.3 \%$ either.

\section{Taste characterization}

GLA $(43.2 \pm 20.9 \mathrm{~mm}$ VAS) was characterized as less neutral than OA $(68.9 \pm 20.5 \mathrm{~mm}$ VAS, $p<0.05)$ and LA $(63.2 \pm 24.2 \mathrm{~mm}$ VAS, $p<0.05)$.

\section{Appetite profile}

The area under the curve (AUC) for feelings of hunger, satiety, fullness, thirst and desire to eat did not differ between the three different treatments on the test day (table 4).

However, at mid-afternoon subjects were less satiated with LA $(46.1 \pm 24.7 \mathrm{~mm}, p<0.05)$ or GLA $(45.1 \pm 23.1 \mathrm{~mm}, \mathrm{p}<0.01)$ compared to OA $(62.5 \pm 19.2 \mathrm{~mm})$ after a two-week use of the same oils (figure 1 ).

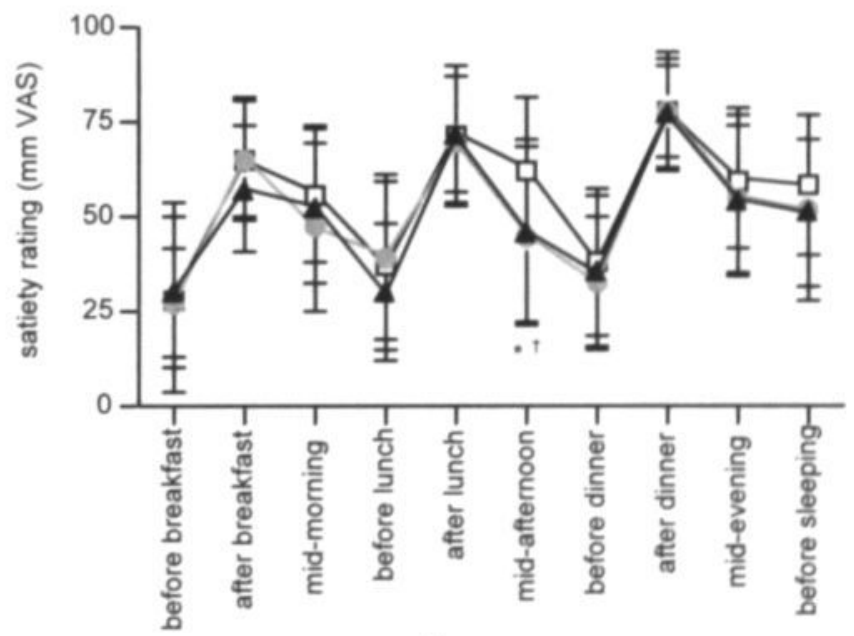

time

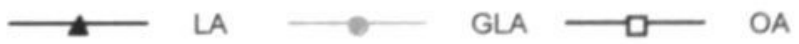

Figure 1: satiety scores at the test days on which LA, GLA and OA were offered, after a twoweek use of the same oils

*LA significantly different from $O A(p<0.05)^{\dagger} G L A$ significantly different from $O A(p<0.05)$. 


\section{Energy intake}

Total energy intake, measured at the test day did not differ between the three treatments (LA: $7.7 \pm 1.7$, GLA: $8.0 \pm 2.6$ and OA: $7.6 \pm 2.1 \mathrm{MJ} / \mathrm{d}$.). Differences in $24 \mathrm{~h}$ macronutrient composition were shown. Percentage energy from protein intake was higher on a test day with LA compared to OA $(12.3 \pm 1.8$ vs. $11.1 \pm 1.7$ energy $\%, p<0.05)$ after a two-week use of the same oils. No differences were seen for carbohydrate and fat intakes (table 5). During dinner at the test day, energy intake was higher after a two-week use of LA $(3.0 \pm 0.8 \mathrm{MJ}, \mathrm{p}<0.05)$ as well as GLA $(3.0 \pm 0.7 \mathrm{MJ}, \mathrm{p}<0.05)$ compared with OA $(2.7 \pm 0.7$ $\mathrm{MJ})$. No differences in protein and carbohydrate intakes between LA, GLA and OA were

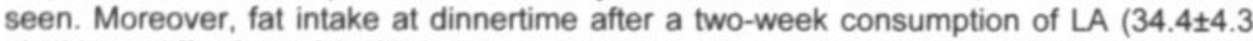
g) did not differ from OA $(32.9 \pm 4.3 \mathrm{~g})$. However, at the GLA condition, subjects ingested more fat than with the OA treatment $(35.0 \pm 4.6$ and $32.9 \pm 4.3 \mathrm{~g}$, respectively, $p<0.05)$ (table 6). Differences in macronutrient composition (\% of energy) during dinner between treatments were observed. Even though energy intake was higher, subjects ate relatively less fat with LA than with OA $(45.0 \pm 9.4$ vs. $48.3 \pm 8.3$ energy $\%, p<0.05)$. On the other hand, relative protein intake with LA $(13.8 \pm 2.2$ energy $\%, p<0.05)$ and GLA $(13.9 \pm 2.1$ energy $\%, p=0.01)$ was significantly higher than with $\mathrm{OA}(13.0 \pm 2.0$ energy $\%)$ after a twoweek use of the same oils (table 7).

\section{Body weight}

Mean body weight loss during each intervention period was $0.7 \pm 1.0 \mathrm{~kg}(p<0.05)$. No differences were observed between the intervention periods.

The cumulative weight loss of the intervention periods was $2.2 \pm 2.2 \mathrm{~kg}$. No significant difference was seen for gender (men: $2.7 \pm 3.5$ and women: $1.9 \pm 2.3 \mathrm{~kg}$ ). Even though PROP tasters lost more weight than non-tasters did, it did not reach the level of significance (3.1 \pm 3.1 and $1.2 \pm 1.9 \mathrm{~kg}$, respectively; $p=0.09)$.

Total weight loss over the intervention period, i.e. body weight at the beginning of the

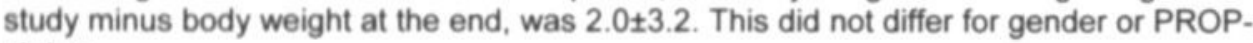
status.

\section{Dietary restraint}

Scores on Factor 1 (cognitive restraint) of the Three-Factor Eating Questionnaire did not change during each treatment. Also, there were no differences between treatments (data not shown).

Table 5: total energy and macronutrient (energy\%) intake at the test day after a two-week consumption of oils high in linoleic acid (LA), $\gamma$-linolenic acid (GLA) and oleic acid (OA).

\begin{tabular}{lrrr}
\hline & \multicolumn{1}{c}{ LA } & \multicolumn{1}{c}{ GLA } & \multicolumn{1}{c}{ OA } \\
\hline energy intake $(\mathrm{MJ})$ & $7.7 \pm 1.7$ & $8.0 \pm 2.6$ & $7.6 \pm 2.1$ \\
protein & $12.3 \pm 1.8^{\prime}$ & $11.8 \pm 1.7$ & $11.1 \pm 1.7$ \\
fat & $35.1 \pm 3.7$ & $36.1 \pm 4.7$ & $36.2 \pm 5.2$ \\
carbohydrate & $51.6 \pm 3.0$ & $50.8 \pm 4.4$ & $50.8 \pm 4.3$ \\
alcohol & $0.9 \pm 2.5$ & $1.3 \pm 3.2$ & $1.9 \pm 3.6$ \\
\hline
\end{tabular}

'p<0.05 compared to OA

Table 6: macronutrient intake $(\mathrm{g})$ during dinner at the test day after a two-week consumption of oils high in linoleic acid (LA), $\gamma$-linolenic acid (GLA) and oleic acid (OA).

\begin{tabular}{llll}
\hline & \multicolumn{1}{c}{ LA } & \multicolumn{1}{c}{ GLA } & \multicolumn{1}{c}{ OA } \\
\hline protein & $26.0 \pm 10.0$ & $25.6 \pm 8.8$ & $21.5 \pm 8.2$ \\
fat & $34.4 \pm 4.3$ & $35.0 \pm 4.6^{\prime}$ & $32.9 \pm 4.3$ \\
carbohydrate & $78.2 \pm 32.1$ & $73.9 \pm 26.1$ & $64.2 \pm 24.9$ \\
\hline
\end{tabular}

'p<0.05 compared to OA 
Table 7: energy intake and macronutrient (energy\%) intake during dinner at the test day after a two-week consumption of oils high in linoleic acid (LA), r-linolenic acid (GLA) and oleic acid (OA).

\begin{tabular}{lrrr}
\hline & \multicolumn{1}{c}{ LA } & \multicolumn{1}{c}{ GLA } & OA \\
\hline energy intake $(\mathrm{MJ})$ & $3.0 \pm 0.8^{\prime}$ & $3.0 \pm 0.7^{\prime}$ & $2.7 \pm 0.7$ \\
protein & $13.8 \pm 2.2^{\prime}$ & $13.9 \pm 2.1^{2}$ & $13.0 \pm 2.0$ \\
fat & $45.0 \pm 9.4^{\prime}$ & $46.0 \pm 8.4$ & $48.3 \pm 8.3$ \\
carbohydrate & $41.3 \pm 7.3$ & $40.1 \pm 6.4$ & $38.7 \pm 6.5$ \\
\hline
\end{tabular}

' $p<0.05$ compared to $O A^{2} p=0.05$ compared to $O A$

\section{Mood}

There were no differences in parameters of mood between each treatment (data not shown). For 'negative' parameters of mood (down, angry, scared, sad), all scores were under $35 \mathrm{~mm}$ measured on a $100 \mathrm{~mm}$ VAS. For 'positive' parameters of mood (relaxed, pleasant), all scores were above $50 \mathrm{~mm}$.

\section{Sensory specific satiety}

The amount of test salad eaten was on average 30 grams and did not differ between the different oil used (LA 29.0 \pm 18.0 , GLA 28.6 \pm 20.1 grams and OA $30.7 \pm 22.8$ ). The change in pleasantness of taste (from before to after the test salad) of the oil used in the test salad did not differ between LA, GLA and OA $(-1.4 \pm 7.1,-6.5 \pm 15.0$ and $-4.9 \pm 15.4 \mathrm{~mm}$ VAS, respectively, $p>0.05$ ). Moreover, the change in pleasantness of taste of the oil used in the test salad (for example LA) did not differ from the change in pleasantness of taste of the oils not used in the test salad (OA and GLA) for LA, GLA and OA.

\section{Blood parameters}

There were no differences in glucose $(5.10 \pm 0.15,5.15 \pm 0.40$ and $5.15 \pm 0.13 \mathrm{mmol} / \mathrm{L}$ ) triglycerides (1586 $\pm 429,1362 \pm 242$ and $1098 \pm 436 \mu \mathrm{mol} / \mathrm{L})$, glycerol $(108.4 \pm 11.0$, $97.8 \pm 13.3$ and $95.0 \pm 11.1 \mu \mathrm{mol} / \mathrm{L}), \beta$-hydroxy butyrate $(73.1 \pm 12.9,89.3 \pm 25.6$ and $75.7 \pm 24.2 \mu \mathrm{mol} / \mathrm{L})$, and insulin $(9.4 \pm 1.6,8.2 \pm 1.3$ and $8.7 \pm 1.1 \mathrm{mU} / \mathrm{L})$ levels between the intervention periods (LA, GLA and OA, respectively).

\section{Relation taste and satiety}

Since no significant differences in taste perception of the oils was shown, but some significant differences in taste characterization of the oils were shown, we examined a possible relationship between taste characterization and satiety.

There was no relation between satiety (mm VAS at mid-afternoon and energy intake during dinner) and taste characterization for LA, GLA and OA ( $r \leq 0.1, p>0.05)$. Moreover, percentage energy from fat intake at dinner was not related to taste characterization for LA, GLA and OA ( $r \leq 0.01, p>0.05)$.

The difference in satiety as measured with difference in mm VAS at mid-afternoon and difference in energy intake at dinner between LA and OA was not related to the differences in taste characterization between these oils $(r=0.01, p>0.05)$. Also difference in relative fat intake during dinner and difference in taste characterization between LA and OA showed no relationship $(r<0.1, p>0.05)$.

\section{DISCUSSION}

After two-week consumption of oils high in LA subjects ate relatively less fat during dinner at the test day, consisting of the same oil as consumed daily in the past two weeks, despite the higher energy intake during dinner compared to OA. Compliance for the two-week consumption of the specific oils was confirmed by the fatty acid composition of the plasma phospholipids. The fat-specific satiety was not related to taste perception $(r<0.1, p>0.05)$, since there were no differences in taste perception between LA and OA. Even though taste characterization with sucrose differed between LA and 
OA, it did not show a relation with differences in relative fat intake during dinner. In rats, a relation between perception of fatty acids and dietary preference for fat has been shown. Gilbertson ${ }^{25.26}$ demonstrated that free poly-unsaturated fatty acids (PUFA's) inhibit delayed rectifying $\mathrm{K}^{+}$channels (DRK channels) in taste receptor cells of SpragueDawley rats. Interestingly, the effects were only seen for cis-PUFA's (arachidonic, linoleic and linolenic acid). The same effects were demonstrated with tongue tissue of S5B/P1 rats, which have a preference for high-carbohydrate diets. However, DRK channels of OM rats, which naturally prefer fats over carbohydrates, were not sensitive for cisPUFA's $^{26}$. In summary, these data suggest an inverse relation between dietary fat preferences and fatty acid sensitivity in rats. To the best of our knowledge, no data are available about the sensitivity of human tongue tissue to cis-PUFA's. Furthermore, our work was conducted with triglycerides in contrast with the studies of Gilbertson, who used free fatty acids (FFA) dissolved in ethanol. Triglycerides need to be hydrolyzed by lipases in order to become free fatty acids. The presence of lingual lipase in humans is demonstrated $^{44,45}$ and activity is detected ${ }^{46}$, however the physiological role is uncertain. Different results might appear when one would use FFA.

The selective satiety for oil high in linoleic acid, that we observed, might be caused by different mechanisms, e.g. DRK channels that are selectively sensitive to cis-PUFA's. in tongue tissue or in other parts of the digestive tract ${ }^{25.26}$. In addition, it has been shown that CCK release is higher after poly-unsaturated fatty acids (LA) than for monounsaturated $(O A)$ and saturated fatty acids ${ }^{47}$. This may contribute to the explanation of the fat specific satiety that we observed in the situation with LA. The higher energy intake at dinner is likely to be due to the lower satiety at mid-afternoon.

Recently, the effect of saturation of fatty acids on satiety was investigated by Lawton et al. $^{29}$ and French et al. ${ }^{30.31}$. Lawton et al. gave subjects 3 lunches with $55 \%$ of energy from fat, in which the degree of saturation was varied; high in OA, high in LA or high in stearic acid. At dinner, subjects consumed significantly more after a lunch high in OA compared to the lunch high in LA. Moreover, post-ingestive ratings of fullness and motivation to eat were effected by the degree of saturation of the fatty acids. French et al. administered intestinal infusions of LA, OA, stearic acid and saline. LA decreased subsequent food intake compared to saline. So, LA was shown to increase satiety in general and to suppress subsequent food intake. Our observations do not seem to be in line with their observations ${ }^{29-31}$ since we found that a meal with $O A$ was more satiating than a meal with LA or GLA. However, Lawton et al. offered a lunch that was very high in fat $(55 \%$, our study $45 \%)$, so their observation expressed as meal size might have been rather fat-specific as well. In our observations a meal with LA showed a higher fatspecific satiety, but a lower total satiety, expressed as meal size. It might be that the fatspecific satiety effect that we observed on the reduced fat intake with LA, after its use for two weeks, is generalized to meal size due to the higher dosage and emphasized by acute effects, in the study reported by Lawton et al.

Other differences in results found between the studies by Lawton and by French, and those reported here might be caused by the period during which the oil was taken. In the study of Lawton et al., subjects consumed the oil only for one meal. In the study of French et al., subjects received the oils as intestinal infusions for 90 minutes, while in our study the oil was already used for two weeks before the effects were tested. So, Lawton, as well as French were studying the acute effects, while in this study longer-term effects were observed. Also, the fact that the subjects had never tasted the oils before in the study of Lawton, can cause different effects compared to our study, in which the subjects already had used the oils for two weeks. Such a difference between acute and long-term observations might be due to possible adaptations to new fat consumption of the gastrointestinal tract ${ }^{48-50}$ although this does not have to change energy intakes. It is possible that short-term changes in appetite and/or energy intake may have been induced initially following commencement of treatment and these may have adapted towards pre-intervention levels at the time of testing. 
The longer-term effect might have been an effect on long-term sensory specific satiety with using the oils ${ }^{51}$. However, we did check for short-term sensory specific satiety, and we found no effects, nor differences between the different oils. Some indications for macronutrient specific satiety were shown by Westerterp et al. ${ }^{23}$ who found a significant decrease in hedonic value for high-fat foods after consumption of fat, a significantly increased desire for a different taste after consumption of carbohydrates, and a significant increase in satiety after consumption of protein all compared to a mixed diet. Johnson and Vickers ${ }^{52}$ also found some indications for macronutrient specific satiety, but not when it was expressed as decreases in food intakes.

No difference in taste perception and characterization, appetite profile and food intake or body weight have been seen between PROP tasters and PROP non-tasters. In our study, 7 out of 18 subjects $(39 \%)$ were non-tasters. This percentage is comparable with the prevalence in a population: around $30 \%$ of the U.S. population are non-tasters ${ }^{27}$. Furthermore, it is known that a greater percentage of women than of men are tasters ${ }^{35^{\circ}}$. In our population the $75 \%$ of the women were tasters, and $38 \%$ of men. Moreover, all supertasters were women. It has been suggested that PROP-tasters could distinguish fats better than non-tasters ${ }^{53}$. A recent study ${ }^{27.28}$ showed a relation between PROP. taster status and ability to discriminate between differences in fat concentrations in humans. PROP medium and supertasters rated the oiliness of a $40 \%$ fat dressing higher than a $10 \%$ fat salad dressing, while non-tasters did not. No differences in overall flavor and oiliness were seen between dressings within and between groups. However, medium and supertasters showed no preference for either dressing, while non-tasters preferred the $40 \%$ fat dressing. On the contrary, in a study of Drenowski ${ }^{54}$ no relation was found between PROP-taster status and perceived intensity of creaminess, nor with hedonic value of different dairy products. Also, in our study, PROP tasters (medium and supertasters together) as well as non-tasters were not able to discriminate between the different oils. However, although tasters gave a higher number of correct answers than non-tasters did, this did not significantly differ from each other. Several studies have been conducted to investigate a relationship between sensitivity to PROP and other tastes. At this moment it is not clear whether PROP tasters are better tasters in general. Recently, a new family of bitter-taste receptors has been discovered ${ }^{55}$. One taste cell contains many receptors, which are specific for different bitter compounds, i.e. caffeine, quinine and PROP. So, it might be that PROP tasters are better tasters for bitter compounds in general.

In summary, oil high in linoleic acid showed after 2-week consumption by humans, a selective satiety effect on fat intake by a relatively decreased percentage of energy as fat in the macronutrient composition, while it did not reduce total energy intake. This fatspecific satiety was not related to taste perception or taste characterization. PROP taster status did not have an effect on energy and macronutrient intakes, and appetite profile.

The hypothesis that humans may detect specific fatty acids in oils could not be supported by the data from this study, probably because we used triglycerides. For that, more observations on taste perception using free fatty acids are needed.

\section{REFERENCES}

1 Kuczmarski M, KM Flegal, SM Campbell, CL Johnson. Increasing prevalence of overweight among US adults. The national health and nutrition examination surveys, 1960 to 1991. JAMA 1994; 272: 205-211

2 Seidell J. The impact of obesity on health status: some implications for health care costs. Int $J$ Obes Relat Metab Disord 1995; 19: S13-16

3 Kannel WB. Effect of weight on cardiovascular disease. Nutrition 1997; 13: 157-158

4 Manson JE, GA Colditz, MJ Stampfer, WC Willett, B Rosner, RR Monson, FE Speizer, CH Hennekens. A prospective study of obesity and risk of coronary heart disease in women. $N$ Engl J Med 1990; 322: 882-889

5 Wing RR, CH Bunker, LH Kuller, KA Matthews. Insulin, body mass index and cardiovascular risk factors in premenopausal women. Arteriosclerosis 1989; 9: 479-484

6 Pi-Sunyer FX. Medical hazards of obesity. Ann Intern Med 1993; 119: 655-660 
7 Tucker LA, M Kano. Dietary fat and body fat: a mulivariate study of 205 adult females. Am J Clin Nutr 1992; 56: 616-622

8 Romieu I, WC Willet, MJ Stampfer, GA Colditz, L Samson, B Rosner, CH Hennekens, FE Speizer. Energy intake and other determinantes of relative weight. Am J Clin Nutr 1988; 47: 406-412

9 Dreon DM, B Frey-Hewitt, N Ellsworth, PT Williams, RB Terry, PD Wood. Dietary fat:carbohydrate ratio and obesity in middle-aged men. Am J Clin Nutr 1988; 47: 995-1000

10 Miller WC, AK Lindeman, J Wallace, M Niederpruem. Diet composition, energy intake, and exercise in relation to body fat in men and women. Am J Clin Nutr 1990; 52: 426-430

11 Tremblay A, G Plourde, JP Despres, C Bouchard. Impact of dietary fat content and fat oxidation on energy intake in humans. Am J Clin Nutr 1989; 49: 799-805

12 Westerterp KR, WP Verboeket-van de Venne, MS Westerterp-Plantenga, EJ Velthuis-te Wierik, C de Graaf, JA Weststrate. Dietary fat and body fat: an intervention study. Int J Obes Relat Metab Disord 1996; 20: 1022-1026

13 Drewnowski A, JD Brunzell, K Sande, PH Iverius, MR Greenwood. Sweet tooth reconsidered: taste responsiveness in human obesity. Physiol Behav 1985; 35: 617-622

14 Drewnowski A. Dietary fats: perceptions and preferences. J Am Coll Nutr 1990; 9: 431-435

15 Drewnowski A. Energy density, palatability, and satiety: implications for weight control. Nutr Rev 1998; 56: $347-353$

16 Holt SH, JC Miller, P Petocz, E Farmakalidis. A satiety index of common foods. Eur J Clin Nutr 1995; 49: 675-690

17 Westerterp-Plantenga MS. Analysis of energy density of food in relation to energy intake regulation in human subjects. Br J Nutr 2001: 85: 351-361

18 Prentice AM. Manipulation of dietary fat and energy density and subsequent effects on substrate flux and food intake. Am J Clin Nutr 1998; 67: 535S-541S

19 Lawton CL, VJ Burley, JK Wales, JE Blundell. Dietary fat and appetite control in obese subjects: weak effects on satiation and satiety. Int J Obes Relat Metab Disord 1993; 17: 409416

20 Blundell JE, JR Cotton, H Delargy, S Green, A Greenough, NA King, CL Lawton. The fat paradox: fat-induced satiety signals versus high fat overconsumption. Int $J$ Obes Relat Metab Disord 1995; 19: 832-835

21 Stubbs RJ, MC van Wyk, AM Johnstone, CG Harbron. Breakfasts high in protein, fat or carbohydrate: effect on within-day appetite and energy balance. Eur J Clin Nutr 1996; 50: 409417

22 Rolls BJ, DJ Shide. 1994. Dietary fat and the control of food intake. In Appetite and body weight regulation; suger, fat, and macronutrient substitutes. Fernstrom JD, Miller, G.D., editor. Boca Raton: CRC Press. 167-177

23 Westerterp-Plantenga MS, MJW IJedema, NEG Wijckmans-Duijsens. The role of macronutrient selection in determining patterns of food intake in obese and non-obese women. Eur J Clin Nutr 1996; 50: 580-591

24 Blundell JE, RJ Stubbs. High and low carbohydrate and fat intakes: limits imposed by appetite and palatability and their implications for energy balance. Eur J Clin Nutr 1999; 53: S148-165

25 Gilbertson TA, T Fontenot, L Liu, L Zhang, WT Monroe. Fatty acid modulation of $\mathrm{K}+$ channels in taste receptor cells: gustatory cues for dietary fat. Am J Physiol 1997; 272: C1203-C1210

26 Gilbertson TA, L Liu, DA York, GA Bray. Dietary fat preferences are inversely correlated with peripheral gustatory fatty acid sensitivity. Ann N Y Acad Sci 1998; 855: 165-168

27 Tepper BJ. Does genetic taste sensitivity to PROP influence food preferences and body weight? Appetite 1999; 32: 422

28 Tepper BJ, RJ Nurse. PROP taster status is related to fat perception and preference. Ann N Y Acad Sci 1998; 30: 802-804

29 Lawton C, H Delargy, F Smith, J Blundell. Does the degree of saturation of fatty acids affect post-ingestive satiety? Int J Obes Relat Metab Disord 1997; 21: S35

30 French S, S Mutuma, J Francis, N Read, G Meijer. 1998. The effect of fatty composition on intestinal satiety in man. In Internation Congress on Obesity. Paris: Int J Obes. S82

31 French SJ. The effects of specific nutrients on the regulation of feeding behaviour in human subjects. Proc Nutr Soc 1999; 58: 533-539

32 Phinney S, M Schirmer, D Metz, A Tang. 1998. Gamma-linolenate reduces weight regain following weight loss by very low calorie diet in humans. In ICO. Paris. S64

33 Stunkard AJ, S Messick. The three-factor eating questionnaire to measure dietary restraint, disinhibition, and hunger. J Psychosom Res 1985; 29: 71-83

34 Herman CP, J Polivy. Restrained Eating. Saunders, W.B.: Philadelphia, 1980

35 Bartoshuk LM, VB Duffy, IJ Miller. PTC/PROP tasting: anatomy, psychophysics, and sex 
effects. Physiol Behav 1994; 56: 1165-1171

36 Lepage G, CC Roy. Direct transesterification of all classes of lipids in a one-step reaction. J Lipid Res 1986; 27: 114-120

37 Meilgaard M, GV Civille, BT Carr. Sensory Evaluation Techniques. CRC Press: Boca Raton, 1991

38 Westerterp-Plantenga MS, V Rolland, SAJ Wilson, KR Westerterp. Satiety related to $24 \mathrm{~h}$ dietinduced thermogenesis during high protein/carbohydrate vs high fat diets measured in a respiration chamber. Eur J Clin Nutr 1999; 53: 495-502

39 Rolls BJ. Sensory-specific Satiety. Nutr Rev 1986; 44: 93-101

40 Moore JJ, M Marcus, SM Sax. Kinetic assay of $\beta$-hydroxy butyrate in plasma with cobas bio centrifugal analyzer. Clin Chem 1982; 73: 1334-1339

41 Bligh EG, WJ Dyer. A rapid method of total lipid extraction and purification. Can J Biochem Physiol 1959; 37: 911-917

42 Kaluzny MA, LA Duncan, MV Merrit, DE Epps. Rapid separation of lipid classes in high yield and purity using bonded phase columns. J Lipid Res 1985; 26: 135-140

43 Morrison WR, LM Smith. Preparation of fatty acid methyl esters and dimethylacetals from lipids with boron fluoride-methanol. J Lipid Res 1964; 5: 600-607

44 Hamosh M, HL. Klaeveman, RO Wolf, RO Scow. Pharyngeal lipase and digestion of dietary triglyceride in man. J Clin Invest 1975; 55: 908-913

45 Hamosh M, WA Burns. Lipolytic activity of human lingual glands (Ebner). Lab Invest 1977; 37 : 603-608

46 Spielman Al, S D'Abundo, RB Field, H Schmale. Protein analysis of human von Ebner saliva and a method for its collection from the foliate papillae. J Dent Res 1993; 72: 1331-1335

47 Beardshall K, Y Morarji, SR Bloom, G Frost, J Domin, J Calam. Saturation of fat and cholecystokinin release: implications for pancreatic carcinogenesis. Lancet 1989; 28: 10081010

48 French SJ, B Murray, RD Rumsey, R Fadzlin, NW Read. Adaptation to high-fat diets: effects on eating behaviour and plasma cholecystokinin. Br J Nutr 1995; 73: 179-189

49 Cunningham KM, J Daly, M Horowitz, NW Read. Gastrointestinal adaptation to diets of differing fat composition in human volunteers. Gut 1991; 32: 483-486

50 Shafat S, B Murray, D Rumsey. Lipid absorption profiles associated with gastrointestinal transit responses to chronic high fat feeding in rats. Proc Nutr Soc 2000; 59: 117a

51 Rolls ET, AWL De Waal. Long-term sensory-specific satiety: evidence from an Ethiopian refugee camp. Physiol Behav 1985; 34: 1017-1020

52 Johnson J, Z Vickers. Effects of flavor and macronutrient composition of food servings on liking, hunger and subsequent intake. Appetite 1993; 21: 25-39

53 Tepper BJ, RJ Nurse. Fat perception is related to PROP taster status. Physiol Behav 1997; 61 : 949-954

54 Drewnowski A, SA Henderson, A Barratt-Fornell. Genetic sensitivity to 6-n-propylthiouracil and sensory responses to sugar and fat mixtures. Physiology and Behavior 1998; 63: 771-777

55 Firestein S. The good taste of genomics. Nature 2000; 404: 552-553 


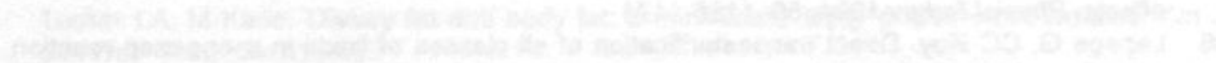

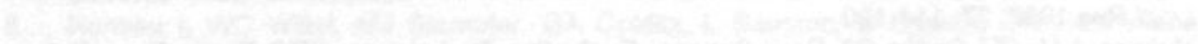

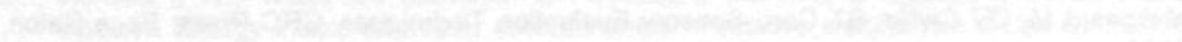

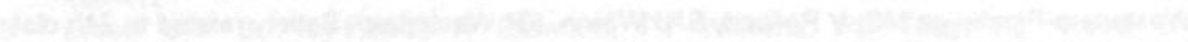

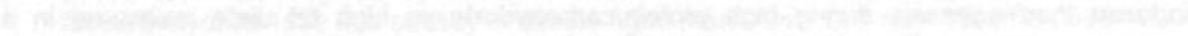
2.

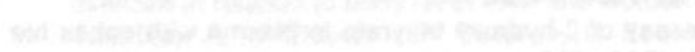




\title{
The role of linoleic acid taste perception in the etiology of obesity
}

\author{
Marleen MJW Kamphuis \\ Margriet S Westerterp-Plantenga \\ Submitted
}




\section{ABSTRACT}

Background: animal studies suggest that linoleic acid sensitivity might affect fat intake and therefore may play a role in the etiology of obesity.

Objective: to determine the taste perception of a $10 \mu \mathrm{M}$ linoleic acid solution and its relationship with body mass index (BMI), body composition, resting metabolic rate, respiratory quotient, age, macronutrient selection and dietary restraint.

Design: 221 subjects conducted a linoleic acid perception test. Subjects had to taste 10 pairs of 2 samples with one sample containing $10 \mu \mathrm{M} L A$ and the other containing the placebo solution. All samples were tasted in a standard manner. Subjects had to answer the question: 'Which sample contains the fatty acid?'. Subjects were classified as linoleic acid tasters with $\geq 9$ correct answers; otherwise they were classified as linoleic acid nontasters. BMI, body composition, RMR, RQ, and dietary restraint were measured. Furthermore, a subgroup of 35 subjects conducted a macronutrient specific food choice test.

Results: of the 221 subjects, $46 \%$ were classified as linoleic acid tasters. Linoleic acid tasters were younger and less dietary restraint than linoleic acid non-tasters. They did not differ in body composition, resting metabolic rate, respiratory quotient or macronutrient selection. In the non-obese subjects (BMI $<30 \mathrm{~kg} / \mathrm{m}^{2}$ ), $10 \mu \mathrm{M}$ linoleic acid tasters had a significantly lower BMI and were less dietary restraint compared to nontasters, whereas in the obese (BMI $\geq 30 \mathrm{~kg} / \mathrm{m}^{2}$ ) these effects were not observed.

Conclusion: Linoleic acid sensitivity might play a role in the etiology of obesity, in subjects in the range of normal weight to overweight.

\section{ACKNOWLEDGEMENTS}

We would like to thank Nicole Mickley for advising on the fatty acid taste perception test and Manuela Lejeune for her assistance with the tests. Furthermore, we would like to thank Novartis Consumer Health Ltd., Nyon, Switserland for their financial support. 
$\mathrm{D}$ uring the past few decades, the prevalence of obesity in the US $\mathrm{S}^{1.2}$ as well as in Europe $^{3}$ has increased and is reaching epidemic proportions. Diet-induced obesity is caused by a long-term imbalance between energy intake and energy expenditure, in which energy intake exceeds energy expenditure. The surplus of energy is stored as fat in the adipose tissue.

In general it is believed that sensory responses of foods (partly) determine food preferences and therefore affect food and energy intake 4 . Humans can assess foods following the basic tastes, i.e. sweet, sour, salty, bitter as well as umami, the taste of mono-sodium glutamate ${ }^{5}$. Accumulating evidence suggests that rats might 'taste' fatty acids $^{6-9}$. It was shown in vitro that a small concentration $(10 \mu \mathrm{M})$ of free linoleic acid dose-dependently inhibits the $\mathrm{K}^{*}$ current of delayed rectifying potassium (DRK) channels in rat tongue epithelium ${ }^{6-8}$, which indicates an increase in activity of those cells by linoleic acid. However, $10 \mu \mathrm{M}$ free oleic acid did not have an increased activity compared to saline ${ }^{6.7}$. Furthermore, in a taste aversion test, the ability to perceive $10 \mu \mathrm{M}$ linoleic acid by rats was confirmed ${ }^{10}$. It was concluded that this low concentration of linoleic acid, but not of oleic acid, could be 'tasted' by rats ${ }^{6-10}$. Moreover, differences in the ability of linoleic acid to inhibit DRK channels in tongue epithelium between fat-preferring and fatavoiding rat strains have been shown ${ }^{8}$, i.e. an increased linoleic acid sensitivity in fatavoiding rats compared to fat-preferring rats was observed. In addition when placed on a high-fat diet, the fat-preferring rat strain got rapidly obese while the fat-avoiding strain reduced their fat intake and remained lean 11 . This underscores the hypothesis that linoleic acid taste sensitivity may affect fat intake and play thus a role in the etiology of obesity.

The aim of the present study was to investigate whether differences in taste perception for a low concentration of linoleic acid in humans exists. Furthermore, the possible relationship of linoleic acid taste perception with body mass index, body composition. resting metabolic rate, substrate oxidation, age and macronutrient selection was determined. Moreover, possible differences between linoleic acid tasters and non-tasters for those parameters within the subgroups of non-obese and obese subjects were assessed. We hypothesized that subjects may be divided in low concentration linoleic acid taster and non-tasters, while this does not hold for the same low concentration of oleic acid, the control fatty acid in the studies by Gilbertson. Furthermore, we hypothesized that subjects who are able to perceive this linoleic acid concentration will have a lower body mass index and a lower fat preference compared to subjects who do not show this linoleic acid taste perception.

\section{SUBJECTS AND METHODS}

\section{Subjects}

Two hundred twenty-one subjects ( 60 men) were recruited by advertisements in local newspapers. Subjects had to be in good health and non-smoking. They did not use any medication and were at most moderate alcohol users. Body weight was measured on a digital balance (SECA, model 220, Hamburg, Germany) after an overnight fast and after voiding, while subjects were wearing underwear. Height was measured to the nearest 0.001 meter using a wall-mounted stadiometer (SECA, Hamburg, Germany). Body mass index (BMI) was calculated as weight $(\mathrm{kg})$ divided by height $(\mathrm{m})$ squared. Percentage of body fat (\%BF) was determined by hydrodensitometry and deuterium dilution $\left({ }^{2} \mathrm{H}_{2} \mathrm{O}\right)$ technique ${ }^{12}$ and calculated using the 3-compartment equation of $\mathrm{Siri}^{13}$. Resting metabolic rate and respiratory quotient were measured after an overnight fast for at least $30 \mathrm{~min}$. Oxygen consumption and carbon dioxide production were measured using a computerized, open-circuit, ventilated hood system. Expired gases were analyzed using a paramagnetic oxygen analyzer (Servomex, Type 500A, Crowborough Sussex, UK) and an infrared carbon dioxide analyzer (Servomex. Type 12-X1). The system was similar to the analysis system for the respiration chambers described before ${ }^{14}$. Calculation of resting metabolic rate was based upon the equation of Weir ${ }^{15}$. 
Table 1: baseline characteristics of the subjects

\begin{tabular}{lcc}
\hline & mean \pm SD & range \\
\hline age $(\mathrm{y})$ & $40 \pm 11$ & $19-61$ \\
body weight $(\mathrm{kg})$ & $82.7 \pm 11.4$ & $53.2-113.3$ \\
BMI $\left(\mathrm{kg} / \mathrm{m}^{2}\right)^{1}$ & $28.6 \pm 3.1$ & $19.4-36.9$ \\
body fat $(\%)$ & $35.5 \pm 6.6$ & $17.0-48.1$ \\
F1 $^{1}$ & $7 \pm 4$ & $0-18$ \\
HP $^{1}$ & $15 \pm 4$ & $6-26$ \\
\hline
\end{tabular}

'body mass index; Factor 1 (cognitive restraint) of the Three-Factor Eating Questionnaire ${ }^{16}$; Herman-Polivy Restraint Questionnaire ${ }^{18}$

Respiratory quotient was calculated as carbon dioxide production divided by oxygen consumption. The degree of dietary restraint was measured using the Dutch language version of the Three-Factor Eating Questionnaire (TFEQ) ${ }^{16,17}$, and Herman-Poliviy restraint questionnaire (HP) ${ }^{18}$. Baseline characteristics are shown in table 1 . The study was approved by the Medical Ethics Committee of Maastricht University, and all subjects gave their written informed consent.

\section{Fatty acid taste perception test}

Since in the studies of Gilbertson linoleic acid, but not oleic acid inhibited the DRK channels $^{6.7}$, the subjects of the present study therefore conducted a fatty acid taste perception test with linoleic acid $(n=221)$. The subjects also conducted an oleic acid taste perception test $(n=201)$ as control, since the study is driven by this hypothesis. Linoleic acid (LA, Na-salt), respectively oleic acid (OA, Na-salt) was diluted with propylene glycol (PG) and de-mineralized $\mathrm{H}_{2} \mathrm{O}$ to a solution of $10 \mathrm{\mu M}$. The placebo solution (solvent) contained only PG and $\mathrm{dH}_{2} \mathrm{O}$. The concentration of $10 \mu \mathrm{M}$ is identical to the concentrations of free fatty acids Gilbertson and colleagues ${ }^{6,7}$ used in the rat studies ${ }^{6,8}$. 11 pairs of 2 samples were offered with one sample containing $10 \mu \mathrm{M} L \mathrm{~A}$, respectively $\mathrm{OA}$ and the other containing the solvent. Subjects were told which sample of the first pair contained the fatty acid and this pair was not included in the score. All samples were tasted in a standard manner. Subjects tasted and expectorated half of the first sample, rinsed with water, tasted and expectorated half of the second sample, rinsed with water, tasted and expectorated the remaining first sample, rinsed with water and tasted and expectorated the remaining of the second sample. After tasting each sample twice, subjects had to answer two questions. 1) Which sample contains the fatty acid? 2) How sure are you about your answer? The last question could be answered from 0 to 9 , with 0 'not sure at all' and 9 'extremely sure'. Between pairs, subjects had to rinse twice with water. The reproducibility of the fatty acid perception test was tested by repeating this test for linoleic acid on a different day $(n=40)$.

\section{PROP taster status}

PROP taster status of the subjects was identified as follows. Since PROP-taster status does not influence intensity judgments for $\mathrm{NaCl}, \mathrm{NaCl}$ serves as a standard against of which the PROP function can be compared. Five concentrations of $\mathrm{NaCl}(0.01-1 \mathrm{M})$ increasing in half-log steps and five concentrations of PROP $\left(3.2 \times 10^{-5}-3.2 \times 10^{-3} \mathrm{M}\right)$ increasing in half log steps were rated using a $150 \mathrm{~mm}$ visual analogue scale (VAS). Samples were tasted and expectorated. Subjects rinsed with water in between each sample. This procedure was used to generate suprathreshold taste intensity functions for the two compounds. When these functions are superimposed, the slope of the PROP curve appears much lower than the slope for the $\mathrm{NaCl}$ curve in non-tasters (NT). The PROP curve overlaps with the $\mathrm{NaCl}$ curve in medium tasters (MT). Supertasters (ST) have a steeper slope for PROP than for $\mathrm{NaCl}$ functions ${ }^{19}$. 


\section{Macronutrient-specific food choice test}

A subgroup of 35 non-obese subjects conducted a macronutrient-specific food choice test to measure fat preference. Subjects came to the university for an ad libitum lunch experiment. They were asked to eat a habitual breakfast that morning and to eat nothing after that until lunch at the university. A lunch consisting of macronutrient specific high-fat and high-carbohydrate products was offered. High-fat products were croissants with fullfat cheese or sliced meat, and sausage rolls, while rolls with low-fat cheese or jam, and currant buns were the high-carbohydrate products. This is a normal type of lunch in the Netherlands. Food intake was ad libitum and the subjects were instructed to eat until they felt comfortably full.

\section{Statistical analysis}

To investigate whether a low concentration of linoleic acid and oleic acid could be tasted by humans, a frequency distribution of the numbers of correct answers out of 10 for the $10 \mu \mathrm{M}$ linoleic perception test, respectively for the $10 \mu \mathrm{M}$ oleic acid perception test were made. To test whether this frequency distribution differs from an expected distribution (chance, $p=0.5, n=10$ ), a Pearson's $\chi^{2}$ test was performed with the two outermost categories take together because of the small expected numbers of subjects. With the linoleic acid taste perception test, a distinction between $10 \mu \mathrm{M}$ linoleic acid taster and 10 $\mu \mathrm{M}$ linoleic acid non-taster could be made as follows. If subjects would not be able to distinguish the fatty acid from the solvent, so if subjects had to guess $(p=0.5, n=10)$, the chance for guessing 10 correct answers is less than $0.1 \%$. The chance for guessing $\geq 9$ correct answers out of 10 is $1.1 \%$, while the chance exceeds the $5 \%$ level with guessing 28 correct answers out of 10 pairs. So, subjects were characterized as $10 \mu \mathrm{M}$ linoleic acid-tasters when they gave $\geq 9$ correct answers out of 10 and as $10 \mu \mathrm{M}$ linoleic acid non-tasters when they gave $<9$ correct answers. The relation between the number of correct answers on the linoleic acid taste perception test, respectively on the oleic acid taste perception test and the certainty of the answer was tested with a Spearman rank correlation test. The relation between linoleic acid taste perception and PROP sensitivity was investigated with a McNemar $\chi^{2}$ test. Differences in BMI, \%body fat, and Factor 1 of the TFEQ between linoleic acid tasters and non-tasters for the overall group as well as within the subgroups of non-obese and obese subjects were tested with an unpaired $t$ test. Differences in macronutrient selection between non-obese linoleic acid tasters and non-tasters were tested with an unpaired $t$-test.

Data are presented as meantstandard deviations (SD). The level of significance was set at $p<0.05$.

\section{RESULTS}

\section{Fatty acid perception}

The frequency distribution of the numbers of corrects answers out of 10 for the $10 \mu \mathrm{M}$ linoleic perception test, respectively for the $10 \mu \mathrm{M}$ oleic acid perception test is shown in figure $1 \mathrm{a}$ and $\mathrm{b}$. When both frequency distributions were tested against an expected distribution $(p=0.5, n=10)$, the $10 \mu \mathrm{M}$ linoleic acid perception test $\left(\chi^{2}=4266\right.$, df 8 ; $p<0.0001)$, as well as the oleic acid perception test $\left(\chi^{2}=92.9\right.$, df $\left.8 ; p<0.001\right)$ showed to be significantly different. The number of correct answers on the linoleic acid perception test was positively related to the certainty of the answer $(\rho=0.5, p<0.0001)$. This relationship, although weaker, was also present for the oleic acid taste perception test ( $\rho=0.2, p<0.05$ ). Of the 221 subjects, $46 \%$ of the subjects $(48 \%$ of the men and $45 \%$ of the women) were classified as a linoleic acid taster, whereas only $7 \%$ of the subjects tasted the $10 \mu \mathrm{M}$ oleic acid ( $7 \%$ of the men and $8 \%$ of the women). Within the non-obese subgroup, $45 \%$ of the subjects were classified as a linoleic acid taster against $50 \%$ in the obese subgroup.

The reproducibility of the test was $95 \%$. Only a few subjects first classified as linoleic acid non-tasters improved their scores. Changes in the opposite direction did not occur. 

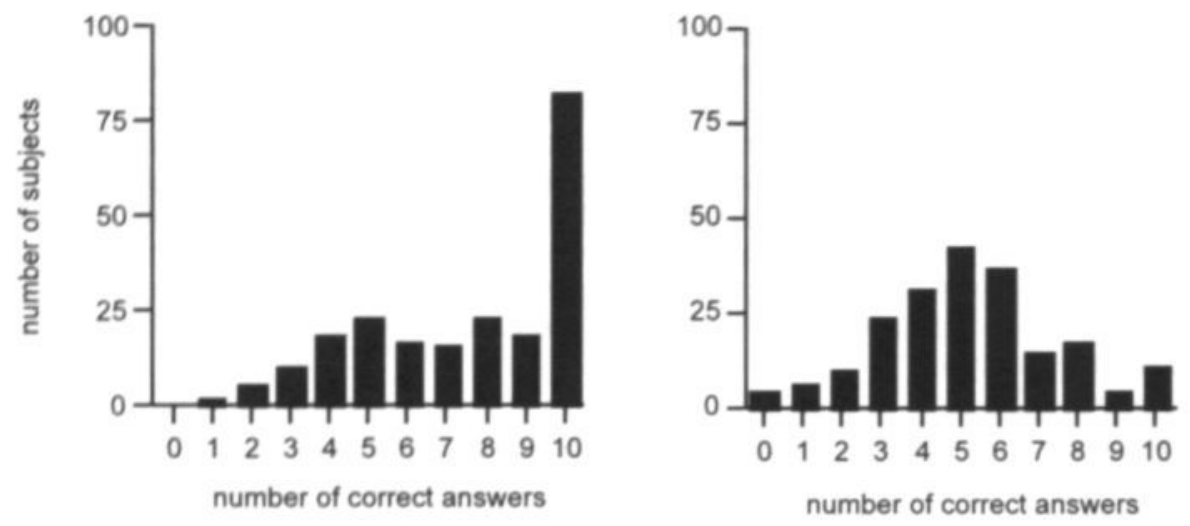

Figure 1a (left) and 1b (right): distribution of subjects on the number of correct answers on the $10 \mu \mathrm{M}$ linoleic (a) and oleic acid (b) taste perception test. The frequency distribution for perception of linoleic acid $\left(x^{2}=4266\right.$, of $\left.8, p<0.0001\right)$ as well as the frequency distribution for perception of oleic acid $\left(x^{2}=92.9\right.$, df $\left.8, p<0.001\right)$ differs from an expected distribution $(p=0.5$, $n=10$ ).

\section{PROP sensitivity}

Linoleic acid taste perception was not related to PROP sensitivity (McNemar $\chi^{2}=3.7$, $\mathrm{df}=1, \mathrm{~ns})$.

\section{Body mass index}

Within the non-obese subjects (BMI $<30 \mathrm{~kg} / \mathrm{m}^{2}$ ), linoleic acid tasters had a significantly lower BMI compared to non-tasters $\left(26.6 \pm 5.6\right.$ vs. $27.3 \pm 3.0 \mathrm{~kg} / \mathrm{m}^{2}$, respectively, $\left.\mathrm{p}<0.05\right)$. whereas in the obese subjects (BMI $\geq 30 \mathrm{~kg} / \mathrm{m}^{2}$ ), BMI did not differ between linoleic acid tasters and non-tasters $\left(32.3 \pm 2.8\right.$ and $32.4 \pm 2.8 \mathrm{~kg} / \mathrm{m}^{2}$, respectively, $\left.\mathrm{ns}\right)$.

\section{Age}

Linoleic acid tasters were significantly younger than linoleic acid non-tasters $(37.2 \pm 10.4$ vs. $43.0 \pm 10.2 y$, respectively, $p<0.0001$ ). The same phenomenon was also seen in the subgroups of non-obese and obese subjects. Linoleic acid tasters were younger in the non-obese $(37.3 \pm 10.7$ vs. $42.5 \pm 10.4 \mathrm{y}$, respectively, $\mathrm{p}<0.01)$ as well as in the obese

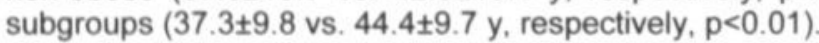

\section{Body fat}

The percentage of body fat did not differ between linoleic acid tasters and non-tasters $(35.8 \pm 7.1$ vs. $35.2 \pm 6.1 \%$, respectively, ns). Also in the subgroups of non-obese and obese subjects, no differences in body composition between linoleic acid tasters and non-tasters were observed (non-obese: $33.9 \pm 6.5$ vs. $34.4 \pm 6.2 \%$, ns; obese $39.1 \pm 6.9$ vs. $37.7 \pm 5.5 \%$, respectively, $n s)$.

\section{Resting metabolic rate}

The resting metabolic rate for linoleic acid taster and non-tasters did not differ significantly $(7.3 \pm 1.0$ vs. $7.1 \pm 1.0 \mathrm{MJ}$, respectively, ns). Within the subgroup of the nonobese as well as in the obese subgroup, no difference with respect to resting metabolic rate was observed between linoleic acid tasters and non-tasters (non-obese: $7.2 \pm 0.9$ vs. $6.9 \pm 0.8 \mathrm{MJ}$, respectively, ns; obese; $7.4 \pm 1.2$ vs. $7.6 \pm 0.9 \mathrm{MJ}$, respectively, $\mathrm{ns}$ )

\section{Respiratory quotient}

The respiratory quotient did not differ between linoleic acid tasters and non-tasters (both $0.83 \pm 0.05$ ). Also within the subgroup of the non-obese subjects, no effect of linoleic acid taster status on respiratory quotient was observed $(0.83 \pm 0.00$ vs. $0.82 \pm 0.00$ for tasters and non-tasters, respectively, ns). Obese linoleic acid tasters $(0.83 \pm 0.00)$ did not differ from obese linoleic acid non-tasters $(0.86 \pm 0.00, n s)$ with respect to respiratory quotient. 


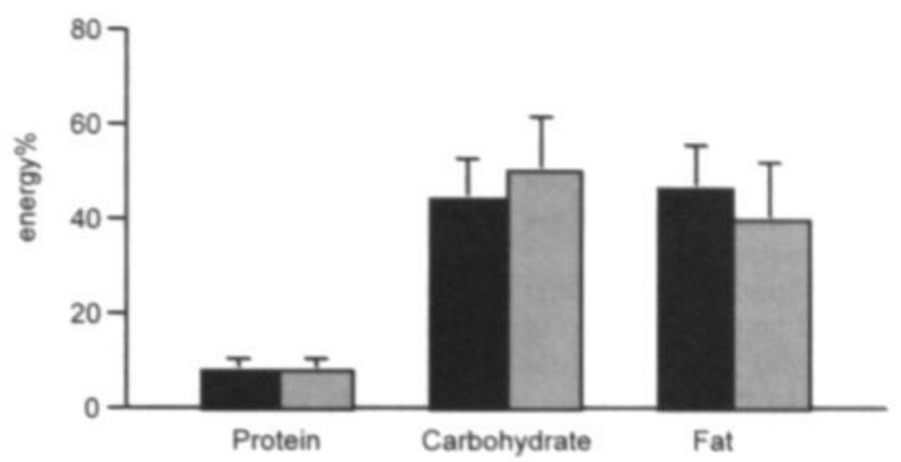

Figure 2: macronutrient selection of $10 \mu \mathrm{M}$ linoleic acid tasters (black) and $10 \mu \mathrm{M}$ linoleic acid non-tasters (grey) at a macronutrient specific food choice test. No significantly differences were observed between $10 \mu \mathrm{M}$ linoleic acid tasters and non-tasters.

\section{Macronutrient selection}

With respect to macronutrient selection, no differences for fat, carbohydrate or protein intake was shown (figure 2). Moreover, linoleic acid tasters did not differ from non-tasters with respect to energy intake ( $3.8 \pm 1.0$ vs. $3.2 \pm 1.0 \mathrm{MJ}$, respectively, ns).

\section{Dietary restraint}

Dietary restraint as measured with Factor 1 of the Three-Factor Eating Questionnaire was lower in linoleic acid tasters than in non-tasters $(6.0 \pm 3.3$ vs. $7.4 \pm 3.9$, respectively; $p<0.01)$. Also in the subgroup of non-obese subjects, linoleic acid tasters were less dietary restraint than non-tasters $(5.7 \pm 3.3$ vs. $7.0 \pm 3.9$, respectively: $p<0.05)$, while no

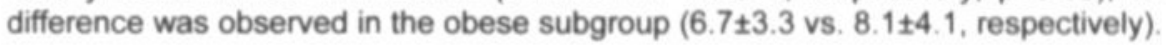

\section{DISCUSSION}

This study investigated the possible role of linoleic acid sensitivity in the etiology of obesity in humans. From two hundred twenty-one subjects who conducted a $10 \mu \mathrm{M}$ linoleic acid taste perception test, $46 \%$ percent was classified as linoleic acid tasters. On the contrast, only $7 \%$ of the subjects were able to perceive oleic acid, the control fatty acid. The reproducibility of the test was $95 \%$. Therefore, we conclude that a clear discrimination can be made between this low concentration linoleic acid tasters and nontasters, whereas hardly anybody could taste oleic acid at the same concentration. This is in line with the 'Gilbertson hypothesis'. To the best of our knowledge no data are available about the taste sensitivity of humans for linoleic acid, although several studies have investigated fat taste perception in general, for example in relation with fat metabolism ${ }^{2021}$ or PROP sensitivity ${ }^{22-26}$, although the latter was not observed in the present study.

In the present study, a lower BMI of the linoleic acid tasters compared to non-tasters was observed in the non-obese subgroup (BMI $<30 \mathrm{~kg} / \mathrm{m}^{2}$ ), but not in the obese subgroup $\left(B M I \geq 30 \mathrm{~kg} / \mathrm{m}^{2}\right)$. Thus linoleic acid taste perception might play a role in body weight regulation in the normal to overweight BMI range, whereas in the obese subjects this sensitivity may be lost. It is known that in general subjects with a normal weight to overweight BMI regulate their body weight better than obese subjects ${ }^{27}$.

Linoleic acid sensitivity was affected by age, which is a general characteristic of taste perception ${ }^{28}$. However, this observation is based on cross-sectional basis. Whether linoleic acid taste perception decreases with age can only be unraveled by longitudinal research.

Dietary restraint is defined as the tendency of persons to restrict their food intake in order to control their body weight ${ }^{16}$. In the present study, an effect of dietary restraint in linoleic acid taste perception was observed, i.e. linoleic acid tasters were less dietary restraint than non-tasters. The same was observed in the subgroup of non-obese subjects, while 
no effect of linoleic acid taster status on dietary restraint was present in the obese subgroup. Interestingly, non-obese linoleic acid tasters had a lower body mass index than non-obese linoleic acid non-tasters. So, despite the fact that non-obese linoleic acid non-tasters showed a tendency to control their body weight by restricting their food intake, their body mass index was higher than of the non-obese linoleic acid tasters. This implies that the difference in body mass index in the non-obese subjects is not caused by a greater dietary restraint.

In the macronutrient-specific food choice test, no clear difference in macronutrient choice between linoleic acid tasters and non-tasters was observed. In a recent twin-study with monozygotic twins who were discordant for BMI, learned dietary fat preference was shown to contribute to the differences in $\mathrm{BMI}^{29}$. This implies that if linoleic acid taste perception has a genetic component, then possible dietary fat preference might not play a large role in the relationship with BMI.

A remaining explanation for the differences in BMI of non-obese linoleic acid tasters and non-tasters then could be found in aspects of fat metabolism, especially since the same subtype of DRK channel is also found in the duodenum, pancreas and liver ${ }^{9}$. Moreover, it has been shown that oral fat exposure may affect fat metabolism, i.e. lead to increased post-prandial triacylglycerol concentrations ${ }^{20,21}$. In the present study, the fat oxidation, expressed as respiratory quotient and resting metabolic rate did not differ significantly between linoleic acid tasters and non-tasters.

Summarizing, a clear discrimination between tasters and non-tasters of $10 \mu \mathrm{M}$ linoleic acid has been shown in this study, in contrast to hardly any discrimination with the same concentration of oleic acid. In addition, non-obese linoleic acid tasters had a lower body mass index and were less dietary restraint compared to non-obese linoleic acid nontasters. However, the relationship between $10 \mu \mathrm{M}$ linoleic acid taster status and BMI was not supported by a possible lower preference for fat, or by a different fat metabolism. We conclude that linoleic acid taste sensitivity might play a role in the etiology of obesity. Further studies should be conducted to unravel this relationship with BMI, and to reveal whether this taste perception ability has a genetic background.

\section{REFERENCES}

1 Kuczmarski M, KM Flegal, SM Campbell, CL Johnson. Increasing prevalence of overweight among US adults. The national health and nutrition examination surveys, 1960 to 1991. JAMA 1994; 272: 205-211

2 Flegal KM, MD Carroll, CL Ogden, CL Johnson. Prevalence and Trends in Obesity Among US Adults, 1999-2000. JAMA 2002; 288: 1723-1727

3 Seidell J. The impact of obesity on health status: some implications for health care costs. Int J Obes Relat Metab Disord 1995; 19: S13-16

4 Drewnowski A. Taste preferences and food intake. Annu Rev Nutr 1997; 17: 237-253

5 Lindemann B. A taste for umami. Nat Neurosci 2000; 3: 99-100.

6 Gilbertson TA, T Fontenot, L Liu, H Zhang, WT Monroe. Fatty acid modulation of K+ channels in taste receptor cells: gustatory cues for dietary fat. Am J Physiol 1997; 272: C1203-C1210

7 Gilbertson TA. Gustatory mechanisms for the detection of fat. Curr Opin Neurobiol 1998; 8: 447-452

8 Gilbertson TA, L Liu, DA York, GA Bray. Dietary fat preferences are inversely correlated with peripheral gustatory fatty acid sensitivity. Ann N Y Acad Sci 1998; 855: 165-168

9 Gilbertson T, I Kim, L Liu. Sensory cues for dietary fat: implications for macronutrient preferences. In: Ailhaud GB Guy-Grand (eds). Progress in Obesity Research. John Libbey \& Company Ltd.: 1998, pp 167-171

10 Smith JC, EM Fisher, V Maleszewski, B McClain. Orosensory factors in the ingestion of corn oil/sucrose mixtures by the rat. Physiol Behav 2000; 69: 135-146

11 Schemmel R, O Mickelsen, JL Gill. Dietary obesity in rats: Body weight and body fat accretion in seven strains of rats. J Nutr 1970; 100: 1041-1048

12 Schoeller DA, E van Santen, DW Peterson, W Dietz, J Jaspan, PD Klein. Total body water measurement in humans with ${ }^{18} \mathrm{O}$ and ${ }^{2} \mathrm{H}$ labeled water. Am J Clin Nutr 1980; 33: 2686-2693

13 Siri WE. Body composition from fluid spaces and density: analysis of methods. 1961. Nutrition 
1993: 9: 480-491

14 Schoffelen PF, KR Westerterp, WH Saris, F Ten Hoor. A dual-respiration chamber system with automated calibration. J Appl Physiol 1997; 83: 2064-2072

15 Weir JB. New methods for calculating metabolic rate with special reference to protein metabolism. 1949. Nutrition 1990; 6: 213-221

16 Stunkard AJ, S Messick. The three-factor eating questionnaire to measure dietary restraint, disinhibition, and hunger. J Psychosom Res 1985; 29: 71-83

17 Westerterp-Plantenga MS, CRT Verwegen. The appetizing effect of an aperitif in overweight and normal-weight humans. Am J Clin Nutr 1999; 69: 205-212

18 Herman CP, J Polivy. Restrained Eating. Saunders, W.B.: Philadelphia, 1980

19 Bartoshuk LM, Duffy, V.B., Miller, I.J. PTC/PROP tasting: anatomy, psychophysics, and sex effects. Physiol Behav 1994; 56: 1165-1171

20 Mattes RD. Oral fat exposure alters postprandial lipid metabolism in humans. Am J Clin Nutr 1996: 63: 911-917

21 Mattes RD. The taste of fat elevates postprandial triacylglycerol. Physiol Behav 2001: 74 : 343 348

22 Yackinous C, JX Guinard. Relation between PROP taster status and fat perception, touch, and olfaction. Physiol Behav 2001; 72: 427-737

23 Tepper BJ, RJ Nurse. Fat perception is related to PROP taster status. Physiol Behav 1997; 61: 949-954

24 Tepper BJ, RJ Nurse. PROP taster status is related to fat perception and preference. Ann N Y Acad Sci 1998; 30: 802-804

25 Nasser JA, CJ Chou, HR Kissileff, CN Boozer, FX Pi-Sunyer. PROP taster status and the ability to detect the presence of added conjugated linoleic acid in high fat ice cream. Obes Res 1999; 7: $87 \mathrm{~S}$

26 Drewnowski A, SA Henderson, A Barratt-Fornell. Genetic sensitivity to 6-n-propylthiouracil and sensory responses to sugar and fat mixtures. Physiol Behav 1998; 63: 771-777

27 Garrow JS. Treat obesity seriously: a clinical manual. Edinburgh, 1981

28 Mojet J, E Christ-Hazelhof, J Heidema. Taste perception with age: generic or specific losses in threshold sensitivity to the five basic tastes? Chem Senses 2001; 26: 845-860

29 Rissanen A, P Hakala, L Lissner, CE Mattlar, M Koskenvuo, T Ronnemaa. Acquired preference especially for dietary fat and obesity: a study of weight-discordant monozygotic twin pairs. Int J Obes Relat Metab Disord 2002; 26: 973-977 


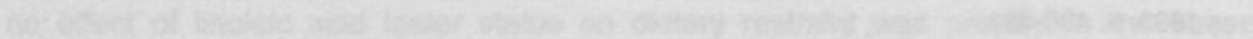
athan

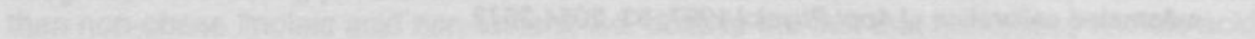
a tan

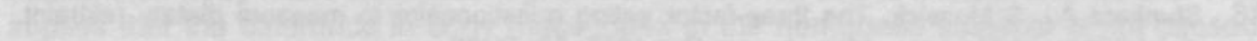
te

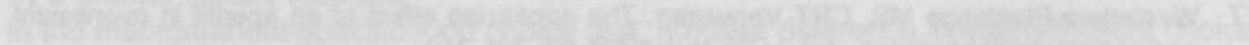

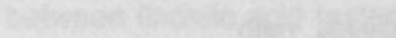

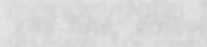

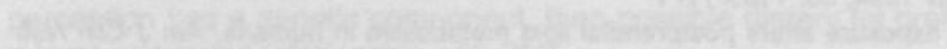
tras

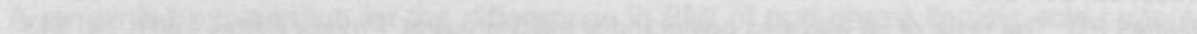

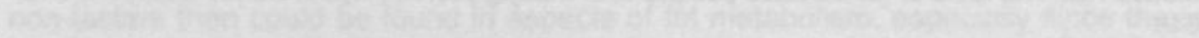

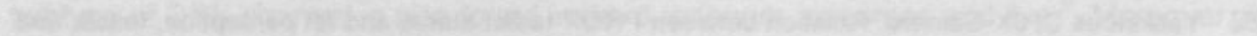

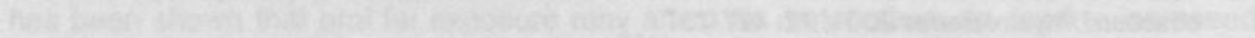

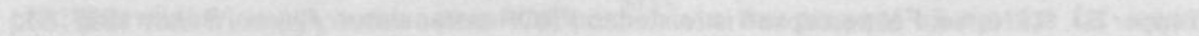
a

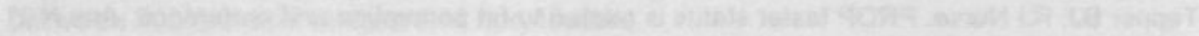

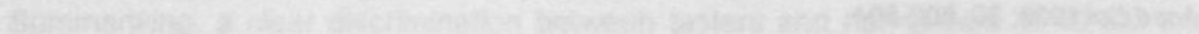

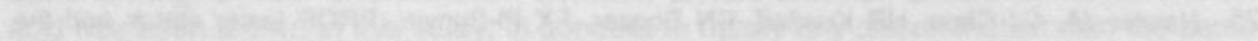
and

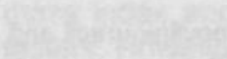

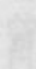

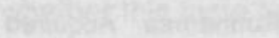

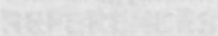




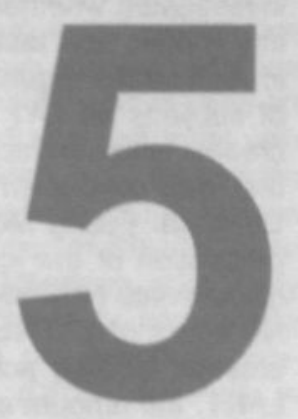

\section{The effect of addition of linoleic acid on food intake regulation in linoleic acid tasters and linoleic acid non- tasters}

Marleen MJW Kamphuis Wim HM Saris

Margriet S Westerterp-Plantenga

I British Journal of Nutrition, in press 


\section{ABSTRACT}

In a randomised, single blind, placebo-controlled cross-over design study, we investigated whether healthy, non-smoking, dietary unrestrained women $(n=24)$, divided into linoleic acid tasters (LAT, $n=14$ ) and linoleic acid non-tasters (LANT, $n=10$ ) differed in food intake regulation when linoleic acid was added to ice creams. The determination of subjects as LAT or LANT was done using a $10 \mu \mathrm{M}$ linoleic acid solution. The ice creams were characterised by the subjects and a taste perception test using the triangle test was conducted three times. Food intake and appetite were measured using the Universal Eating Monitor. LAT and LANT did not differ in characterisation or in taste perception of the ice creams, even though LAT were able to increase their ability to discriminate between the ice cream with linoleic acid from the one containing oleic acid. No effect of LAT-status or type of ice cream was found for hedonic value of the ice creams. Linoleic acid taster status did affect food intake regulation. For LAT, but not LANT, the amount eaten was a function of $\Delta$ satiety. Subjects ate by weight of food and not by energy content. In conclusion, a difference in food intake regulation was seen between LAT and LANT, in that the amount eaten by LAT was a function of $\Delta$ satiety, but was not for LANT.

\section{ACKNOWLEDGEMENT}

Supported by Novartis Consumer Health, Ltd., Nyon, Switzerland.

We would like to thank Nicole Mickley for advising on the fatty acid perception test. We also want to thank Mr. Belfi of 'ijssalon Venezia' for his help by the manufacture of the ice creams. 
$\mathrm{M}$ any studies have examined the effect of fat intake in comparison with other macronutrients on satiety and/or food intake, without discriminating between different types of fat. Only a few studies investigated the effects of saturation of fats on satiety and found that fats containing linoleic acid were more satiating than fats containing oleic acid on equi-energetic basis ${ }^{13}$. In a recent study, we showed evidence for fat-specific satiety in that after a two-week use of oil high in linoleic acid relative fat intake was lower at a dinner test meal with linoleic acid compared to a test meal with oleic acid after a two-week use of oil high in oleic acid ${ }^{4}$. This evidence for fat-specific satiety appeared not to be related to taste perception of the different oils, but in fact we hypothesised that fat-specific satiety may be related to taste perception of different (nonesterified) fatty acids. This hypothesis is based upon studies by Gilbertson et al. They found a relation between perception of fatty acids in taste receptor cells and dietary preference for fat in rats. Gilbertson et al. ${ }^{5}$ demonstrated that non-esterified polyunsaturated fatty acids (PUFA's) inhibit delayed rectifying $\mathrm{K}^{*}$ (DRK) channels in mammalian taste receptor cells, which in turn lead to an increase in activity of the taste cells. Interestingly, the effects were only seen for cis-PUFA's (arachidonic, linoleic and linolenic acid), and not for the mono-unsaturated fatty acid oleic acid. Moreover, DRK channels in tongue tissue of Osborne-Mendel rats with a preference for high-fat diets were less sensitive to the cis-PUFA's than DRK channels of S5B rats. The latter rats prefer diets high in carbohydrates ${ }^{6}$. Thus, an inverse relation between fatty acid perception, i.e. linoleic acid perception and fat preference is seen in rats. Some evidence for a possible role of fat perception in humans has been shown by Tepper and Nurse and Tepper ${ }^{7.8}$. They found a relation between PROP-taster status and the ability to discriminate between differences in fat concentrations. Moreover, Nasser et al." investigated the role of PROP-taster status on sensitivity to fat intake. They hypothesised that PROP tasters would be more sensitive to the presence of fatty acids and showed some evidence for this hypothesis in experiments in which linoleic acid was administered as part of conjugated linoleic acid (CLA) added to high fat ice cream. However, Tepper and Nurse, Tepper as well as Nasser et al. did not test whether subjects differed with respect to linoleic acid taste perception, and whether this was related to food intake regulation. In a previous study, we investigated whether subjects $(n=221)$ were able to taste a low concentration of linoleic acid $(10 \mu \mathrm{M})$. It was shown that $46 \%$ of the subjects were classified as linoleic acid tasters (LAT). Moreover, we showed that linoleic acid taste sensitivity might play a role in the etiology of obesity ${ }^{10}$

In the present study we tested whether there is a relationship between linoleic acid taste perception and food intake regulation in terms of food or energy intake, or satiety. Thus, we first distinguished LAT from linoleic acid non-tasters (LANT). Naturally, non-esterified linoleic acid is present in foods of which we are not aware, because we do not recognise it consciously. This phenomenon is similar to monosodium glutamate recognition. Despite lack of recognition, ingestion of non-esterified linoleic acid in foods may have consequences for food intake regulation. We therefore added linoleic acid in low concentrations to a food in order to study whether LAT and LANT would show a different response with respect to food intake regulation. We tested low and high-energy foods containing linoleic acid, oleic acid or no addition of fatty acids.

\section{MATERIAL AND METHODS}

\section{Subjects}

Thirty-five women were recruited by advertisements in local newspapers. Twenty-four subjects were selected for the experiment. Selection was based upon being healthy and at least 3 months weight-stable prior to the study, not using any medication known to affect body weight and/or appetite, being non-smoking, and at most moderate alcoholusers (max 10 glasses/week). Subjects had to be unrestrained eaters. The degree of dietary restraint was determined by the Three-Factor Eating Questionnaire (TFEQ, score Factor $1 \leq 9)^{11,12}$ and by the Herman/Polivy restraint questionnaire (HP, scores 15$)^{13^{\prime}}$. 
Table 1: baseline characteristics of the female subjects $(n=24)$

\begin{tabular}{lcc}
\hline & LAT $(n=14)$ & LANT $(n=10)$ \\
\hline \# correct answers ${ }^{2}$ & $10.0 \pm 0.0$ & $6.8 \pm 1.7^{1}$ \\
age $(y)$ & $25.9 \pm 7.3$ & $27.8 \pm 4.7$ \\
body weight $(\mathrm{kg})$ & $70.5 \pm 7.8$ & $70.4 \pm 9.8$ \\
BMI $^{3}(\mathrm{~kg} / \mathrm{m} 2)$ & $24.0 \pm 3.8$ & $24.3 \pm 2.6$ \\
HP $^{4}$ & $10.9 \pm 3.2$ & $13.1 \pm 2.3$ \\
F1 $^{5}$ (restrained eating) & $3.8 \pm 2.9$ & $5.6 \pm 4.2$ \\
F2 $^{5}$ (disinhibition) & $3.8 \pm 2.8$ & $4.4 \pm 3.4$ \\
F3 $^{5}$ (hunger) & $3.6 \pm 2.8$ & $5.0 \pm 3.4$ \\
\hline
\end{tabular}

'Significantly different from LAT, p<0.0001 ${ }^{2}$ on the question 'which sample contains the fatty acid' to identify linoleic acid taster status. Subjects were characterised as linoleic acid tasters (LAT) when given $\geq 9$ correct answers out of 10 or as linoleic acid non-tasters (LANT) when given $<9$ correct answers ${ }^{3} \mathrm{BMl}=\mathrm{Body}$ mass index ${ }^{4} \mathrm{HP}=$ Herman-Polivy restraint ${ }^{5}$ Factor 1 (cognitive restraint), Factor 2 (disinhibition) and Factor 3 (hunger) from ThreeFactor Eating Questionnaire (TFEQ) ${ }^{11,12}$

Body weight (after an overnight fast) was measured on a digital balance (SECA, model 707. Hamburg. Germany, weighing accuracy of $0.01 \mathrm{~kg}$ ) while subjects were wearing underwear. Body weight was measured before the study had started. Height was measured to the nearest 0.001 meter using a wall-mounted stadiometer (SECA, Hamburg) and body mass index (BMI; $\mathrm{kg} / \mathrm{m}^{2}$ ) was calculated as body weight $(\mathrm{kg})$ divided by height $(m)$ squared. Furthermore, all subjects completed a linoleic acid taster test to divide them into LAT and LANT (see Linoleic acid taste perception test ${ }^{10}$ ). Table 1 shows the baseline characteristics of the 24 subjects divided in LAT and LANT. All subjects gave their written informed consent. The study was approved by the Medical Ethics Committee of Maastricht University.

\section{Linoleic acid taste perception test}

Linoleic acid taster status was determined as follows. Linoleic acid ( $\mathrm{Na}$-salt) was diluted with propylene glycol (PG) and de-mineralised $\mathrm{H}_{2} \mathrm{O}(10 \mu \mathrm{M})$, while the placebo solution contained only $P G$ and $\mathrm{dH}_{2} \mathrm{O}$. The concentration of $10 \mu \mathrm{M}$ is identical to the concentrations of non-esterified fatty acids Gilbertson et al. ${ }^{5.6}$ used in the rat studies and as we ${ }^{10}$ used in a previous study. Twelve pairs of 2 samples were offered with one sample containing $10 \mu \mathrm{M}$ linoleic acid and the other containing the solution. The first two pairs were practice samples and were not included in the score. Subjects were asked to taste and expectorate half of the first sample, rinse with water, taste and expectorate half of the second sample, rinse with water, taste and expectorate the remaining first sample, rinse with water and to taste and expectorate the remaining of the second sample. After tasting each sample twice, i.e. after tasting a pair of two samples, subjects had to answer the question: which sample contains fatty acids? Between pairs, subjects had to rinse with water twice. With the linoleic acid taste perception test, a distinction between $10 \mu \mathrm{M}$ LAT and LANT could be made as follows. If subjects were not be able to distinguish the fatty acid from the placebo solution, and so had to guess $(p=0.5, n=10)$, the chance for guessing 10 correct answers is less than $0.1 \%$. The chance for guessing $>9$ correct answers out of 10 is $1.1 \%$, while the chance exceeds the $5 \%$ level with guessing $\geq 8$ correct answers out of 10 pairs. So, subjects were characterised as LAT when they gave $z 9$ correct answers out of 10 and as LANT when they gave $<9$ correct answers. Subjects were tested twice, with one week in between the tests. The outcome of the second test was used in order to identify subjects as LAT and LANT. In a previous study, we showed that the reproducibility of the linoleic acid perception test was $95 \%{ }^{10}$ 


\section{PROP taster status}

PROP taster status of the subjects was identified as follows. Five concentrations of $\mathrm{NaCl}$ $(0.01-1 \mathrm{M})$ increasing in half-log steps in random order and five concentrations of PROP $\left(3.2 \times 10^{-5}-3.2 \times 10^{-3} \mathrm{M}\right)$ increasing in half log steps in random order were rated using a $150 \mathrm{~mm}$ visual analogue scale (VAS). Samples were tasted and expectorated. Subjects rinsed with water in between each sample until the taste of PROP or $\mathrm{NaCl}$ was disappeared. This procedure was used to generate suprathreshold taste intensity functions for the two compounds. When these two functions were superimposed and the slope of the PROP curve appears much lower than the slope for the $\mathrm{NaCl}$ curve, a subject was classified as a PROP non-taster. When the PROP curve overlaps with the $\mathrm{NaCl}$ curve, a subject was classified as a PROP medium taster. A subject was classified as a PROP supertaster when the slope of the PROP curve was steeper than the $\mathrm{NaCl}$ slope ${ }^{4,14}$

\section{Experimental Design}

The study was a single blind, randomised placebo-controlled trial, which consisted of 6 test days. The subjects came 6 times on the same day of the week and the same time of the day to our department after a $3 \mathrm{~h}$ fast, for a test. During each test, one type of ice cream was offered ad libitum from the universal eating monitor ${ }^{15}$ in random order. Before this ad libitum test meal, subjects were asked to characterise the type of ice cream they were offered on that day using a $25 \mathrm{~g}$ sample (see Test protocol for characterisation of the ice creams). To assess whether energy content or type of ice cream with respect to fatty acid content would influence energy intake or satiety, variables of meal consumption and appetite for six different ice creams were determined during each test (see Test protocol eating profile). Moreover, to assess whether subjects were able to distinguish between ice creams, a taste perception test for the ice creams was conducted during the last 4 visits (see Test protocol taste perception).

Non-esterified linoleic acid is present in foods in low concentrations, although we do not taste it and we are not aware of its presence. In the present study non-esterified linoleic acid was added in low concentrations to study whether LAT and LANT would show a different response with respect to food intake regulation. Linoleic acid was offered as a non-esterified fatty acid, which is present in conjugated linoleic acid in a concentration of $3 \mathrm{~g} / 100 \mathrm{~g}$. Since non-esterified fatty acids oxidise rapidly at room temperature, the study was conducted with ice creams in order to minimise oxidation. The low-energy ice cream with linoleic acid (LL) was tested against a low-energy ice cream without linoleic acid (L) and a low-energy ice cream with oleic acid (LO). Moreover, LL was tested against a high-energy ice cream with linoleic acid (HL). The latter was tested against a high-energy ice cream without linoleic acid $(\mathrm{H})$ and a high-energy ice cream with oleic acid $(\mathrm{HO})$.

The non-esterified fatty acid and triacylglycerol composition of the ice creams were analyzed with the following procedure. Lipids were extracted according to the method of Folch ${ }^{16}$. TLC plates were used to separate non-esterified fatty acids and triacylglycerols from the total lipid extract ${ }^{17}$. The fatty acids were transmethylated to the corresponding methylesters (FAME) by reaction with acetylchloride and methanol at $100^{\circ} \mathrm{C}$ for one hour $^{18}$. The FAME's were separated and quantified by using a HP 5890 II gas chromatograph, fitted with a $50 \mathrm{~m} \mathrm{CP}$ sil88 capillary column with $0.25 \mathrm{~mm}$ ID and 0.12 $\mu \mathrm{m}$ film thickness (Chrompack®, Middelburg. The Netherlands). A standard fame mixture was used to identify the FAME's by means of the retention times. The nonesterified fatty acid and triacylglycerol composition of the ice creams are presented in table 2.

\section{Ice cream}

One unit for the low-energy ice creams contained 1 litre low-fat milk, $250 \mathrm{~g}$ of sugar, $5 \mathrm{~g}$ of coffee powder (Nescafe Mild, Nestle, Switzerland), $15 \mathrm{~g}$ cacao (Blooker, Amsterdam, The Netherlands) and $3 \mathrm{~g}$ thickener (Mobexgel F500, Black B.V., De Meern, The Netherlands). In the high-energy ice creams, the low-fat milk was replaced by $500 \mathrm{ml}$ fullfat milk and $500 \mathrm{ml}$ cream. 
Table 2: linoleic acid and oleic acid content ( $\mu \mathrm{g} / \mathrm{mg}$ ice cream) of the ice creams as nonesterified fatty acid (NEFA) and as triacylglycerol (TG)

\begin{tabular}{lcccccc}
\hline & L & U & LO & H & HL & HO \\
\hline NEFA linoleic acid & 0.00 & 0.01 & 0.00 & 0.01 & 0.03 & 0.01 \\
NEFA oleic acid & 0.01 & 0.1 & 0.01 & 0.12 & 0.17 & 0.31 \\
TG linoleic acid & 0.1 & 0.2 & 0.1 & 1.14 & 2.5 & 2.2 \\
TG linoleic acid & 1.0 & 1.0 & 1.8 & 16.6 & 25.3 & 29.7 \\
\hline
\end{tabular}

The milk products (low-fat milk or high-fat milk with cream) together with the sugar, coffee powder, cacao and thickener were heated until the boiling point. After that, they were cooled and stored at $4^{\circ} \mathrm{C}$ for $24 \mathrm{~h}$ before making the ice creams. Just before making ice cream, linoleic acid ( $0.03 \mathrm{~g}$ linoleic acid/unit), placebo (oleic acid) or nothing was added.

The low-energy ice creams contained $4.6 \mathrm{~kJ} / \mathrm{g}$ and had a macronutrient composition (Protein/Fat/Carbohydrate) of 11/2/87 percentage of energy, while the high-energy ice creams contained $10.1 \mathrm{~kJ} / \mathrm{g}$ and had a macronutrient composition (P/F/C) of 4/58/38 percentage of energy. Addition of linoleic acid or placebo did not change macronutrient composition.

The ice creams were always produced by the same experimenter in the week preceding the test days. The ice creams were stored at $-20^{\circ} \mathrm{C}$ in $750 \mathrm{ml}$ dishes. One hour before tests, the ice cream was taken out the freezer and put in a fridge, so that during the test meal the ice creams had an acceptable temperature $\left( \pm-2^{\circ} \mathrm{C}\right)$ and texture.

\section{Test protocol for characterisation of the ice creams}

Before the subjects started a test meal, they tasted and characterised $25 \mathrm{~g}$ of the ice cream they were offered that day ${ }^{4}$. They were asked: 'How sweet, bitter, sour, salty, neutral, full of taste and how creamy is the ice cream?' and 'How much do you like the ice cream?'. The subjects scored every question on a $100 \mathrm{~mm}$ VAS anchored 'not at all' on the left and 'extremely' on the right.

\section{Test protocol eating profile}

During the six times the subjects came to the department, they ate the different ice creams in random order (one type each test) from the Universal Eating Monitor. Meal size, meal duration and eating rate were measured, as well as satiation during the meal. Before and every $90 \mathrm{~s}$ during the test meal subjects were asked: 'How satiated are you?' and 'How strong is your desire to eat this ice cream?'. Fifteen seconds after starting the meal and after termination of the meal, they were asked how pleasant the taste of the ice cream was at that moment. The subjects rated the answers on these questions on a VAS, which appeared on a computer screen in front of the subjects. They were instructed to answer the questions in between bites, so not to disrupt their eating rate.

\section{Test protocol taste perception}

The ability of subjects to discriminate between the ice cream with linoleic acid against no addition, and with linoleic acid against oleic acid was tested using the triangle test. This test is effective for determining if overall differences exist. Moreover, it can select subjects for ability to discriminate differences ${ }^{19}$.

In each trial three samples of ice cream were offered: 2 the same and 1 different. Subjects had to taste each sample and expectorate it. Between each sample subjects rinsed their mouth with bread and water, which had to be expectorated also. The procedure of a trial of three samples had to be repeated before the subjects answered the question: 'Which ice cream is the odd one out?'.

Four tests were conducted over 4 weeks. During the first test, subjects had to test ice cream with linoleic acid against ice cream without linoleic acid in order to test if the subjects were able to distinguish LL from L. During the last three tests, ice cream with linoleic acid was tested against ice cream with oleic acid. After the second test, i.e. the 
first one testing LL against LO subjects took both ice creams home. They were asked to practice the test at home every day. With this set-up we were able to test the learning effect of the discrimination.

\section{Statistical analysis}

The relationship between linoleic acid taster status and PROP taster status was analysed with a $\chi^{2}$-test. For the test protocol taste perception, subjects had to correctly identify 5 samples out of 6 in order to say that they were able to discriminate the linoleic acid containing ice cream from the ice cream with oleic acid or from the ice cream with no addition. Improvements in taste perception between the ice cream with linoleic acid and the ice cream with oleic acid for LAT and LANT were analysed with a two-factor repeated-measures analysis of variance (ANOVA). Post hoc analysis was executed with a Scheffe F-test (Statview SE GraphicsTM). Possible differences in characterisation, food and energy intake, meal duration, eating rate and appetite profile between LAT and LANT for the individual ice creams were analysed with a two-factor repeated-measures analysis of variance (ANOVA). Post hoc analysis between ice creams was done with the Scheffe F-test (Statview SE GraphicsTM) and between linoleic acid taster groups with an unpaired $t$-test (Statview SE GraphicsTM). The relationship between amount eaten ( 9 and $\mathrm{kJ}$ ) and $\Delta$ satiety as well as between $\Delta$ pleasantness of taste and hedonic value were tested with a simple regression (Statview SE GraphicsTM).

The data are presented as meantstandard deviations (SD). The level of significance was set at $\mathrm{p}<0.05$.

\section{RESULTS}

\section{Subject characteristics}

Of the 24 female subjects, 14 subjects were characterised as LAT and 10 as LANT. These two groups in the present study did not differ in age, body weight, BMI and dietary restraint (table 1). Of the LAT group 63\% and of LANT 60\% were PROP tasters. There was no relation between linoleic acid taster status and PROP taster status (results not shown).

Table 3: characterisation of the six ice creams (mm VAS) together by female subjects divided in linoleic acid tasters (LAT, $n=14$ ) and linoleic acids non-tasters (LANT, $n=10$ )

\begin{tabular}{lcc}
\hline & LAT & LANT \\
\hline sweet & $52.3 \pm 17.0$ & $53.1 \pm 12.0$ \\
sour & $12.1 \pm 12.3$ & $5.4 \pm 5.6$ \\
salty & $15.6 \pm 14.4$ & $11.9 \pm 13.1$ \\
bitter & $29.0 \pm 18.1$ & $16.3 \pm 11.5$ \\
neutral of taste & $32.7 \pm 14.2$ & $39.1 \pm 17.8$ \\
full of taste & $56.0 \pm 10.0$ & $55.1 \pm 11.7$ \\
creamy & $52.7 \pm 13.4$ & $52.8 \pm 12.4$ \\
hedonic & $46.3 \pm 16.5$ & $56.1 \pm 18.0$ \\
\hline
\end{tabular}

\section{Characterisation of the ice creams}

LAT and LANT did not differ in characterisation of the ice creams (table 3). Moreover, no differences in characterisation with respect to sweet, sour, salty and neutral of taste between the ice creams were seen (table 4). However, differences between ice creams for 'bitterness', 'full of taste' and 'creaminess' were observed. Addition of linoleic acid made the high-energy ice cream less bitter and more full of taste and creamy compared to high-energy ice cream without addition of any fatty acid. Moreover, subjects found high-energy ice cream with linoleic acid more full of taste and more creamy compared to 
the low-energy variant. Furthermore, the high-energy ice cream with oleic acid was observed to be more creamy than the high-energy ice cream without addition of any fatty acid as well as the low-energy ice cream with oleic acid. The latter, in turn, was observed to be more creamy than the low-energy ice cream with linoleic acid (table 4). No differences in hedonic value between ice creams, or between linoleic acid taster groups were seen. There was no Taster $\mathrm{x}$ Ice cream interaction for any variable.

\section{Eating profile}

No differences in meal size, meal duration or eating rate were seen between the types of ice creams or between LAT and LANT, nor was there a Taster $x$ lce cream interaction. Therefore, these variables of all types of ice creams are taken together (table 5).

The amount eaten $(\mathrm{g})$ did not differ between ice creams. Because of the differences in energy content, the amount eaten (kJ) differed between the ice creams. Subjects ate more from the high-energy ice creams than from the low-energy ice creams $(\mathrm{H}$ 1649.9 \pm 615.9 , HL $2069.0 \pm 944.9$ and HO $2012.4 \pm 929.0$ vs. L $854.4 \pm 529.5$, LL $889.3 \pm 437.5$ and LO: $910.5 \pm 409.4 \mathrm{~kJ}, \mathrm{p}<0.0001$ ). Moreover, within the high-energy ice creams, subjects ate more from the high-energy ice cream with addition of linoleic acid compared with the high-energy ice cream without addition of a fatty acid $(p<0.0001)$.

Because the satiety levels before and at the end, and $\Delta$ satiety did not differ between ice creams or between LAT and LANT, the results are presented as mean values (table 5). The difference with respect to food intake regulation between LAT and LANT consisted of an interaction between linoleic acid perception and $\Delta$ satiety $(F 3,54=3.0, p=0.039)$. For the LAT there was a strong positive relationship between amount eaten $(\mathrm{g}$ and $\mathrm{kJ})$ and $\Delta$ satiety for LL $\left(r^{2}=0.6, p<0.001\right.$; figure 1), H $\left(r^{2}=0.6, p<0.001\right), \mathrm{HO}\left(r^{2}=0.5, p<0.01\right)$, and a trend for $\mathrm{HL}\left(r^{2}=0.2, p<0.08\right)$. In contrast, no relationship for any ice cream between amount eaten ( $g$ and $\mathrm{kJ}$ ) and $\Delta$ satiety was seen for the LANT.

No differences between LAT and LANT were observed with respect to the pleasantness of taste levels before and after the meal. However, $\Delta$ pleasantness of taste with the low energy ice cream with addition of linoleic acid was higher for LANT $(-20.5 \pm 13.5 \mathrm{~mm}$ VAS) compared to LAT $(-9.6 \pm 13.5 \mathrm{~mm}$ VAS), but did not reach the level of significance $(p<0.1)$. Between ice creams, the pleasantness of taste levels after the meal was lower with $\mathrm{H}(30.1 \pm 23.3 \mathrm{~mm}$ VAS) compared to $\mathrm{HL}(54.4 \pm 24.7 \mathrm{~mm}$ VAS, $\mathrm{p}<0.001)$ and $\mathrm{HO}$ (55.2 $\pm 29.2 \mathrm{~mm}$ VAS, $\mathrm{p}<0.001)$. Moreover, the $\Delta$ pleasantness of $\mathrm{H}(-28.2 \pm 23.7 \mathrm{~mm}$ VAS $)$ was greater than the $\Delta$ pleasantness of taste with $\mathrm{HL}(-11.3 \pm 15.4 \mathrm{~mm}$ VAS, $\mathrm{p}<0.01)$.

Table 4: characterisation of the six ice creams (mm VAS) for female linoleic acid tasters and linoleic acids non-tasters together

\begin{tabular}{lccccccc}
\hline & $\mathrm{L}$ & $\mathrm{LL}$ & $\mathrm{LO}$ & $\mathrm{H}$ & $\mathrm{HL}$ & $\mathrm{LL}$ & $\mathrm{p}$-value \\
\hline sweet & $55.2 \pm 18.6$ & $47.7 \pm 19.9$ & $52.9 \pm 16.5$ & $50.0 \pm 20.6$ & $53.2 \pm 19.0$ & $56.8 \pm 17.9$ & $\mathrm{~ns}$ \\
sour & $11.5 \pm 16.8$ & $9.3 \pm 11.6$ & $9.5 \pm 9.7$ & $10.5 \pm 14.1$ & $5.9 \pm 9.0$ & $10.3 \pm 16.3$ & $\mathrm{~ns}$ \\
salty & $13.6 \pm 17.4$ & $15.6 \pm 18.7$ & $11.7 \pm 13.4$ & $18.8 \pm 24.1$ & $12.1 \pm 14.9$ & $13.2 \pm 18.2$ & $\mathrm{~ns}$ \\
bitter & $25.5 \pm 24.9$ & $22.1 \pm 22.3$ & $26.1 \pm 24.9$ & $34.3 \pm 24.4$ & $16.2 \pm 17.8^{\prime}$ & $20.0 \pm 20.9$ & $<0.01$ \\
$\begin{array}{l}\text { neutral of } \\
\text { taste }\end{array}$ & $37.5 \pm 16.9$ & $40.0 \pm 21.8$ & $37.2 \pm 24.0$ & $29.5 \pm 18.8$ & $33.9 \pm 19.1$ & $33.2 \pm 23.8$ & $\mathrm{~ns}$ \\
full of taste & $51.1 \pm 19.7$ & $40.5 \pm 18.7$ & $53.1 \pm 16.0$ & $52.5 \pm 18.7$ & $68.9 \pm 15.3^{1.2}$ & $67.5 \pm 19.5$ & $<0.0001$ \\
creamy & $47.0 \pm 17.5$ & $32.4 \pm 23.2$ & $49.3 \pm 15.7^{2}$ & $46.3 \pm 19.9$ & $69.7 \pm 17.1^{12}$ & $71.6 \pm 20.2^{1}$ & $<0.0001$ \\
hedonic & $50.9 \pm 22.9$ & $43.6 \pm 23.7$ & $50.0 \pm 21.2$ & $44.6 \pm 18.3$ & $56.0 \pm 18.9$ & $55.8 \pm 24.5$ & $\mathrm{~ns}$ \\
\hline
\end{tabular}

'significantly different from $\mathrm{H}$

${ }^{2}$ significantly different from LL 
Table 5: eating and appetite profile parameters presented as the average oSif the six ice creams together by female subjects divided in linoleic acid tasters (LAT, $n=14$ ) and linoleic acids non-tasters (LANT, $\mathrm{n}=10$ )

\begin{tabular}{|c|c|c|}
\hline & LAT & LANT \\
\hline meal duration (s) & $500.6 \pm 156.4$ & $399.9 \pm 182.7$ \\
\hline amount eaten (g) & $200.5 \pm 81.2$ & $175.5 \pm 81.9$ \\
\hline amount eaten $(\mathrm{kJ})$ & $1316.7 \pm 534.1$ & $1140.2 \pm 534.5$ \\
\hline eating rate $(g / s)$ & $0.4 \pm 0.2$ & $0.5 \pm 0.2$ \\
\hline bite size (g) & $4.2 \pm 1.2$ & $4.8 \pm 2.1$ \\
\hline bite frequency (bites/s) & $0.1 \pm 0.0$ & $0.1 \pm 0.0$ \\
\hline satiety $t=0^{\prime}$ & $19.0 \pm 11.3$ & $20.0 \pm 18.3$ \\
\hline satiety end' & $84.7 \pm 8.3$ & $82.7 \pm 9.1$ \\
\hline$\Delta$ satiety' & $64.2 \pm 14.6$ & $62.8 \pm 22.5$ \\
\hline pleasantness of taste $t=0$ & $56.5 \pm 18.1$ & $64.8 \pm 20.8$ \\
\hline pleasantness of taste end & $42.9 \pm 21.6$ & $44.7 \pm 17.5$ \\
\hline$\Delta$ pleasantness of taste' & $-14.5 \pm 12.2$ & $-20.1 \pm 10.6$ \\
\hline
\end{tabular}

'mm VAS

\section{Taste perception}

Because in general subjects gave less than 5 correct answers in each taste perception test, they were not able to discriminate consciously between the different ice creams. However, large individual differences were seen, but there was no relationship between the number of correct answers on the taste perception test (linoleic acid vs no addition and linoleic acid vs oleic acid) and number of correct answers on the linoleic acid perception test. Interestingly, LAT significantly increased their abilities to discriminate the ice cream with linoleic acid from the ice cream containing oleic acid from the first to the third test $(2.7 \pm 1.3$ vs. $3.9 \pm 1.1, p<0.05)$, but did not differ from LANT. ANOVA showed significance for repeated measurements; LAT gave more correct answers with linoleic acid against no supplementation than with linoleic acid against oleic acid during its first test $(p<0.01)$.

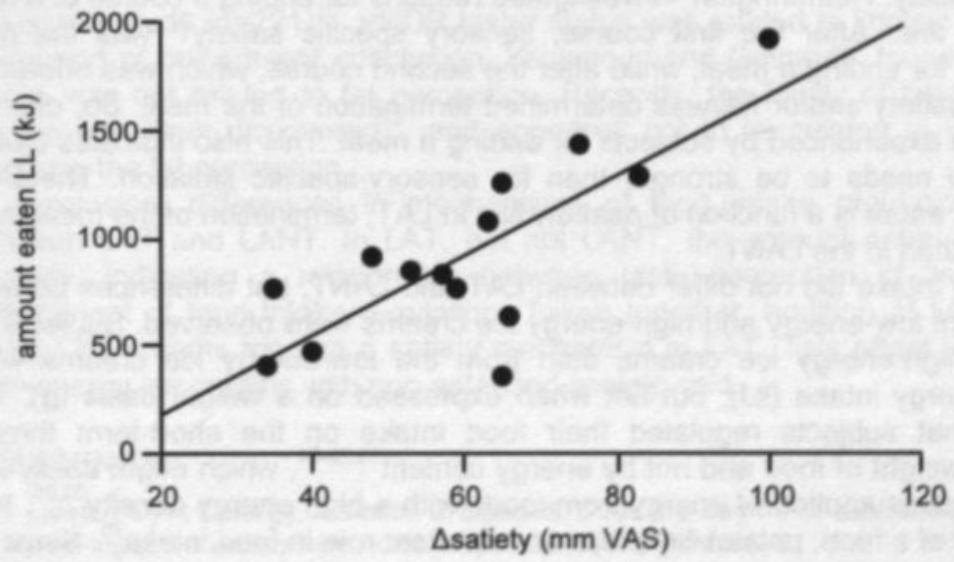

Figure 1: relationship between amount eaten of a low-energy ice cream with linoleic acid (LL) and $\Delta$ satiety levels for 14 female subjects who were characterised as linoleic acid tasters. $r^{2}=0.6, y=18.6 x-194.9, p<0.001$ 


\section{DISCUSSION}

In general, we observed in a group of 221 subjects that $46 \%$ of the subjects could be classified as $10 \mu \mathrm{M}$ LAT $^{10}$. In the present study, we selected 14 LAT and 10 LANT to participate in the study. Subjects had to give 9 or more correct answers out of 10 to be characterised LAT. Next to the correct answer on the test pair, we also asked how sure subjects were about their answer. All subjects who were characterised as LAT said they were absolutely sure about their answers, while the LANT were not. So, even though LANT scored higher than a random guess ( 6.8 instead of 5), they were not able to taste it consciously like the LAT did.

From the taste perception tests, it was shown that LAT increased their ability to discriminate between a low-energy ice cream with linoleic acid and a low-energy ice cream with oleic acid. This indicates a relatively higher sensitivity to a low concentration of linoleic acid in food of LAT compared to LANT. In LAT, in contrast to LANT, the amount eaten was a function of $\Delta$ satiety, particularly for the low-energy ice cream with non-esterified linoleic acid and some high energy ice creams, which also contained nonesterified linoleic acid. In contrast, LANT showed a tendency for a greater $\Delta$ pleasantness of taste compared with LAT from before to after eating the low-energy ice cream with addition of linoleic acid. This finding implies that linoleic acid perception may play a role in food intake regulation, in that it may explain different reasons for terminating a meal. In addition, the relationships between $\Delta$ satiety and the amount eaten only observed in the LAT imply a more general sensitivity for fat in tasters. This is also confirmed by the generally higher scores on characteristics of the ice creams by the tasters.

Since in LAT all high-energy ice creams, which contained non-esterified linoleic acid, were shown to affect the relationship between $\Delta$ satiety and amount eaten, as well as the low energy ice cream with addition of linoleic acid, it can be suggested that addition of linoleic acid in low-energy foods might affect food intake regulation in LAT to the same extent as high-energy foods.

In our present study, only LAT terminated their meals consisting of ice creams because they were satiated. With this observation, we showed that linoleic acid taster status might affect food intake regulation. Although this was limited to showing the mechanism, i.e. amount eaten was a function of satiety and was not extended to the amount eaten itself, we suggest that it still gives evidence for supporting the Gilbertson hypothesis ${ }^{6}$. The satiating capacity might not only take place through tasting, since DRK channels also have been discovered in other parts of the gastrointestinal tract ${ }^{20}$.

In the present study, LAT and LANT differed with respect to the relation between amount eaten $(\mathrm{kJ})$ and satiety. Hetherington ${ }^{21}$ investigated reasons for ending a course of a meal of a two-course test. After the first course, sensory specific satiety ${ }^{22}$ was the most important reason for ending a meal, while after the second course, which was offered ad libitum $1 \mathrm{~h}$ later, satiety and/or fullness determined termination of the meal. So, different reasons might be experienced by subjects for ending a meal. This also indicates that for satiety the signal needs to be stronger than for sensory-specific satiation. Therefore, when the amount eaten is a function of $\Delta$ satiety like in LAT, termination of the meal might be more definite than in the LANT.

Food and energy intake did not differ between LAT and LANT, but differences between energy intake from low-energy and high-energy ice creams were observed. Subjects ate more from the high-energy ice creams than from the low-energy ice creams when expressed as energy intake $(\mathrm{kJ})$, but not when expressed on a weight basis $(\mathrm{g})$. This showed again that subjects regulated their food intake on the short-term through consumption by weight of food and not by energy content ${ }^{15.23-24}$, which might easily lead to a passive overconsumption of energy from foods with a high energy density ${ }^{23.25}$. Next to energy density of a food, palatability plays an important role in food intake ${ }^{26}$. Since the hedonic value did not differ between ice creams, the palatability was not a confounder in the present study. In the present study, a small texture effect was shown. With respect to oral texture sensation, it appeared that high-energy ice creams were perceived as more creamy when fatty acids were added. Subsequently, subjects ate more from the HL ice 
cream, which was perceived as more creamy, than from $\mathrm{H}$.

The concentration of the added linoleic acid to the ice creams was $1.4 \mathrm{mM}$ while the linoleic acid taster test was conducted with solutions of $10 \mu \mathrm{M}$. Even though the concentration in the ice creams were 140-fold greater than in the solutions, the taste intensity may be masked, since the ice creams contained many compounds (e.g. cacao, coffee) masking the taste of the fatty acid. This may explain why the ice creams were not clearly different perceived or characterised.

In an earlier study, we found evidence for fat-specific satiety for oils high in linoleic acid compared to oils high in oleic acid ${ }^{4}$. However, this fat-specific satiety was not related to taste perception of the different oils. Because we used oils for the taste perception test in that study, we tested whether subjects were able to perceive triacylglycerol instead of non-esterified fatty acids. Triacylglycerols need to be hydrolysed by lipases in order to become non-esterified fatty acids. The presence of lingual lipase in humans has been demonstrated ${ }^{27.28}$ and activity has been detected ${ }^{29}$; however, the physiological role is uncertain. Possible activity of lingual lipase in humans remains to be demonstrated in relation to linoleic acid perception in oils. However, several foods contain non-esterified fatty acids, so breaking down triacylglycerol by lingual lipase is not the only prerequisite for a function of fatty acid perception in satiety.

In the present study we used non-esterified linoleic acid for the taste perception test and we found differences concerning food intake regulation between subjects who perceive the linoleic acid compared to subjects who do not. However, no relation was seen between the number of correct answers on the linoleic acid taster test and on the taste perception test. This might be due to the fact that subjects, LAT as well as LANT were not able to consciously discriminate between ice creams with linoleic acid and ice creams with oleic acid or no fatty acid. The finding that LAT increased their ability to discriminate between the ice cream with linoleic acid from the one containing oleic acid and the fact they gave more correct answers in the taste perception test with linoleic acid vs no supplementation shows that LAT are more sensitive for the linoleic acid than LANT.

It has been hypothesised that sensitivity for fat and fat perception might be related to the ability to sense PROP. Tepper and Nurse, and Tepper ${ }^{8.30}$ found that PROP tasters had an increased ability to discriminate between salad dressings with different fat content. Moreover, Nasser et al. ${ }^{9}$ found that PROP tasters were more sensitive to the presence of conjugated linoleic acid in ice cream than PROP non-tasters. However, they did not investigate whether PROP taster status was related to the ability to perceive nonesterified linoleic acid. In contrast to these findings, neither in the present study nor in our earlier study $(n=221)^{10}$, PROP taster status was related to linoleic acid taster status. In support of our present conclusion, Yackinous and Guinard ${ }^{31}$ found that PROP taster status was not related to fat perception. Recently, the family of bitter receptors in the tongue has been discovered ${ }^{32}$, and appeared not to be related to the DRK channels involving the fat perception.

In conclusion, differences in mechanisms of food intake regulation were observed between LAT and LANT. In LAT, but not LANT, the amount eaten was a function of $\Delta$ satiety, indicating a relationship between taste perception of linoleic acid and a determinant of food intake regulation. Taken together, addition of linoleic acid to lowenergy ice creams triggers a satiety mechanism in LAT. This effect is comparable with high-energy ice creams with non-esterified linoleic acid.

\section{REFERENCES}

1 Lawton C, H Delargy, F Smith, J Blundell. Does the degree of saturation of fatty acids affect post-ingestive satiety? Int J Obes Relat Metab Disord 1997; 21: S35

2 French S, S Mutuma, J Francis, N Read, G Meijer. 1998. The effect of fatty composition on intestinal satiety in man. In Internation Congress on Obesity. Paris: Int J Obes. S82

3 French SJ. The effects of specific nutrients on the regulation of feeding behaviour in human subjects. Proc Nutr Soc 1999; 58: 533-539 
4 Kamphuis MMJW, MS Westerterp-Plantenga, WHM Saris. Fat specific satiety in humans for fat high in linoleic acid versus fat high in oleic acid. Eur J Clin Nutrition 2001; 55: 499-508

5 Gilbertson TA, T Fontenot, L Liu, H Zhang, WT Monroe. Fatty acid modulation of K+ channels in taste receptor cells: gustatory cues for dietary fat. Am J Physiol 1997; 272: C1203-C1210

6 Gilbertson TA, L Liu, DA York, GA Bray. Dietary fat preferences are inversely correlated with peripheral gustatory fatty acid sensitivity. Ann N Y Acad Sci 1998; 855: 165-168

7 Tepper BJ. Does genetic taste sensitivity to PROP influence food preferences and body weight? Appetite 1999; $32: 422$

8 Tepper BJ, RJ Nurse. PROP taster status is related to fat perception and preference. Ann N Y Acad Sci 1998; 30: 802-804

9 Nasser JA, CJ Chou, HR Kissileff, CN Boozer, FX Pi-Sunyer. PROP taster status and the ability to detect the presence of added conjugated linoleic acid in high fat ice cream. Obes Res 1999; 7: 87S

10 Kamphuis MMJW, MS Westerterp-Plantenga. The role of linoleic acid taste perception in the etiology of obesity. submitted

11 Stunkard AJ, S Messick. The three-factor eating questionnaire to measure dietary restraint, disinhibition, and hunger. J Psychosom Res 1985; 29: 71-83

12 Westerterp-Plantenga MS, V Rolland, SAJ Wilson, KR Westerterp. Satiety related to $24 \mathrm{~h}$ dietinduced thermogenesis during high protein/carbohydrate vs high fat diets measured in a respiration chamber. Eur J Clin Nutr 1999; 53: 495-502

13 Herman CP, J Polivy. Restrained Eating. Saunders, W.B.: Philadelphia, 1980

14 Bartoshuk LM, Duffy, V.B., Miller, I.J. PTC/PROP tasting: anatomy, psychophysics, and sex effects. Physiol Behav 1994; 56: 1165-1171

15 Westerterp-Plantenga MS. Eating behavior in humans, characterized by cumulative food intake curves-a review. Neurosci Biobehav Rev 2000; 24: 239-248

16 Folch J, M Lees, GH Sloane-Stanley. J Biol Chem 1957; 226: 497-509

17 Kaluzny MA, LA Duncan, MV Merrit, DE Epps. Rapid separation of lipid classes in high yield and purity using bonded phase columns. J Lipid Res 1985; 26: 135-140

18 Lepage G, CC Roy. Direct transesterification of all classes of lipids in a one-step reaction. J Lipid Res 1986; 27: 114-120

19 Meilgaard M, GV Civille, BT Carr. Sensory Evaluation Techniques. CRC Press: Boca Raton, 1991

20 Gilbertson T, I Kim, L Liu. Sensory cues for dietary fat: implications for macronutrient preferences. In: Ailhaud GB Guy-Grand (eds). Progress in Obesity Research. John Libbey \& Company Ltd.: 1998, pp 167-171

21 Hetherington MM. Sensory-specific satiety and its importance in meal termination. Neurosci Biobehav Rev 1996; 20: 113-117

22 Rolls BJ. Sensory-specific Satiety. Nutr Rev 1986; 44: 93-101

23 Blundell JE, JR Cotton, H Delargy, S Green, A Greenough, NA King, CL Lawton. The fat paradox: fat-induced satiety signals versus high fat overconsumption. Int $J$ Obes Relat Metab Disord 1995; 19: 832-835

24 Westerterp-Plantenga MS. Analysis of energy density of food in relation to energy intake regulation in human subjects. Br J Nutr 2001; $85: 351-361$

25 Blundell JE, JI MacDiarmid. Fat as a risk factor for overconsumption: satiation, satiety, and patterns of eating. J Am Diet Assoc 1997; 97: S63-69

26 Drewnowski A. Energy density, palatability, and satiety: implications for weight control. Nutr Rev 1998; 56: 347-353

27 Hamosh M, Klaeveman, H.L., Wolf, R.O., Scow, R.O. Pharyngeal lipase and digestion of dietary triglyceride in man. $J$ Clin Invest 1975; 55: 908-913

28 Hamosh M, WA Burns. Lipolytic activity of human lingual glands (Ebner). Lab Invest 1977; 37: 603-608

29 Spielman Al, S D'Abundo, RB Field, H Schmale. Protein analysis of human von Ebner saliva and a method for its collection from the foliate papillae. J Dent Res 1993; 72: 1331-1335

30 Tepper BJ, RJ Nurse. Fat perception is related to PROP taster status. Physiol Behav 1997; 61: 949-954

31 Yackinous C, JX Guinard. Relation between PROP taster status and fat perception, touch, and olfaction. Physiol Behav 2001; 72: 427-737

32 Firestein S. The good taste of genomics. Nature 2000; 404: 552-553 


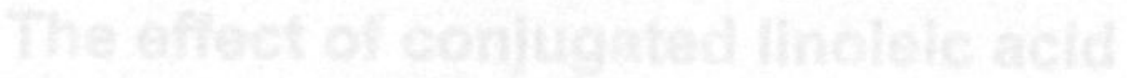

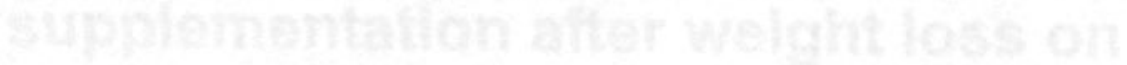

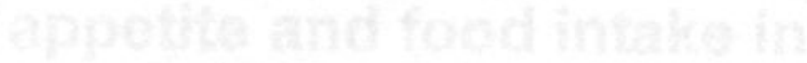

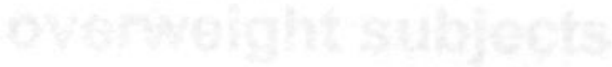





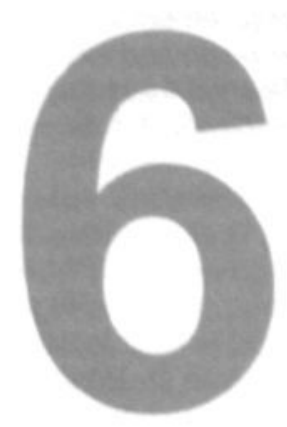

The effect of conjugated linoleic acid supplementation after weight loss on appetite and food intake in overweight subjects

Marleen MJW Kamphuis

Manuela PGM Lejeune

Wim HM Saris

Margriet S Westerterp-Plantenga

| European Journal of Clinical Nutrition, in press 


\section{ABSTRACT}

Objective: to study the effects of 13 weeks conjugated linoleic acid (CLA) supplementation in overweight subjects on body weight maintenance, parameters of appetite and energy intake at breakfast after weight loss.

Design: this study had a double-blind, placebo-controlled randomized design.

Subjects: A total of 26 men and 28 women (age $37.8 \pm 7.7$ y; body mass index $27.8 \pm 1.5$ $\mathrm{kg} / \mathrm{m}^{2}$ )

Interventions: subjects were first submitted to a very-low-calorie-diet (VLCD; $2.1 \mathrm{MJ} /$ day) for 3 weeks after which they started with the 13-week intervention period. They either received $1.8 \mathrm{~g} \mathrm{CLA}$ or placebo per day or $3.6 \mathrm{~g} \mathrm{CLA}$ or placebo per day. Additionally, subjects of the high dosage intervention replaced their habitual lunch by one meal of a protein-rich, low-energy supplement. Energy intake was measured at breakfast and appetite profile after an overnight fast.

Results: mean body weight loss was $6.9 \pm 1.7 \%$ of their original body weight. Multiple regression analysis showed that at the end of the 13-week intervention, CLA did not have an effect on body weight regain. Feelings of fullness and satiety were increased and feelings of hunger were decreased after 13 weeks intervention by CLA compared to placebo, independently of \% body weight regain. However, El measured at breakfast was not affected by CLA.

Conclusion: appetite (hunger, satiety and fullness) was favorably, dose-independently affected by a 13-week consumption of 1.8 or $3.6 \mathrm{~g} \mathrm{CLA} / \mathrm{d}$. This did not result in a lower energy intake at breakfast or an improved body weight maintenance after weight loss.

\section{ACKNOWLEDGEMENTS}

This study was supported by Novartis Consumer Health Ltd., Nyon, Switzerland. We want to thank Tonalin Hovdebygda, Norway for providing the CLA and placebo capsules and Winyee To for her assistance. 
onjugated linoleic acid (CLA) refers to a group of positional and geometrical isomers of linoleic acid containing conjugated double bonds. It is naturally found in beef, milk and milk products since it is produced by rumen bacteria from linoleic acid $^{1.2}$

Numerous physiological effects in relation to body weight regulation have been attributed to CLA ingestion in animals. In different animal models, consumption of CLA has been shown to increase lean body mass ${ }^{3-6}$ and to reduce body fat mass ${ }^{3 \cdot 9}$. However, different effects in lean and obese rats have been observed ${ }^{10}$, that is CLA ingestion decreased fat mass in lean rats, whereas it caused an increase of fat mass in obese rats. The results of studies on effects of CLA on body weight are inconsistent. Some investigators found a reduced body weight after a CLA diet ${ }^{4.7}$, whereas others found no effect ${ }^{3.5 .2 .11}$ or an increase in body weight ${ }^{11}$. Furthermore, CLA supplementation is associated with an increased energy expenditure ${ }^{7.9 .12}$. The results of studies on the effects of CLA on energy, intakes are inconsistent. Some studies found decreased energy intakes by CLA $^{5,11}$, whereas others observed no effect on food intake ${ }^{6.8-10}$.

Only a few human studies have been conducted to study the effect of CLA ingestion on body weight and/or fat mass. Even though fat mass ${ }^{13}$ and sagital abdominal diameter ${ }^{14}$ were lowered by CLA, it did not result in body weight loss ${ }^{13-18}$. In these studies, weight loss or fat mass loss was assessed. However, the effects of CLA supplementation might appear more clearly while subjects are in a state of weight (re)gain, since CLA reduces fat uptake into adipocytes ${ }^{3.4 .17}$, but does not enhance lipolysis ${ }^{16}$ and therefore it could block body fat gain instead of reducing body fat level. Blocking body fat gain during weight regain may lead to relatively more regain of fat-free mass. Since gain of fat-free mass is more costly than gain of fat mass ${ }^{19}$ this may lead to a relatively smaller weight regain. Only two studies have been investigating the effect of CLA supplementation on appetite ${ }^{13.20}$ and observed no effect. Moreover, no human study has investigated the effect of CLA ingestion on energy intake. It is known that intake of CLA decreases the uptake of fatty acids in adipocytes and enhances the $\beta$-oxidation in muscle cells. So, there might be an increased flux of fatty acids towards muscle cells and therefore a shift to fat oxidation. So, glycogen will be spared, which in turn may serve as a satiety signal as has been proposed by different researchers ${ }^{21-23}$.

The aim of this study was to determine the effect of two dosages of CLA after weight loss on body weight maintenance, appetite profile and energy intake at breakfast. We hypothesized that CLA supplementation might affect appetite profile, that is reduced feeling of hunger and increased feelings of satiety and fullness, which in turn might lower energy intake and therefore improve weight maintenance.

\section{RESEARCH METHODS AND PROCEDURES}

\section{Subjects}

A total of 60 overweight men and women (body mass index (BMI) between 25 and 30 $\mathrm{kg} / \mathrm{m}^{2}$ ) aged between 20 and 50 y were recruited by advertisements in local newspapers and participated in this study. Selection was based upon being healthy and at least 3 months weight stable prior to the study, no use of any medication known to affect body weight and/or appetite, being non-smoking, and at most moderate alcohol-users ( $\max 10$ glasses/week). Subjects had to be unrestrained eaters. The degree of dietary restraint was determined by the Three-Factor Eating Questionnaire (TFEQ, score F1s9) ${ }^{2425}$ and by the Herman/Polivy restraint questionnaire (HP, scores15) ${ }^{26}$. Height (m) was measured using a wall-mounted stadiometer (Seca, model 220, Hamburg. Germany). Body weight (in underwear) was measured on a digital balance (Seca, model 707 . Hamburg, Germany; weighing accuracy of $0.1 \mathrm{~kg}$ ) in fasted state and after voiding the bladder. BMI was calculated as weight/(height ${ }^{2}$ ).

In all, 54 subjects completed the study. Six subjects dropped out for several reasons: one subject for illness not related to the treatment, one subject because of use of medication and 4 subjects because of motivation reasons. 27 subjects (15 women and 
12 men) completed the low-dosage study and 27 (13 women and 14 men) subjects completed the high-dosage study. Table 1 shows the baseline characteristics of the subjects. There were no significant differences in the characteristics between CLA and placebo groups at baseline.

All subjects gave their written informed consent. The study was approved by the Medical Ethics Committee of Maastricht University.

\section{Intervention protocol}

The study had a randomized placebo-controlled and double-blind design.

Before the intervention period, all subjects were submitted to a 3-week very-low-calorie diet (VLCD, 2.1 MJ; Modifast, Novartis). Subjects replaced their habitual breakfast, lunch and dinner by 3 meals of Modifast. No snacks, except fruit or salad (no dressing) were allowed. Drinks consisting of coffee, tea (without milk and sugar) and water, were allowed ad libitum. After the three weeks on a VLCD, subjects started the intervention period. At that moment, subjects were randomly assigned to the low-dosage study or to the high-dosage study. In the low-dosage study, subjects were randomized to $1.8 \mathrm{~g}$ CLA (Tonalin ${ }^{\mathrm{TM}}$ CLA $75 \%$ TG, Tonalin ${ }^{\mathrm{TM}}$, Hovdebygda, Norway) (3 capsules/d with $600 \mathrm{mg}$ CLA/capsule, $n=14$ ) or $1.8 \mathrm{~g}$ placebo (oleic acid, 3 capsules $/ \mathrm{d}$ with $600 \mathrm{mg}$ oleic acid/capsule, $n=13$ ) to be taken before breakfast, lunch and dinner. In the high-dosage study, subjects were randomized to $3.6 \mathrm{~g}$ CLA (6 capsules/d with $600 \mathrm{mg} \mathrm{CLA} /$ capsule, $\mathrm{n}=13$ ) or $3.6 \mathrm{~g}$ placebo (oleic acid, 6 capsules/d with $600 \mathrm{mg}$ oleic acid/capsule, $n=14$ ) to be taken before breakfast, lunch and dinner. Additionally, all subjects of the high-dosage study were required to replace their habitual lunch by one meal of a protein-rich, lowenergy supplement $(0.7 \mathrm{MJ}, 17.3 \mathrm{~g}$ protein) to prevent possible decrease of protein intake in case of decreased food intake. Since CLA appears to enhance fat-free mass ${ }^{3-}$ ${ }^{6.13}$, an optimal supply of amino acids is desirable.

The duration of the intervention period in both studies was 13 weeks.

\section{Test protocol}

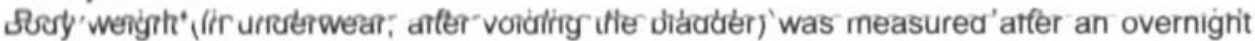
fast before the VLCD (week -3), before (week 0), during (weeks 3 and 8 ) and at the end of the treatment period (week 13). During three of the visits (week -3, 0 and 13), a ThreeFactor Eating Questionnaire (TFEQ) ${ }^{24}$ and a questionnaire for parameters of appetite were completed. The appetite profile was measured with the following questions using an anchored $100 \mathrm{~mm}$ visual analogue scale: 'How full are you?', 'How hungry are you?', and How satiated are you?'. Those questions were anchored with 'not at all' 'extremely'.

Energy intake during breakfast after an overnight fast, after ingesting the usual dosage CLA or placebo, was measured using the Universal Eating Monitor ${ }^{27}$ on week $-3,0$ and 13. At week -3 , subjects could choose between fruit yogurt $(3.2 \mathrm{~kJ} / \mathrm{g})$ and yogurt with cereals $(5.35 \mathrm{~kJ} / \mathrm{g})$. The breakfast they had chosen had to be consumed also at week 0 and 13.

Table 1: baseline characteristics of the subjects in the conjugated linoleic acid (CLA) and placebo (oleic acid) supplementation group

\begin{tabular}{lcc}
\hline & CLA $(n=27)$ & Placebo $(n=27)$ \\
\hline age $(y)$ & $39 \pm 7$ & $37 \pm 9$ \\
body weight $(\mathrm{kg})$ & $85.1 \pm 8.0$ & $82.7 \pm 9.0$ \\
BMI $\left(\mathrm{kg} / \mathrm{m}^{2}\right)$ & $27.8 \pm 1.6$ & $27.8 \pm 1.4$ \\
Body fat $(\%)$ & $31.3 \pm 7.5$ & $33.0 \pm 7.0$ \\
$\mathrm{~F}^{1}$ & $5 \pm 3$ & $5 \pm 2$ \\
\hline
\end{tabular}

'Factor 1 (cognitive restraint) of the Three-Factor Eating Questionnaire ${ }^{24}$ 


\section{Tolerance}

Tolerance of the capsules was determined at the end of the intervention period using a questionnaire on the occurrence of gastrointestinal and other complaints and scored on a 5 -point scale ( $0=$ not at all, $1=$ little, $2=$ sometimes, $3=$ relatively much, $4=0$ ften).

\section{Statistics}

Differences between subjects of the CLA and placebo intervention groups for baseline characteristics were analyzed with an unpaired $t$-test (Statview SE Graphics ${ }^{\mathrm{M}}$ ).

Changes in body weight, feelings of hunger, satiety and fullness, energy intake at breakfast, and Factors 1-3 of the TFEQ from week -3 to week 0 were tested with a paired $t$-test (Statview SE Graphics ${ }^{\mathrm{TM}}$ ) for all subjects together.

The effect of CLA supplementation at week 13 for the dependent variables \%body weight regain, feelings of hunger, satiety and fullness, energy intake at breakfast, and Factor $1-3$ of the TFEQ were analyzed by linear multiple regression model with treatment $(0=$ placebo; $1=C L A)$, gender $(0=$ men; $1=$ women) and dosage $(0=L D, 1=H D)$ as independent variables. Furthermore, for the dependent variables energy intake at breakfast and the factors of TFEQ, the values at week -3 and 0 of those parameters were also included in the model as independent variables. For the dependent variables satiety, fullness and hunger, the values at week -3 and 0 of those parameters and $\%$ regain of body weight were included in the model as independent variables (SPSS Inc. Chicago, Illinois, USA).

A possible relationship between any of the parameters of appetite and energy intake at breakfast was tested with a simple linear regression (Statview SE Graphics ${ }^{\mathrm{m}}$ ).

The regression coefficient (RC) with $95 \%$ confidence interval $(\mathrm{CI})$ of the CLA intervention was calculated for each dependent variable. The level of significance is set at $p<0.05$. Data are presented as meanststandard deviations (SD).

\section{RESULTS}

\section{Tolerance}

The occurrence of adverse events remained low and was not different between CLA and placebo intervention (data not shown).

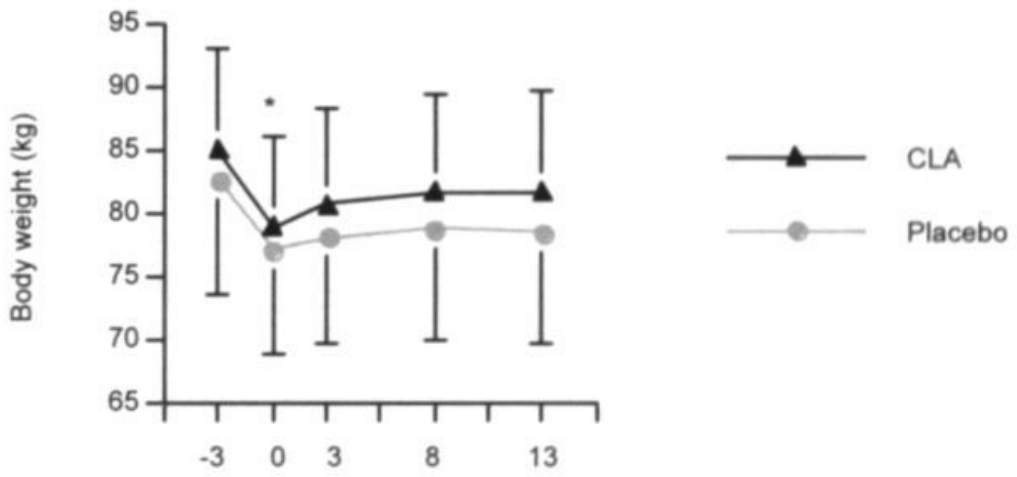

Week

Figure 1: body weight $(\mathrm{kg})$ of subjects before $\operatorname{VLCD}(-3)$, after VLCD and before intervention $(0)$ and at 3,8 and 13 weeks of intervention with $1.8 \mathrm{~g}$ or $3.6 \mathrm{~g}$ conjugated linoleic acid/d (CLA, $n=27$ ), and $1.8 \mathrm{~g}$ and $3.6 \mathrm{~g}$ placebo/d (oleic acid, $n=27$ ). The results are presented as CLA and placebo, with the low and high dosage combined."Repeated Measures ANOVA for all subjects together showed a significant decrease in body weight from week -3 to week 0 $(p<0.0001)$. Multiple regression showed that the body weight regain was not affected by CLA supplementation (Regression Coefficient: 13.9 (-16.1 to 44.0), ns) 


\section{Body weight}

As a consequence of the VLCD, body weight at week 0 was significantly lowered (figure 1). The mean weight loss was $6.9 \pm 1.7 \%$ from the original body weight.

After 13 weeks intervention, the subjects of the CLA group had a regain of $40.2 \pm 69.3 \%$ while the placebo group had a regain of $24.8 \pm 33.6 \%$ (ns). Thus, body weight regain during the intervention (week 13) was not influenced by CLA (RC 13.9; Cl -16.1 to 44.0, $\mathrm{ns}$ ). Moreover, both independent variables dosage (RC $-11.5 ; \mathrm{Cl}-41.5$ to $18.6, \mathrm{~ns}$ ) and gender (RC $-14.4 ; \mathrm{Cl}-44.5$ to $15.7, \mathrm{~ns}$ ) did not affect body weight regain.

\section{Appetite profile}

The feeling of fullness (figure 2) and satiety (figure 3 ) remained unchanged after the VLCD compared to before. CLA intake increased the feelings of fullness (RC 14.9; Cl 3.46 to $26.4, p<0.05$ ) as well as satiety ( $R C 12.2 ; \mathrm{Cl} 0.9$ to $25.3, p<0.05$ ) during the intervention. The rise in feelings of fullness was independently of \% body weight regain (RC $0.01 ; \mathrm{Cl}-0.13$ to 0.13 , ns), dosage (RC $-1.7 ; \mathrm{Cl}-13.2$ to 9.8 , ns) and gender (RC $0.2 ; \mathrm{Cl}-11.2$ to $11.6, \mathrm{~ns})$. Also the increase in feelings of satiety was independently of $\%$ body weight regain ( $\mathrm{RC}-0.01 ; \mathrm{Cl}-0.14$ to 0.13 , ns), dosage ( $\mathrm{RC}-6.5 ; \mathrm{Cl}-17.8$ to $4.9, \mathrm{~ns}$ ) and gender ( $\mathrm{RC}-3.6 ; \mathrm{Cl}-14.6$ to $7.3, \mathrm{~ns}$ ).

The hunger level (figure 4) was increased after the VLCD compared to before $(p<0.001)$. The feeling of hunger was significantly decreased by CLA (RC $-14.0 ;-25.0$ to $-3, p<0.05$ ) during the intervention independently of \% body weight regain (RC $-0.05 ; \mathrm{Cl}-0.2$ to 0.08 , $\mathrm{ns}$ ), dosage (RC $7.7 ;-3.3$ to $18.7, \mathrm{~ns}$ ) or gender (RC $-5.1 ;-16.1$ to $5.8, \mathrm{~ns}$ ).

\section{Energy intake}

The energy intake at breakfast after VLCD was similar to before the diet $(1.2 \pm 0.6$ and $1.1 \pm 0.6 \mathrm{MJ}$, respectively; ns). CLA used for 13 weeks as well as just before the testbreakfast, did not affect energy intake at breakfast at week 13 (CLA: $1.2 \pm 0.6$ and placebo $1.1 \pm 0.6 \mathrm{MJ}$; RC: $-0.07 ; \mathrm{Cl}:-0.3$ to $0.1, \mathrm{~ns}$ ). Moreover, dosage (RC $0.1 ; \mathrm{Cl}-0.1$ to 0.3 , ns) did not affect the energy intake at breakfast although a gender effect was

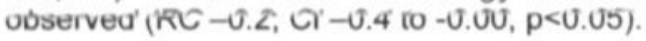

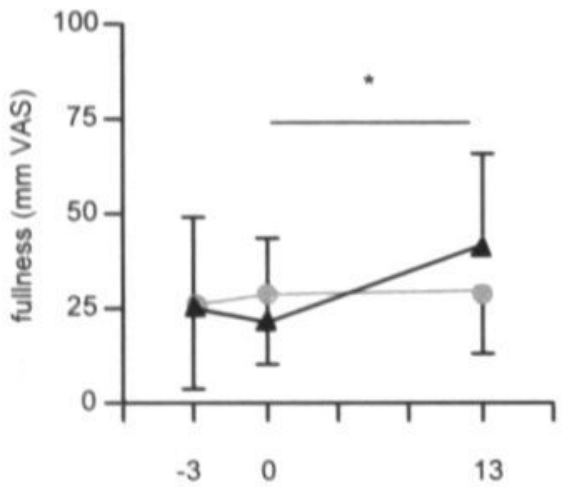

Week

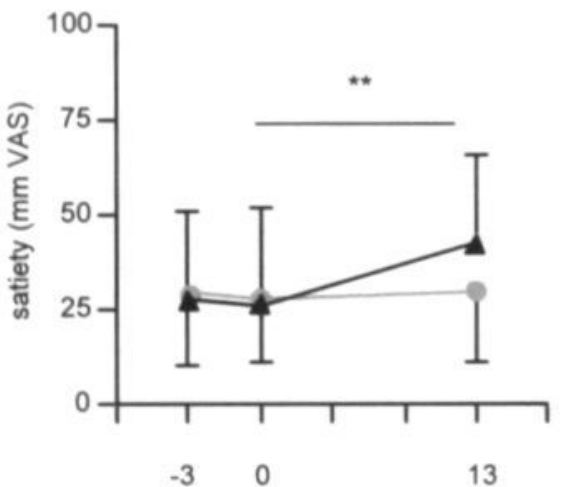

Week

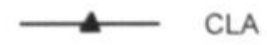

Plac

Figure 2 (left) and 3 (right): feelings of fullness (figure 2) and satiety (figure 3 ) measured with an anchored $100 \mathrm{~mm}$ visual analogue scale (VAS) before VLCD (-3) after VLCD and before intervention $(0)$ and at 13 weeks of intervention with 1.8 or $3.6 \mathrm{~g}$ conjugated linoleic acid/d $(C L A, n=27$ ) and 1.8 or $3.6 \mathrm{~g}$ placebo/d (oleic acid, $n=27$ ). The results are presented as CLA and placebo, with the low and high dosage combined." Multiple regression showed that the feeling of fullness during intervention was increased by CLA compared to placebo (Regression coefficient 14.9 (3.46 to 26.4$)$, p<0.05). "* Multiple regression showed that the feeling of satiety during intervention was increased by CLA compared to placebo (Regression coefficient 12.2 (0.9 to 23.5), $p<0.05)$. 


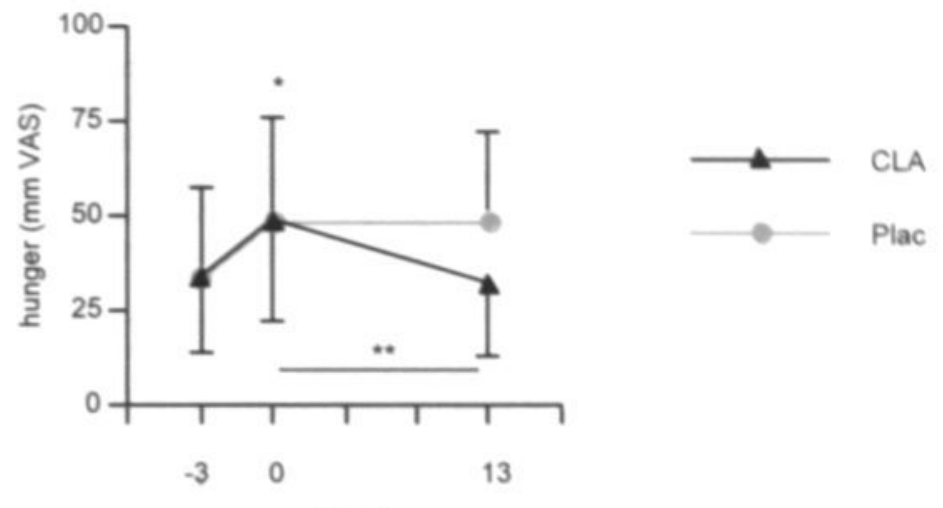

Week

Figure 4: feelings of hunger measured with an anchored $100 \mathrm{~mm}$ visual analogue scale (VAS) before VLCD $(-3)$ after VLCD and before intervention $(0)$ and at 13 weeks of intervention with 1.8 or $3.6 \mathrm{~g}$ conjugated linoleic acid/d (CLA, $n=27$ ) and 1.8 or $3.6 \mathrm{~g}$ placebo/d (oleic acid, $n=27$ ). The results are presented as CLA and placebo, with the low and high dosage combined.

"Repeated Measures ANOVA for all subjects together showed a significant increase in feelings of hunger from week -3 to week $0(p<0.001)$.

*Multiple regression showed that the feeling of hunger during intervention was decreased by CLA compared to placebo (Regression coefficient $-14.0(-25.0$ to -3$), p<0.05$ ).

There was no relationship between any of the appetite scores and energy intake at breakfast at week -3 and 0 . For the CLA as well as for the placebo groups, no relation between any parameters of appetite and energy intake at breakfast at week 13 was observed. Furthermore, there was no relationship between change in any of the appetite scores from week 0 to 13 and change in energy intakes from week 0 to 13 for the CLA groups and placebo groups.

Table 2: cognitive restraint (Factor 1 of the TFEQ'), disinhibition (Factor 2 of the TFEQ') and general hunger (Factor 3 of the TFEQ') before the VLCD $(-3)$, after VLCD but before intervention (week 0 ) and at the end of intervention (week 13) with conjugated linoleic acid (CLA, $n=27$ ) or placebo (oleic acid, $n=27$ )

\begin{tabular}{lccccc}
\hline & CLA & Placebo & CLA $^{2}$ & dose $^{2}$ & gender $^{2}$ \\
\hline Factor 1 (-3) & $5.0 \pm 2.8$ & $4.9 \pm 2.1$ & & \\
Factor 1 (0) & $5.2 \pm 2.7$ & $6.5 \pm 2.7$ & & \\
Factor 1 (13) & $5.6 \pm 2.8$ & $6.9 \pm 3.0$ & $-0.6(-2.0-0.9)$ & $0.7(-0.7-2.1)$ & $-0.1(-1.5-1.3)$ \\
Factor 2 (-3) & $5.2 \pm 2.6$ & $5.6 \pm 2.4$ & & \\
Factor 2 (0) & $4.7 \pm 3.0$ & $4.5 \pm 2.4$ & & \\
Factor 2 (13) & $5.4 \pm 3.0$ & $4.6 \pm 2.7$ & $1.1(-0.0-2.1)$ & $-0.4(-1.7-0.8)$ & $-0.1(-1.2-0.9)$ \\
Factor 3 (-3) & $4.0 \pm 3.1$ & $3.9 \pm 2.8$ & & \\
Factor 3 (0) & $3.1 \pm 2.8$ & $3.3 \pm 3.3$ & & \\
Factor 3 (13) & $3.2 \pm 2.4$ & $3.2 \pm 2.9$ & $0.1(-1.1-1.3)$ & $0.6(-0.6-1.8)$ & $-0.1(-1.4-1.2)$ \\
\hline
\end{tabular}

'Three-Factor Eating Questionnaire ${ }^{24}$

${ }^{2}$ Multiple regression analysis: Regression Coefficient (Confidence interval) 


\section{Three-factor eating questionnaire}

All subjects were unrestrained eaters measured with Factor 1 of the TFEQ (cognitive restraint) at the start of the study (table 1). Cognitive restraint was significantly increased by VLCD $(p<0.01)$, disinhibition (Factor 2 of TFEQ) significantly decreased $(p<0.01)$, while general hunger (Factor 3 of TFEQ) remained unchanged after the VLCD compared to before. Cognitive restraint, disinhibition and general hunger were not affected by the CLA intervention or by dosage or gender (table 2).

\section{DISCUSSION}

In the present study, the effect of CLA or placebo (oleic acid) after a 3-week VLCD on body weight maintenance, parameters of appetite and energy intake was investigated. It was shown that a 13-week supplementation with CLA after body weight loss did not affect body weight maintenance, but favorably altered the parameters of appetite compared to placebo independently of \%body weight regain. We observed that feelings of fullness and satiety were increased by CLA ingestion compared to placebo, while the feeling of hunger was decreased during the weight maintenance period. However, this did not result in a lower energy intake measured at breakfast as well as overall weight maintenance.

Previously, in two studies the effects of CLA on appetite was investigated, although both did not observe an effect compared to placebo. The mechanisms by which CLA might affect appetite as reported here are speculative. It is possible that the post-ingestive effects of CLA could have modulated satiety since it is known from in vitro studies that CLA reduces lipid uptake by adipose cells because of an effect on lipoprotein lipase . $^{3.4}$ and stearoyl-COA desaturase ${ }^{17,18}$. As a result of a decreased uptake of fatty acids by adipocytes, there might be an increased flux of fatty acids to muscle cells. When the use of fatty acids is increased, less glucose is needed for combustion. So, glycogen will be spared which in turn has been proposed to serve as a satiety signal ${ }^{1-23}$. However, glycogen stores were not measured in the present study since a precise measurement of glycogen stores is not feasible in this kind of study.

Even though appetite was affected by CLA supplementation, this did not result in a decreased energy intake during breakfast. Also $24 \mathrm{~h}$ energy intake seems not to be reduced, since body weight was similar in the CLA and placebo groups. Results on the effect of CLA on food intake in animals are controversial. In some studies, a lowered food intake by CLA has been observed ${ }^{5,7.11}$, whereas in others CLA supplementation did not affect food intake ${ }^{6.8-10}$. In our study, the appetite scores in the fasting state were not related to the energy consumed at breakfast. This implies that the improved parameters of appetite (lowered feeling of hunger, higher feeling of satiety and fullness) by CLA supplementation were not strong enough to lower energy intake compared to placebo. In fact, a relationship between appetite parameters and subsequent energy intake is not always present ${ }^{28.29}$.

In this study. CLA did not enhance body weight maintenance more than placebo. In animals, especially mice studies, the effects of CLA on body weight ${ }^{3-7.9-11}$ have been studied extensively. In humans, however, only a few studies have been conducted to study the effect of CLA supplementation and no study observed an effect on body weight. Blankson et al. ${ }^{13}$ found that after 12 weeks, $1.7,3.4,5.1$ or $6.8 \mathrm{~g} \mathrm{CLA} / \mathrm{d}$ did not affect body weight in overweight and obese subjects, although fat mass decreased with 1.7 and $5.1 \mathrm{~g} \mathrm{CLA} / \mathrm{d}$. Also in a study from Berven et al. ${ }^{15}$ body weight remained unchanged. They showed that a daily consumption of $3.4 \mathrm{~g} \mathrm{CLA} / \mathrm{d}$ had no more effect on body weight, BMI or fat mass than placebo in obese subjects. Also, Zambell et al. ${ }^{16}$ observed no effect of $3 \mathrm{~g} \mathrm{CLA} / \mathrm{d}$ on body weight or composition. Next to body weight and fat mass, Risérus et al. ${ }^{94}$ studied the effect of $4.2 \mathrm{~g} \mathrm{CLA} / \mathrm{d}$ on abdominal obesity. Even though sagital abdominal diameter in obese men was lowered, body weight and fat mass were not affected by CLA. Owing to the action of CLA, i.e. lowering fat uptake by adipose cells because of a lower lipoprotein lipase activity, it seemed to be of interest to investigate the effects of CLA on weight (re)gain. However, neither 1.8 nor $3.6 \mathrm{~g} \mathrm{CLA} / \mathrm{d}$ 
improved body weight maintenance more than placebo, even when protein intake was supported as was done in the high-dosage study in the CLA as well as in the placebo group. However, CLA supplementation caused changes in body composition, that is, increase of fat-free mass ${ }^{30}$.

Differences between humans and animals for the effect of CLA on body composition might be due to several factors, for example dosage or length of intervention, although a recent publication suggest that differences in metabolic rate might be of more importance than other factors ${ }^{31}$.

In the present study, subjects received either 1.8 or $3.6 \mathrm{~g} \mathrm{CLA} / \mathrm{d}$ while in previous studies doses between 1.7-6.8 $\mathrm{g}$ CLA/d were used. A dosage as low as $1.7 \mathrm{~g} \mathrm{CLA} / \mathrm{d}$ was effective in lowering fat mass ${ }^{13}$, whereas in the present study a dose of $1.8 \mathrm{~g}$ CLA/d was effective in improving the appetite profile, but not energy intake at breakfast. Since the habitual intake of CLA was assessed between 0.1 and $0.3 \mathrm{~g} / \mathrm{d}^{32}$, even a high intake of milk, milk products or beef by a subject will most likely not have confounded the results of the present study.

There is growing evidence that the different isomers of CLA $(c 9, t 11$ and $t 10, c 12)$ might have different effects ${ }^{4,17,18.33}$. The $c 9, t 11$ isomer is the principal dietary form of CLA (80$90 \%$ ) and seems to be the most active, because of its abundance and incorporation into membranes, but the $t 10, c 12$ isomer seems to be the most important in energy metabolism ${ }^{18}$. In our study, a mixture of equal amounts of both isomers was used, so the effects of this study could result from either or both isomers.

During the study, subjects completed three times a TFEQ to measure dietary restraint. At the start of the study, all subjects were unrestrained eaters measured with Factor 1 of the TFEQ, but dietary restraint increased by VLCD presumably since subjects are being forced to restrain eating. Disinhibition (Factor 2 of TFEQ) decreased after VLCD compared to before. A possible explanation for this decrease might be that disinhibited eating is removed by the study. Factor 3 (hunger) remained unchanged, although shortterm hunger feelings were increased after VLCD. The CLA and placebo interventions did not show to have an effect on any factor of the TFEQ. This implies that the effects observed are because of physiological effects rather than cognitive behaviour.

In the present study subjects of the high-dosage groups were asked to replace their habitual lunch by one meal of the VLCD to increase to protein supply. It has been shown that a single meal replacement can be a tool for weight management ${ }^{34}$, however this seems not to be the case in the present study. The increase in dietary restraint of the subjects of the low-dosage interventions compared to the high dosage interventions was similar. Furthermore, when the average increase in energy intake above energy requirement during the weight regain period was calculated, there were no differences between subjects of the low-dosage intervention, who did not replace their lunch and subjects of the high-dosage intervention, who replaced their lunch $(0.8$ and $0.5 \mathrm{MJ}$, respectively). This means that the impact of one meal replacement was not significantly present during the weight regain period of this study.

In summary, 13-week supplementation with 1.8 or $3.6 \mathrm{~g} \mathrm{CLA} / \mathrm{d}$ after a 3-week VLCD was not effective in reducing energy intake at breakfast or improving body weight maintenance compared to placebo (1.8 or $3.6 \mathrm{~g}$ oleic acid/d), but affected doseindependently parameters of appetite. CLA supplementation increased the feelings of fullness and satiety, and decreased the feeling of hunger.

\section{REFERENCES}

1 Kepler CR, WP Tucker, SB Tove. Biohydrogenation of unsaturated fatty acids. IV. Substrate specificity and inhibition of linoleate delta-12-cis, delta-11-trans-isomerase from Butyrivibrio fibrisolvens. J Biol Chem 1970; 245: 3612-3620

2 Kepler CR, WP Tucker, SB Tove. Biohydrogenation of unsaturated fatty acids. V. Stereospecificity of proton addition and mechanism of action of linoleic acid delta 12-cis, delta 11-trans-isomerase from Butyrivibrio fibrisolvens. J Biol Chem 1971; 246: 2765-2771

3 Park Y, KJ Albright, W Liu, JM Storkson, ME Cook, MW Pariza. Effect of conjugated linoleic acid on body composition in mice. Lipids 1997; 32:853-858 
4 Park Y, JM Storkson, KJ Albright, W Liu, MW Pariza. Evidence that the trans-10,cis-12 isomer of conjugated linoleic acid induces body composition changes in mice. Lipids 1999; 34: 235 241

5 Park Y, KJ Albright, JM Storkson, W Liu, ME Cook, MW Pariza. Changes in body composition in mice during feeding and withdrawal of conjugated linoleic acid. Lipids 1999; 34: 243-248

6 DeLany JP, F Blohm, AA Truett, JA Scimeca, DB West. Conjugated linoleic acid rapidly reduces body fat content in mice without affecting energy intake. Am J Physiol 1999; 276: R1172-R1179

7 West DB, JP Delany, PM Camet, FY Blohm, AA Truett, J Scimeca. Effects of conjugated linoleic acid on body fat and energy metabolism in the mouse. Am J Physiol 1998; 275: R667. R672

8 Azain MJ, DB Hausman, MB Sisk, WP Flatt, DE Jewell. Dietary conjugated linoleic acid reduces rat adipose tissue cell size rather than cell number. J Nutr 2000; 130: 1548-1554

9 West DB, FY Blohm, AA Truett, JP DeLany. Conjugated linoleic acid persistently increases total energy expenditure in AKR/J mice without increasing uncoupling protein gene expression. $J$ Nutr 2000; 130: 2471-2477

10 Sisk MB, DB Hausman, RJ Martin, MJ Azain. Dietary conjugated linoleic acid reduces adiposity in lean but not obese Zucker rats. J Nutr 2001; 131: 1668-1674

11 Miner JL, CA Cederberg, MK Nielsen, X Chen, CA Baile. Conjugated linoleic acid (CLA), body fat, and apoptosis. Obes Res 2001: 9: 129-134

12 Ohnuki K, S Haramizu, K Oki, K Ishihara, T Fushiki. A single oral administration of conjugated linoleic acid enhanced energy metabolism in mice. Lipids 2001; 36: 583-587

13 Blankson H, JA Stakkestad, H Fagertun, E Thom, J Wadstein, O Gudmundsen. Conjugated linoleic acid reduces body fat mass in overweight and obese humans. J Nutr 2000; 130: 29432948

14 Riserus U, L Berglund, B Vessby. Conjugated linoleic acid (CLA) reduced abdominal adipose tissue in obese middle-aged men with signs of the metabolic syndrome: a randomised controlled trial. Int J Obes Relat Metab Disord 2001; 25: 1129-1135

15 Berven G, A Bye, O Hals, H Blankson, H Fagertun, E Thom, J Wadstein, O Gudmundsen. Safety of conjugated linoleic acid (CLA) in overweight and obese human volunteers. Eur $J$ Lipid Sci Technol. 2000; 102: 155-462

16 Zambell KL, NL Keim, MD Van Loan, B Gale, P Benito, DS Kelley, GJ Nelson. Conjugated linoleic acid supplementation in humans: effects on body composition and energy expenditure. Lipids 2000; 35: 777-782.

17 Choi Y, YC Kim, YB Han, Y Park, MW Pariza, JM Ntambi. The trans-10,cis-12 isomer of conjugated linoleic acid downregulates stearoyl-CoA desaturase 1 gene expression in 3T3-L1 adipocytes. J Nutr 2000; 130: 1920-1924

18 Pariza MW, Y Park, ME Cook. The biologically active isomers of conjugated linoleic acid. Prog Lipid Res 2001; 40: 283-298

19 Stock MJ. Gluttony and thermogenesis revisited. Int J Obes Relat Metab Disord 1999; 23: 1105-1107

20 Medina EA, WF Horn, NL Keim, PJ Havel, P Benito, DS Kelley, GJ Nelson, KL Erickson. Conjugated linoleic acid supplementation in humans: effects on circulating leptin concentrations and appetite. Lipids 2000; $35: 783-788$

21 Westerterp-Plantenga MS, EM Kovacs. The effect of (-)-hydroxycitrate on energy intake and satiety in overweight humans. Int J Obes Relat Metab Disord 2002; 26: 870-872

22 Melanson KJ, MS Westerterp-Plantenga, LA Campfield, WHM Saris. Appetite and blood glucose profiles in humans after glycogen-depleting exercise. J Appl Physiol 1999; 87: 947954

23 Flatt JP. Glycogen levels and obesity. Int J Obes Relat Metab Disord 1996; 20 Suppl 2: S1-11

24 Stunkard AJ, S Messick. The three-factor eating questionnaire to measure dietary restraint, disinhibition, and hunger. J Psychosom Res 1985; 29: 71-83

25 Westerterp-Plantenga MS, CRT Verwegen. The appetizing effect of an aperitif in overweight and normal-weight humans. Am J Clin Nutr 1999; 69: 205-212

26 Herman CP, J Polivy. Restrained Eating. Saunders, W.B.: Philadelphia, 1980

27 Westerterp-Plantenga MS. Eating behavior in humans, characterized by cumulative food intake curves--a review. Neurosci Biobehav Rev 2000; 24: 239-248

28 Mattes RD. Hunger ratings are not a valid proxy measure of reported food intake in humans. Appetite 1990; 15: 103-113

29 Westerterp-Plantenga MS, WH Saris, CJ Hukshorn, LA Campfield. Effects of weekly administration of pegylated recombinant human $\mathrm{OB}$ protein on appetite profile and energy metabolism in obese men. Am J Clin Nutr 2001; 74: 426-434 
30 Kamphuis MMJW, MPGM Lejeune, WHM Saris, MS Westerterp-Plantenga. Effect of Conjugated Linoleic Acid supplementation after weight loss on body weight regain, body composition, and resting metabolic rate in overweight subjects. Int J Obes Relat Metab Disord in press

31 Terpstra AH. Differences between humans and mice in efficacy of the body fat lowering effect of conjugated linoleic acid: role of metabolic rate. J Nutr 2001; 131: 2067-2068

32 Ens JG, DW Ma, KS Cole, C.J Field, MT Clandinin. An assessment of c9,t11 linoleic acid intake in a small group of young Canadians. Nutr Res 2001; 21: 955-960

33 Halvorsen YD, R Lea-Currie, C Geigerman, M McIntosh. 2000. Conjugated linoleic acid (CLA) attenuates human preadipocyte triglyceride (TG) content and lipogenesis. In NAASO meeting. Long Beach, USA: Obes Res. 121S

34 Ashley JM, ST St Jeor, S Perumean-Chaney, J Schrage, V Bovee. Meal replacements in weight intervention. Obes Res 2001; 9 Suppl 4: 312S-320S 


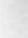




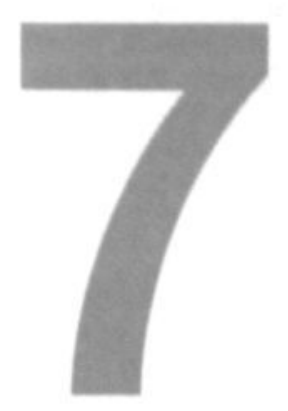

The effect of conjugated linoleic acid supplementation after weight loss on body weight regain, body

composition, and resting metabolic rate in overweight subjects

Marleen MJW Kamphuis

Manuela PGM Lejeune

Wim HM Saris

Margriet S Westerterp-Plantenga

International Journal of Obesity and Related Metabolic Disorders, in press 


\begin{abstract}
Objective: to study the effects of 13 weeks conjugated linoleic acid (CLA) supplementation in overweight subjects after weight loss on weight regain, body composition, resting metabolic rate, substrate oxidation and blood plasma parameters.

Design: this study had a double-blind, placebo-controlled randomized design. Subjects were first submitted to a very-low-calorie diet (VLCD $2.1 \mathrm{MJ} / \mathrm{d}$ ) for 3 weeks after which they started with the 13-week intervention period. They either received $1.8 \mathrm{~g} \mathrm{CLA}$ or placebo per day (low dosage, LD) or $3.6 \mathrm{~g} \mathrm{CLA}$ or placebo per day (high dosage, HD).

Subjects: a total of 26 men and 28 women (age $37.8 \pm 7.7$ y; body mass index $27.8 \pm 1.5$ $\mathrm{kg} / \mathrm{m}^{2}$ )

Measurements: Before VLCD ( $\mathrm{t}=-3)$, after VLCD but before CLA or placebo intervention $(t=0)$ and after 13 week CLA or placebo intervention $(t=13)$, body weight, body composition (hydrodensitometry and deuterium dilution), resting metabolic rate, substrate oxidation, physical activity and blood plasma parameters (glucose, insulin, triacylglycerol, free fatty acids, glycerol and $\beta$-hydroxy butyrate) were measured.

Results: the VLCD significantly lowered body weight $(6.9 \pm 1.7 \%)$, \%body fat, fat mass, fat-free mass, resting metabolic rate, respiratory quotient and plasma glucose, insulin, and triacylglycerol concentrations, while free fatty acids, glycerol and $\beta$-hydroxy butyrate concentrations were increased. Multiple regression analysis showed that at the end of the 13-week intervention, CLA did not affect \%body weight regain (CLA LD $47.9 \pm 88.2 \%$, CLA HD $27.4 \pm 29.8 \%$, Placebo LD $32.0 \pm 42.8 \%$, Placebo HD $22.5 \pm 37.9 \%$ ). The regain of fat-free mass was increased by CLA (LD $6.2 \pm 3.9$, HD $4.6 \pm 2.4 \%$ ) compared to placebo (LD $2.8 \pm 3.2 \%$, HD $3.4 \pm 3.6 \%$ ), independently of \%body weight regain and physical activity. As a consequence of an increased regain of fat-free mass by CLA, resting metabolic rate was increased by CLA (LD $12.0 \pm 11.4 \%$, HD $13.7 \pm 14.4 \%$ ) compared to placebo (LD $9.1 \pm 11.0 \%, \mathrm{HD} 8.6 \pm 8.5 \%$ ). Substrate oxidation and blood plasma parameters were not affected by CLA.

Concrision: in conclusion, the regain of fat-free mass was favorabily, dose-independently affected by a 13-week consumption of 1.8 or $3.6 \mathrm{~g} \mathrm{CLA} / \mathrm{d}$ and consequently increased resting metabolic rate. However, it did not result in improved body weight maintenance after weight loss.
\end{abstract}

\title{
ACKNOWLEDGEMENTS
}

This study was supported by Novartis Consumer Health Ltd., Nyon, Switzerland. We want to thank Tonalin, Hovdebygda, Norway for providing the CLA and placebo capsules and Winyee To for her assistance. 


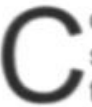

onjugated linoleic acid (CLA) is naturally found in beef, milk and milk products since it is an intermediate in the biohydrogenation of linoleic acid that occurs in the rumen by bacteria ${ }^{1.2}$. CLA refers to a group of positional and geometrical isomers of linoleic acid containing conjugated double bonds. The natural form is predominantly the cis-9, trans-11 isomer.

Numerous physiological effects in relation to body weight control have been attributed to CLA in animals. In different animal models, CLA has been shown to reduce body fat ${ }^{3-10}$ and to increase lean body mass ${ }^{3.5-7}$. However, effects on body weight are controversial. Some investigators found reduced body weight after a CLA diet ${ }^{25.7}$, whereas others found no effect ${ }^{3.6 .9-11}$ or an increase in body weight ${ }^{11}$. Furthermore, CLA intake has been associated with an increased energy expenditure 4.12 . Only a few human studies have been conducted to study the effect of CLA on body weight, body mass index (BMI) and/or fat mass. Even though fat mass ${ }^{13}, 1^{14}$ and sagital abdominal diameter ${ }^{15}$ were lowered by CLA, it did not result in body weight loss ${ }^{13-18}$. These studies assessed weight loss or loss of fat mass. However, the effects of CLA might appear more clearly while subjects are in a state of weight (re)gain, since CLA reduces fat uptake into adipocytes by lowering the lipoprotein lipase activity ${ }^{3.5 .19}$ as well as stearoyl-CoA desaturase ${ }^{3.19}$, rather than enhancing lipolysis ${ }^{20}$ and therefore it could block body fat gain instead of reducing body fat level. At the time of the beginning of the present study, the effect of CLA on substrate oxidation and resting metabolic rate was not investigated in humans. The aim of this study was to investigate the effect of two dosages of CLA after weight loss on body weight maintenance, substrate oxidation and resting metabolic rate. We hypothesized that CLA might affect body composition, i.e. reduce regain of body fat mass and enhance regain of fat-free mass, which in turn might affect resting metabolic rate and therefore improve weight maintenance.

\section{MATERIAL AND METHODS}

\section{Subjects}

In all, 60 overweight men and women (BMI between 25 and $30 \mathrm{~kg} / \mathrm{m}^{2}$ ) aged between 20 and 50 years were recruited by advertisements in local newspapers and participated in this study. Selection was based upon being healthy and at least 3 months weight stable prior to the study, no use any medication known to affect body weight and/or appetite, being non-smoking, and at most moderate alcohol-users (max 10 glasses/week). Subjects had to be unrestrained eaters. The degree of dietary restraint was determined by the Three-Factor Eating Questionnaire (TFEQ, score Factor 1, i.e. cognitive restraint $\leq 9)^{21.22}$ and by the Herman/Polivy restraint questionnaire (HP, scores 15$)^{23}$. Height was measured using a wall-mounted stadiometer (Seca, model 220, Hamburg. Germany). Body weight (in underwear) was measured on a digital balance (Seca, model 707. Hamburg, Germany; weighing accuracy of $0.1 \mathrm{~kg}$ ) in fasted state and after voiding their bladder. Body mass index (BMI) was calculated as weight/(height ${ }^{2}$ ). A total of 54 subjects completed the study. Six subjects dropped out for several reasons: one subjects for illness not related to the treatment, one subject because of use of medication and 4 subjects because of motivation reasons. In all, 27 subjects ( 15 women and 12 men) completed the low-dosage study (LD) and 27 (13 women and 14 men) subjects completed the high-dosage study (HD). Both studies were run concurrently.

All subjects gave their written informed consent. The study was approved by the Medical Ethics Committee of Maastricht University.

\section{Intervention protocol}

The study had a randomized placebo-controlled and double-blind design.

Before the intervention period, all subjects were submitted to a 3-week very-low-caloriediet (VLCD, 2.1 MJ; Modifast, Novartis). After the three weeks on a VLCD, subjects started the intervention period. In order to achieve equi-caloric supplementation subjects were randomized to study I (LD) or study II (HD). In study I, subjects were randomized to $1.8 \mathrm{~g}$ CLA (Tonalin ${ }^{\mathrm{T} M}$ CLA $75 \%$ TG. Tonalin ${ }^{\mathrm{TM}}$. Hovdebygda, Norway) (3 capsules/d with 
$600 \mathrm{mg}$ CLA/capsule, $\mathrm{n}=14$ ) or $1.8 \mathrm{~g}$ placebo (oleic acid, 3 capsules/d with $600 \mathrm{mg}$ oleic acid/capsule, $n=13$ ) to be taken before breakfast, lunch and dinner. In study II, subjects were randomized to $3.6 \mathrm{~g}$ CLA (6 capsules/d with $600 \mathrm{mg}$ CLA/capsule, $\mathrm{n=13}$ ) or $3.6 \mathrm{~g}$ placebo (oleic acid, 6 capsules/d with $600 \mathrm{mg}$ oleic acid/capsule, $n=14$ ) to be taken before breakfast, lunch and dinner. The duration of the intervention period in both studies was 13 weeks.

\section{Test protocol}

Before the VLCD (week -3), after VLCD but before intervention (week 0), during (weeks 3 and 8 ) and at the end of the intervention period (week 13), subjects came after an overnight fast to the university. On each visit body weight was measured. A fasting blood sample was taken and body composition, resting metabolic rate, substrate oxidation as respiratory quotient, and physical activity were measured on week $-3,0$ and 13 .

Body weight (in underwear or swimming clothes) was measured on a digital balance (Seca, model 707, Hamburg. Germany; weighing accuracy of $0.1 \mathrm{~kg}$ ). Subjects were in fasted state and voided their bladder before measuring. Height was measured to the nearest 0.001 meter using a wall-mounted stadiometer (SECA, Hamburg); BMI was calculated as body weight $(\mathrm{kg})$ divided by height $(\mathrm{m})$ squared. Body composition was determined by hydrodensitometry and deuterium dilution $\left({ }^{2} \mathrm{H}_{2} \mathrm{O}\right)$ technique ${ }^{24}$ and was calculated using the combined equation of $\mathrm{Siri}^{25}$. Whole body density was determined by underwater weighing with simultaneously assessment of long volume residual with the helium dilution technique (Volugraph 2000, Mijnhardt, the Netherlands). The dilution of the deuterium isotope is a measure for total body water ${ }^{26}$. Subjects were asked to collect a urine sample in the evening just before drinking a weighed amount of deuteriumenriched water solution. After ingestion of the deuterium solution no further fluid or food consumption was permitted. Ten hours after ingestion of the deuterium solution a second urine sample (second voiding) was collected. Deuterium concentration in the urine samples was measured using an isotope ratio mass spectrometer (Micromass Optima, Manchester. UK). Total bogv. water , was obtained hbv dividing the measured deuterium dilution space by $1.04^{24}$. Body composition was calculated from the 3-component model by $\mathrm{Siri}^{25}$. A total of 10 subjects did not undergo underwater weighing, so body composition was determined only with deuterium dilution.

Resting metabolic rate and respiratory quotient were measured after an overnight fast for at least $30 \mathrm{~min}$. Oxygen consumption and carbon dioxide production were measured using a computerized, open-circuit, ventilated hood system. Expired gases were analyzed using a paramagnetic oxygen analyzer (Servomex, Type 500A, Crowborough Sussex, UK) and an infrared carbon dioxide analyzer (Servomex, Type 12-X1). The system was similar to the analysis system for the respiration chambers described before $^{27}$. Calculation of resting metabolic rate was based upon the equation of Weir ${ }^{28}$. Respiratory quotient was calculated as carbon dioxide production divided by oxygen consumption.

In order to distinguish a possible effect of CLA on fat-free mass from a possible increased physical activity effect, objective assessment of physical activity was obtained using the Computer Science and Applications Inc. (CSA) activity monitor (model 7164). CSA is a small and light ( $5 \times 4 \times 1.5 \mathrm{~cm}, 43$ grams) uni-axial accelerometer that is designed to detect normal body movements. Owing to limiting problems, only subjects of the HDgroup were asked to wear the CSA for 1 week at the beginning of the VLCD (week -3), during the first week of intervention (week 1) and during the last week of intervention (week 13). The monitor was held in place by an elastic belt at the lower back, i.e. as close as possible to the center of gravity. Subjects were instructed to put on the CSA monitor as quickly as possible after waking up and to put it off before going to bed. Also it could not be worn during water activities. The same monitor was used for each subject on each test occasion, and after each testing session the activity monitor was immediately removed and data downloaded.

The blood samples were mixed with EDTA to prevent clotting. Plasma was obtained by centrifugation $\left(4^{\circ} \mathrm{C}, 3000 \mathrm{rpm}, 10 \mathrm{~min}\right)$ and stored at $-80^{\circ} \mathrm{C}$ until analysis of glucose by a 
hexokinase method (Roche Diagnostics, Hoffman-La Roche, Basel, Switzerland), triglycerides by the method of McGowan (GPO-trinder 337, Sigma), glycerol by a glycerolkinase-lipase method (Boehringer, Mannheim, Germany), free fatty acids by an ACS-ACOD method (Wako chemicals, Neuss, Germany), $\beta$-hydroxy butyrate by the method of Moore et al. ${ }^{29}$ using a semi-automated centrifugal spectrophotometer (Cobas Fara, Roche Diagnostics), and insulin with ELISA (Mercodia 10-1113-01).

\section{Statistics}

Possible differences between subjects of the low and high CLA and placebo intervention groups for baseline characteristics (age, body weight, BMI, \%body fat and dietary restraint) were analyzed with a factorial ANOVA (Statview SE Graphics ${ }^{\mathrm{TM}}$ ). Changes in body weight, BMI, \%body fat, fat mass, fat-free mass, resting metabolic rate, respiratory quotient, physical activity (counts) and blood parameters from week -3 to 0 were tested with repeated measures ANOVA (Statview SE Graphics ${ }^{\mathrm{TM}}$ ) for all groups together. The effect of CLA at week 13 on the dependent variable \%body weight regain was analyzed by linear multiple regression model with treatment $(0=$ placebo; $1=C L A)$, gender $(0=m e n$; $1=$ women) and dosage $(0=L D, 1=H D)$ as independent variables. Similarly, the effect of CLA at week 13 for the dependent variables plasma glucose, insulin, free fatty acids. glycerol and $\beta$-hydroxy butyrate were analyzed by linear multiple regression model with treatment $(0=$ placebo; $1=C L A)$, gender $(0=$ men; $1=$ women $)$ and dosage $(0=L D, 1=H D)$ and the values of week -3 and 0 of those parameters as independent variables (SPSS Inc. Chicago, Illinois, USA). The effect of CLA at week 13 for the dependent variables fat mass, fat-free mass, resting metabolic rate and respiratory quotient were analyzed by linear multiple regression model with treatment $(0=$ placebo; $1=C L A)$, gender $(0=$ men; $1=$ women) and dosage $(0=L D, 1=H D)$ and the values of week -3 and 0 of those parameters as well as \%body weight regain as independent variables (SPSS Inc. Chicago, Illinois, USA). Finally, the effect of CLA on physical activity (counts) was analyzed by linear multiple regression model with treatment $(0=$ placebo; $1=C L A)$, gender $(0=$ men; $1=$ women $)$ and the values of week -3 and 0 of those parameters as well as \%body weight regain as independent variables (SPSS Inc. Chicago, Illinois, USA). The regression coefficient $(\mathrm{RC})$ with $95 \%$ confidence interval $(\mathrm{CI})$ of the CLA intervention was calculated for each dependent variable. The level of significance is set at $p<0.05$. Data are presented as means \pm standard deviations (SD).

\section{RESULTS}

At the start of the study, subjects of the four subgroups did not differ with respect to age, body weight, BMI, \%body fat and dietary restraint (table 1).

As a consequence of the VLCD, body weight at week 0 was significantly lower compared to week $-3(p<0.0001)$. The mean weight loss was $6.9 \pm 1.7 \%$ of the original body weight. Also the BMI was decreased as a consequence of the VLCD $(p<0.0001)$. Percentage of body fat $(p<0.0001)$, as well as fat mass $(p<0.0001)$ and fat-free mass $(p<0.0001)$ were significantly decreased after VLCD compared to before. The VLCD did not affect physical activity $\left(65.1 \pm 18.1\right.$ vs. $67.6 \pm 22.3$ counts $\left.\times 10^{3}, \mathrm{~ns}\right)$ (table 1). Furthermore, resting metabolic rate $(p<0.0001)$ and the respiratory quotient $(p<0.0001)$ were significantly lowered after the VLCD compared to before (table 2). Plasma concentrations of glucose $(p<0.001)$, insulin $(p<0.001)$, and triglycerides $(p<0.0001)$ were lowered after the VLCD. The plasma concentrations of glycerol $(p<0.05)$, free fatty acids $(p<0.01)$, and $\beta$-hydroxy butyrate $(p<0.0001)$ were increased by the VLCD (table 3 ).

After 13 weeks intervention, the subjects of the CLA group had a body weight regain of $40.2 \pm 69.3 \%$ (LD $47.9 \pm 88.2 \%$, HD $27.4 \pm 29.8 \%$ ) while the placebo group had a body weight regain of $24.8 \pm 33.6 \%$ (LD $32.0 \pm 42.8 \%$, HD $22.5 \pm 37.9 \%$ ) (ns) (table 1). Thus, body weight regain during the intervention (week 13) was not influenced by CLA. Moreover, both independent variables dosage (RC $-11.5 ; \mathrm{Cl}-41.5$ to $18.6, \mathrm{~ns}$ ) and gender ( $\mathrm{RC}-14.4 ; \mathrm{Cl}-44.5$ to $15.7, \mathrm{~ns}$ ) did not affect body weight regain. 
After 13 weeks intervention, CLA (LD $-3.0 \pm 6.6 \%$, HD $-5.1 \pm 5.8 \%$ ) compared to placebo (LD $-1.6 \pm 4.6 \%, \mathrm{HD}-3.1 \pm 4.5 \%)$ significantly reduced \%body fat $(p<0.05)$, independently of \%body weight regain ( $\mathrm{RC} 0.0 ; \mathrm{Cl} 0.0$ to 0.0 , ns), dosage (RC-0.3; $\mathrm{Cl}-1.0$ to 0.4 , ns) and gender (RC $0.7 ; \mathrm{Cl}-0.4$ to $1.8, \mathrm{~ns}$ ) (table 1). Expressing body composition as absolute fat mass and fat-free mass, CLA (LD 1.5 $\pm 10.8 \%$, HD $-2.8 \pm 7.6 \%$ ) compared to placebo (LD $0.2 \pm 5.3 \%$, HD $-1.5 \pm 4.5 \%$ ) appeared not to affect fat mass, nor did dosage (RC $-0.5 ; \mathrm{Cl}-1.2$ to 0.2 , ns) or gender ( $\mathrm{RC} 0.2 ; \mathrm{Cl}-0.7$ to $1.0, \mathrm{~ns}$ ), but significantly increased fat-free mass (LD $6.2 \pm 3.9 \%$, HD $4.6 \pm 2.4 \%$ ) compared to placebo (LD $2.8 \pm$ $3.2 \%, \mathrm{HD} 3.4 \pm 3.6 \%)(\mathrm{p}<0.05)$, independently of \%body weight regain (RC $-0.0 ; \mathrm{Cl}-0.0$ to $0.0, \mathrm{~ns}$ ), dosage ( $\mathrm{RC} 0.3 ; \mathrm{Cl}-0.4$ to $1.1, \mathrm{~ns}$ ) and gender ( $\mathrm{RC}-1.0 ; \mathrm{Cl}-2.7$ to $0.7, \mathrm{~ns}$ ) (table 1).

Table 1: age and degree of dietary restraint (F1) before weight loss, and body weight (BW), body mass index (BMI), \%body fat, fat mass (FM) and fat-free mass (FFM) before and after weight loss with a 3 -week very-low-calorie diet and after 13 weeks intervention with CLA (1.8 or $3.6 \mathrm{~g})$ or placebo (Plac 1.8 or $3.6 \mathrm{~g}$, oleic acid)

\begin{tabular}{|c|c|c|c|c|c|c|c|}
\hline & $1.8 \mathrm{~g} \mathrm{CLA}$ & $1.8 \mathrm{~g} \mathrm{Plac}$ & $3.6 \mathrm{~g} \mathrm{CLA}$ & $3.6 \mathrm{~g} \mathrm{Plac}$ & $R^{\prime}$ & $\mathrm{Cl}^{\prime}$ & p \\
\hline age (y) & $40.9 \pm 5.0$ & $39.5 \pm 7.7$ & $36.2 \pm 7.6$ & $34.0 \pm 9.1$ & & & \\
\hline$F_{1}{ }^{2}$ & $4.8 \pm 2.9$ & $5.4 \pm 2.1$ & $5.4 \pm 2.9$ & $4.3 \pm 2.0$ & & & \\
\hline$B W(\mathrm{~kg}) w-3$ & $83.5 \pm 7.4$ & $83.5 \pm 8.9$ & $86.8 \pm 8.4$ & $81.9 \pm 9.3$ & & & \\
\hline BW $(\mathrm{kg})$ w 0 & $77.6 \pm 6.4^{4}$ & $78.0 \pm 8.1^{4}$ & $80.5 \pm 7.7^{4}$ & $76.2 \pm 8.3^{4}$ & & & \\
\hline$B W(k g)$ w 13 & $81.0 \pm 8.1$ & $79.4 \pm 8.5$ & $82.4 \pm 8.3$ & $77.5 \pm 9.1$ & 13.9 & $-16.1-44.0$ & ns \\
\hline BMI $\left(\mathrm{kg} / \mathrm{m}^{2}\right)$ w - 3 & $27.6 \pm 1.1$ & $28.0 \pm 1.6$ & $28.3 \pm 1.7$ & $27.6 \pm 1.5$ & & & \\
\hline BMI $\left(\mathrm{kg} / \mathrm{m}^{2}\right)$ w 0 & $25.6 \pm 1.1^{4}$ & $26.1 \pm 1.4^{4}$ & $26.2 \pm 1.7^{4}$ & $25.7 \pm 1.4^{4}$ & & & \\
\hline BMI $\left(\mathrm{kg} / \mathrm{m}^{2}\right)$ w 13 & $26.8 \pm 1.2$ & $26.7 \pm 1.6$ & $26.8 \pm 1.7$ & $26.3 \pm 1.6$ & 0.3 & $0.1-1.2$ & ns \\
\hline$\%$ body fat w -3 & $32.2 \pm 7.5$ & $33.2 \pm 7.5$ & $30.3 \pm 7.6$ & $32.8 \pm 6.3$ & & & \\
\hline$\%$ body fat w 0 & $30.8 \pm 6.9^{4}$ & $31.3 \pm 8.1^{4}$ & $28.7 \pm 7.7^{4}$ & $31.1 \pm 7.1^{4}$ & & & \\
\hline \%body fat w 13 & $29.7 \pm 5.9$ & $30.8 \pm 7.8$ & $27.3 \pm 7.4$ & $30.1 \pm 6.6$ & -0.8 & $-1.0--0.4$ & $<0.05$ \\
\hline FM $(\mathrm{kg}) w-3$ & $26.8 \pm 6.1$ & $27.4 \pm 5.7$ & $26.2 \pm 6.3$ & $26.6 \pm 4.6$ & & & \\
\hline$F M(k g) w 0$ & $23.8 \pm 5.3^{4}$ & $24.2 \pm 5.5^{4}$ & $23.1 \pm 6.4^{4}$ & $23.5 \pm 5.3^{4}$ & & & \\
\hline $\mathrm{FM}(\mathrm{kg})$ w 13 & $24.0 \pm 4.5$ & $24.2 \pm 5.4$ & $22.4 \pm 6.0$ & $23.2 \pm 5.3$ & -0.4 & $-1.1-0.3$ & ns \\
\hline FFM $(\mathrm{kg}) \mathrm{w}-3$ & $56.7 \pm 8.9$ & $56.1 \pm 10.0$ & $60.6 \pm 9.8$ & $55.3 \pm 9.8$ & & & \\
\hline FFM $(\mathrm{kg})$ w 0 & $53.8 \pm 8.1^{4}$ & $53.9 \pm 10.0^{4}$ & $57.4 \pm 8.7^{4}$ & $52.6 \pm 9.1^{4}$ & & & \\
\hline FFM (kg) w 13 & $57.1 \pm 7.7$ & $55.3 \pm 10.0$ & $60.1 \pm 9.3$ & $54.4 \pm 9.3$ & 0.9 & $0.1-1.6$ & $<0.05$ \\
\hline $\mathrm{PA}^{3}$ (counts $\times 10^{3}$ ) w-3 & & & $69.5 \pm 22.0$ & $61.5 \pm 14.3$ & & & \\
\hline $\mathrm{PA}^{3}$ (counts $\times 10^{3}$ ) w0 & & & $67.5 \pm 22.9$ & $67.7 \pm 23.0$ & & & \\
\hline $\mathrm{PA}^{3}$ (counts $\times 10^{3}$ ) w 13 & & & $77.6 \pm 31.4$ & $66.1 \pm 23.3$ & 8.6 & $-6.5-23.7$ & ns \\
\hline
\end{tabular}

'regression coefficient (RC) and confidence interval $(\mathrm{Cl})$ for the CLA effect (1.8 and $3.6 \mathrm{~g}$ CLAvd, pooled groups) compared to placebo (1.8 and $3.6 \mathrm{~g}$ oleic acid/d, pooled groups), corrected for dosage (except for physical activity), gender and \%body weight regain

${ }^{2}$ dietary restraint measured with Factor 1 of the Three-Factor Eating Questionnaire ${ }^{21}$

'physical activity

"significantly different compared to before the VLCD measured for all groups together $(p<0.0001)$ 
Table 2: resting metabolic rate (RMR) and respiratory quotient (RQ) before and after weight loss with a 3-week very-low-calorie diet and after 13 weeks intervention with CLA (1.8 or $3.6 \mathrm{~g})$ or placebo (Plac 1.8 or $3.6 \mathrm{~g}$ oleic acid)

\begin{tabular}{lccccccc}
\hline & $1.8 \mathrm{~g}$ CLA & $1.8 \mathrm{~g}$ Plac & $3.6 \mathrm{~g}$ CLA & $3.6 \mathrm{~g} \mathrm{Plac}$ & $\mathrm{RC}^{\prime}$ & $\mathrm{Cl}^{\prime}$ & $\mathrm{p}$ \\
\hline RMR (MJ) w -3 & $7.3 \pm 0.6$ & $7.2 \pm 0.9$ & $7.6 \pm 0.9$ & $7.4 \pm 0.8$ & & & \\
RMR (MJ) w 0 & $6.7 \pm 0.7^{2}$ & $6.8 \pm 0.6^{2}$ & $6.9 \pm 0.6^{2}$ & $6.8 \pm 0.9^{2}$ & & & \\
RMR (MJ) w 13 & $7.5 \pm 0.9$ & $7.4 \pm 0.8$ & $7.8 \pm 1.2$ & $7.4 \pm 0.8$ & 0.8 & $0.0-1.5$ & $<0.05$ \\
RQ w -3 & $0.82 \pm 0.04$ & $0.83 \pm 0.04$ & $0.81 \pm 0.06$ & $0.82 \pm 0.04$ & & \\
RQ w 0 & $0.77 \pm 0.05^{2}$ & $0.78 \pm 0.04^{2}$ & $0.78 \pm 0.04^{2}$ & $0.76 \pm 0.04^{2}$ & & \\
RQ w 13 & $0.84 \pm 0.04$ & $0.81 \pm 0.05$ & $0.87 \pm 0.07$ & $0.85 \pm 0.03$ & 0.02 & $-0.00-0.05$ & $\mathrm{~ns}$ \\
\hline
\end{tabular}

'regression coefficient (RC) and confidence interval $(\mathrm{Cl})$ for the CLA effect (1.8 and $3.6 \mathrm{~g} \mathrm{CLAVd}$, pooled groups) compared to placebo (1.8 and $3.6 \mathrm{~g}$ oleic acid/d, pooled groups), corrected for dosage, gender, \%body weight regain

'significantly different compared to before the VLCD measured for all groups together $(p<0.0001)$

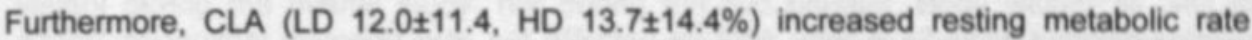
compared to placebo (LD 9.1 $\pm 11.0 \%$, HD $8.6 \pm 8.5 \%)(p<0.05)$, independently of \%body weight regain ( $\mathrm{RC} 0.0 ; \mathrm{Cl}-0.0$ to $0.0, \mathrm{~ns}$ ), dosage ( $\mathrm{RC} 0.6 ; \mathrm{Cl}-0.1$ to $1.4, \mathrm{~ns}$ ) and gender (RC $-0.9 ; \mathrm{Cl}-2.1$ to 0.2 , ns) (table 2). However, the resting metabolic rate was not affected by CLA independently of fat-free mass ( $\mathrm{RC} 0.6 ; \mathrm{Cl}-0.2$ to $1.3, \mathrm{~ns}$ ). Thus resting metabolic rate was increased as a function of an increased fat-free mass (figure 1). The respiratory quotient was not significantly affected by CLA compared to placebo $(p<0.1$; table 2).

At the end of the intervention, the physical activity was not affected by CLA (table 1; RC $8.6 ; \mathrm{Cl}-6.5$ to $23.7, \mathrm{~ns}$ ) or gender ( $\mathrm{RC}-3.5 ; \mathrm{Cl}-18.0$ to $11.01, \mathrm{~ns}$ ), indicating that the increased resting metabolic rate as a function of fat-free mass was not due to a possible physical activity effect.

A 13-week intervention with CLA did not affect plasma glucose, insulin, triglycerides, glycerol $(p<0.1)$, free fatty acids $(p<0.1)$, and $\beta$-hydroxy butyrate concentrations (table 3 ).

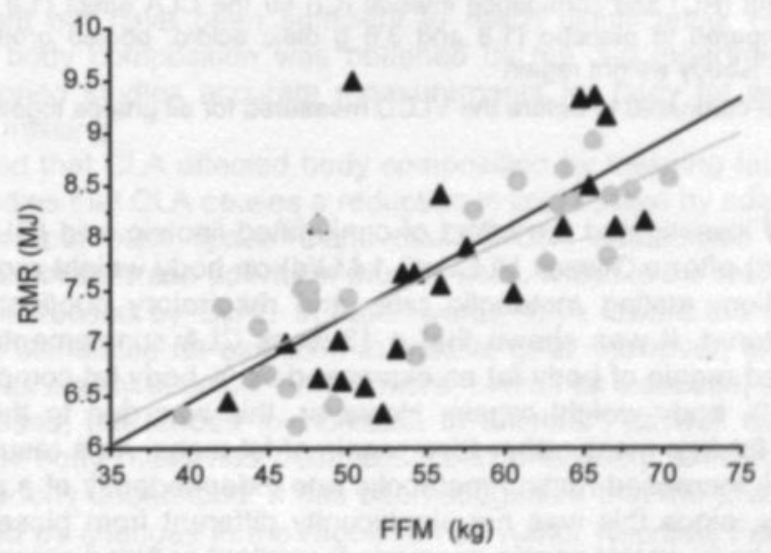

$\triangle$ CLA Plac

Figure 1: resting metabolic rate (RMR, MJ/d) as a function of fat-free mass (FFM, $\mathrm{kg}$ ) after 13 weeks intervention with conjugated linoleic acid (CLA, $\left.n=23 ; r^{2}=0.4, p<0.001\right)$ and placebo (oleic acid, $n=27 ; r^{2}=0.6, p<0.0001$ ). Multiple regression analysis showed that the resting metabolic rate at week 13 was not affected by CLA independently of the fat-free mass ( $\mathrm{RC} 0.6 ; \mathrm{Cl}-0.2-1.3, \mathrm{~ns})$. 
Table 3: plasma glucose, insulin, triacylglycerol (TG), free fatty acids (FFA), glycerol and $\beta$-hydroxy butyrate $(\mathrm{BHB})$ concentrations before and after weight loss with a 3-week very-low-calorie diet and after 13 weeks intervention with CLA (1.8 or $3.6 \mathrm{~g})$ or placebo (Plac 1.8 or $3.6 \mathrm{~g}$ oleic acid)

\begin{tabular}{|c|c|c|c|c|c|c|c|}
\hline & $1.8 \mathrm{~g} \mathrm{CLA}$ & $1.8 \mathrm{~g}$ Plac & $3.6 \mathrm{~g}$ CLA & $3.6 \mathrm{~g} \mathrm{Plac}$ & $\mathrm{RC}^{1}$ & $\mathrm{Cl}^{\prime}$ & $p$ \\
\hline glucose (mmoll) w -3 & $5.0 \pm 0.4$ & $5.0 \pm 0.6$ & $5.3 \pm 0.6$ & $5.3 \pm 0.5$ & & & \\
\hline glucose $(\mathrm{mmol} / \mathrm{L})$ w 0 & $4.6 \pm 0.3^{2}$ & $4.7 \pm 0.5^{2}$ & $5.0 \pm 0.4^{2}$ & $4.9 \pm 0.3^{2}$ & & & \\
\hline glucose (mmol/L) w 13 & $5.0 \pm 0.3$ & $5.0 \pm 0.4$ & $5.2 \pm 0.6$ & $5.1 \pm 0.4$ & 0.05 & $-0.09-0.19$ & ns \\
\hline insulin $(\mu \cup / L) w-3$ & $4.8 \pm 2.5$ & $3.1 \pm 1.7$ & $9.0 \pm 2.2$ & $7.6 \pm 2.9$ & & & \\
\hline insulin $(\mu \cup / \mathrm{L})$ w 0 & $2.3 \pm 1.9^{2}$ & $2.0 \pm 1.2^{2}$ & $4.7 \pm 1.6^{2}$ & $5.7 \pm 2.5^{2}$ & & & \\
\hline insulin $(\mu \mathrm{U} / \mathrm{L})$ w 13 & $4.1 \pm 2.5$ & $3.0 \pm 1.7$ & $7.9 \pm 4.3$ & $7.8 \pm 4.4$ & 0.1 & $-1.4-1.7$ & ns \\
\hline TG $(\mu \mathrm{mol} / \mathrm{L}) \mathrm{w}-3$ & $1555 \pm 864$ & $1216 \pm 1007$ & $1192 \pm 379$ & $1123 \pm 398$ & & & \\
\hline $\mathrm{TG}(\mu \mathrm{mol} / \mathrm{L}) \mathrm{w} 0$ & $828 \pm 195^{2}$ & $757 \pm 184^{2}$ & $753 \pm 237^{2}$ & $809 \pm 223^{2}$ & & & \\
\hline TG $(\mu \mathrm{mol} / \mathrm{L}) \mathrm{w} 13$ & $1334 \pm 704$ & $1035 \pm 564$ & $1213 \pm 584$ & $1088 \pm 447$ & 176 & $-38-390$ & ns \\
\hline FFA $(\mu \mathrm{mol} / \mathrm{L}) \mathrm{w}-3$ & $292 \pm 122$ & $325 \pm 150$ & $318 \pm 168$ & $306 \pm 151$ & & & \\
\hline $\mathrm{FFA}(\mu \mathrm{mol} / \mathrm{L}) \mathrm{w} 0$ & $372 \pm 221^{2}$ & $440 \pm 204^{2}$ & $321 \pm 101^{2}$ & $429 \pm 226^{2}$ & & & \\
\hline $\mathrm{FFA}(\mu \mathrm{mol} / \mathrm{L}) \mathrm{w} 13$ & $226 \pm 92$ & $298 \pm 120$ & $250 \pm 104$ & $307 \pm 156$ & -74 & $-149-1$ & ns \\
\hline glycerol $(\mu \mathrm{mol} / \mathrm{L}) \mathrm{w}-3$ & $73 \pm 28$ & $86 \pm 34$ & $93 \pm 51$ & $91 \pm 48$ & & & \\
\hline glycerol( $\mu \mathrm{mol} / \mathrm{L})$ w 0 & $104 \pm 66^{2}$ & $128 \pm 76^{2}$ & $74 \pm 25^{2}$ & $108 \pm 70^{2}$ & & & \\
\hline glycerol $(\mu \mathrm{mol} / \mathrm{L})$ w 13 & $70 \pm 28$ & $81 \pm 24$ & $52 \pm 21$ & $72 \pm 40$ & -17 & $-35-1$ & ns \\
\hline BHB $(\mu \mathrm{mol} / \mathrm{L}) w-3$ & $275 \pm 72$ & $239 \pm 87$ & $262 \pm 55$ & $258 \pm 81$ & & & \\
\hline $\mathrm{BHB}(\mu \mathrm{mol} / \mathrm{L}) \mathrm{w} 0$ & $852 \pm 427^{2}$ & $687 \pm 547^{2}$ & $496 \pm 217^{2}$ & $646 \pm 428^{2}$ & & & \\
\hline $\mathrm{BHB}(\mu \mathrm{mol} / \mathrm{L})$ w 13 & $211 \pm 51$ & $218 \pm 88$ & $249 \pm 73$ & $250 \pm 87$ & -22 & $-62-19$ & ns \\
\hline
\end{tabular}

'regression coefficient (RC) and confidence interval $(\mathrm{Cl})$ for the CLA effect (1.8 and $3.6 \mathrm{~g} \mathrm{CLAd,}$ pooled groups) compared to placebo (1.8 and $3.6 \mathrm{~g}$ oleic acid/d, pooled groups), corrected for dosage, gender and \%body weight regain

${ }^{2}$ significantly different compared to before the VLCD measured for all groups together $(p<0.0001)$

\section{DISCUSSION}

The present study investigated the effect of conjugated linoleic acid (CLA) compared to placebo (oleic acid) after a 3-week VLCD (2.1 MJ/d) on body weight regain, parameters of body composition, resting metabolic rate, and respiratory quotient while physical activity was monitored. It was shown that a 13-week CLA supplementation after body weight loss lowered regain of body fat as expressed as \% body fat compared to placebo independently of $\%$ body weight regain. However, this was due to the fact that CLA affected regain of fat-free mass rather than regain of fat mass. As a result of its effect on fat-free mass, CLA increased resting metabolic rate independently of a possible change in physical activity, since this was not significantly different from placebo. In contrast, CLA did not affect body weight regain, respiratory quotient or blood parameters.

In different animal models, CLA has been shown to alter body composition, i.e. decrease fat mass $^{3-10}$ and increase fat-free mass ${ }^{3.5-7}$, while the effects in humans are inconsequent. Differences between humans and animals for the effect of CLA on body composition might be because of several factors, e.g. dosage or length of intervention, although a recent publication suggests that differences in metabolic rate might be of more importance than other factors ${ }^{30}$. 
Even though in the present study, body weight regain was not affected by CLA, it was mainly due to an increase in fat-free mass and hardly of fat mass, which was even stronger in the groups using CLA. So, body composition rather than body weight was affected by CLA. This is in line with previous studies conducted in humans ${ }^{3-15}$, although the effects of CLA on body composition are inconsistent. Blankson et al. ${ }^{13}$ observed no effect from 12 weeks CLA supplementation $(1.7,3.4,5.1$ or $6.8 \mathrm{~g} / \mathrm{d}$ ) on body weight in overweight and obese subjects. Fat mass $(\mathrm{kg})$, measured with DEXA, decreased with 1.7 and $5.1 \mathrm{~g} \mathrm{CLA} / \mathrm{d}$, but not with the other concentrations. Furthermore, there was a trend in favor of increased fat-free mass in all groups receiving CLA, but reached only significance in the group receiving the highest dose. CLA had no effect on body weight or composition in a study of Berven et al. ${ }^{16}$. They observed after a daily consumption of $3.4 \mathrm{~g} \mathrm{CLA}$ for 12 weeks no effect on body weight, BMI or fat mass, measured with bioimpedance measures compared to placebo in obese subjects. Also, Zambell and colleagues ${ }^{17}$ found no effect of CLA ( $3 \mathrm{~g} / \mathrm{d}$, 9 weeks) on body weight and composition. measured by total body electrical conductivity. In contrast, a daily intake of $0.7 \mathrm{~g}$ CLA for 4 weeks followed by a 4 -week $1.4 \mathrm{~g}$ CLA supplementation, lowered fat mass measured with skin fold thickness during the second period, but had no effect on overall decrease in fat mass in a study of Mougios et al. ${ }^{14}$. Furthermore, CLA did not influence body weight during the overall study, nor during the two periods. Body weight as well as sagital abdominal diameter was not affected by CLA after a 12-week supplementation with $4.2 \mathrm{~g} / \mathrm{d}$ in a study by Smedman and Vessby ${ }^{18}$. However, a reduction of body fat, measured with skin fold thickness and bio-impedance, in the CLA supplemented group was observed. Also, Riserus et al. ${ }^{15}$ studied the effect of $4.2 \mathrm{~g} \mathrm{CLA} / \mathrm{d}$ for 4 weeks on body fat distribution. Even though body weight and waist-hip ratio were not affected by CLA, in this study the sagital abdominal diameter in obese men was lowered. However, more precise measures of fat mass and fat-free mass were not conducted. The inconsistent and contradictory results between the present and previous studies could be due to number of factors, including differences in methodology and subject groups, the quantity and duration of CLA intake, the fatty acid composition of CLA, but also by the executed measurements for body composition and body fat distribution. In the present study fat-free mass rather than fat mass affected \%body fat, while in previous studies fat mass was often significantly reduced ${ }^{13,14}$. Since body weight was not reduced, but fat mass was, it is possible that previously CLA also (slightly) affected fat-free mass, although it might not have been sufficient to reach significance. Furthermore, in the present study, body composition was obtained by the 3-compartment model while in previous mentioned studies accurate measurements for body fat as well as body fat distribution are missing ${ }^{31}$.

It was suggested that CLA affected body composition by lowering fat mass. It is known from in vitro studies that CLA causes a reduction in lipid uptake by adipose cells because of an effect on lipoprotein lipase ${ }^{3.5}$ and stearoyl-CoA desaturase ${ }^{10.20}$. Moreover, the carnitine palmitoyltransferase activity in muscle cells, which is the rate limiting enzyme in $\beta$-oxidation, is increased by CLA ${ }^{3}$. In other words, CLA lowers the uptake of lipids by adipocytes and stimulates fat oxidation in muscle cells. However, in the present study fat-free mass was mainly affected. Furthermore, overall fat oxidation, as obtained by RQ. was not decreased, but tended to increase. In animals ${ }^{3}$, as well as in humans ${ }^{13}$, the increase of lean body mass has been described previously, although the responsible mechanism is poorly understood. It has been suggested that the anabolic effect of CLA might be caused by changes in the regulation of Tumor Necrosis Factor-alpha (TNF- $\alpha$ ) and Interleukin-1 (IL-1) ${ }^{20}$. In the present study, the increase in fat-free mass is not due to differences between the CLA and placebo groups in physical activity or energy intake, although CLA decreased appetite ${ }^{32}$.

We found that CLA increased resting metabolic rate indirectly as a function of an increased fat-free mass, independently of dose, gender and weight \%regain. This finding is in contrast with a study by Zambell et al. in which no effect of CLA on resting metabolic rate was observed in humans ${ }^{17}$. However, in the study by Zambell et al., CLA did not 
affect body composition. In mice, however, CLA was observed to increase energy expenditure $4.9,12$. Also here, the discrepancy between animal and human studies might be caused by differences in metabolic rate ${ }^{30}$.

There is growing evidence that the different isomers of CLA (c9,t11 and $t 10, c 12)$ might have different effects ${ }^{5,19,20,33}$. The $c 9, t 11$ isomer is the principal dietary form of CLA (80$90 \%$ ) and is incorporated into membranes, but the $t 10, c 12$ isomer seems to be the most important in energy metabolism ${ }^{20}$. In our study, a mixture of equal amounts of both isomers was used, so the effects of this study could result from either or both isomers.

In the present study no difference between the low and high dosage CLA for body composition and resting metabolic rate was observed. Compared to other studies, the dosages used in this study were rather low, but despite the low concentrations effects were observed. This is probably due to the circumstances during the CLA intervention. Since subjects are in a state of weight regain, the body might be more vulnerable for CLA compared to a state of weight stability. Apparently, a relatively low dosage of CLA, which is much higher than usual CLA intake $(0.2 \mathrm{~g} / \mathrm{d})^{34}$, affects fat-free mass already during weight regain, while a larger dosage hardly increases this effect.

In conclusion, 13 weeks supplementation with 1.8 or $3.6 \mathrm{~g} \mathrm{CLA} / \mathrm{d}$ after a 3-week VLCD was not effective in improving body weight maintenance after weight loss compared to placebo ( 1.8 or $3.6 \mathrm{~g}$ oleic acid/d), but affected dose-independently body composition. CLA lowered regain of \%body fat by increasing regain of fat-free mass, and consequently increased resting metabolic rate.

\section{REFERENCES}

1 Kepler CR, WP Tucker, SB Tove. Biohydrogenation of unsaturated fatty acids. IV. Substrate specificity and inhibition of linoleate delta-12-cis, delta-11-trans-isomerase from Butyrivibrio fibrisolvens. J Biol Chem 1970; 245: 3612-3620

2 Kepler CR, WP Tucker, SB Tove. Biohydrogenation of unsaturated fatty acids. V. Stereospecificity of proton addition and mechanism of action of linoleic acid delta 12-cis, delta 11-trans-isomerase from Butyrivibrio fibrisolvens. J Biol Chem 1971; 246: 2765-2771

3 Park Y, KJ Albright, W Liu, JM Storkson, ME Cook, MW Pariza. Effect of conjugated linoleic acid on body composition in mice. Lipids 1997; 32: 853-858

4 West DB, JP Delany, PM Camet, FY Blohm, AA Truett, J Scimeca. Effects of conjugated linoleic acid on body fat and energy metabolism in the mouse. Am J Physiol 1998; 275: R667R672

5 Park Y, JM Storkson, KJ Albright, W Liu, MW Pariza. Evidence that the trans-10,cis-12 isomer of conjugated linoleic acid induces body composition changes in mice. Lipids 1999; 34: 235241

6 Park Y, KJ Albright, JM Storkson, W Liu, ME Cook, MW Pariza. Changes in body composition in mice during feeding and withdrawal of conjugated linoleic acid. Lipids 1999; 34: 243-248

7 DeLany JP, F Blohm, AA Truett, JA Scimeca, DB West. Conjugated linoleic acid rapidly reduces body fat content in mice without affecting energy intake. Am J Physiol 1999; 276: R1172-R1179

8 Azain MJ, DB Hausman, MB Sisk, WP Flatt, DE Jewell. Dietary conjugated linoleic acid reduces rat adipose tissue cell size rather than cell number. J Nutr 2000; 130: 1548-1554

9 West DB, FY Blohm, AA Truett, JP DeLany. Conjugated linoleic acid persistently increases total energy expenditure in AKR/J mice without increasing uncoupling protein gene expression. J Nutr 2000; 130: 2471-2477

10 Sisk MB, DB Hausman, RJ Martin, MJ Azain. Dietary conjugated linoleic acid reduces adiposity in lean but not obese Zucker rats. J Nutr 2001; 131: 1668-1674

11 Miner JL, CA Cederberg, MK Nielsen, X Chen, CA Baile. Conjugated linoleic acid (CLA), body fat, and apoptosis. Obes Res 2001; 9: 129-134

12 Ohnuki K, S Haramizu, K Oki, K Ishihara, T Fushiki. A single oral administration of conjugated linoleic acid enhanced energy metabolism in mice. Lipids 2001; 36: 583-587

13 Blankson H, JA Stakkestad, H Fagertun, E Thom, J Wadstein, O Gudmundsen. Conjugated linoleic acid reduces body fat mass in overweight and obese humans. J Nutr 2000; 130: 29432948

14 Mougios V, A Matsakas, A Petridou, S Ring, A Sagredos, A Melissopulou, N Tsigilis, M 
Nikolaidis. Effect of supplementation with conjugated linoleic acid on human serum lipids and body fat. J Nutr Biochem 2001; 12: 585-594

15 Riserus U, L Berglund, B Vessby. Conjugated linoleic acid (CLA) reduced abdominal adipose tissue in obese middle-aged men with signs of the metabolic syndrome: a randomised controlled trial. Int J Obes Relat Metab Disord 2001; 25: 1129-1135

16 Berven G, A Bye, O Hals, H Blankson, H Fagertun, E Thom, J Wadstein, O Gudmundsen. Safety of conjugated linoleic acid (CLA) in overweight and obese human volunteers. Eur J Lipid Sci Technol 2000; 102: 155-462

17 Zambell KL, NL. Keim, MD Van Loan, B Gale, P Benito, DS Kelley, GJ Nelson. Conjugated linoleic acid supplementation in humans: effects on body composition and energy expenditure. Lipids 2000; 35: 777-782

18 Smedman A, B Vessby. Conjugated linoleic acid supplementation in humans-metabolic effects. Lipids 2001; 36: 773-781

19 Choi Y, YC Kim, YB Han, Y Park, MW Pariza, JM Ntambi. The trans-10, cis-12 isomer of conjugated linoleic acid downregulates stearoyl-CoA desaturase 1 gene expression in 3T3-L1 adipocytes. J Nutr 2000; 130: 1920-1924

20 Pariza MW, Y Park, ME Cook. The biologically active isomers of conjugated linoleic acid. Prog Lipid Res 2001; 40: 283-298

21 Stunkard AJ, S Messick. The three-factor eating questionnaire to measure dietary restraint, disinhibition, and hunger. J Psychosom Res 1985; 29: 71-83

22 Westerterp-Plantenga MS, CRT Verwegen. The appetizing effect of an aperitif in overweight and normal-weight humans. Am J Clin Nutr 1999; 69: 205-212

23 Herman CP, J Polivy. Restrained Eating. Saunders, W.B.: Philadelphia, 1980

24 Schoeller DA, E van Santen, DW Peterson, W Dietz, J Jaspan, PD Klein. Total body water measurement in humans with 180 and $2 \mathrm{H}$ labeled water. Am J Clin Nutr 1980; 33: 2686-2693

25 Siri WE. Body composition from fluid spaces and density: analysis of methods. 1961. Nutrition 1993: 9: 480-491

26 van Marken Lichtenbelt WD, KR Westerterp, L Wouters. Deuterium dilution as a method for determining total body water: effect of test protocol and sampling time. Br J Nutr 1994; 72: 491. 497

27 Schoffelen PF, KR Westerterp, WH Saris, F Ten Hoor. A dual-respiration chamber system with automated calibration. J Appl Physiol 1997; 83: 2064-2072

28 Weir JB. New methods for calculating metabolic rate with special reference to protein metabolism. 1949. Nutrition 1990; 6: 213-221.

29 Moore JJ, M Marcus, SM Sax. Kinetic assay of $\beta$-hydroxy butyrate in plasma with cobas bio centrifugal analyzer. Clin Chem 1982; 73: 1334-1339

30 Terpstra AH. Differences between humans and mice in efficacy of the body fat lowering effect of conjugated linoleic acid: role of metabolic rate. J Nutr 2001; 131: 2067-2068

31 Bergsma-Kadijk JA, B Baumeister, P Deurenberg. Measurement of body fat in young and elderly women: comparison between a four-compartment model and widely used reference methods. Br J Nutr 1996; 75: 649-657

32 Kamphuis MMJW, MPGM Lejeune, WHM Saris, MS Westerterp-Plantenga. Effect of Conjugated Linoleic Acid supplementation after weight loss on appetite and food intake in overweight subjects. Eur J Clin Nutr in press

33 Halvorsen YD, R Lea-Currie, C Geigerman, M McIntosh. 2000. Conjugated linoleic acid (CLA) attenuates human preadipocyte triglyceride (TG) content and lipogenesis. In NAASO meeting. Long Beach, USA: Obes Res. 121S

34 Ens JG, DW Ma, KS Cole, CJ Field, MT Clandinin. An assessment of c9,t11 linoleic acid intake in a small group of young Canadians. Nutr Res 2001; 21: 955-960 



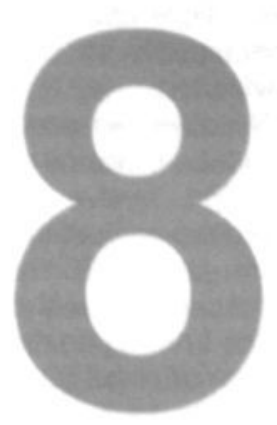

\section{Diacylglycerols affect substrate oxidation and appetite in humans}

Marleen MJW Kamphuis

David J Mela

Margriet S Westerterp-Plantenga

| American Journal of Clinical Nutrition 2003;77(5) 1133-1139 


\section{ABSTRACT}

Background: meals rich in diacylglycerols (DGs) instead of triacylglycerols (TGs) show beneficial effects on lipid metabolism and energy balance. These effects are probably attributable to differences in DG and TG metabolism, especially post-prandial fat oxidation.

Objective: we assessed the effects of partial replacement of TGs by DGs on substrate oxidation, energy expenditure (EE), relevant blood variables, and appetite.

Design: twelve healthy, dietary unrestrained women participated in a single-blind, placebo-controlled, randomized trial with cross-over design. For 3d before and throughout a $36 \mathrm{~h}$ stay in the respiration chamber, subjects were fed energy-maintenance amounts of a diet consisting of $55 \%$ of energy from carbohydrate, $15 \%$ from protein and $30 \%$ from fat. In the respiration chamber, $40 \%$ of the fat was consumed as DG-rich $(80 \%$ DGs) oil or as TG-based control oil with a similar fatty acid profile.

Results: fat oxidation was significantly higher with DG treatment than with TG treatment. Appetite profiles during day $1(24 \mathrm{~h})$ did not differ significantly between DG and TG treatments; however, feelings of hunger, appetite, estimated prospective food intake and desire to eat were all significantly lower on day $2(12 \mathrm{~h})$ with DG treatment. Mean plasma $\beta$-hydroxy butyrate tended to be higher with DG treatment, and the difference between the two treatments was significant at 11.30 on day 2. Plasma lipid concentrations and resting and $24 \mathrm{~h}$ EE did not differ significantly between the two treatments.

Conclusion: consumption of DGs in place of TGs does not alter EE but produces metabolic effects, particularly increases in fat oxidation, which may be associated with improved appetite control and energy balance.

\section{ACKNOWLEDGEMENTS}

The study was sponsored by the Unilever Health Institute, Unilever R\&D Vlaardingen, The Netherlands.

We thank Paul Schoffelen, Joan Senden, Jos Stegen, Wendy Sluijsmans, Loek Wouters and Manuela Lejeune for their assistance during the experiments. 
$\mathrm{T}$ he incidence and prevalence of obesity are increasing in the United States ${ }^{1}$ as well as in Europe ${ }^{2}$ and throughout the developed and developing world. Obesity is a result of an imbalance between energy intake (EI) and energy expenditure (EE), by which surplus of El is stored as triacylglycerol in adipose tissue. Prevention and treatment of obesity are major public health challenges. Although weight loss can readily be achieved experimentally, long-term weight maintenance is often unsuccessful ${ }^{3-5}$. Therefore, food ingredients affecting energy metabolism, e.g. EE, fat oxidation, satiety, and El, may help people to successfully control or manage their weight.

One of those ingredients might be diacylglyerol (DG). Fat consumed in the diet normally consist of triacylglycerols (TGs), although small amounts of DGs are usually present. Studies in rats and humans suggest that modest intakes of DGs may have a beneficial effect on lipid metabolism. Compared with consumption of TGs, consumption of DGs may produce less post-prandial elevation in plasma TG concentrations in humans ${ }^{6.7}$ and lower fasting serum TG concentrations in rats ${ }^{8.9}$ and humans ${ }^{10}$. Consumption of DGs also reduces total body fat accumulation ${ }^{11}$ and visceral fat accumulation ${ }^{12}$ in rats and humans $^{13,14}$. Although the mechanisms are still speculative, these effects appear to be most likely attributable to differences in DG utilization, especially promotion of enhanced (post-prandial) $\beta$-oxidation ${ }^{8.9 .14}$. This enhanced $\beta$-oxidation is probably due to the enhanced post-absorptive availability of free fatty acids (FFAs) in the portal circulation. Notably, DG oil has the same digestion and absorption routes that comparable TG oils have and has bioavailability and a physiological fuel value that are similar to those of comparable TG oils ${ }^{15}$.

The aim of the present study was to determine whether DG and TG (as control) treatment have different effects on substrate oxidation, energy metabolism, post-prandial plasma TG and $\beta$-hydroxy butyrate $(\mathrm{BHB})$ concentrations, and appetite in humans. We assessed these variables under controlled conditions, i.e. in a respiration chamber. We hypothesized that DG treatment would lead to greater fat oxidation and therefore lower respiratory quotients (RQs) than would TG treatment. Furthermore, we hypothesized that in comparison with TG treatment, DG treatment would produce lower post-prandial TG concentrations and higher $\mathrm{BHB}$ concentrations as a consequence of greater hepatic fatty acid oxidation. Because hepatic fat oxidation is inversely associated with appetite and food intake ${ }^{16,17}$, we hypothesized that measures of appetite are also affected by DG compared to TG.

\section{SUBJECTS AND METHODS}

\section{Subjects}

Twelve healthy, non-smoking women were recruited by advertisements in local newspapers. Subjects had to have a body mass index (BMI) of $23-30 \mathrm{~kg} / \mathrm{m}^{2}$, be in good health, and report a stable body weight for $\geq 3$ months before the study. They did not use any medication and were at most moderate alcohol users. The degree of dietary restraint was measured by using Dutch language versions of the Three-Factor Eating Questionnaire (TFEQ) ${ }^{18,19}$ and Herman-Polivy restraint questionnaire (HP) ${ }^{20}$. Subjects were only accepted into the study if their restraint scores were $\leq 9$ on Factor 1 (cognitive restraint) of the TFEQ and $\leq 15$ on the HP. All of these characteristics were measured during screening, and a $10 \mathrm{ml}$ blood sample was taken for baseline measurements. The baseline characteristics of the subjects are shown in table 1. The study was approved by the Medical Ethics Committee of Maastricht University, and all subjects gave their written informed consent.

\section{Anthropometry}

Anthropometric measurements were made at baseline. After the subjects had fasted overnight and voided and while they wore underwear or a swimsuit, their body weight was measured by using a digital balance accurate to $0.005 \mathrm{~kg}$ (E1200, Mettler, AlbstadtlEbingen, Germany). Height was measured to the nearest $0.001 \mathrm{~m}$ by using a wall- 
mounted stadiometer (SECA, Hamburg. Germany). BMI $\left(\mathrm{kg} / \mathrm{m}^{2}\right)$ was calculated as weight $(\mathrm{kg})$ divided by height $(\mathrm{m})$ squared. Body composition was determined by using a hydrodensitometry and deuterium dilution $\left({ }^{2} \mathrm{H}_{2} \mathrm{O}\right)$ technique ${ }^{21}$ and calculated using the combined equation of $\mathrm{Siri}^{22}$.

Whole-body density was determined by underwater weighing, and residual lung volume was simultaneously measured by using the helium dilution technique (Volugraph 2000 , Mijnhardt, Bunnik, the Netherlands). The dilution of the deuterium isotope is a measure of total body water (TBW $)^{23}$. Subjects were asked to collect a urine sample in the evening just before drinking a weighed amount of deuterium-enriched water. After ingestion of the deuterium solution, no further fluid or food consumption was permitted. A second urine sample (second voiding) was collected 10 hours after ingestion of the deuterium solution. Deuterium concentrations in the urine samples were measured by using an isotope ratio mass spectrometer (Micromass Optima, Manchester, United Kingdom). TBW was obtained by dividing the measured deuterium dilution space by $1.04^{21}$. Percentage body fat was calculated by using the 3-compartment model of $\mathrm{Siri}^{22}$.

\section{Experimental design and test oils}

The study had a randomized, single-blind, placebo-controlled, cross-over design.

Diacylglycerol (DG) was the experimental oil, and a normal triacylglycerol (TG)-based oil served as the control. DG was supplied as 'Healthy Econa' brand oil (Kao Corporation, Tokyo, Japan). This oil is $\approx 80 \%$ DG, of which $65-70 \%$ is in the $1,3-D G$ form. After analysis of the fatty acid profile of the DG-rich oil, the TG control oil was blended from a combination of $45 \%$ rapeseed oil and $55 \%$ sunflower oil to generate a similar fatty acid profile (table 2).

Table 1: baseline characteristics of the 12 female subjects

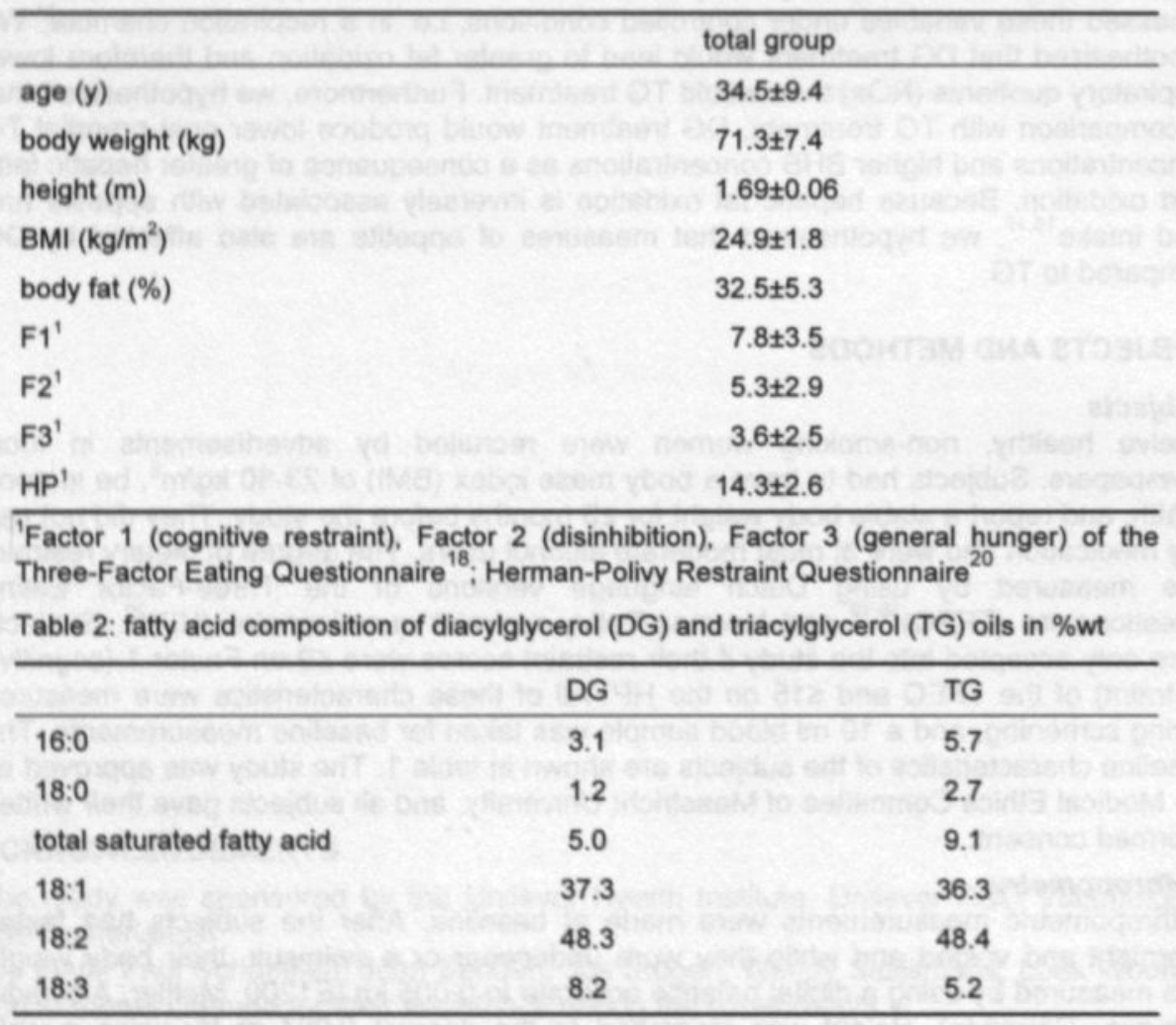




\section{Test protocol}

Subjects underwent two $36 \mathrm{~h}$ sessions in a respiration chamber for indirect calorimetry, $\mathrm{EE}$ and substrate oxidation measurements. The two respiration chamber sessions were conducted 4 weeks apart, so that the subjects would be in the same phase of their menstrual cycle. At one session, $40 \%$ of fat was provided as the DG-rich oil, whereas in the other session, $40 \%$ of fat was provided as the TG control oil. The order of DG and TG was randomized. For 3 days before each respiration chamber session, the subjects were required to consume an energy-maintenance diet provided by the experimenters. The energy content of the diet was calculated for each subject by multiplying her estimated basal metabolic rate (BMR) by a physical activity level (PAL) of 1.75. BMR was estimated using the Harris-Benedict equation ${ }^{24}$ :

BMR $(\mathrm{kcal} / \mathrm{d})=655+(9.6 \times \mathrm{W})+(1.7 \times \mathrm{H})-(4.7 \times \mathrm{A})$

where $W$ is weight $(\mathrm{kg}), H$ is height $(\mathrm{cm})$ and $A$ is age $(y)$.

All meals served before the respiration chamber sessions consisted of $55 \%$ of energy from carbohydrate, $15 \%$ from protein, and $30 \%$ from fat. The mean El of the subjects for these 3 days before the respiration chamber sessions was $10.7 \pm 0.7 \mathrm{MJ} / \mathrm{d}$.

\section{Respiration chamber protocol}

The respiration chamber was a $14 \mathrm{~m}^{3}$ room furnished with a bed, chair, computer, television, radio and cassette player, telephone, intercom, sink, and toilet. Subjects entered the chamber at 7.30 on day 1 of each experimental period. The experimental period then started at 8.00 am on day 1 and finished at 20.00 on day 2. Full details of the procedures, diets, and data-collection procedures are given below.

\section{Energy intake during respiration chamber experiment}

During the $36 \mathrm{~h}$ respiration experiments, the subjects were fed in such a way that they would be in energy balance (estimated as BMR $\times 1.6$; mean El days $1(24 \mathrm{~h})$ and days 2 $(12 \mathrm{~h})$ were $10.2 \pm 0.7$ and $6.2 \pm 0.5 \mathrm{MJ}$, respectively) ${ }^{25}$. On day 1 , all meals served in the respiration chamber consisted of $55 \%$ of energy from carbohydrate, $15 \%$ from protein and $30 \%$ from fat. El was divided over the meals as $20 \%$ for breakfast, $30 \%$ for lunch, $40 \%$ for dinner, and $10 \%$ for the evening snack. With breakfast, lunch and dinner, $40 \%$ of the fat (i.e. $12 \%$ of EI) was taken as the DG-rich or TG oil mixed with yogurt. Mean fat intake from the DG-rich oils was $33.0 \pm 2.3 \mathrm{~g}(=26.4 \pm 1.9 \mathrm{~g} \mathrm{DG})$ on day 1 . During the stay in the respiration chamber, breakfast was served at 8.00 , lunch at 12.30 , dinner at 17.00 , and evening snack at 21.30. All meals had to be finished within $0.5 \mathrm{~h}$ after being served. Subjects had ad libitum access to water for coffee or tea. Coffee and tea consumption was according to subjects' usual habits. Subjects were requested to go to sleep at 23.00 . On day 2, El was divided over the meals as $20 \%$ for breakfast, $30 \%$ for lunch, but no dinner was served. At 17.00 the subjects were given a snack that contained $10 \%$ of daily $\mathrm{El}$ and consisted of $70 \%$ of energy from carbohydrate, $15 \%$ from protein, and $15 \%$ from fat. The fat contained in the snack was comprised entirely of DG-rich or TG oil. Breakfast and lunch were served at 8.00 and 12.30 respectively. Breakfast and lunch each consisted of $55 \%$ of energy from carbohydrate, $15 \%$ from protein, and $30 \%$ from fat. Mean fat intake from DG-rich oil on day 2 was $22.2 \pm 1.4 \mathrm{~g}(17.8 \pm 1.1 \mathrm{~g} \mathrm{DG})$. All meals had to be finished within $0.5 \mathrm{~h}$ after being served. Subjects had ad libitum access to water for coffee or tea.

\section{Physical activity}

In the respiration chamber, the subjects were required to follow a low-intensity activity protocol consisting of bench-stepping exercises. These exercises were performed twice a day, i.e. at 12.00 and at 16.30 , for 30 minutes with 5 min intervals of exercise alternated with $5 \mathrm{~min}$ rest. Apart from the exercise protocol, the subjects were not restricted in their activities, except that sleeping and strenuous physical activity were not allowed. Physical activity was monitored using a radar system that operated on the Doppler principle. 


\section{Energy expenditure and substrate oxidation}

Oxygen consumption and carbon dioxide production were measured in the respiration chamber. The temperature was set at $21^{\circ} \mathrm{C}$ during day time and at $18^{\circ} \mathrm{C}$ during the night. The room was ventilated with fresh air at a rate of $70-80 \mathrm{~L} / \mathrm{min}$. The ventilation rate was measured with a dry gas meter (type 4, Schlumberger, Dordrecht, the Netherlands). The concentration of oxygen and carbon dioxide was measured using a paramagnetic oxygen analyzer (Magnos 6G, Hartmann and Braun, Frankfurt, Germany; and OA184A, Servomex, Crowborough, United Kingdom) and an infrared carbon dioxide analyzer (Uras 3G, Hartmann and Braun, Frankfurt, Germany). Six samples of outgoing air for each subject, and one sample each of fresh air, zero gas (nitrogen), and calibration gas were measured during respective 15-min periods. The collection of gas samples to be measured was controlled by a computer that also stored and processed the data ${ }^{26}$.

Twenty-four hour EE (24h EE) consisted of sleeping metabolic rate (SMR), diet-induced thermogenesis (DIT), and activity-induced EE (AEE). 24h EE was calculated twice during the $36 \mathrm{~h}$ stay in the respiration chamber by using overlapping data: from 8.00 on day 1 to 8.00 on day 2 (EE1) and from 20.00 on day 1 until 20.00 on day 2 (EE2). SMR was defined as the lowest mean EE over 3 consecutive hours between 0.00 and 7.00. DIT was calculated by plotting EE against radar output, both of which were averaged over 30 min periods. The intercept of the regression line at the lowest radar output represented the EE in the inactive state (resting metabolic rate, RMR), consisting of SMR and DIT ${ }^{25}$. DIT was calculated as RMR minus SMR. AEE was determined by subtracting RMR from 24h EE. AEE and DIT were calculated twice per respiration chamber period (AEE1 and AEE2, and DIT1 and DIT2) by using the same overlapping time periods that were used for EE1 and EE2. RQ was calculated as carbon dioxide production divided by oxygen consumption. $24 \mathrm{~h}$ RQ was calculated twice during each $36 \mathrm{~h}$ stay in the respiration chamber (RQ1 and RQ2) by using the same time periods as those used for EE1 and EE2. Mean RQ was calculated over $36 \mathrm{~h}$.

Carbohydrate and fat oxidation were calculated by using oxygen consumption and carbon dioxide production as follows ${ }^{27}$ :

Fat oxidation $(\mathrm{g} / \mathrm{d})=1.718 \times \mathrm{VO}_{2}-1.718 \times \mathrm{VCO}_{2}-0.315 \times \mathrm{P}$

Carbohydrate oxidation $(\mathrm{g} / \mathrm{d})=4.17 \times \mathrm{VCO}_{2}-2.965 \times \mathrm{VO}_{2}-0.390 \times \mathrm{P}$

where $\mathrm{VO}_{2}$ is oxygen consumption (L/day) and $\mathrm{VCO}_{2}$ is carbon dioxide production (L/day). $\mathrm{P}$ is protein oxidation $(\mathrm{g} / \mathrm{d})$ calculated from protein intake. Carbohydrate and fat oxidation were calculated twice by using the same time periods as those used for EE1 and EE2.

\section{Blood analysis}

At the screening, a baseline $10 \mathrm{ml}$ blood sample was obtained from the subjects after they had fasted overnight. During respiration chamber sessions, post-prandial blood samples were taken at 11.30 and 16.00 each day. An air lock was constructed for blood sampling during the respiration chamber sessions. After each subject opened the air lock on the inside, she wrapped a plastic bag tied to the air lock tightly around her upper arm so that no air from inside the respiration chamber could escape. After that, the air lock was opened on the outside and each subject could stretch her arm out so that a blood sample could be taken. The blood samples were mixed with EDTA to prevent clotting. Plasma was obtained by centrifugation (type1302, Hettich Zentrifugen, Tuttlingen, Germany) at $4^{\circ} \mathrm{C}$ and $3000 \mathrm{rpm}$ for $10 \mathrm{~min}$ and stored at $-80^{\circ} \mathrm{C}$ until analyzed. Glucose was analyzed by a hexokinase method (Roche Diagnostics, Basel, Switzerland), TG by the method of McGowan et al. ${ }^{28}$ (GPO-trinder 337, Sigma, St Louis), glycerol by a glycerolkinase-lipase method (Boehringer, Mannheim, Germany), FFAs by an ACSACOD method (Wako chemicals, Neuss, Germany), BHB by the method of Moore et al. ${ }^{29}$ with a semiautomated centrifugal spectrophotometer (Cobas Fara, Roche Diagnostics), and insulin by ELISA (10-1113-01, Mercodia, Upsala, Sweden). Mean plasma glucose, TG, glycerol, FFAs, BHB and insulin concentrations were calculated as the mean of 4 blood samples during the $36 \mathrm{~h}$ stay in the respiration chamber. 


\section{Appetite}

Appetite variables (hunger, fullness, appetite, satiety, thirst, estimate of prospective food intake, and desire to eat) were measured with anchored $100 \mathrm{~mm}$ line scales. The scales were anchored with phrases such as 'not hungry at all' at the left anchor and 'extremely hungry' at the right anchor. Appetite variables were measured 10 times on day 1: before and after breakfast, during the morning, before and after lunch, during the afternoon. before and after dinner, during the evening and before sleeping. Appetite variables were measured 9 times on day 2: before and after breakfast, during the morning, before and after lunch, during the afternoon, before and after the snack and before leaving the respiration chamber. Twenty-four-hour ( 08.00 on day 1 to 08.00 on day 2) appetite scores were calculated as the area under the curve (AUC) by interpolating between the last measurement on day 1 and the first measurement on day 2 . The AUC on day 2 (08.00 to 20.00$)$ was also calculated.

\section{Statistical analysis}

All data are presented as meanststandard deviations (SD). Differences in blood variables between DG and TG treatments were tested by using a one- or two-tailed 2factor repeated-measures ANOVA (treatment $x$ time of day), depending on our hypothesis. Post hoc analysis was done with a paired $t$-test. The same analysis could not be executed for the other variables, i.e. for energy balance, 24h EE, SMR, DIT, AEE, fat and carbohydrate oxidation, RQ, and appetite. For EE and substrate oxidation, this analysis could not be executed because of the overlapping time between days 1 and 2 . For the appetite variables, this analysis could not be executed because of differences in time span. Therefore, differences between values for those variables were analyzed by using a one or two-tailed paired $t$-test, depending on our hypothesis. Because of problems with blood sampling, the data analysis for the blood variables was based on only 10 subjects. Because only 5 subjects completely rated their appetite on day 2 of the $36 \mathrm{~h}$ stay in the respiration chamber, appetite scores on day 2 were analyzed with a twotailed Wilcoxon signed-ranks test. All statistics were conducted with the use of Statview SE Graphics ${ }^{\mathrm{TM}}$ software (version 4.5, Abacus Concepts Inc, Berkeley, CA, USA), and the criterion for significance was set at $p<0.05$.

\section{RESULTS}

\section{Energy balance}

On the basis of estimated EE, 24h El was intended to achieve energy balance for each subject. Actual energy balance was determined by subtracting measured EE from El. This was done only for day 1 in the respiration chamber, because on day 2 the subjects received only $60 \%$ of their calculated $24 \mathrm{~h} \mathrm{El}$. Energy balance with the DG treatment was $0.7 \pm 0.7 \mathrm{MJ}$ and was not significantly different from that with the TG treatment $(0.8 \pm 0.5$ $\mathrm{MJ}$ ), but both were significantly different from zero (both $p<0.01$ ), indicating a slightly positive energy balance.

\section{Energy expenditure}

Mean 24h EE and its components are shown in figure 1. EE during the DG treatment did not differ significantly from that during the TG treatment. The values for SMR, DIT, and AEE during DG also did not differ significantly from those during the TG treatment.

\section{Substrate oxidation}

Fat oxidation (figure 2$)$ on day 1 was significantly $(p=0.004)$ higher with the DG treatment $(60.7 \pm 15.8 \mathrm{~g} / \mathrm{d})$ than with the TG treatment $(55.8 \pm 14.4 \mathrm{~g} / \mathrm{d})$. On day 2 , fat oxidation was also significantly higher $(p<0.05)$ with the DG treatment $(64.6 \pm 16.1 \mathrm{~g} / \mathrm{d})$ than with the TG treatment $(60.6 \pm 13.7 \mathrm{~g} / \mathrm{d})$. Carbohydrate oxidation did not differ significantly between the DG and TG treatments (150.8 \pm 23.8 and $164.3 \pm 20.0 \mathrm{~g} / \mathrm{d}$, respectively) on day 1 . On day 2 , a trend toward lower carbohydrate oxidation was observed with the DG treatment than with the TG treatment $(158.0 \pm 24.1$ and $171.2 \pm 19.7 \mathrm{~g} / \mathrm{d}$, respectively; $p<0.1)$. 

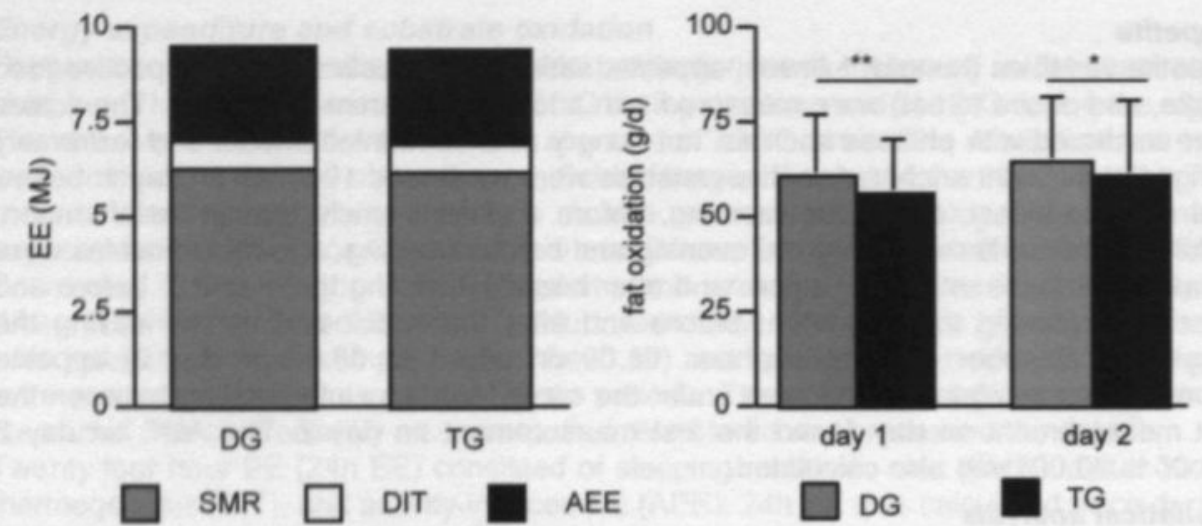

Figure 1: mean 24h energy expenditure consisting of sleeping metabolic rate (SMR), diet-induced thermogenesis (DIT) and activity-induced energy expenditure (AEE) of 12 women during treatment with diacylglycerol (DG)-rich oil or triacylglycerol (TG) control oil. There were no significant differences between the treatments.

Figure 2: mean fat oxidation in 12 women during days 1 and 2 of treatment with diacylglycerol (DG)rich oil or triacylglycerol (TG) control oil

$\because$.significantly different from TG $(" p<0.05, " p=0.004)$

Twenty-four hour RQs for days 1 and 2, as well as $36 \mathrm{~h}$ mean RQs are shown in table 3. All RQs were significantly lower during DG treatment than during the TG treatment, indicating higher fat oxidation with DG treatment than with TG treatment.

\section{Blood parameters}

Plasma concentrations of glucose, TG, glycerol, FFAs, BHB and insulin at baseline (fasted) and on days 1 and 2 (mean values from 2 samples) of each $36 \mathrm{~h}$ stay in the respiration chamber are shown in table 4 . There were no significant differences between the DG and TG treatments in glucose, TG, glycerol, FFA, and insulin concentrations on days 1 and 2. However, there was a significant $(p<0.05)$ treatment $x$ time of day effect for BHB on day 2. Post hoc analysis showed that BHB concentrations at 11.30 on day 2 of the DG treatment $(350.2 \pm 233.1 \mu \mathrm{mol} / \mathrm{L})$ were significantly higher $(p<0.05)$ than those at the corresponding time on day 2 of the TG treatment $(208.8 \pm 70.8 \mu \mathrm{mol} / \mathrm{L})$, indicating greater hepatic fat oxidation with the DG treatment than with the TG treatment. However, no other significant differences in BHB concentrations were observed between the two treatments.

Table 3: $24 \mathrm{~h}$ respiratory quotients (RQs) and $36 \mathrm{~h}$ mean RQs during days 1 and 2 of treatment with diacylglycerol (DG)-rich oil or triacylglycerol (TG) control oil ( $n=12)$

\begin{tabular}{|c|c|c|}
\hline time & DG & TG \\
\hline$R Q 1^{\prime}$ & $0.846 \pm 0.020^{3}$ & $0.853 \pm 0.018$ \\
\hline $\operatorname{RQ} 2^{2}$ & $0.851 \pm 0.017^{3}$ & $0.857 \pm 0.017$ \\
\hline $36 \mathrm{~h}$ mean RQ & $0.849 \pm 0.018^{3}$ & $0.855 \pm 0.017$ \\
\hline
\end{tabular}

from 8.00 day 1 until 8.00 day 2

'from 20.00 day 1 until 20.00 day 2

ssignificantly different from TG ( $p<0.05$, paired $t$-test) 
Table 4: plasma concentrations of free fatty acids (FFA), triacylglycerol (TG), glycerol, $\beta$ hydroxy butyrate (BHB), glucose and insulin at baseline (fasted) and on days 1 and 2 (mean values of 2 samples') of treatment with diacylglycerol (DG)-rich oil or triacylglycerol (TG) control oil $(n=10)$

\begin{tabular}{lccccc}
\hline & baseline & DG day 1 & DG day 2 & TG day 1 & TG day 2 \\
\hline FFA $(\mu \mathrm{mo} / \mathrm{L})$ & $279 \pm 112$ & $203 \pm 136$ & $181 \pm 126$ & $190 \pm 142$ & $135 \pm 89$ \\
TG $(\mu \mathrm{mo} / \mathrm{L})$ & $1125 \pm 621$ & $1288 \pm 648$ & $1374 \pm 533$ & $1254 \pm 369$ & $1320 \pm 463$ \\
glycerol $(\mu \mathrm{mol} / \mathrm{L})$ & $85 \pm 33$ & $56 \pm 21$ & $57 \pm 26$ & $64 \pm 33$ & $53 \pm 21$ \\
BHB $(\mu \mathrm{mo} / \mathrm{L})$ & $233 \pm 85$ & $251 \pm 129$ & $274 \pm 188$ & $226 \pm 136$ & $209 \pm 76$ \\
glucose $(\mathrm{mmol} / \mathrm{L})$ & $5.1 \pm 0.5$ & $5.1 \pm 0.4$ & $5.2 \pm 0.5$ & $5.1 \pm 0.4$ & $5.2 \pm 0.6$ \\
insulin $(\mathrm{mU} / \mathrm{L})$ & $9 \pm 4$ & $14 \pm 9$ & $17 \pm 11$ & $18 \pm 17$ & $16 \pm 10$ \\
\hline
\end{tabular}

'blood samples were taken at 11.30 and 16.00 on days 1 and 2; There were no significant differences between the treatments. However, $\mathrm{BHB}$ concentrations at 11.30 on day 2 of the DG treatment $(350.2 \pm 233.1 \mu \mathrm{mol} / \mathrm{L})$ were significantly higher $(\mathrm{p}<0.05$ post hoc analysis) than those at 11.30 on day 2 of the TG treatment $(208.8 \pm 70.8 \mu \mathrm{mol} / \mathrm{L})$.

\section{Appetite}

There were no significant differences between the DG and TG treatments in $24 \mathrm{~h}$ appetite profile on day 1 (table 5). However, with the DG treatment, the AUCs over $12 \mathrm{~h}$ on day 2 (table 6) for feelings of hunger, appetite, estimate of prospective food intake and desire to eat were significantly lower than those for the TG treatment. No significant differences between the two treatments were seen for feelings of fullness, satiety, or thirst.

Table 5: $24 \mathrm{~h}$ appetite variables (AUC in $\mathrm{mm} . \mathrm{h}$ ) during day 1 of treatment with diacylglycerol (DG)-rich oil or triacylglycerol (TG) control oil ( $n=12)$

\begin{tabular}{lrr}
\hline & \multicolumn{1}{c}{ DG } & \multicolumn{1}{c}{ TG } \\
\hline hunger & $752 \pm 297$ & $684 \pm 288$ \\
fullness & $1149 \pm 296$ & $1250 \pm 306$ \\
appetite & $864 \pm 311$ & $842 \pm 333$ \\
satiety & $1270 \pm 280$ & $1296 \pm 330$ \\
thirst & $1123 \pm 390$ & $1189 \pm 261$ \\
estimate of prospective food intake & $937 \pm 182$ & $912 \pm 238$ \\
desire to eat & $883 \pm 363$ & $878 \pm 330$ \\
\hline
\end{tabular}

Table 6: $12 \mathrm{~h}$ appetite variables (AUC in $\mathrm{mm} . \mathrm{h}$ ) during day 2 of treatment with diacylglycerol (DG)-rich oil or triacylglycerol (TG) control oil $(n=5)$

\begin{tabular}{lll}
\hline & DG & TG \\
\hline hunger & $281 \pm 115^{1}$ & $472 \pm 138$ \\
fullness & $624 \pm 266$ & $496 \pm 154$ \\
appetite & $375 \pm 169^{2}$ & $554 \pm 69$ \\
satiety & $646 \pm 268$ & $509 \pm 188$ \\
thirst & $540 \pm 260$ & $631 \pm 134$ \\
estimate of prospective food intake & $465 \pm 126^{\prime}$ & $605 \pm 143$ \\
desire to eat & $371 \pm 204^{2}$ & $585 \pm 194$ \\
\hline
\end{tabular}

${ }^{12}$ significantly different from TG (Wilcoxon signed-ranks test): ' $p<0.01,{ }^{2} p<0.05$ 


\section{DISCUSSION}

Compared with consumption of TG oil, consumption of DG-rich oil ( $80 \%$ DG) for 36 h was associated with greater fat oxidation and lower appetite, but there were no significant differences between the 2 treatments in total EE or blood variables. The results of the present study support the hypothesis that DG increases $\beta$-oxidation, i.e. that it enhances fat oxidation and lowers the RQ. Evidence of higher BHB concentrations during the DG treatment points to higher hepatic fat oxidation with DG treatment. However, DG consumption did not affect post-prandial TG concentrations or total $24 \mathrm{~h}$ EE. The data suggest that carbohydrate oxidation was lower with the DG treatment than with the TG treatment, but these data did not differ significantly between treatments. Although appetite profiles over day 1 did not differ significantly between the DG and TG treatments, feelings of hunger, appetite, estimated prospective food intake, and desire to eat on day 2 were significantly lower with the DG treatment than with the TG treatment.

Several studies indicated that in comparison with TG oil, dietary DG oils have beneficial effects on lipid metabolism. Consumption of DGs has been shown to produce less postprandial elevation in TG concentrations in humans ${ }^{6,7}$ and lower serum TG concentrations in humans ${ }^{10}$ and rats $^{8.9}$. Increased concentrations of ketone bodies in the serum of human subjects ${ }^{7}$ and in the urine of rats ${ }^{11}$ have been taken as an indication of higher fat oxidation. Long-term DG consumption has been reported to reduce body fat accumulation in rats ${ }^{11}$ and visceral fat in rats ${ }^{12}$ and humans ${ }^{13.14}$.

Our observations of higher fat oxidation and a lower RQ after consumption of the DG oil than after consumption of the TG oil are in line with the results of previous studies in animals that indicating alterations in fatty acid oxidation and synthesis in the liver'. In that study, the activities of enzymes involved in $\beta$-oxidation and of enzymes necessary for fatty acid synthesis in the liver were higher and lower, respectively, in rats fed DG than those fed TG. This may have caused the decreased liver TG concentrations observed in that study. Indications of increased (hepatic) fat oxidation were also observed by Wanatabe et al. ${ }^{11}$. They reported that in comparison with TG, a single dose of DG produced higher oxygen consumption in rats for up to 80 minutes after administration.

In the present study, there was modest evidence of higher $\mathrm{BHB}$ concentrations with the DG treatment than with the TG treatment, which may reflect higher (hepatic) fat oxidation during the DG intervention. However, Watanabe et al. ${ }^{7}$ observed no effect of DG on serum $\mathrm{BHB}$ concentrations. Other studies have reported lower post-prandial ${ }^{6}$ and fasting serum TG concentrations ${ }^{8,10}$ with DG oil than with TG oil, but we did not observe this in the present study. The discrepancy may be due to differences in methodology. We collected single blood samples $3.5 \mathrm{~h}$ after serving breakfast and lunch, whereas the other human studies sampled blood at multiple time points after DG supplementation or when the subjects were in a fasted state after DG consumption. In those studies, the lower plasma TG concentrations were observed in the late post-prandial (4-8h) period but not early post-prandial $(0.5-3.5 \mathrm{~h})$ period. Thus, the time between ingestion of DG and the time at which post-prandial TG levels concentrations were measured may have been too short in our study. Also, the amount of DG in other studies was much higher than that at the present study.

Hepatic fat oxidation has been shown to feed back into food intake regulation ${ }^{16,17}$. Thus, the effect of DG on appetite, especially on the second day, may have been caused by the higher fat oxidation observed.

The possible mechanism by which DG compared to TG affect lipid metabolism differentially is still speculative. The differential effects of DG and TG are not attributable to differences in digestibility or energy value. According to Taguchi $e t$ al. ${ }^{15}$, the energy contents of DG and TG measured by bomb calorimeter are 38.9 and $39.6 \mathrm{~kJ} / \mathrm{g}$, respectively. They also found no difference in digestibility between DG and TG $(96.3 \pm 0.4$ and $96.3 \pm 0.3 \%$, respectively). Wanatabe et al. ${ }^{11}$ investigated the differences in digestibility between DG and TG and also observed no difference in the amount of undigested lipids in feces. Furthermore, in the present and in previous studies, the fatty 
acid composition of TG oil was closely comparable to that of the DG oil.

It has been suggested that the position of the fatty acid on the glycerol skeleton causes the differences in lipid metabolism. During digestion, TG is hydrolyzed by 1,3-lipases to 1,2-DG and 2,3-DG, but not 1,3-DG, because the lipases only cleave at the 1 or 3 position. Further action of lipase on 1,2-DG and 2,3-DG leads to end products 2-monoacylglycerol and FFAs. These are the normal end products of TG digestion that are absorbed by intestinal mucosa cells and then used for reconstructing circulating chylomicron TG. At equilibrium, DG is composed of $65-70 \% 1,3-\mathrm{DG}$ and $30-35 \% 1,2-\mathrm{DG}$. The main end products of lipase action on 1,3-DG are free glycerol and FFAs ${ }^{8,10.30}$, These end products of DG digestion may be less readily resynthesized to chylomicron TG because such synthesis requires a glycerol-3-phosphate intermediate. FFAs may therefore be more likely to be directly transported towards the liver, where they are used for $\beta$-oxidation. This may explain why replacement of TG by DG can lower serum TG in the fasted state $^{8-10}$ and in the post-prandial state ${ }^{6.7}$ and produce a lower TG content in chylomicrons ${ }^{6}$.

In the present study, replacement of dietary TG with a DG-rich oil increased fat oxidation of $4.9 \mathrm{~g} / \mathrm{d}$ on day 1 and by $4 \mathrm{~g} / \mathrm{d}$ on day 2. Although this effect seems small on a daily basis, a sustained change in fat balance of $4 \mathrm{~g}$ fat/d generates an effect of $\approx 1460 \mathrm{~g}$ fat $/ \mathrm{y}$. In our opinion, this is quite substantial. The difference in fat oxidation of $4 \mathrm{~g} / \mathrm{d}$ could make a difference in the long term between successful and unsuccessful weight control, and therefore the replacement of TG with DG could contribute to the prevention of increasing body weight and related co-morbidities.

In conclusion, the results of the present study support the proposed beneficial effects of consumption of DG compared to TG on body composition and lipid metabolism by providing direct evidence of higher fat oxidation and lower appetite scores in humans with DG treatment than with TG treatment. In the present study, replacement of modest amounts of TG by DG decreased RQs and increased fat oxidation. The higher $\beta$-hydroxy butyrate concentrations with DG treatment indicate higher hepatic fat oxidation. There were no significantly differences between the two treatments in plasma TG concentrations, other blood variables, or total EE. Several measures of appetite, i.e. hunger, appetite, estimate of prospective food intake and desire to eat were, were significantly lower with DG treatment than with TG treatment. The putative beneficial effects of DG-rich oil on energy balance may be mediated by the secondary effects of increased hepatic fat oxidation on appetite and food intake.

\section{REFERENCES}

1 Kuczmarski M, KM Flegal, SM Campbell, CL Johnson. Increasing prevalence of overweight among US adults. The national health and nutrition examination surveys, 1960 to 1991. JAMA 1994; 272: 205-211

2 Seidell J. The impact of obesity on health status: some implications for health care costs. international journal of obesity 1995; 19: S13-16

3 Pasman WJ, WH Saris, MS Westerterp-Plantenga. Predictors of weight maintenance. Obes Res 1999; 7: 43-50

4 Westerterp-Plantenga MS, KPG Kempen, WHM Saris. Determinants of weight maintenance in women after diet-induced weight reduction. International joumal of obesity 1998; 22: 1-6

5 Saris WH. Very-low-calorie diets and sustained weight loss. Obes Res 2001; 9 Suppl 4: 295S$301 \mathrm{~S}$

6 Taguchi H, H Watanabe, K Onizawa, T Nagao, N Gotoh, T Yasukawa, R Tsushima, H Shimasaki, H Itakura. Double-blind controlled study on the effects of dietary diacylglycerol on postprandial serum and chylomicron triacylglycerol responses in healthy humans. J Am Coll Nutr 2000; 19: 789-796

7 Watanabe H, K Onizawa, H Taguchi, N Fujimori, S Naito, N Gotoh, T Yasukawa, M Hattori, H Shimasaki. Effects of diacylglycerols on lipid metabolism in human. Nippon Yukagaku Kaishi 1997: 46: 309-314

8 Hara K, K Onizawa, H Honda, K Otsuji, T Ide, M Murata. Dietary diacylglycerol-dependent 
reduction in serum triacylglycerol concentration in rats. Ann Nutr Metab 1993; 37: 185-191

9 Murata M, T Ide, K Hara. Reciprocal responses to dietary diacylglycerol of hepatic enzymes of fatty acid synthesis and oxidation in the rat. Br J Nutr 1997; 77: 107-121

10 Yamamoto K, H Asakawa, K Tokunaga, H Watanabe, N Matsuo, I Tokimitsu, N Yagi. Longterm ingestion of dietary diacylglycerol lowers serum triacylglycerol in type II diabetic patients with hypertriglyceridemia. J Nutr 2001; 131: 3204-3207

11 Watanabe H, K Onizawa, H Taguchi, M Kobori, H Chiba, S Naito, N Matsuo, T Yasukawa, M Hattori, H Shimasaki. Nutritional characterization of diacylglycerols in rats. J Japan Oil Chem Soc 1997; 46: 301-307

12 Murase T, T Mizuno, T Omachi, K Onizawa, Y Komine, H Kondo, T Hase, I Tokimitsu. Dietary diacylglycerol suppresses high fat and high sucrose diet- induced body fat accumulation in C57BL/6J mice. J Lipid Res 2001; 42: 372-378

13 Nagao T, H Watanabe, N Goto, K Onizawa, H Taguchi, N Matsuo, T Yasukawa, R Tsushima, $\mathrm{H}$ Shimasaki, $\mathrm{H}$ Itakura. Dietary diacylglycerol suppresses accumulation of body fat compared to triacylglycerol in men in a double-blind controlled trial. J Nutr 2000; 130: 792-797

14 Watanabe H, T Nagao, N Goto, Y Fukushima, K Onizawa, H Taguchi, T Ohmachi, T Yasukawa, S Naito, H Shimasaki, H Itakura. Long-term effects of dietary diacylglycerols on body fat metabolism in man. Nippon Yukagaku Kaishi 1998; 47: 369-376

15 Taguchi H, T Nagao, H Watanabe, K Onizawa, N Matsuo, I Tokimitsu, H Itakura. Energy value and digestibility of dietary oil containing mainly 1,3- diacylglycerol are similar to those of triacylglycerol. Lipids 2001: 36: 379-382

16 Kahler A, M Zimmermann, W Langhans. Suppression of hepatic fatty acid oxidation and food intake in men. Nutrition 1999; 15: 819-828

17 Scharrer E, W Langhans. Control of food intake by fatty acid oxidation. Am J Physiol 1986; 250: R1003-1006

18 Stunkard AJ, S Messick. The three-factor eating questionnaire to measure dietary restraint, disinhibition, and hunger. J Psychosom Res 1985; 29: 71-83

19 Westerterp-Plantenga MS, CRT Verwegen. The appetizing effect of an aperitif in overweight and normal-weight humans. Am J Clin Nutr 1999; 69: 205-212

20 Herman CP, J Polivy. Restrained Eating. Saunders, W.B.: Philadelphia, 1980

21 Schoeller DA E van Santen. DW Peterson. W Dietz. J Jaspan. PD Klein. Total body water measurement in humans with $O$ and $H$ labeied water. Am Clin Nutr 1980; 33: 2686-2693

22 Siri WE. Body composition from fluid spaces and density: analysis of methods. 1961. Nutrition 1993; 9: $480-491$

23 van Marken Lichtenbelt WD, KR Westerterp, L Wouters. Deuterium dilution as a method for determining total body water: effect of test protocol and sampling time. Br J Nutr 1994; 72 : 491-497

24 Harris JA, FG Benedict. A biometric study of basal metabolism in man. Carnegie Institution: Washington, DC, 1919

25 Westerterp KR, SA Wilson, V Rolland. Diet induced thermogenesis measured over $24 \mathrm{~h}$ in a respiration chamber: effect of diet composition. Int J Obes Relat Metab Disord 1999; 23: 287 292

26 Schoffelen PF, KR Westerterp, WH Saris, F Ten Hoor. A dual-respiration chamber system with automated calibration. J Appl Physiol 1997; 83: 2064-2072

27 Brouwer E. A simple formulae for calculating the heat expenditure and the quantities of carbohydrate and fat oxidised in metabolism of men and animals, from gaseous exchange (oxygen intake and carbonic output) and urine-N. Acta Physiol Pharmacol Neerlandica 1957; 6: 795-802

28 McGowan MW, JD Artiss, DR Strandbergh, B Zak. A peroxidase-coupled method for the colorimetric determination of serum triglycerides. Clin Chem 1983; 29: 538-542

29 Moore JJ, M Marcus, SM Sax. Kinetic assay of B-hydroxybutyraat in plasma with cobas bio centrifugal analyzer. Clin. Chem. 1982; 73: 1334-1339

30 Murata M, K Hara, T Ide. Alteration by diacylglycerols of the transport and fatty acid composition of lymph chylomicrons in rats. Biosci Biotech Biochem 1994; 58: 1416-1419 


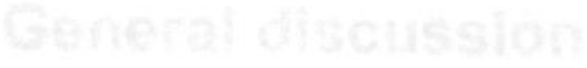




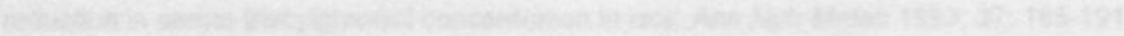

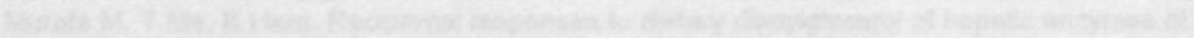
and

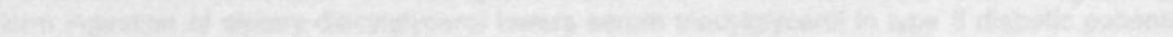

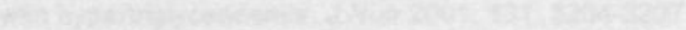

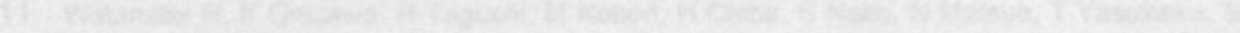

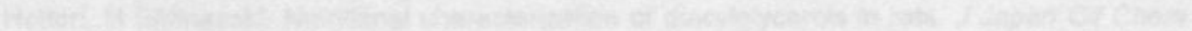

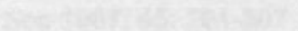

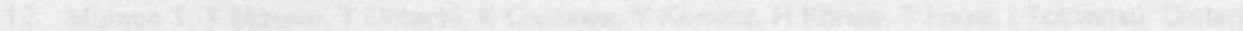

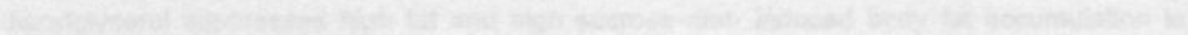

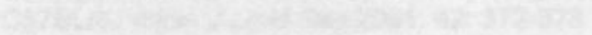

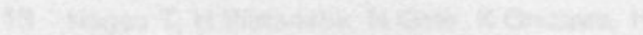

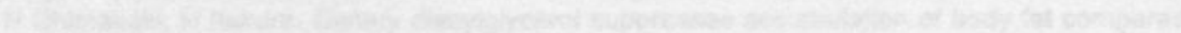

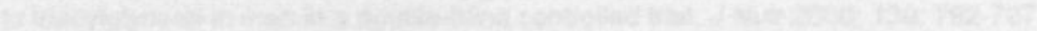




\section{General discussion}


$\mathrm{T}$

he sense of dietary fat in assessment of the etiology, prevention and treatment of obesity is to a great extent in its risk identification in the process of perception, ingestion, oxidation and/or storage. With respect to the etiology of obesity assessment of how dietary fat is perceived, why it is easily passively overconsumed, how it results in energy expenditure or body fat stored makes sense. This may consequently lead to insights in the role of dietary fat in prevention and treatment of obesity. In the following sections the state of the art with respect to fat perception, consumption, oxidation, energy expenditure and storage is discussed implying the results of the present thesis. Furthermore, dietary-fat-related possibilities for obesity prevention or treatment are presented.

\section{DIETARY FAT IN THE ETIOLOGY OF OBESITY}

\section{Dietary fat}

Dietary fats are edible fats which are visible and invisible present in food products. Fats are water non-soluble compounds. The main component of dietary fat is triacylglycerol $(98 \%)$ which is composed of three fatty acids and one glycerol molecule, but also free fatty acids $(<1 \%)$, phospholipids, glycolipids, cholesterol and cholesterol esters are present in a diet. In the present thesis, dietary fat implies (long-chain) triacylglycerol and its components, i.e. free fatty acids. The fatty acids differ with respect to chain length and degree of saturation, which both affect the main physical characteristic of triacylglycerol, i.e. its 'hardness' (e.g. oils vs. butter).

The energy density of fat is more as twice as high compared to the energy density of other macronutrients ( $37 \mathrm{vs} .17 \mathrm{~kJ} / \mathrm{g}$ for both carbohydrate and protein) which makes dietary fat an important risk factor in the etiology of obesity, since on the short-term humans regulate food intake by weight of food and not by the energy content ${ }^{1-4}$.

\section{Dietary fat consumption and obesity}

Dietary fat is often associated with obesity ${ }^{5}$. In several studies the relation between fat intake or fat preference, and fat mass of subjects has been shown ${ }^{6-9}$, but we have to keep in mind that this relationship is the result of the relation between fat intake and energy intake ${ }^{10}$. The recommended total fat intake per July 2001 in the Netherlands is $20-40 \%$ of energy for adults with a normal body weight, whereas the recommendation is $20-30 / 35 \%$ of energy for adults with an increasing body weight or who are overweight ${ }^{11}$. The Dutch National Food Consumption Survey shows that the mean reported fat intake from 1987 till 1997 is decreased with almost $3 \%$ of energy $(38.7 \%$ of energy in 1987 compared to $35.9 \%$ of energy in 1997$)^{12}$, while the incidence of obesity is increasing ${ }^{13}$. This discrepancy is probably due to selective underreporting of fat, especially by obese subjects $^{14}$. Researchers should be aware of the impact of selective underreporting especially by obese subjects, since observations may be misinterpreted and lead to false conclusions.

\section{Oral fat perception}

Considering that humans can taste carbohydrates (sweet) as well as proteins (umami), one can speculate about the existence of a specific taste receptor for fat. Studies in rats by Gilbertson and co-workers suggest that fatty acids are sensed by inhibition of delayed rectifying potassium channels present in taste receptor cells, indicating an increased activity of those cells. However, this is only true for free linoleic acid and other free cispoly-unsaturated fatty acids, but not for e.g. free oleic acid ${ }^{15-18}$. Other studies in rats have confirmed the findings of Gilbertson, i.e. in a taste aversion test, the ability to perceive this low concentration of $10 \mu \mathrm{M}$ of linoleic acid was shown ${ }^{19}$. Moreover, in a 2-bottle preference test, preference for linoleic acid over oleic acid has been shown, indicating that rats can distinguish between these different fatty acids ${ }^{20}$. In humans, we investigated the effect of free linoleic acid sensitivity for the first time. We developed a fatty acid taste perception test to investigate taste sensitivity for a low concentration $(10 \mu \mathrm{M})$ of linoleic and oleic acid. With this test, linoleic or oleic acid tasters can be discriminated from 
linoleic or oleic acid non-tasters. Our results show that $46 \%$ of the humans were able to perceive this low concentration of free linoleic acid, in contrast to only $7 \%$ of the subjects who were able to perceive oleic acid ${ }^{21}$. This implies that like in rats, also in humans there might be a specific taste sensitivity for cis-poly-unsaturated fatty acids. As for PROP taste sensitivity, this linoleic acid taste sensitivity might also have a genetic background. Linoleic acid taste tests with twins may provide evidence for a genetic background.

In humans, dietary fat sensitivity has been related to PROP sensitivity. Most studies showed that an increase in PROP sensitivity was positively related with oral fat perception ${ }^{22-25}$. However, we showed that PROP sensitivity was not related to free linoleic acid taste sensitivity ${ }^{21}$. The main reason for this discrepancy could be due to fact that the fats used in previous studies consisted of triacylglycerol in stead of one specific free fatty acid as we ${ }^{1.21}$ and Gilbertson ${ }^{15-18}$ have used. Since PROP tasters have an increased density of fungiform papillae ${ }^{26}$, they might be better tasters in general ${ }^{27}$, which may explain the positive relation between PROP and dietary fat sensitivity. The lack of a relationship between PROP sensitivity and free linoleic acid is caused by the fact that PROP and free linoleic acid have different transduction mechanisms, i.e. delayed rectifying potassium channels for linoleic acid and G-protein-coupled receptors by which PROP is sensed ${ }^{28}$, which are both laying in taste receptors cells.

Stimuli sensed by taste receptors in primates are sent to the nucleus of the solitary tract in the brainstem by three taste nerves i.e. the facial $\left(7^{\text {th }}\right)$, the glossopharyngeal $\left(9^{t}\right)$ and vagus $\left(10^{\text {th }}\right)$. From here, signals go mono-synaptically to the thalamic taste nucleus. This thalamic taste area then projects to the primary cortices in the frontal opercular cortex and anterior insular cortex, and to the secondary taste cortex in the orbifrontal cortex ${ }^{20.30}$. Next to taste information, the orbital frontal cortex also receives visual and olfactory (smell) information which is integrated in an overall sensory perception. In those regions, representation of flavor (olfaction and taste) is generated.

The texture of dietary fat, i.e. mouth feel is a component by which fat is sensed. Rolls and co-workers have shown that neurons in the orbito-frontal cortex of the brain respond when fat is in the mouth ${ }^{30}$. However, this mouth feel of fat appeared to be caused by texture rather than by the chemical structure of fat, since the same neurons also fire with silicon and paraffin oil which have the same texture but a different chemical structure than triacylglycerol ${ }^{31}$. Whether there is a specific center in the primary or secondary taste cortex for the perception of fatty acids such as free linoleic acid, is not known. The use of functional MRI scans might perhaps provide more information about the representation in the brain.

\section{Dietary fat selection and consumption}

Dietary fat is palatable ${ }^{32}$ and this relatively high hedonic value implies a risk factor with respect to the etiology of obesity.

In rats, dietary fat sensitivity, i.e. free linoleic acid taste sensitivity is related to macronutrient selection. A dietary fat-avoiding rat strain showed an increased linoleic acid taste sensitivity compared to a dietary fat-preferring rat strain. Furthermore, when placed on a high-fat diet, the fat-avoiding rat strain reduces the energy intake and remain lean, whereas the fat-preferring rat strain become rapidly obese ${ }^{33}$. In our population, we found that in non-obese humans, linoleic acid taste perception is related to body weight, in that the body mass index of linoleic acid tasters is lower than that of linoleic acid nontasters, but this relation is not present in obese subjects ${ }^{21}$. This implies that linoleic acid sensitivity may play a role in body weight regulation in the normal to overweight BMI range, whereas in the obese the importance of linoleic acid taste sensitivity on body weight regulation may be lost. With respect to fat intake regulation, we did not observe a clear observation of linoleic acid sensitivity on macronutrient selection during an ad libitum lunch experiment ${ }^{21}$. Nevertheless, this linoleic acid taste sensitivity may be a mechanism by which dietary fats are sensed and by which fat intake is regulated and may therefore be a bright spot regarding the etiology of obesity related to dietary fat.

Macronutrient selection may have a genetic background, since for instance PROP 
sensitivity which is positively related to fungiform papillae density ${ }^{26}$, appears to be related to a more general taste sensitivity ${ }^{27}$ and consequent food choice. Previous studies report contradictory results with respect to the relation between PROP sensitivity and macronutrient selection. Whereas one study observed a lower (reported) intake of dietary fat ${ }^{34}$, another found the opposite ${ }^{35}$. In our study ${ }^{36}$ we focused on actual intakes rather than reported intakes because of selective underreporting of dietary fat ${ }^{14}$. In our study, PROP tasters ate relatively more fat and less carbohydrates than PROP nontasters during an ad libitum lunch experiment with high-carbohydrate and high-fat products $^{36}$. So, difference in taste sensitivity in humans is important with respect to macronutrient selection. Therefore, in subsequent research the importance of PROP sensitivity should be acknowledged since it has been shown that PROP sensitivity affects food selection and therefore energy intake.

In addition to a genetic background, there is strong indication for a learned component in fat preference. A recent study with mono-zygotic twins who were discordant for body weight, showed that a preference for dietary fat that probably played a role in the discordance, was learned during childhood ${ }^{37}$.

\section{Fat digestion and absorption}

After triacylglycerol is ingested, it is digested by lipases to free fatty acids and 2monoacyl glycerol before absorption by intestinal mucosal cells takes place. Digestion of dietary fats starts in the mouth and stomach, although the main place of triacylglycerol hydrolysis takes place in the small intestine. Lingual lipase (mouth) and gastric lipase (stomach) causes digestion of triacylglycerol, but the amount of digestion is very small. The digestion of triacylglycerol to its main end products, i.e. free fatty acids and 2-monoacylglycerol by pancreatic lipase in the duodenum is preceded by the emulsification of triacylglycerol by bile acids. Because the hydrolysis of triacylglycerol is a highly reversible process, the free fatty acids and 2-mono-acylglycerol form, together with bile salts, mixed micelles. The end products are released by the micelles and are taken up by diffusion in the epithelial cells of the jejunum. Here, the free fatty acids and 2-monoacylglycerol are re-synthesized to triacylglycerol and transported as chylomicrons in the lymphatic circulation before it enters the blood circulation.

In contrast to long-chain fatty acids, short-chain and medium-chain fatty acids are not transported in chylomicrons through the lymphatic system before they enter the blood circulation, but are directly absorbed into the portal vein and transported to the liver where oxidation of those fatty acids takes place.

Once in the blood circulation, most of the triacylglycerol of the chylomicrons is released by lipoprotein lipase as free fatty acids and mono-acylglycerol, especially in adipose tissue and liver. After uptake, these end products are re-synthesized to triacylglycerol.

Conjugated linoleic acid (CLA) is thought to lower fat uptake by adipocytes through inhibition of lipoprotein lipase ${ }^{38.39}$ and stearoyl COA desaturase ${ }^{39.40}$. Many animal ${ }^{39.41-47}$ and some human ${ }^{48-50}$ studies have shown positive results regarding lowering fat mass. In our study on body weight maintenance, we observed positive effects on body composition. After a 3-week very-low-calorie-diet (2.1 MJ/d), a 13-week supplementation with 1.8 or $3.6 \mathrm{~g} \mathrm{CLA}$ in comparison to placebo (oleic acid) lowered \%body fat, due to an increase in fat-free mass rather than a decrease in fat mass ${ }^{51}$. Because of this increase in fat-free mass, resting metabolic rate was increased ${ }^{51}$. Taken together those results imply that a fat-based functional ingredient exists that improves body composition and therefore affects energy expenditure and as a consequence energy balance. Possible mechanisms for the effect of CLA on fat-free mass were proposed, i.e. interleukin-1 and tumor necrosis factor- $\alpha$, but more studies are needed to investigate those suggested mechanisms. Also the fact that in rats, positive results with respect to body composition after CLA administration were obtained in lean rats, but not in obese ${ }^{47}$, needs more investigation. 


\section{Dietary fat perception and metabolism}

In humans, a sensory effect of dietary fat i.e. triacylglycerol has been shown with experiments using 'modified' sham-feeding as set up. With this kind of experiments oral stimulation obtained by the 'masticating-and-expectorating' method, stimulates oral sensation without giving post-ingestive or post-absorptive effects. Gastrointestinal responses to food are generally divided into the cephalic, gastric and intestinal phases. A cephalic phase response to food is a consequence of thought, sight, smell and/or taste of food and is initiated by the parasympatic nervous system ${ }^{52}$. Using this method, a cephalic phase response, i.e. an effect of oral stimulation on gastrointestinal responses, was shown for fat. It was shown that post-prandial, but not post-absorptive ${ }^{53}$ oral exposure to fat cream cheese led to a greater plasma triacylglycerol release than did a non-fat cream cheese, crackers or no stimulus ${ }^{52}$. This phenomenon appears to be due to taste perception and to be independent of textural characteristics ${ }^{55}$ or olfactory cues ${ }^{56}$. Although an increased post-prandial triacylglycerol concentration is a risk factor for coronary heart disease ${ }^{57}$, also the positive effect of this cephalic response to dietary fat i.e. a metabolic preparation through a taste signal for subsequent food intake should be mentioned.

\section{The satiating effects of dietary fat}

Fat causes effects on satiation and satiety by different mechanisms represented in the satiety cascade ${ }^{58}$.

\section{Sensory}

Specific satiety may be dependent of sensory properties of foods, but also macronutrient specific satiety occurs ${ }^{59}$. We showed that fat-specific satiety occurred at dinner after a two-week use of oil high in linoleic acid compared to the oil high in oleic acid ${ }^{60}$. At dinner subjects ate relatively less fat when linoleic acid was present in the food and was consumed during the two weeks preceding the test day, compared to oleic acid (45 vs. 48 energy\%). This indicates that different fatty acids have different metabolic effects. Furthermore this fat-specific satiety may affect fat storage, since the energy cost of fat storage originating from dietary carbohydrate or protein is much higher than from dietary $\mathrm{fat}^{61}$. Fat-specific satiety in comparison to other macronutrients had been shown before ${ }^{62}$, while in the present study the effects of fatty acids saturation on fat-specific satiety was observed. Since previously the relation of saturation with satiety was shown in that linoleic acid was more satiating than oleic acid ${ }^{63.64}$, the effects we observed ${ }^{60}$ may have been fat-specific, i.e. caused by the differences in saturation of the fatty acids. So, the use of linoleic acid might lower (relative) fat intake by fat-specific satiety and/or energy intake by an decreased appetite and could therefore be a tool in the prevention or treatment of obesity.

Although the metabolic effect of lingual lipase in humans is small, it might be of importance in taste sensitivity. Through secretion of lingual lipase by the von Ebner Gland in humans ${ }^{65-68}$, free fatty acids are formed that, in addition to the small concentration of free fatty acids present in foods, might be sufficient to be perceived ${ }^{55}$ and might induce affects on food intake regulation as has been shown by Gilbertson ${ }^{17}$. However, it remains to be shown how specific or general this applies to consequences of fat intake. We did not observe a relationship of linoleic acid sensitivity with fat selection in humans at a mixed lunch experiment ${ }^{21}$. But when linoleic acid was present in a low concentration in the food offered, we showed that linoleic acid taste sensitivity played a role in food intake regulation". Linoleic acid tasters finished their meals because of satiation whereas linoleic acid non-tasters tended to terminate their meals because of sensory influences. This was the case for a low energy food with addition of a low concentration of free linoleic acid, but also for high energy foods in which free linoleic acid was present'. Taken together, this implicates that addition of free linoleic acid to low-fat, low-energy foods affects food intake regulation, i.e. meal termination in linoleic acid tasters to the same extent as high-fat, high-energy foods. Since it was again shown that on the short-term subjects eat by weight of food rather than by energy content', a 
practical implication lays in the fact that addition of a low concentration free linoleic acid might lower energy intake and consequently affect energy balance in about half of the population.

\section{Cognitive}

When eating familiar food items, as a consequence of previous intakes regulation of food intake and macronutrient selection through learned satiety may occur ${ }^{69}$. Within one meal, regulation of intake happens by weight of food rather than by energy content ${ }^{1-4}$. However, energy intake compensation may take place during the day through previous cognitive learning of energy content of food.

\section{Post-ingestive}

Both the stomach and the gut give post-ingestive satiety signals after dietary fat intake. First of all, gastric distension is a satiety signal ${ }^{70}$. When a high-fat soup was directly infused into the stomach, the emptying rate, which is inversely related to gastric distension, as well as the satiating efficiency, appeared not to be different from an isoenergetic and equal-volume carbohydrate infusion. However, when given the same soups orally, the gastric emptying was delayed with the high-fat soup compared to the high-carbohydrate soup, which means that the gastric distension was prolonged, leading to an increased satiating capacity ${ }^{71}$. Furthermore, oral infusions of corn oil compared to gastric infusions delayed gastric emptying in rats ${ }^{72}$. The distinction between oral and gastric delivery suggests that orosensory stimulation has influence on gastric emptying and therefore on distension ${ }^{73}$ which in turn affects satiety ${ }^{70}$. In the previous study, no effect of fat compared to an equal-volume carbohydrate load was observed regarding gastric emptying when administered intra-gastrically. However, one can speculate that under normal conditions because of the high energy density, dietary fat will give a relatively small satiety effect compared to an iso-energetic carbohydrate or protein load. Although after gastric infusion, fat showed the same satiating efficiency compared to carbohydrate $^{71}$, differences between different fatty acids might occur. Indeed, it was shown that intestinal infusion of linoleic acid was a more potent inhibitor of food intake than oleic acid ${ }^{74}$. This may be caused by inhibition of the same type of delayed rectifying potassium channels in taste receptor cells as Gilbertson investigated in tongue tissue, since those channels have been shown to be also present in duodenum, pancreas and liver $^{18}$. Therefore the effect of free linoleic acid on food intake regulation might also be caused by linoleic acid sensitivity of the digestive tract.

Once fats and fatty acids are present in the digestive tract, they cause several actions mostly present to optimize fat absorption. When fat is present in the duodenum it stimulates the release of bile salts and pancreatic lipase which are necessary for triacylglycerol digestion. Furthermore, cholecystokinin (CCK) which is produced by endocrine cells of the intestinal mucosa of duodenum and proximal jejunum, is released into the blood circulation. Next to functions to optimize fat uptake (increase of the pancreatic enzyme secretion, increase of the contraction of the gall bladder, relaxation of the sphincter of Oddi, inhibition of gastric emptying and increase of the motility of the intestine), CCK is regarded as a satiety signal ${ }^{75}$ in rats as well as in humans ${ }^{76}$. It has been shown that CCK inhibits food intake and is positively affects satiety ${ }^{77.78}$, whereas CCK receptor antagonists increases food intake ${ }^{79,80}$. Next to indirect affects via e.g. stomach emptying. CCK also shows direct effects on food intake. When administered centrally, CCK suppressed food intake ${ }^{81}$, while CCK plasma concentrations were not affected. Again, it has been shown that also regarding CCK release, chain length as well as saturation is of importance, i.e. the longer the fatty acid and the more unsaturated the fatty acid, the greater the CCK release ${ }^{82,83}$. Whether e.g. diacylglycerol would affect CCK differently from triacylglycerol needs to be elucidated. Next to CCK, triacylglycerol and free fatty acids in the intestinal tract cause secretion of pancreatic procolipase, which after trypsin cleavage, is formed to enterostatin. Enterostatin has been linked to satiety. It has been shown that peripherally and centrally administration of enterostatin decreases food intake ${ }^{84}$, specifically fat intake in rats ${ }^{85}$, indicating a peripheral and central site of 
action. The peripheral response involves an afferent vagal signaling pathway, whereas the central response is mediated through serotonergic and opiodergic pathways ${ }^{\text {s4 }}$. Furthermore, when free fatty acids reach the ileum before absorption, an 'ileal brake' is provoked. This mechanism is present in order to optimize nutrient digestion and absorption by delaying intestinal transit time ${ }^{86}$. Meanwhile this mechanism might affect satiety, because the prolonged presence of free fatty acids in the intestine might cause more time for release of satiating compounds like CCK and enterostatin.

\section{Post-absorptive}

The metabolic control of food intake is mainly caused by the liver. Hepatic macronutrient oxidation is inversely related with eating ${ }^{87}$. This is also true for dietary fat. In humans as well as in rats, it has been shown that when fat oxidation is inhibited, for example with etomoxir (carnitine palmitoyltransferase-1 inhibitor) or mercapto-acetate (acyl-CoAdehyrogenase inhibitor), meal size and/or intermeal interval was affected ${ }^{87-89}$. Furthermore, ingestion of medium chain fatty acids, which are hepatically oxidized more rapidly than long-chain fatty acids, lowered subsequent energy intake ${ }^{90.91}$. Vagotomy setups indicate that the pathway for this metabolic satiety involves presumably hepatic afferent signals to the brain ${ }^{92.93}$. So, hepatic fat oxidation is regarded as a metabolic satiety signal, responsible for a prolonged intermeal interval ${ }^{99}$ after fat consumption compared to carbohydrate consumption.

In addition to gastrointestinal factors, signals arising from the adipose tissue, e.g. leptin might affect satiety and therefore food intake ${ }^{95}$.

In summary, dietary fat induces potent satiating signals, but seems to have a smaller effect on short-term satiation and satiety than carbohydrate or protein, and therefore dietary fat is a risk factor for the etiology of obesity. However, the prolonged intermeal interval caused by dietary fat compared to carbohydrate ${ }^{94}$ is a bright spot with respect to the fat-related etiology of obesity.

\section{Storage capacity of fat}

Regarding body storage, protein and carbohydrate have limited storage capacity in contrast to fat, which has an almost unlimited storage capacity. For example a lean nonobese man of $80 \mathrm{~kg}$ with a percentage of body fat of $15 \%$ has a fat mass, i.e. fat storage of $12 \mathrm{~kg}$ in contrast to glycogen storages in liver and muscle of $\sim 0.5 \mathrm{~kg}$. Because of the limited capacity of protein and glycogen storage, excess intake of protein, carbohydrate and fat will be stored as body fat mainly in adipose tissue.

Next to an efficient nutrient utilization for fat $(\sim 98 \%)$ compared to carbohydrate $(\sim 93 \%)$ and protein $(\sim 75 \%)^{96}$, also the storage of dietary fat as body fat is much more (energy) efficient compared to the storage of dietary protein and carbohydrate as body fat (energy cost as body fat, i.e. $\sim 0.02 \mathrm{MJ}$ per $\mathrm{MJ}$ ingested dietary fat vs. $\sim 0.25 \mathrm{MJ}$ per MJ ingested protein or carbohydrate). This is the result of the major conversion needed by the latter two before storage as body fat is possible ${ }^{61}$. Furthermore, because of the macronutrient oxidation hierarchy, dietary fat seems the most obvious macronutrient for storage after consumption. Taken together, the efficiency and capacity of body fat storage from dietary fat is a major risk factor for the etiology of obesity.

\section{Fat oxidation}

$\mathrm{We}^{97}$ and others ${ }^{98,99}$ have shown that diacylglycerol compared to triacylglycerol increased fatty acid oxidation. In a $36 \mathrm{~h}$ respiration chamber experiment we showed that absolute $(\mathrm{g})$ as well as relative (RQ) fat oxidation was increased by diacylglycerol compared to triacylglycerol when subjects were fed in energy balance. Although not directly proven, this is probably due to an increased hepatic fat oxidation, since mean plasma $\beta$-hydroxy-butyrate level, as a biomarker for hepatic fat oxidation, tended to be higher with diacylglycerol compared to triacylglycerol intervention. Since $\sim 70 \%$ of diacylglycerides consist of 1,3 diacylglycerol, the end products caused by 1,3-pancreatic lipases are free fatty acids and glycerol, which are presumably directly absorbed into portal vein and transported to the liver, where fat oxidation can take place. In our study. 
we observed an increase of $\sim 4.5 \mathrm{~g}$ fat oxidation per day. Although the effect seems small on daily basis, a sustained change in fat balance of $4.5 \mathrm{~g}$ fat per day generates an effect of $\sim 1640 \mathrm{~g}$ fat per year. Furthermore, diacylglycerol was shown to decrease parameters of appetite, most likely due to an increase in hepatic fat oxidation. So, replacement of 'normal' triacylglycerol by a fat-based functional ingredient, i.e. diacylglycerol affects fatty acid oxidation and may consequently lower fat storage on the long term. Furthermore, the improved appetite might prevent excessive energy intake and could also positively affect the energy balance. Although a trustworthy mechanism is proposed, the exact mechanism of diacylglycerol needs more investigation, probably with the use of tracers $^{100}$.

To reach energy balance, macronutrient balance is necessary ${ }^{101}$. This implicates that after a high-fat meal, fat oxidation should be increased and after a high-carbohydrate meal, carbohydrate oxidation should be increased. This is true for carbohydrate in contrast to dietary fat, which lacks the ability to promote its own oxidation on the shortterm $^{102-104}$, which might be a risk factor for the etiology of obesity. This is due to the metabolic priority of macronutrient oxidation, i.e. first alcohol, than protein, than carbohydrate and at last fat. Therefore, later during the intermeal interval fat oxidation increases $^{105}$. The inability of dietary fat to promote its oxidation is not unlimited. Under normal conditions, after several days ( $<7$ days) of high fat feeding, fat oxidation is increased $^{106}$. Flatt opposed two mechanisms by which fat oxidation can be increased to match fat intake; 1) by maintaining glycogen stores in a lower range or 2) by increasing the adipose tissue mass. The first hypothesis was confirmed in a study in which fat oxidation increased after a high-fat diet using exercise to lower glycogen stores compared to no-exercise and high-fat diet in lean subjects ${ }^{107}$. In general fat oxidation is increased in obese subjects compared to lean individuals ${ }^{108}$ because of their high fat mass $^{109}$. It is however thought that obese lack the ability to adjust to fat oxidation after a high fat meal ${ }^{110}$. Nevertheless when glycogen stores are lowered with exercise, fat oxidation after a high-fat diet was increased to the same extent as lean subjects when corrected for energy intake ${ }^{111}$.

When suggesting a switch of a high-fat diet to a high-carbohydrate diet we have to keep in mind that this might only be beneficial when overall energy intake is lowered. Since carbohydrates can be converted to dietary fat, one expects that a high-carbohydrate diet increases hepatic de novo lipogenesis in humans. Although under normal circumstances this is not of quantitative significance on the short term ${ }^{112}$, this does not mean that excessive intake of carbohydrate will not affect fat storage. Although carbohydrates promote carbohydrate oxidation and therefore energy expenditure, fat oxidation will be decreased by the effect of insulin on hormone sensitive lipase ${ }^{113}$. Therefore lipogenesis as well as fat oxidation are inhibited, resulting in storage of ingested fat in adipose tissue $^{112}$. However, because of differences in storage efficiency, carbohydrate overfeeding compared to an iso-energetic fat overfeeding, led to an energy storage of $75-85 \%$ in contrast to a $90-95 \%$ energy storage when overfeeding with fat ${ }^{11^{4}}$.

Functional ingredients that increase fat oxidation and therefore lower fat storage, may be effective for the treatment or prevention of obesity.

\section{Dietary fat and energy expenditure}

It has been suggested that a reduced thermogenic response after food intake, e.g. diet induced thermogenesis is related to the incidence of obesity. Compared to protein and carbohydrate, the $24 \mathrm{~h}$ diet-induced thermogenesis generated after consumption is rather low for dietary fat $(\sim 10 \%$ compared to $\sim 15 \%$ of $24 \mathrm{~h}$ energy expenditure for a high fat and a high carbohydrate/high protein diet respectively) ${ }^{115,19}$. This decreased diet-induced thermogenesis resulted in a tendency for an decreased energy expenditure at the highfat intervention compared to the high-carbohydrate/high protein intervention. On the longer term, however, this effect seems to disappear. After a 6-month use of full-fat compared to reduced-fat products, no differences with respect to diet-induced thermogenesis or energy expenditure was observed. This might be explained by the fact 
that the group consuming full-fat products, fat oxidation was increased and did not differ from fat intake ${ }^{117}$, indicating that macronutrient balance was reached.

Stimulation of fat oxidation affects energy expenditure only when there is no compensation with respect to carbohydrate oxidation. The effect of fat oxidation on energy expenditure might give more positive results when fat storage, e.g. body composition is affected by lowering fat mass or increasing fat-free mass. This is because fat-free mass is the main component of variance of the resting metabolic rate, which is the main determinant of energy expenditure ${ }^{118}$.

Until so far, dietary fat related to risk factors in the etiology of obesity are discussed. In summary, the high energy density together with the hedonic value and the delayed satiating capacity promotes passive overconsumption of dietary fat. Furthermore, the lack of dietary fat in promoting its own (short-term) oxidation as well as being a poor stimulant of diet-induced thermogenesis and its efficient and almost unlimited storage capacity are metabolic risk factors in the etiology of obesity. From an evolutionary point of view, it can be understood that during the early days, when food was not commonly available, the possibility for high fat hyperphagia might have been necessary for survival of the individual during periods with food shortage. However, nowadays, with high availability of high-fat food products, the incidence of obesity can be regarded as a psychological adaptation to a new environment ${ }^{119}$.

Next to those risk factors, dietary fat also shows some bright spots with respect to the etiology of obesity. First of all, linoleic acid taste sensitivity affects macronutrient selection, e.g. lowered fat intake in rats ${ }^{17}$. Furthermore, dietary fat intake may be reduced as a consequence of fat-specific satiety ${ }^{62}$. Satiety and therefore energy intake may be affected by the use of fats with different chemical compositions, possibly through the relation between (hepatic) fat oxidation and satiety. Also the prolonged intermeal interval after fat consumption compared to carbohydrate ${ }^{34}$ is a bright spot with respect to the relation between fat intake and obesity.

\section{TREATMENT OF OBESITY RELATED TO DIETARY FAT WITH THE USE OF FAT- RELATED FUNCTIONAL INGREDIENTS}

The identified risk factors in the etiology of obesity related to dietary fat may be used as concepts in changing dietary fat intake or fat metabolism by means of functional ingredients in order to prevent or treat obesity.

\section{Hedonic value}

First of all, when investigating possible ingredients, it is important to pay attention to the hedonic value of those ingredients. Since fat is palatable ${ }^{120}$, the ingredients should also have the same hedonic value in order to prevent that one will revert to dietary fat in stead of to this ingredient. However, the key characteristics of dietary fat that cause the high hedonic value are not completely understood.

\section{Energy density}

One solution to fight against dietary fat-induced obesity is by ingredients that tackle the energy density of foods by lowering the energy content and/or absorption. Fat replacers are ingredients that (partly) replace dietary fat in foods, and are thought to reduce energy intake by lowering fat intake. Different fat replacers are on the market, e.g. Olestra, and Olibra $^{\mathrm{T} M}$. Olestra is a sucrose polyester (SPE), i.e. a synthetic fat made by a chemically substitution of a sucrose molecule to long-chain fatty acids derived from edible fats. Olibra $^{\mathrm{TM}}$ is also based on fat, consisting of a fat emulsion. Next to fat-based fat replacers, also carbohydrate-based, e.g. Passelli and protein-based, e.g. Simplesse exist. The most common fat replacer is Olestra. Olestra is not hydrolyzed by pancreatic lipase and therefore the fatty acids substituted to sucrose are not absorbed in the intestine $^{121}$. Furthermore, the sensory properties are comparable to normal edible dietary fats, so applying fat replacers in a diet promises positive results which indeed have been 
observed. On the short-term, Olestra ${ }^{122-125}$ as well as Olibra ${ }^{\mathrm{m}}{ }^{126}$ reduces energy intake. However, energy intake compensation for the reduction in energy intake ${ }^{123}$ by increasing carbohydrate intake ${ }^{127}$ has been observed. On the longer term positive results have been shown ${ }^{128-130}$, but also no difference in energy intake and body weight after 3 months use of SPE has been observed ${ }^{131}$. The latter is probably due to the effects of SPE on metabolic pathways. Even though no differences regarding sensory properties are observed, SPE accelerates gastric emptying, tends to decrease gut transit time, and decreases the release of CCK in comparison to fat ${ }^{132}$. Furthermore, since the fatty acids are not absorbed, the metabolic satiety signal caused by hepatic fat oxidation will not take place. So, all these metabolic effects of SPE imply a reduced satiety and therefore energy intake compensation might occur. This energy intake compensation observed is subject-specific; gender, body weight, dietary restraint, duration of the use of the replacer are all factors that affect energy intake compensation ${ }^{61}$.

Another functional ingredient related to fat absorption is chitosan. It is extracted from shells of crustaceans and thought to lower fat absorption by binding to dietary fat. Although chitosan is widely available on the market, under a variety of names (Fat blocker, Fat absorb), there is only limited evidence for positive effects regarding longterm body weight control from placebo-controlled, double-blind studies ${ }^{133}$. The lack of positive results is probably due to the fact that fat absorption, measured as fecal fat content is not inhibited by chitosan compared to placebo ${ }^{134,135}$. In contrast, Orlistat (Xenical®), which is a gastrointestinal lipase inhibitor ${ }^{136}$ prevents dietary fat absorption with $30 \%$ shown by an increased fecal fat content ${ }^{134}$. This mechanism explains the positive observations from medium and long-term clinical studies. Orlistat together with a hypo-caloric diet enhances weight loss ${ }^{137,130}$ and sustains a lowered body weight during weight maintenance ${ }^{137}$ compared to control.

\section{Storage}

The previous mentioned functional ingredients all affected fat metabolism by inhibition of fat absorption in the intestine and therefore lowering energy densitv. However. ingredients might also affect fat uptake in the adipose tissue and therefore prevent fat storage. Conjugated linoleic acid (CLA) lowers fat uptake by adipocytes ${ }^{38-40}$ and therefore positive results regarding lowering fat mass in animal ${ }^{39.41-47}$ and human ${ }^{48-50}$ studies have been shown. Moreover, CLA increases fat-free mass ${ }^{39.41-43}$ and therefore increases energy expenditure ${ }^{41.51}$.

\section{Oxidation}

Diacylglycerol as well as medium-chain fatty acids are dietary fats that promote fat oxidation, and therefore might affect energy expenditure and/or fat storage and consequently body composition.

In this sense, the substitution of triacylglycerol with diacylglycerol might therefore be a tool in the approach of obesity. We ${ }^{97}$ and others ${ }^{98.99}$ have shown that diacylglycerol compared to triacylglycerol increased fatty acid oxidation, probably due to an increased hepatic fat oxidation. Until now, only two (longer term) studies have been published regarding triacylglycerol substitution by diacylglycerol on weight loss, in which both the subjects receiving diacylglycerol lost significantly more body weight after 4 , respectively 24 weeks of consumption compared to triacylglycerol ${ }^{139,140}$.

Also medium-chain fatty acids have been shown to increase fat oxidation ${ }^{141,142}$ compared to 'normal' long-chain fatty acids. Furthermore in comparison with long-chain fatty acids, medium-chain fatty acids increase thermogenesis and energy expenditure ${ }^{141.143}$. However, because of gastric-intestinal discomfort, large doses of medium-chain triacylglycerides can not applied in the diet. 


\section{Satiety}

Ingredients that interact with the poor satiating capacity of dietary fat directly or via e.g. an increased hepatic fat oxidation, also might be of interest regarding the (over)consumption of dietary fat and its relation in the etiology of obesity.

Linoleic acid might be one of those ingredients. We ${ }^{60}$ and others ${ }^{64.142}$ have shown that linoleic acid compared to oleic acid induces a greater (fat-specific) satiety. Furthermore with respect to linoleic acid taste sensitivity, free linoleic acid might affect meal termination in linoleic acid tasters, although no effect on the amount eaten was observed'.

With respect to CLA, we showed, a clear effect of a 13-week supplementation on appetite ${ }^{125}$. Although energy intake was not affected at breakfast, CLA may affect $24 \mathrm{~h}$ energy intake by the suppression of appetite.

Also diacylglycerol was shown to decrease appetite compared to triacylglycerol ${ }^{97}$, probably due to the increase of (hepatic) fat oxidation.

Enterostatin, a peptide released by the digestive tract after dietary fat consumption might also be an ingredient involved in reduced food, i.e. fat intake since it has been linked to satiety. It has been shown that administration of enterostatin decreases food intake ${ }^{84}$, specifically fat intake in rats ${ }^{85}$. In humans, however, the effect of enterostatin administration is not as unambiguous as in rats. Neither intravenous nor oral administration has been shown to decrease food intake ${ }^{146,147}$.

\section{CONCLUSIONS}

Dietary fat is related to the etiology of obesity by several components. Dietary fat has a high energy density and together with the hedonic value and the delayed satiating capacity, it promotes passive overconsumption. Furthermore, the lack of dietary fat in promoting its own (short-term) oxidation as well as being a poor stimulant of diet-induced thermogenesis and its efficient and an almost unlimited storage capacity are metabolic risk factors in the etiology of obesity. However, next to those effects of dietary fat on the etiology of obesity, there are also some bright spots with respect to this relationship. Those bright spots, i.e. linoleic acid taste sensitivity ${ }^{21}$ and its relation with food intake regulation ${ }^{r}$, and body mass index ${ }^{21}$, as well as the effect of dietary fats with different chemical structures on (fat-specific) satiety ${ }^{62.145,148}$, (hepatic) fat oxidation and therefore on satiety ${ }^{97}$, or fat storage ${ }^{51}$ are all aspects that increase the sense of dietary fat.

\section{REFERENCES}

1 Kamphuis MMJW, MS Westerterp-Plantenga, WHM Saris. The effect of addition of linoleic acid on food intake regulation in linoleic acid tasters and linoleic acid non-tasters. Br J Nutr in press

2 Westerterp-Plantenga MS. Eating behavior in humans, characterized by cumulative food intake curves--a review. Neurosci Biobehav Rev 2000; 24: 239-248

3 Blundell JE, JR Cotton, H Delargy, S Green, A Greenough, NA King, CL Lawton. The fat paradox: fat-induced satiety signals versus high fat overconsumption. Int $J$ Obes Relat Metab Disord 1995; 19: 832-835

4 Stubbs RJ, P Ritz, WA Coward, AM Prentice. Covert manipulation of the ratio of dietary fat to carbohydrate and energy density: effect on food intake and energy balance in free-living men eating ad libitum. Am J Clin Nutr 1995; 62: 330-337

5 Tucker LA, M Kano. Dietary fat and body fat: a mulivariate study of 205 adult females. Am J Clin Nutr 1992; 56: 616-622

6 Romieu I, WC Willet, MJ Stampfer, GA Colditz, L Samson, B Rosner, CH Hennekens, FE Speizer. Energy intake and other determinantes of relative weight. Am J Clin Nutr 1988; 47 : 406-412

7 Tremblay A, G Plourde, JP Despres, C Bouchard. Impact of dietary fat content and fat oxidation on energy intake in humans. Am J Clin Nutr 1989; 49: 799-805

8 Miller WC, AK Lindeman, J Wallace, M Niederpruem. Diet composition, energy intake, and exercise in relation to body fat in men and women. Am J Clin Nutr 1990; 52: 426-430

9 Mela DJ. Sacchetti, D.A. Sensory preferences for fats: relationships with diet and body 
composition. Am J Clin Nutr 1991; 53: 908-915

10 Westerterp KR, WP Verboeket-van de Venne, MS Westerterp-Plantenga, EJ Velthuis-te Wierik, C de Graaf, JA Weststrate. Dietary fat and body fat: an intervention study. Int J Obes Relat Metab Disord 1996; 20: 1022-1026

11 Gezondheidsraad. 2001. voedingsnormen-energie, eiwitten, vetten en verteerbare koolhydraten. Den Haag: Gezondheidsraad. 85-140

12 Voedingscentrum. 1997. voedselconsumptiepeiling. Den Haag: Voedingscentrum

13 Seidell JC. Obesity, insulin resistance and diabetes-a worldwide epidemic. Br J Nutr 2000; 83 Suppl 1: S5-8

14 Goris AHC, MS Westerterp-Plantenga, KR Westerterp. Undereating and underrecording of habitual food intake in obese men: selective underreporting of fat intake. Am J Clin Nutr 2000; 71: $130-134$

15 Gilbertson TA, T Fontenot, L Liu, H Zhang, WT Monroe. Fatty acid modulation of K+ channels in taste receptor cells: gustatory cues for dietary fat. Am J Physiol 1997; 272: C1203-C1210

16 Gilbertson TA. Gustatory mechanisms for the detection of fat. Curr Opin Neurobiol 1998; 8: 447-452

17 Gilbertson TA, L Liu, DA York, GA Bray. Dietary fat preferences are inversely correlated with peripheral gustatory fatty acid sensitivity. Ann N Y Acad Sci 1998; 855: 165-168

18 Gilbertson T, I Kim, L Liu. Sensory cues for dietary fat: implications for macronutrient preferences. In: Ailhaud GB Guy-Grand (eds). Progress in Obesity Research. John Libbey \& Company Ltd.: 1998, pp 167-171

19 Smith JC, EM Fisher, V Maleszewski, B McClain. Orosensory factors in the ingestion of corn oil/sucrose mixtures by the rat. Physiol Behav 2000; 69: 135-146

20 Tsuruta M, T Kawada, T Fukuwatari, T Fushiki. The orosensory recognition of long-chain fatty acids in rats. Physiol Behav 1999; 66: 285-288

21 Kamphuis MMJW, MS Westerterp-Plantenga. The role of linoleic acid taste perception in the etiology of obesity. submitted

22 Nasser JA, CJ Chou, HR Kissileff, CN Boozer, FX Pi-Sunyer. PROP taster status and the ability to detect the presence of added conjugated linoleic acid in high fat ice cream. Obes Res 1999; 7:87S

23 Duffy VB, LM Baroshuk, LA Lucchina, LH Snyder, A Tym. 1996. Supertasters of PROP (6-npropylthiouracil) rate the highest creaminess to high-fat milk products. In AChemS. Sarisota, Florida. 598

24 Tepper BJ, RJ Nurse. Fat perception is related to PROP taster status. Physiol Behav 1997; 61: 949-954

25 Tepper BJ, RJ Nurse. PROP taster status is related to fat perception and preference. Ann N Y Acad Sci 1998; 30: 802-804

26 Bartoshuk LM, VB Duffy, IJ Miller. PTC/PROP tasting: anatomy, psychophysics, and sex effects. Physiol Behav 1994; 56: 1165-1171

27 Bartoshuk LM, VB Duffy, LA Lucchina, J Prutkin, K Fast. PROP (6-n-propylthiouracil) supertasters and the saltiness of $\mathrm{NaCl}$. Ann N Y Acad Sci 1998; 855: 793-796

28 Firestein S. The good taste of genomics. Nature 2000; 404: 552-553

29 Katz DB, MA Nicolelis, SA Simon. Nutrient tasting and signaling mechanisms in the gut. IV. There is more to taste than meets the tongue. Am J Physiol Gastrointest Liver Physiol 2000; 278: G6-9

30 Rolls ET. Taste and olfactory processing in the brain, and its relation to the regulation of food intake. In: Westerterp-Plantenga MS, AB SteffensA Tremblay (eds). Regulation of food intake and energy expenditure. Edra: Milan, 1999

31 Rolls ET, HD Critchley, AS Browning, I Hernadi, L Lenard. Responses to the sensory properties of fat of neurons in the primate orbitofrontal cortex. J Neurosci 1999; 19: 1532-1540

32 Drewnowski A. Energy density, palatability, and satiety: implications for weight control. Nutr Rev 1998; 56: $347-353$

33 Schemmel R, O Mickelsen, JL Gill. Dietary obesity in rats: Body weight and body fat accretion in seven strains of rats. J Nutr 1970; 100: 1041-1048

34 Savage J, HIM Davidson. 2000. Genetic sensitivity to PROP and its relationship with energy intake and short time satiety. Paris: European Journal of Clinical Nutrition. S15

35 Yackinous C, JX Guinard. Relation between PROP taster status and fat perception, touch, and olfaction. Physiol Behav 2001; 72: 427-737 
36 Kamphuis MMJW, MS Westerterp-Plantenga. PROP sensitivity affects macronutrient selection. Physiol Behav in press

37 Rissanen A, P Hakala, L Lissner, CE Mattlar, M Koskenvuo, T Ronnemaa. Acquired preference especially for dietary fat and obesity: a study of weight-discordant monozygotic twin pairs. Int J Obes Relat Metab Disord 2002; 26: $973-977$

38 Lin Y, A Kreeft, JA Schuurbiers, R Draijer. Different effects of conjugated linoleic acid isomers on lipoprotein lipase activity in 3T3-L1 adipocytes. J Nutr Biochem 2001; 12: 183-189

39 Park Y, KJ Albright, W Liu, JM Storkson, ME Cook, MW Pariza. Effect of conjugated linoleic acid on body composition in mice. Lipids 1997; 32: 853-858

40 Choi Y, YC Kim, YB Han, Y Park, MW Pariza, JM Ntambi. The trans-10,cis-12 isomer of conjugated linoleic acid downregulates stearoyl-CoA desaturase 1 gene expression in 3T3-L1 adipocytes. J Nutr 2000; 130: 1920-1924

41 West DB, JP Delany, PM Camet, FY Blohm, AA Truett, J Scimeca. Effects of conjugated linoleic acid on body fat and energy metabolism in the mouse. Am J Physiol 1998; 275: R667. R672

42 Park Y, JM Storkson, KJ Albright, W Liu, MW Pariza. Evidence that the trans-10, cis-12 isomer of conjugated linoleic acid induces body composition changes in mice. Lipids 1999; 34: 235. 241

43 Park Y, KJ Albright, JM Storkson, W Liu, ME Cook, MW Pariza. Changes in body composition in mice during feeding and withdrawal of conjugated linoleic acid. Lipids 1999; 34: 243-248

44 Delany JP, F Blohm, AA Truett, JA Scimeca, DB West. Conjugated linoleic acid rapidly reduces body fat content in mice without affecting energy intake. Am J Physiol 1999; 276: R1172-R1179

45 Azain MJ, DB Hausman, MB Sisk, WP Flatt, DE Jewell. Dietary conjugated linoleic acid reduces rat adipose tissue cell size rather than cell number. J Nutr 2000; 130: 1548-1554

46 West DB, FY Blohm, AA Truett, JP DeLany. Conjugated linoleic acid persistently increases total energy expenditure in AKR/J mice without increasing uncoupling protein gene expression. $J$ Nutr 2000; 130: 2471-2477

47 Sisk MB, DB Hausman, RJ Martin, MJ Azain. Dietary conjugated linoleic acid reduces adiposity in lean but not obese Zucker rats. J Nutr 2001; 131: 1668-1674

48 Blankson H, JA Stakkestad, H Fagertun, E Thom, J Wadstein, O Gudmundsen. Conjugated linoleic acid reduces body fat mass in overweight and obese humans. J Nutr 2000; 130: 29432948

49 Riserus U, L Berglund, B Vessby. Conjugated linoleic acid (CLA) reduced abdominal adipose tissue in obese middle-aged men with signs of the metabolic syndrome: a randomised controlled trial. Int J Obes Relat Metab Disord 2001; 25: 1129-1135

50 Zambell KL, NL Keim, MD Van Loan, B Gale, P Benito, DS Kelley, GJ Nelson. Conjugated linoleic acid supplementation in humans: effects on body composition and energy expenditure. Lipids 2000; 35: 777-782

51 Kamphuis MMJW, MPGM Lejeune, WHM Saris, MS Westerterp-Plantenga. Effect of Conjugated Linoleic Acid supplementation after weight loss on body weight regain, body composition, and resting metabolic rate in overweight subjects. Int J Obes Relat Metab Disord in press

52 Naim M, MR Kare, AM Merrie. Effects of oral stimulation on the cephalic phase of pancreatic exocrine in dogs. Physiol Behav 1978; 20: 563-570

53 Jackson KG, MD Robertson, BA Fielding, KN Frayn, CM Williams. Second meal effect: modified sham feeding does not provoke the release of stored triacylglycerol from a previous high-fat meal. Br J Nutr 2001: 85: 149-156

54 Mattes RD. Oral fat exposure alters postprandial lipid metabolism in humans. Am J Clin Nutr 1996; 63: 911-917

55 Mattes RD. Oral exposure to butter, but not fat replacers elevates postprandial triacylglycerol concentration in humans. J Nutr 2001; 131: 1491-1496

56 Mattes RD. The taste of fat elevates postprandial triacylglycerol. Physiol Behav 2001; 74: $343-$ 348

57 Patsch JR, G Miesenbock, T Hopferwieser, V Muhlberger, E Knapp, JK Dunn, AM Gotto, Jr., W Patsch. Relation of triglyceride metabolism and coronary artery disease. Studies in the postprandial state. Arterioscler Thromb 1992; 12: 1336-1345

58 Melanson KJ, MS Westerterp-Plantenga, LA Campfield, WH Saris. Short-term regulation of 
food intake in humans. In: Westerterp-Plantenga MS, AB SteffensA Tremblay (eds). Regulation of food intake and energy expenditure. EDRA: Milano, 1999, pp 37-84

59 Rolls BJ. Sensory-specific Satiety. Nutr Rev 1986; 44: 93-101

60 Kamphuis MMJW, MS Westerterp-Plantenga, WHM Saris. Fat specific satiety in humans for fat high in linoleic acid versus fat high in oleic acid. Eur J Clin Nutr 2001; 55: 499-508

61 Stubbs JR, A Raben, MS Westerterp-Plantenga. Macronutrient metabolism and appetite. In: Westerterp-Plantenga MS, AB SteffensA Tremblay (eds). Regulation of food intake and energy expenditure. EDRA: Milano, 1999, pp 59-84

62 Westerterp-Plantenga MS, MJW IJedema, NEG Wijckmans-Duijsens. The role of macronutrient selection in determining patterns of food intake in obese and non-obese women. Eur J Clin Nutr 1996; 50: 580-591

63 Lawton C, H Delargy, F Smith, J Blundell. Does the degree of saturation of fatty acids affect post-ingestive satiety? Int J Obes Relat Metab Disord 1997; 21: S35

64 Lawton CL, HJ Delargy, J Brockman, FC Smith, JE Blundell. The degree of saturation of fatty acids influences post-ingestive satiety. Br J Nutr 2000; 83: 473-482

65 Hamosh M, RO Scow. Lingual lipase and its role in the digestion of dietary lipid. $J$ Clin Invest 1973: 52: 88-95

66 Hamosh M, Burns, W.A. Lipolytic activity of human lingual glands (Ebner). Lab Invest 1977; 37: $603-608$

67 Hamosh M. Lingual lipase. Gastroenterology 1986; 90: 1290-1292

68 DeNigris SJ, M Hamosh, DK Kasbekar, TC Lee, P Hamosh. Lingual and gastric lipases: species differences in the origin of prepancreatic digestive lipases and in the localization of gastric lipase. Biochimica et Biophysica Acta 1988; 959: 38-45

69 Westerterp-Plantenga MS. Analysis of energy density of food in relation to energy intake regulation in human subjects. Br J Nutr 2001; 85: 351-361.

70 Geliebter A, S Westreich, D Gage. Gastric distention by balloon and test-meal intake in obese and lean subjects. Am J Clin Nutr 1988; 48: 592-594

71 Cecil JE, J Francis, NW Read. Comparison of the effects of a high-fat and high-carbohydrate soup delivered orally and intragastrically on gastric emptying, appetite, and eating behaviour. Physiol Behav 1999; 67: 299-306

72 Kaplan JM, W Siemers, HJ Grill. Effect of oral versus gastric delivery on gastric emptying of corn oil emulsions. Am J Physiol 1997; 273: R1263-1270

73 Cecil JE, J Francis, NW Read. Relative contributions of intestinal, gastric, oro-sensory influences and information to changes in appetite induced by the same liquid meal. Appetite 1998; $31: 377-390$

74 French SJ. The effects of specific nutrients on the regulation of feeding behaviour in human subjects. Proc Nutr Soc 1999; 58: 533-539

75 Liddle RA. Cholecystokinin cells. Annu Rev Physiol 1997; 59: 221-242

76 Degen L, D Matzinger, J Drewe, C Beglinger. The effect of cholecystokinin in controlling appetite and food intake in humans. Peptides 2001; 22: 1265-1269

77 Burton-Freeman B, PA Davis, BO Schneeman. Plasma cholecystokinin is associated with subjective measures of satiety in women. Am J Clin Nutr 2002; 76: 659-667

78 Lieverse RJ, JBMJ Jansen, AAM Masclee, CBHW Lamers. Role of cholecystokinin in the regulation of satiation and satiety in humans. Ann N Y Acad Sci 1994; 23: 268-272

79 Smith GP, J Gibbs. Satiating effect of cholecystokinin. Ann N Y Acad Sci 1994; 23: 236-241

80 Ritter RC, LA Brenner, CS Tamura. Endogenous CCK and the peripheral neural substrates of intestinal satiety. Ann N Y Acad Sci 1994; 23: 255-267

81 Schick RR, V Schusdziarra, TL Yaksh, VYW Go. Brain regions where cholecystokinin exerts its effect on satiety. Ann N Y Acad Sci 1994; 23: 242-254

82 Beardshall K, Y Morarji, SR Bloom, G Frost, J Domin, J Calam. Saturation of fat and cholecystokinin release: implications for pancreatic carcinogenesis. Lancet 1989; 28: 10081010

83 Raybould HE. Nutrient tasting and signaling mechanisms in the gut. I. Sensing of lipid by the intestinal mucosa. Am J Physiol 1999; 277: G751-755

84 Erlanson-Albertsson C, D York. Enterostatin-a peptide regulating fat intake. Obes Res 1997; 5: $360-372$

85 Erlanson-Albertsson C, J Mei, S Okada, D York, GA Bray. Pancreatic procolipase propeptide, enterostatin, specifically inhibits fat intake. Physiol Behav 1991; 49: 1191-1194 
86 Spiller RC, IF Trotman, BE Higgins, MA Ghatei, GK Grimble, YC Lee, SR Bloom, JJ Misiewicz, DB Silk. The ileal brake--inhibition of jejunal motility after ileal fat perfusion in man. Gut 1984; 25: $365-374$

87 Langhans W. Metabolic control of food intake. Role of the liver. In: Westerterp-Plantenga MS, AB SteffensA Tremblay (eds). Regulation of food intake and energy expenditure. EDRA: Milano, 1999, pp 185-199

88 Scharrer E, W Langhans. Control of food intake by fatty acid oxidation. Am J Physiol 1986; 250: R1003-1006

89 Kahler A, M Zimmermann, W Langhans. Suppression of hepatic fatty acid oxidation and food intake in men. Nutrition 1999; 15: 819-828

90 Stubbs RJ, CG Harbron. Covert manipulation of the ratio of medium-to long-chain triglycerides in isoenergetically dense diets: effect on food intake in ad libitum feeding men. Int $J$ Obes Relat Metab Disord 1996; 20: 435-444

91 Van Wymelbeke V. Himaya, A., Louis-Sylvestre, J., Fantino, M. Influence of medium-chain and long-chain triacylglycerols on the control of food intake in men. Am J Clin Nutr 1998; 68: 226234

92 Beverly JL, ZJ Yang. MM Meguid. Hepatic vagotomy effects on metabolic challenges during parenteral nutrition in rats. Am J Physiol 1994; 266: R646-649

93 Langhans W, E Scharrer. Evidence for a vagally mediated satiety signal derived from hepatic fatty acid oxidation. J Auton Nerv Syst 1987; 18: 13-18

94 Melanson KJ, MS Westerterp-Plantenga, WHM Saris, FJ Smith, LA Campfield. Blood glucose patterns and appetite in time-blinded humans: carbohydrate versus fat. J Appl Physiol 1999; 277: R337-R345

95 Jequier E. Leptin signaling, adiposity, and energy balance. Ann N Y Acad Sci 2002; 967: 379 388

96 Jequier E. Pathways to obesity. Int J Obes Relat Metab Disord 2002; 26 Suppl 2: S12-17

97 Kamphuis MMJW, DJ Mela, MS Westerterp-Plantenga. Diacylglycerides affects substrate oxidation and appetite in humans. Am J Clin Nutr in press

98 Watanabe H, T Nagao, N Goto, Y Fukushima, K Onizawa, H Taguchi, T Ohmachi, T Yasukawa, S Naito, H Shimasaki, H Itakura. Long-term effects of dietary diacylglycerols on body fat metabolism in man. Nippon Yukagaku Kaishi 1998; 47: 369-376

99 Murata M, T Ide, K Hara. Reciprocal responses to dietary diacylglycerol of hepatic enzymes of fatty acid synthesis and oxidation in the rat. Br J Nutr 1997: 77: 107-121

100 Votruba SB, SM Zeddun, DA Schoeller. Validation of deuterium labeled fatty acids for the measurement of dietary fat oxidation: a method for measuring fat-oxidation in free-living subjects. Int J Obes Relat Metab Disord 2001; 25: 1240-1245

101 Tremblay A, C Bouchard. Dietary fats and thermogenesis. Ann N Y Acad Sci 1997; 827: 408416

102 Westerterp KR. Food quotient, respiratory quotient, and energy balance. Am J Clin Nutr 1993; 57: 759S-764S; discussion 764S-765S

103 Flatt JP, E Ravussin, KJ Acheson, E Jequier. Effects of dietary fat on postprandial substrate oxidation and on carbohydrate and fat balances. J Clin Invest 1985; 76: 1019-1024

104 Flatt JP. Use and storage of carbohydrate and fat. Am J Clin Nutr 1995; 61: 952S-959S

105 Verboeket-van de Venne WP, KR Westerterp. Influence of the feeding frequency on nutrient utilization in man: consequences for energy metabolism. Eur J Clin Nutr 1991; 45: 161-169

106 Schrauwen P, WD van Marken Lichtenbelt, WH Saris, KR Westerterp. Changes in fat oxidation in response to a high-fat diet. Am J Clin Nutr 1997; 66: 276-282

107 Schrauwen P, WD van Marken Lichtenbelt, WH Saris, KR Westerterp. Role of glycogenlowering exercise in the change of fat oxidation in response to a high-fat diet. Am J Physiol 1997; 273: E623-629

108 Kunz I, U Schorr, K Rommling. S Klaus, AM Sharma. Habitual fat intake and basal fat oxidation in obese and non-obese Caucasians. Int J Obes Relat Metab Disord 2002; 26: 150156

109 Schutz Y, A Tremblay, RL Weinsier, KM Nelson. Role of fat oxidation in the long-term stabilization of body weight in obese women. Am J Clin Nutr 1992; 55: 670-674

110 Thomas CD, JC Peters, GW Reed, NN Abumrad, M Sun, JO Hill. Nutrient balance and energy expenditure during ad libitum feeding of high-fat and high-carbohydrate diets in humans. Am J Clin Nutr 1992; 55: 934-942 
111 Schrauwen P, WD Lichtenbelt, WH Saris, KR Westerterp. Fat balance in obese subjects: role of glycogen stores. Am J Physiol 1998; 274: E1027-1033

112 Aarsland A, D Chinkes, RR Wolfe. Hepatic and whole-body fat synthesis in humans during carbohydrate overfeeding. Am J Clin Nutr 1997; 65: 1774-1782

113 Jequier E. Carbohydrates as a source of energy. Am J Clin Nutr 1994; 59: S682-S685

114 Horton TJ, H Drougas, A Brachey, GW Reed, JC Peters, JO Hill. Fat and carbohydrate overfeeding in humans: different effects on energy storage. Am J Clin Nutr 1995; 62: 19-29

115 Westerterp-Plantenga MS, V Rolland, SAJ Wilson, KR Westerterp. Satiety related to $24 \mathrm{~h}$ dietinduced thermogenesis during high protein/carbohydrate vs high fat diets measured in a respiration chamber. Eur J Clin Nutr 1999: 53: 495-502

116 Westerterp KR, SA Wilson, V Rolland. Diet induced thermogenesis measured over 24h in a respiration chamber: effect of diet composition. Int J Obes Relat Metab Disord 1999; 23: 287 292

117 Verboeket-van de Venne WP, KR Westerterp, TJ Hermans-Limpens, C de Graaf, KH van het Hof, JA Weststrate. Long-term effects of consumption of full-fat or reduced-fat products in healthy non-obese volunteers: assessment of energy expenditure and substrate oxidation. Metabolism 1996; 45: 1004-1010

118 Westerterp KR. Energy expenditure. In: Westerterp-Plantenga MS, EWHM FredrixAB Steffens (eds). Food intake and energy expenditure. CRC Press: Boca Raton, 1994, pp 235-258

119 Egger G, B Swinburn. An "ecological" approach to the obesity pandemic. BMJ 1997; 315: 477 480

120 Drewnowski A. Dietary fats: perceptions and preferences. J Am Coll Nutr 1990; 9: 431-435

121 Miller KW, KD Lawson, DH Tallmadge, BL Madison, JR Okenfuss, P Hudson, S Wilson, J Thorstenson, P Vanderploeg. Disposition of ingested olestra in the Fischer 344 rat. Fundam Appl Toxicol 1995; 24: 229-237

122 Miller DL. EA Bell, CL Pelkman, JC Peters, BJ Rolls. Effects of dietary fat, nutrition labels, and repeated consumption on sensory-specific satiety. Physiol Behav 2000; 71: 153-158

123 Westerterp-Plantenga MS. NE Wijckmans-Duijsens, F ten Hoor, JA Weststrate. Effect of replacement of fat by nonabsorbable fat (sucrose polyester) in meals or snacks as a function of dietary restraint. Physiol Behav 1997; 61: 939-947

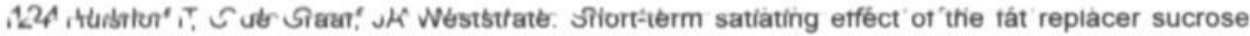
polyester (SPE) in man. Br J Nutr 1995; 74: 569-585

125 Hill JO, HM Seagle, SL Johnson, S Smith, GW Reed, ZV Tran, D Cooper, M Stone, JC Peters. Effects of $14 \mathrm{~d}$ of covert substitution of olestra for conventional fat on spontaneous food intake. Am J Clin Nutr 1998; 67: 1178-1185

126 Burns AA, MB Livingstone, RW Welch, A Dunne, IR Rowland. Dose-response effects of a novel fat emulsion (Olibra) on energy and macronutrient intakes up to $36 \mathrm{~h}$ post-consumption. Eur J Clin Nutr 2002; 56: 368-377

127 Rolls BJ, PA Pirraglia, MB Jones, JC Peters. Effects of olestra, a noncaloric fat substitute, on daily energy and fat intakes in lean men. Am J Clin Nutr 1992; 56: 84-92

128 Bray GA, JC Lovejoy, M Most-Windhauser, SR Smith, J Volaufova, Y Denkins, L de Jonge, J Rood, M Lefevre, AL Eldridge, JC Peters. A 9-mo randomized clinical trial comparing fatsubstituted and fat-reduced diets in healthy obese men: the Ole Study. Am J Clin Nutr 2002: 76: $928-934$

129 Eldridge AL, DA Cooper, JC Peters. A role for olestra in body weight management. Obes Rev 2002; $3: 17-25$

130 De Graaf C. T Hulshof, JA Weststrate, JG Hautvast. Nonabsorbable fat (sucrose polyester) and the regulation of energy intake and body weight. Am J Physiol 1996; 270: R1386-1393

131 Kelly SM, M Shorthouse, JC Cotterell, AM Riordan, AJ Lee, DI Thurnham, R Hanka, JO Hunter. A 3-month, double-blind, controlled trial of feeding with sucrose polyester in human volunteers. Br J Nutr 1998; 80: 41-49

132 Kelly SM, JO Hunter. The effect of a non-absorbable fat substitute, sucrose polyester, on gastrointestinal function. Aliment Pharmacol Ther 1996; 10: 715-720

133 Pittler MH, NC Abbot, EF Harkness. E Emst. Randomized, double-blind trial of chitosan for body weight reduction. Eur J Clin Nutr 1999; 53: 379-381

134 Guerciolini R, L Radu-Radulescu, M Boldrin, J Dallas, R Moore. Comparative evaluation of fecal fat excretion induced by orlistat and chitosan. Obes Res 2001; 9: 364-367

135 Gades MD, JS Stern. Chitosan supplementation does not affect fat absorption in healthy 
males fed a high-fat diet, a pilot study. Int J Obes Relat Metab Disord 2002; 26: 119-122

136 Sternby B, D Hartmann, B Borgstrom, A Nilsson. Degree of in vivo inhibition of human gastric and pancreatic lipases by Orlistat (Tetrahydrolipstatin. THL) in the stomach and small intestine. Clin Nutr 2002; 21: 395-402

137 Rossner S, L Sjostrom, R Noack, AE Meinders, G Noseda. Weight loss, weight maintenance, and improved cardiovascular risk factors after 2 years treatment with orlistat for obesity. European Orlistat Obesity Study Group. Obes Res 2000; 8: 49-61

138 Muls E, J Kolanowski, A Scheen, L Van Gaal. The effects of orlistat on weight and on serum lipids in obese patients with hypercholesterolemia: a randomized, double-blind, placebocontrolled, multicentre study. Int J Obes Relat Metab Disord 2001; 25: 1713-1721

139 Nagao T, H Watanabe, N Goto, K Onizawa, H Taguchi, N Matsuo, T Yasukawa, R Tsushima, H Shimasaki, H Itakura. Dietary diacylglycerol suppresses accumulation of body fat compared to triacylglycerol in men in a double-blind controlled trial. $J$ Nutr 2000; 130: 792-797

140 Maki KC, MH Davidson, R Tsushima, N Matsuo, I Tokimitsu, DM Umporowicz, MR Dicklin, GS Foster, KA Ingram, BD Anderson, SD Frost, M Bell. Consumption of diacylglycerol oil as part of a reduced-energy diet enhances loss of body weight and fat in comparison with consumption of a triacylglycerol control oil. Am J Clin Nutr 2002; 76: 1230-1236

141 St-Onge MP, C Bourque, PJ Jones, R Ross, WE Parsons. Medium- versus long-chain triglycerides for 27 days increases fat oxidation and energy expenditure without resulting in changes in body composition in overweight women. Int $J$ Obes Relat Metab Disord 2003; 27: 95-102

142 DeLany JP, MM Windhauser, CM Champagne, GA Bray. Differential oxidation of individual dietary fatty acids in humans. Am J Clin Nutr 2000; 72: 905-911

143 Hill JO, JC Peters, D Yang. T Sharp, M Kaler, NN Abumrad, HL Greene. Thermogenesis in humans during overfeeding with medium-chain triglycerides. Metabolism 1989; 38: 641-648

144 French S, S Mutuma, J Francis, N Read, G Meijer. 1998. The effect of fatty composition on intestinal satiety in man. In Internation Congress on Obesity. Paris: International Journal of Obesity. $\mathrm{S} 82$

145 Kamphuis MMJW, MPGM Lejeune, WHM Saris, MS Westerterp-Plantenga. Effect of conjugated linoleic acid supplementation after weight loss on appetite and food intake in overweight subjects. Eur $J$ Clin Nutr in press

146 Rossner S, B Barkeling, C Erlanson-Albertsson, P Larsson, E Wahlin-Boll. Intravenous enterostatin does not affect single meal food intake in man. Appetite $1995 ; 24: 37-42$

147 Kovacs EMR, MPGM Lejeune, MS Westerterp-Plantenga. The effects of enterostatin intake on food intake and energy expenditure. Int J Obes Relat Metab Disord 2002; 26: S159

148 Lawton CL, VJ Burley, JK Wales, JE Blundell. Dietary fat and appetite control in obese subjects: weak effects on satiation and satiety. Int J Obes Relat Metab Disord 1993; 17: 409416 


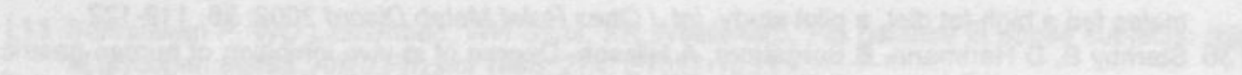

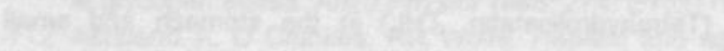

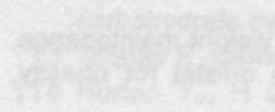

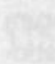

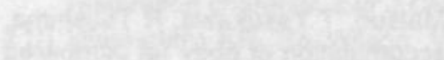

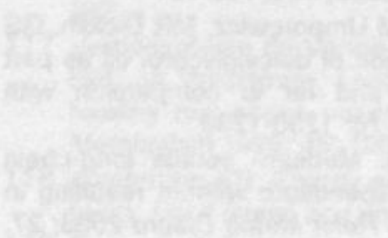

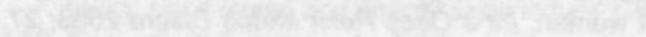

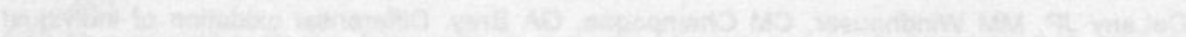

-

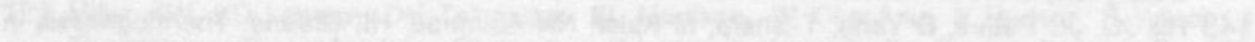

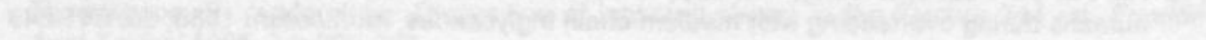

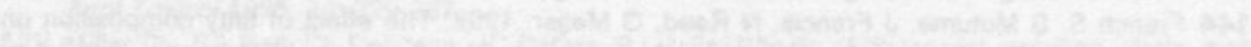

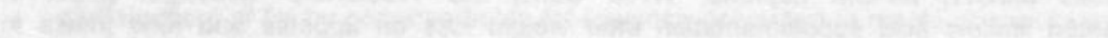

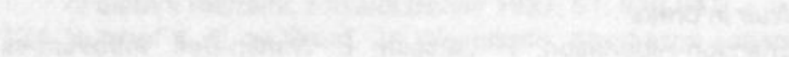




\section{Summary}


$\mathrm{O}$ verweight and obesity are characterized by an excessive accumulation of body fat resulting in an increased body mass. The incidence of obesity is increasing during the past decades in developed countries, as well as in developing countries. This can lead to very high health care costs because obesity is related to an increased risk for e.g. type 2 diabetes and cardio-vascular diseases. Obesity is caused by an imbalance between energy intake and energy expenditure by which the surplus of energy is stored as triacylglycerol in the adipose tissue. Dietary fat is often related to a high energy intake, since fat has a high energy density and hedonic value and on the short-term fat is less satiating compared to protein and carbohydrate. Because of these aspects, the passive consumption of energy is stimulated. Additionally, dietary fat is related to a relatively low energy expenditure, since on the short-term it does not promote its own oxidation and dietary fat causes a low diet-induced thermogenesis in comparison with protein and carbohydrate. Furthermore, fat has an almost unlimited storage capacity in contrast to other macronutrients.

The research described in this thesis addresses several aspects of dietary fat in relation to food intake and/or body weight regulation. The first studies investigated the effect of 6 n-propylthiouracyl (PROP) and linoleic acid sensitivity, and fatty acid composition on food intake regulation (energy intake, appetite, macronutrient choice). Furthermore, the effect of a fat-based functional ingredient, conjugated linoleic acid, on food intake and body weight regulation, body composition and energy expenditure was studied. The effect of another fat-based functional ingredient, diacylglycerol, on (hepatic) fat oxidation was investigated in the last study.

To investigate the relation between taste perception and food intake, the effect of PROP sensitivity on macronutrient choice was studied. PROP is a bitter compound for which a genetic taste sensitivity exists. PROP tasters compared to non-tasters ate more fat and less carbohydrates during an ad libitum lunch experiment with high-fat and highcarbohydrate products. Macronutrient choice seems therefore be related to PROP sensitivity.

The effect of dietary fat on appetite and food intake has been studied frequently, but the relation between fatty acid composition and these parameters is not clear. To investigate this, the effect of oil high in linoleic acid or high in $\gamma$-linolenic acid in comparison with oil high in oleic acid on food intake and/or appetite was studied. For this purpose, subjects consumed the three oils with different fatty acid compositions incorporated in meals during a two-week period. Each period was ended with a test day on which the meals were consumed at the university. These meals were prepared with the same oil which was used in the preceding two weeks. At dinner, subjects ate relatively less fat with oil high in linoleic acid compared to oil high in oleic acid, without affecting $24 \mathrm{~h}$ energy intake and appetite. In other words, the use of an oil high in linoleic acid caused a fat-specific satiety.

In rats, the ability of tongue taste cells to perceive free linoleic acid and other polyunsaturated fatty acids, but not oleic acid has been demonstrated. Furthermore, a relationship between the degree of linoleic acid taste sensitivity and fat intake has been observed. Rats that lower their food intake on a high-fat diet and therefore remain lean, showed a high linoleic acid sensitivity. This in contrast to rats with a much lower linoleic acid sensitivity, who have a high-fat intake on a high-fat diet and as a result become obese. We developed a taste perception test for a low concentration linoleic acid to test whether linoleic acid sensitivity is related to fat intake and body weight in humans. With this test, $46 \%$ of subjects were able to perceive linoleic acid compared to $7 \%$ who were able to taste oleic acid. Within the non-obese subjects, linoleic acid taste sensitivity was related to body weight, e.g. linoleic acid tasters had a lower body mass index than nontasters. Within the obese subjects, no relation between linoleic acid sensitivity and body weight was observed. The possible effect of linoleic acid sensitivity on the prevention of obesity was not related to macronutrient choice as was observed in rats. The 
macronutrient choice was not different between linoleic acid tasters and non-tasters during an ad libitum lunch experiment. The relation between linoleic acid sensitivity and food intake regulation was further studied by investigating the effect of foods with addition of free linoleic acid on food intake and satiety in linoleic acid tasters and nontasters. Linoleic acid, oleic acid or no fatty acid was added to low-fat, low-energy ice creams as well as to high-fat, high-energy ice creams. A relation between linoleic acid sensitivity and food intake regulation was observed. The amount eaten was related to satiety in linoleic acid tasters, but not linoleic acid non-tasters. This was the case for the low-fat, low-energy ice cream with addition of linoleic acid as well as for all high-fat, highenergy ice creams in which free linoleic acid was present. This relation was not observed in linoleic acid tasters for ice creams without free linoleic acid. The differences in food intake regulation did not result in a difference in energy intake between linoleic acid tasters and non-tasters. Thus, linoleic acid sensitivity seems to be of importance in food intake regulation.

Conjugated linoleic acid (CLA) is an isomer of linoleic acid which has been associated with a decrease in body fat storage. The effect of CLA on body composition, energy expenditure, food intake and appetite has been studied during a 13-week CLA intervention after weight loss. CLA in comparison with placebo (oleic acid) decreased appetite, although this did not result into a lower energy intake measured with a testbreakfast. Furthermore, CLA affected the \% body fat during weight gain, by relatively increasing fat-free mass. With this increase in fat-free mass, CLA increased the resting metabolic rate in comparison with placebo. In summary, the consumption of CLA affects appetite and body composition and therefore energy expenditure.

Diacylglycerol (glycerol with 2 fatty acids) compared to triacylglycerol (glycerol with 3 fatty acids) is thought to enhance post-prandial hepatic fatty acid oxidation and therefore to affect appetite. We tested this hypothesis with a $36 \mathrm{~h}$ stay in the respiration chamber experiment. The subjects were fed in energy balance with a normal macronutrient composition. In random order, $40 \%$ of the dietary fat consisted of diacylglycerol or triacylglycerol. Consumption of diacylglycerol in comparison with triacylglycerol enhanced fat oxidation without affecting energy expenditure. Furthermore, appetite was lowered by diacylglycerol consumption compared to triacylglycerol consumption. This effect is probably caused by the increase in hepatic fatty acid oxidation, since plasma $\beta$ hydroxy butyrate concentrations were higher at the diacylglycerol intervention than at the triacylglycerol intervention. Thus, consumption of diacylglycerol stimulates the (hepatic) fatty acid oxidation and consequently affects appetite.

The results of the studies as described in the present thesis can be used for the prevention or treatment of obesity. When investigating food intake and/or choice in future studies, the sensitivity for PROP has to be taken in account, because of its relation with fat intake. Dietary fat intake can be lowered by fat-specific satiety caused by the consumption of oil high in linoleic acid. Furthermore, in about half of the population addition of free linoleic acid to low-fat products can affect food intake regulation to the same extent as with high-fat products which also contain free linoleic acid. The energy balance can favourable be affected by CLA, a fat-based functional ingredient, through its effect on appetite and body composition. Also the consumption of diacylglycerol instead of triacylglycerol can contribute to the prevention and treatment of obesity because it stimulates the (hepatic) fatty acid oxidation and therefore it may lower body fat storage. Besides, consumption of diacylglycerol lowers appetite which can consequently affect energy intake.

From the studies described in this thesis, we can conclude that in addition to the risks of of dietary fat related to the etiology of obesity, there are some bright spots with respect to this relationship, which may contribute to the treatment or prevention of obesity. 


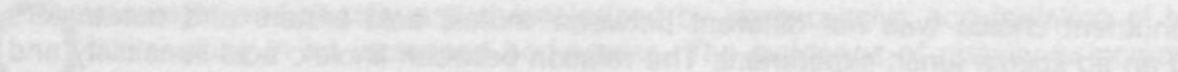

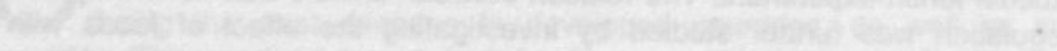

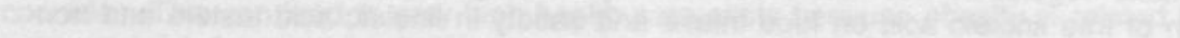

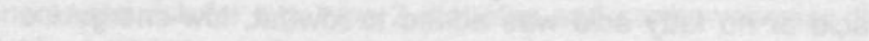

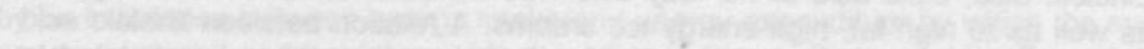

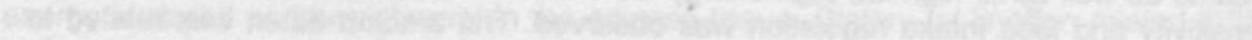

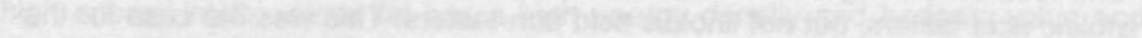

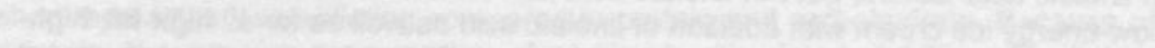
than

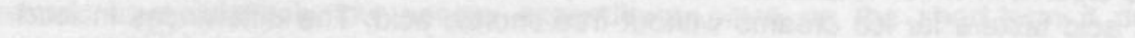

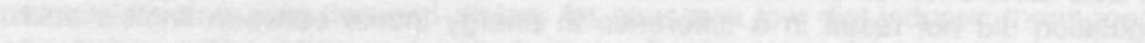

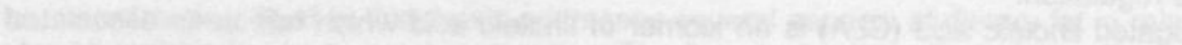

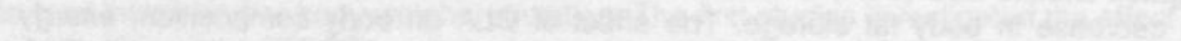

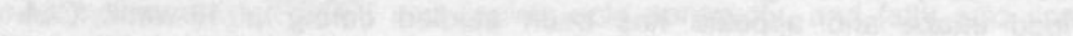
and

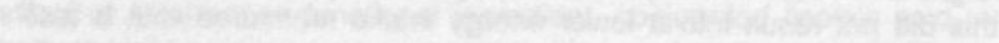

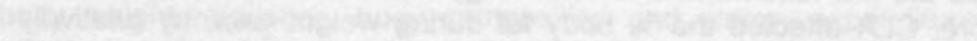

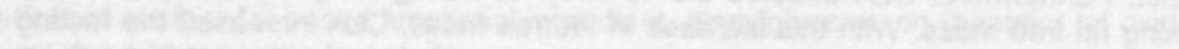

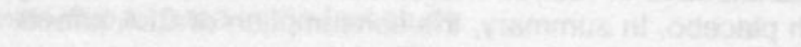

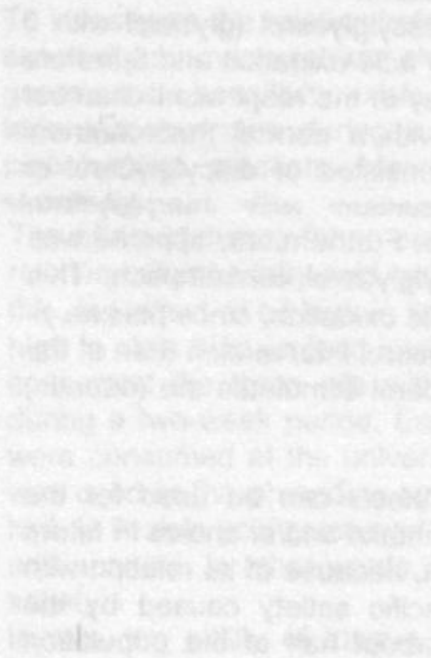


Samenvatting 
$\mathrm{O}$ vergewicht en obesitas zijn aandoeningen die gekenmerkt worden door een grote vetmassa, resulterend in een hoog lichaamsgewicht. In westerse landen, maar ook in ontwikkelingslanden neemt de incidentie van obesitas de laatste jaren sterk toe. Dit kan leiden tot hoge gezondheidskosten, omdat obesitas is gerelateerd aan een verhoogd risico op o.a. type 2 diabetes en hart- en vaatziekten. Obesitas wordt veroorzaakt door een verstoorde energiebalans die op zijn beurt veroorzaakt wordt door een te hoge energie-inname in relatie tot het energiegebruik, waarbij de overtollige energie wordt opgeslagen als vet. Voedingsvet wordt vaak gerelateerd aan een hoge energie-inname, omdat vet een hoge energiedichtheid en hedonische waarde heeft en het op korte termijn minder verzadigend is in vergelijking met eiwitten en koolhydraten. Door deze kenmerken wordt de passieve inname van energie bevorderd. Daarnaast is voedingsvet ook gerelateerd aan een relatief laag energiegebruik, doordat het op korte termijn zijn eigen verbranding niet stimuleert en de diëet-geïnduceerde thermogenese laag is. Verder is er een bijna grenzeloze opslagmogelijkheid voor vet in tegenstelling tot opslagmogelijkheden voor koolhydraten en eiwit.

Het onderzoek beschreven in dit proefschrift richt zich op verschillende aspecten van vet in relatie tot voedselinname- en/of lichaamsgewichtregulatie. De eerste studies zijn gericht op de invloed van 6-n-propylthiouracyl (PROP)- en linolzuurgevoeligheid en vetzuursamenstelling op voedselinnameregulatie (energie-inname, eetlust, macronutriëntkeuze). Vervolgens is het effect van een op-vet-gebaseerd functioneel ingrediënt, geconjugeerd linolzuur, op voedselinname- en lichaamsgewichtregulatie, lichaamssamenstelling en energiegebruik onderzocht. De laatste studie richtte zich op de invloed van een andere op-vet-gebaseerd functioneel ingrediënt op de (hepatische) vetoxidatie en op eetlust.

Om de relatie tussen smaakwaarneming en voedselinname te onderzoeken, hebben we het effect van PROP-gevoeligheid op macronutriëntkeuze bestudeerd. PROP is een bittere stof waarvoor een erfelijke smaakgevoeligheid bestaat. Tijdens een ad libitum lunch experiment met hoog-vet en hoog-koolhydraat producten aten PROP-proevers meer vet en minder koolhydraten in vergelijking met PROP niet-proevers. Macronutriëntkeuze blijkt dus gerelateerd te zijn aan PROP-gevoeligheid.

Het effect van voedingsvet op eetlust en voedselinname is veelvuldig onderzocht, maar de relatie tussen vetzuursamenstelling en deze parameters is niet duidelijk. Om dit te onderzoeken, hebben we nagegaan of olie hoog in linolzuur of hoog in $\gamma$-linoleenzuur vergeleken met een olie hoog in oliezuur effect heeft op voedselinname en/of eetlust. Hiertoe hebben proefpersonen drie perioden van twee weken deze drie oliën die verschilden in vetzuursamenstelling geconsumeerd; deze werden verwerkt in hun maaltijden. Elke periode werd afgesloten met een testdag, waarop de maaltijden werden gegeten op de universiteit. Deze maaltijden waren bereid met de olie die ook in de periode daarvoor thuis was gebruikt. Tijdens het gebruik van olie hoog in linolzuur werd, in vergelijking met een olie hoog in oliezuur, relatief minder vet gegeten tijdens het diner. De 24 uurs energie-inname en eetlust waren niet veranderd. Het gebruik van een olie hoog in linolzuur veroorzaakte dus een vet-specifieke verzadiging.

$\mathrm{Bij}$ ratten is aangetoond dat vrij linolzuur en andere meervoudige onverzadigde vetzuren, maar niet vrij oliezuur kan worden waargenomen door smaakcellen op de tong. Tevens is er een relatie gevonden tussen de mate van linolzuurgevoeligheid en vetinname. Ratten die hun vetinname reduceren op een hoog-vet dięet en hierdoor slank blijven, vertoonden een hoge linolzuurgevoeligheid. Dit in tegenstelling tot ratten met een veel geringere gevoeligheid voor linolzuur, die een hoge vet inname lieten zien op een hoogvet dièet en als gevolg daarvan toenamen in gewicht. Om te testen of bij mensen deze linolzuurgevoeligheid ook gerelateerd zou zijn aan vetinname en lichaamsgewicht, hebben we een smaaktest voor een lage concentratie linolzuur ontwikkeld. Hieruit bleek dat $46 \%$ van de mensen linolzuur konden proeven, terwijl slechts $7 \%$ oliezuur kon waarnemen. $\mathrm{Bij}$ mensen met normaal lichaamsgewicht bleek linolzuurgevoeligheid gerelateerd te zijn aan het lichaamsgewicht, dwz dat linolzuurproevers een lagere body 
mass index hadden dan niet-proevers. Bij obese mensen was er echter geen relatie tussen linolzuurgevoeligheid en lichaamsgewicht. Het mogelijke effect van linolzuurgevoeligheid op de preventie van obesitas was niet, zoals bij de ratten het geval was, gerelateerd aan macronutriëntvoorkeur. Deze bleek niet te verschillen tussen linolzuurproevers en niet-proevers tijdens een ad libitum lunch experiment. De relatie tussen linolzuurgevoeligheid en voedselinnameregulatie is tevens onderzocht door het effect van toevoeging van vrij linolzuur aan voedsel op voedselinname en verzadiging te bestuderen bij linolzuurproevers en niet-proevers. Aan laag-vet, laag-energetische en aan hoog-vet, hoog-energetische consumptie ijs werd linolzuur, oliezuur of geen extra vetzuur toegevoegd. Er werd een relatie tussen linolzuurgevoeligheid en voedselinnameregulatie gevonden. Bij linolzuurproevers, maar niet bij niet-proevers, was er een relatie tussen de hoeveelheid gegeten en de mate van verzadiging bij zowel het laag-vet, laagenergetisch ijs waaraan linolzuur was toegediend als bij alle hoog-vet, hoogenergetische ijs waarin ook vrij linolzuur aanwezig was. Deze relatie was niet aanwezig wanneer linolzuurproevers ijs aten zonder vrij linolzuur. Het verschil in voedselinnameregulatie leidde niet tot een verschil in energie-inname. Linolzuurgevoeligheid lijkt dus een rol te spelen in de voedselinname-regulatie.

Geconjugeerd linolzuur (CLA) is een isomeer van linolzuur die wordt geassociêerd met een vermindering van vetopslag. Het effect van CLA op lichaamssamenstelling, energiegebruik, voedselinname en eetlust werd onderzocht tijdens een CLA interventie van 13 weken na een periode van gewichtsverlies. Het gebruik van CLA in vergelijking met placebo (oliezuur) verminderde de eetlust, hetgeen niet leidde tot een verlaagde energieinname gemeten tijdens een testontbijt. Verder verlaagde CLA tijdens de gewichtstoename het percentage lichaamsvet, wat werd veroorzaakt door een relatieve toename in vetvrije massa. Met deze toename in vetvrije massa, verhoogde CLA het energiegebruik in rust. Samenvattend, het gebruik van CLA beïnvloedt zowel de eetlust als de lichaams-samenstelling en hierdoor ook het energiegebruik.

Van diacylglycerol (glycerol met 2 vetzuren) in vergelijking met triacylglycerol (glycerol met 3 vetzuren) wordt verondersteld dat het de post-prandiale hepatische vetverbranding stimuleert en daardoor de eetlust zou kunnen beïnvloeden. Dit hebben we onderzocht tijdens een 36 uurs verblijf in de respiratiekamer. De proefpersonen werden in energiebalans gevoed met een normale macronutriëntsamenstelling, waarbij in willekeurige volgorde $40 \%$ van het vet diacylglycerol of triacylglycerol was. Het gebruik van diacylglycerol stimuleerde de vetverbranding bij gelijkblijvend energiegebruik. Tevens remde het gebruik van diacylglycerol de eetlust. Dit effect werd wellicht veroorzaakt door een toename van de hepatische vetverbranding, aangezien de plasma $\beta$-hydroxy butyraat concentratie was toegenomen. Dus, het gebruik van diacylglycerol stimuleert de (hepatische) vetverbranding en beïnvloedt daarmee de eetlust.

Bij de behandeling en preventie van obesitas kan gebruik worden gemaakt van bevindingen zoals beschreven in dit proefschrift. In toekomstige studies naar voedselinname en/of -voorkeur zal met PROP-gevoeligheid rekening gehouden moeten worden, omdat deze gerelateerd is aan vetinname. Het gebruik van een olie hoog in linolzuur kan de vetinname verlagen door vet-specifieke verzadiging. Tevens kan toevoeging van vrij linolzuur aan laag-vet producten een vergelijkbare voedselinnameregulatie bevorderen als bij hoog-vet producten die vrij linolzuur bevatten, in ongeveer $50 \%$ van de bevolking. Verder kan het gebruik van een op-vet-gebaseerd functioneel ingredient, CLA, de energiebalans op een gunstige manier beïnvloeden door effecten op eetlust en lichaamssamenstelling. Ook kan het gebruik van diacylglycerol in plaats van triacylglcyerol bijdragen aan de preventie en behandeling van obesitas doordat het de vetverbranding verhoogt en hiermee de vetopslag kan verlagen. Tevens verlaagt diacylglycerol de eetlust, waardoor de energie-inname beĩnvloed kan worden.

Uit de studies beschreven in dit proefschrift kunnen we concluderen dat naast de risico's van vetconsumptie gerelateerd aan de etiologie van obesitas, er ook enkele lichtpuntjes zijn in deze relatie die kunnen bijdragen aan de behandeling of preventie van obesitas. 

Dankwoord 
$\mathrm{N}$ a 4 jaar is het zover... Het heeft soms wat moeite gekost, maar nu kan er dan ook gezegd worden: dit einddoel is bereikt, het boekje is af!!

Ook al draagt dit proefschrift mijn naam, dat betekent niet dat ik het allemaal alleen heb gedaan. In de vier jaar dat ik toegewerkt heb naar dit eindresultaat, zijn er veel mensen geweest die mij op een of andere manier bijgestaan hebben. Zonder jullie hulp zouden jullie dit misschien nu niet aan het lezen zijn...

Als eerste zou ik graag mijn co-promotor en promotor willen bedanken. Margriet, jij was diegene die me naar Maastricht heeft gehaald, ondanks het feit dat ik nog niet helemaal klaar was met mijn studie in Wageningen. Ik wil je bedanken voor het geduld waarmee je alle kleine en grote vragen hebt aangehoord ('domme vragen bestaan niet'). Doordat we niet altijd op één lijn zaten, heb ik veel geleerd van onze discussies. Ook heb ik de snelheid waarmee je mijn stukken nakeek altijd gewaardeerd. Wim, je maakte altijd tijd voor me vrij als het nodig was en dat heb ik zeer gewaardeerd. Tevens wil ik je bedanken voor de kritische manier waarop je naar mijn stukken keek.

I would like to thank Prof Dr Ir P v.d Brandt, Dr Ir K de Graaf, Prof Dr Ir R Mensink, Prof Dr P Soeters, and Prof Dr A Tremblay for your critical examination of this thesis. Kees, tevens wil ik je graag bedanken voor het gestelde vertrouwen in me. Ik heb erg veel zin om 'terug' naar Wageningen te gaan! Cher Angelo, je sais que mon séjour à Québec etais le debut de ma carrière scientifique. Je voudrais remercier toi et les autres du PEPS et CHUL (Alfred, Eric, Jean-Pièrre, Jonathan, Natalie, Pascal, Sylvie et Vicky et les autres) pour toutes; merci beaucoup!!

Tijdens de verdediging zullen twee meiden letterlijk en figuurlijk achter me staan. Marja en Monica, ik ben erg blij dat jullie tijdens deze belangrijke dag mijn paranimfen willen zijn! Moon, als deskundige op zowel fysiologisch als smaakgebied, reken ik natuurlijk op je inhoudelijke kennis (voor het geval dat). Geniet er deze keer maar van, want de volgende keer ben jij aan de beurt! Marja, ik leerde je kennen als proefpersoon (heb je hoofdstuk 5 al gelezen?), maar ondertussen heb ik je al wat beter leren kennen. En wie weet komt jou tijd ook nog!

Eva, je was mijn steun en toeverlaat vooral tijdens het begin van mijn AlO-schap. In de 'meterkast' hadden we geen ruimte om elkaar te ontwijken, maar dat was gelukkig ook niet echt nodig. Vooral onze 'T-opstelling' was goed voor discussies, vitamientjes en M\&M's (leeft de machine nog?!). Niet alleen op de uni, maar ook op congressen en buiten werktijd heb ik je aanwezigheid gewaardeerd...

Ook alle andere mensen van 'de groep' wil ik graag bedanken; Bert (door jou ben ik zeker kritischer naar mijn eigen studies gaan kijken), Camiel (het is alweer lang geleden, maar ik herinner me nog maar al te goed hoeveel lol we samen hadden...), Caroline, Christianne, Ilse, Manuela (bedankt voor je hulp bij vele studies en je gezelschap tijdens vele kilometers op de fiets), Neeltje en Tanja.

Natuurlijk wil ik ook alle andere (ex) collega's van Humane Biologie bedanken voor hun bijdrage tijdens de vier jaar dat ik bij Humane Biologie rondrende. Hierbij zou ik in het bijzonder willen noemen Claudia (wanneer ga je nu eens mee klimmen?), Annelies, Annemarie (schaatsen kan ik nog steeds niet echt goed, maar de lol was het zeker waard!), Annemiek, Elke, Erwin (trek jij Kamphuis-en aan of zo?!), andere Erwin, Freddy, Guy, Hasibe (bedankt voor je uitleg voor de vetzuuranalyse en de vele maatschappelijke discussies die we hebben gevoerd), Joost (heel veel geluk in de liefde! (en dat is net cynisch bedoeld)), Loek (dank voor het snelle beantwoorden van al mijn computer-gerelateerde vragen en tevens voor de vele deuterium analyses), Luc (ja, ik weet wat ik moet doen als het met m'n carrière niet wil vlotten..), Marieke (bedankt voor de vele uren aerobics, schaatsen, squash, tennis, eten en heel heeeeeel veel kletsen..), Marije (waar hebben we het samen niet over gehad?!), Michiel (wanneer gaan we weer samen hardlopen?!), Mirjam (ik vind het erg jammer dat we elkaar niet eerder hebben leren kennen, 'kleintje'..), Paul (zonder jouw zouden er geen respiratiekamer experimenten plaatsvinden!), Peggy (hoeveel rondjes zullen we samen 
hebben gelopen?!), Petra, Renate (de vakantie was het begin van een goede vriendschap. Veel succes met jouw laatste loodjes...), Sandra en natuurlijk Truus. Ook wil ik graag Chris, Gabby, Joan, Marco en Margriet bedanken voor de vele malen dat jullie (direct) op mijn (zoveelste) verzoek in gingen om bloed te prikken als het me zelf niet lukte... Joan, Jos en Wendy, ik weet niet hoeveel bloedanalyses jullie voor me hebben uitgevoerd, ik weet wel dat het er erg veel waren, waarvoor dank!

Linda, Winyee en Henrike, het was de bedoeling dat jullie als stagières wat van mij zouden leren (wat jullie hopelijk ook hebben gedaan..), maar ik heb ook zeker veel door jullie geleerd!

Meneer Belfi, graag zou ik u nogmaals willen danken voor de tijd die u vrij heeft gemaakt om me te helpen met het ijsmaken. Zoals u weet, heeft het geleid tot een geaccepteerd artikel en natuurlijk een hoofdstuk (hst 5) in dit boekje.

Eén ding is zeker, dit proefschrift kon niet worden geschreven zonder de (vrijwillige) medewerking van 'proefpersonen'. Nogmaals wil ik alle deelnemers van de studies bedanken voor jullie medewerking.

Gie, Marleen, Monica en Rik, alweer bijna 10 jaar geleden begonnen we met de studie 'Voeding van de Mens'; vrienden vanaf het eerste jaar. Alle vijf zijn we AlO's geworden. waardoor we allemaal weten we wat dat leven inhoudt. Ik mag nu het voortouw nemen, maar spoedig zullen jullie ook volgen! lk vond het fijn dat ik mijn hart bij jullie kon luchten als het weer eens nodig was... Gie, doordat je mijn boven- en daarna benedenbuurman was, hebben we in Wageningen vele uren samen doorgebracht (weet je nog dat we samen zaten te studeren in de bieb?). Ook tijdens ons AIO-schap heb ik veel van je geleerd (smaak, het houdt je bezig, niet?) Marleen, niet alleen hebben we dezelfde naam, ook onze gedachten en ideeën zijn vaak hetzelfde. Tijdens onze eerste afstudeervak heb ik je pas goed leren kennen en van jou perfectie heb ik veel opgestoken. Ik waardeer je oprechtheid en natuurlijk je gastvrijheid. Monica, doordat het onderwerp van ons promotie-onderzoek in hetzelfde gebied lag gingen we vaak naar dezelfde cursussen en congressen. Daardoor zagen we elkaar ook geregeld onder werktijd, wat we natuurlijk helemaal niet erg vonden! (gelukkig hebben we in Wageningen een half jaar tijd om een klets-achterstand van \pm 4 jaar in te halen, hahaha). Moon en Marleen, tevens wil ik jullie bedanken voor alle (bij 'de mannen' beruchte) 'meidenweekenden'. Af en toe waren ze broodnodig, vooral voor de ontspanning. Ik hoop dan ook dat we lang zullen doorgaan met deze traditiel Rik, in Wageningen hadden we misschien niet erg veel contact met elkaar, maar door onze tijd in Maastricht, is dat absoluut veranderd. Naast vrienden, waren we ook ruim een jaar huisgenoten. Ik vond dat altijd erg gezellig en ik waardeerde vooral je 'kookkunsten' (oké, ik moet toegeven dat het bij mij ook wel eens anders proefde dan bedoeld was...). Ondertussen zijn we alle twee onze eigen 'huis'weg ingeslagen, maar natuurlijk zijn we elkaar niet uit het oog verloren.

Simone, bijna 15 jaar ken ik je al (zullen we in september een jubileum houden?!). Ooit hadden we een droom dat we samen naar Groningen zouden gaan, maar 'helaas' is dat niet zo gelopen. Ondanks dat onze fysieke afstand groter is dan gewild, weerhoudt ons dat niet om elkaar vaak te zien. De afgelopen 4 jaar hebben we vele weekenden en vakanties samen doorgebracht; hopelijk volgen er nog vele meer...

Gertrude, hoe toevallig kan het leven niet zijn? Dat ik jouw heb leren kennen valt daar zeker onder! Ik hoop dat we onze traditie nog lang zullen gaan doorzetten. Dit jaar zat het NK er niet in (Rome is zeker zo leuk!), maar het WK in eigen land mogen we niet laten lopen..

Mélanie, since I left Québec, we definitely did not lose contact. In fact we were able to see eachother even 4 times during the last 4 years.. Hopefully, there will be many more opportunities in the future. Mel, always keep in mind; if you really want it, you can do it!

Bas, hoewel op dit moment ons contact wat minder frequent is (wie gaat er dan ook naar Canada?!), was dit een aantal jaren geleden wel anders. Het begon met een borrel, maar spoedig volgde meer (hoeveel (kilo)meter touw zul je door je acht hebben gehaald 
tijdens alle keren dat je me hebt gezekerd?!). Al weer twee jaar zit je nu in Canada en ik hoop dat ook jij snel je promotieonderzoek kan afronden. Hopelijk heb ik voor die tijd nog eens de kans om langs te komen...

Natuurlijk wil ik ook alle MaasSAC-ers bedanken voor de vele klimuurtjes en plezier, met speciale dank aan Daan, Henk, Johan en Victor en in het bijzonder Iris en Janna. Meiden, het begon met klimmen, maar het eindigde met veel meer! Ik wil jullie graag bedanken voor de vele gezellige (eet, lunch, thee en klim)'dates'. Ik hoop dat wel elkaar nog vaak blijven zien ondanks de fysieke afstand...

Tevens wil ik graag de (loop)leden en trainers van de thriathlon club Maastricht (Aart, Anouk, Bart, Indra, Iris, Gerinno, John, Lei, Marie-Louise, Noël, Norbert, en alle anderen) bedanken voor de vele kilometers die we per voet, fiets of ski's hebben afgelegd.

Pap, mam, misschien hebben jullie niet de meeste bijdrage geleverd aan dit boekje, ik realiseer me wel degelijk dat mede dankzij jullie dit boekje tot stand is gekomen! Ook jullie hebben de consequenties van het AIO-schap mogen ervaren (en dat natuurlijk niet alleen door mij); niet altijd was er de tijd of puf om naar 'thuis-thuis' te komen. Maar gelukkig hadden jullie hiervoor begrip. Tevens ben ik blij dat jullie de weg naar Maastricht ook geregeld vinden... Marieke, last but not least, toch?! Ga lekker je eigen gang en het zal allemaal goed komen hoor! Ik ga er van uit dat we binnenkort een glas kunnen gaan heffen op jouw diploma... Patrick en Marjan, ook jullie waren zo gek om 4 jaar van jullie leven te wijden aan het AIO-schap. In 2001 en 2002 hebben jullie al even laten zien hoe het moet... Nu ik nog!

LLL Lex, ik weet niet hoe ik deze klus zonder jou had moeten klaren. Het is onvoorstelbaar hoe vaak jij voor me klaar hebt gestaan. Jouw praktische en mentale ondersteuning heeft me zeker vaak (er doorheen) geholpen. Graag wil ik je, voor de zoveelste keer, bedanken voor alles (en dat is erg veel!) wat je voor me hebt gedaan. Ik kan nu alleen nog maar zeggen: dit doel is bereikt, nu de onze nog...

Bedankt allemaal!!

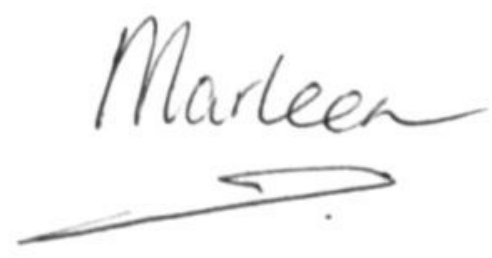


Curriculum Vitae 

Marleen Maria Johanna Willemien Kamphuis was born on July $6^{\text {th }} 1976$ in Losser. She completed secondary school at the Thijcollege in Oldenzaal in 1994. The same year she started her study in Human Nutrition at the Wageningen Agricultural University. As part of the training. she conducted several internships. Her first training period was at the Department of Human Nutrition and Epidemiology of the Wageningen Agricultural University. At the Lipid Research Centre of the Centre Hopital de Universite Laval in Québec, Canada, she conducted her second training period. Her last internship was spent at the Rudolf Magnus Institute in Utrecht, The Netherlands. She graduated in 1999.

She started as a Ph.D. fellow at the Department of Human Biology of Maastricht University in 1999. She conducted research which was focused on several aspects of dietary fat on food intake and body weight regulation. The research performed during this period is described in this thesis. She presented parts of the research findings at several national and international conferences. In 2000, she was winner of the 'Young Investigator Award' of the 'Society for the Studies of Ingestive Behavior'.

From May $1^{\text {st }}$ 2003, she is working at the Department of Human Nutrition and Epidemiology of the Wageningen University and Research Centre.

Marleen Maria Johanna Willemien Kamphuis werd geboren op 6 juli 1976 te Losser. Ze behaalde haar WWO diploma in 1994 aan het Thijcollege te Oldenzaal. Datzelfde jaar begon ze met de studie Voeding van de Mens aan de toenmalige Landbouw Universiteit te Wageningen. Ze heeft 3 stages gelopen als onderdeel van haar studie. De eerste werd uitgevoerd bij de vakgroep Humane Voeding en Epidemiologie van de toenmalige Landbouw Universiteit te Wageningen. Bij het 'Lipid Research Centre' in Québec, Canada heeft ze haar tweede stage gelopen. Haar laatste stage werd uitgevoerd aan Rudolf Magnus Instituut in Utrecht. Ze behaalde haar diploma in 1999.

In 1999 begon ze met haar promotieonderzoek aan de Capaciteitsgroep Humane Biologie van de Universiteit Maastricht. Ze heeft verschillende studies uitgevoerd die gericht waren op verschillende aspecten van voedingsvet op voedselinname- en lichaamsgewichtregulatie. Het onderzoek uitgevoerd tijdens deze periode staat beschreven in dit proefschrift. Delen van de onderzoeksresultaten zijn gepresenteerd op verschillende nationale en internationale congressen. $\mathrm{Ze}$ won de 'Young Investigator Award' van de 'Society for the Studies of Ingestive Behavior' in 2000.

Sinds 1 mei 2003 is ze werkzaam bij de vakgroep Humane Voeding en Epidemiologie van Wageningen Universiteit en Research Centrum. 
